\title{
Energy Optimized Configuration of Concrete Element with PCM
}





\title{
Energy Optimized Configuration of Concrete Element with PCM
}

\author{
Revised Version \\ PhD Thesis \\ Defended in public at Aalborg University \\ January 2013 \\ Michal Pomianowski \\ Department of Civil Engineering, \\ The Faculty of Engineering and Science, \\ Aalborg University, Aalborg, Denmark
}

River Publishers

Aalborg 
ISBN 978-87-93102-49-1 (e-book)

Published, sold and distributed by:

River Publishers

Niels Jernes Vej 10

9220 Aalborg Ø

Denmark

Tel.: +45369953197

www.riverpublishers.com

Copyright for this work belongs to the author, River Publishers have the sole right to distribute this work commercially.

All rights reserved (c) 2013 Michal Pomianowski.

No part of this work may be reproduced, stored in a retrieval system, or transmitted in any form or by any means, electronic, mechanical, photocopying, microfilming, recording or otherwise, without prior written permission from the Publisher. 


\section{Mandatory page in PhD theses:}

1. Energy Optimization of PCM Concrete Element Configuration

2. Michal Zbigniew Pomianowski

3. Per Heiselberg- Professor, Rasums Lund Jensen- Associate Professor

4. List of published papers:

o Paper 1: M.Z. Pomianowski, P. Heiselberg, R.L. Jensen, “Initial development of a combined PCM and TABS solution for heat storage and cooling”, Proceedings of NSB, Tampre, Finland, 2011.

o Paper 2: M.Z. Pomianowski, P. Heiselberg, R.L. Jensen, Experimental investigation of thermal conductivity of concrete containing micro-encapsulated Phase Change Materials, Proceedings of ISHVAC, Shanghai, China, 2011.

o Paper 3: M.Z. Pomianowski, P. Heiselberg, R.L. Jensen, R. Cheng, Y. Zhang,” A new experimental method to determine specific heat capacity of inhomogeneous concrete material with incorporated microencapsulated-PCM", Submitted to Cement and Concrete Research.

o Paper 4: M.Z. Pomianowski, P. Heiselberg, R.L. Jensen, H. Johra, Numerical analysis of heat storage and heat conductivity in the concrete hollow core deck element, Proceedings of IBPSA, Sydney, Australia, 2011.

o Paper 5: M.Z. Pomianowski, P. Heiselberg, R.L. Jensen: "Dynamic heat storage and cooling capacity of a concrete deck with PCM and thermally activated building system, Energy and Buildings, 53 (2012), 96 - 107.

o Paper 6:M.Z. Pomianowski, P. Heiselberg, R.L. Jensen, Full-scale investigation of the dynamic heat storage of the concrete decks with PCM and enhanced heat transfer surface area, Submitted to Energy and Buildings.

This thesis has been submitted for assessment in partial fulfillment of the $\mathrm{PhD}$ degree. The thesis is based on the submitted or published scientific papers which are listed above. Parts of the papers are used directly or indirectly in the extended summary of the thesis. As part of the assessment, coauthor statements have been made available to the assessment committee and are also available at the Faculty. The thesis is not in its present form acceptable for open publication but only in limited and closed circulation as copyright may not be ensured. 


\section{ABSTRACT}

The building sector accounts for approximately $40 \%$ of the world's total use of primary energy, and the majority of this energy is used to maintain satisfactory indoor climate conditions by heating, cooling and ventilation.

Further on, traditional energy sources are irretrievably decreasing and the price of energy and fuel is gradually increasing. On top of that, the gas emissions to the atmosphere cause long-term and hazardous changes to the global climate. As a response to that, countries started to enforce new, more demanding legislations and standards for the newly constructed and renovated buildings. For example, in Denmark the new energy frames assume a reduction of primary energy use for buildings of respectively $25 \%$ in 2010 , 50\% in 2015 and 75\% in 2020 compared to year 2006 figures. As a consequence, the building sector has to be equipped with the new technologies that would enable fulfillment of the new requirements regarding the new energy frames.

The concept presented and developed in the thesis focuses on the energy optimization and potential of the new product that could utilize the high thermal energy storage (TES) and thermally activated building system (TABS). The work investigates the potential of combining the microencapsulated phase change material (PCM) in the hollow core concrete deck element in order to increase the dynamic heat storage capacity of the internal envelope of the multi-storey buildings. Moreover, the study investigates the cooling capacity and performance of the concrete deck with PCM and integrated TABS and highlights limitations and challenges of the new technology.

The presented work utilizes numerical methods to study the dynamic performance of the new product developed. Consequently, the experimental set-ups and methodologies are developed firstly to determine the thermal properties of the new material, such as combined PCM concrete, and secondly to investigate the performance of the developed decks in 1:1 scale.

The research is scheduled in an iterative manner, where the initial numerical study of the deck with PCM is performed with use of the theoretically determined thermal properties of the PCM concrete material. The reason for the iterative research is due to the lack of experimentally determined thermal properties of this relatively new material. In the second step of the research, the thermal properties of the PCM concrete are determined by experimental manner and afterwards, the initial numerical models are updated with the measured thermal properties of the new composite material. Finally, the results from numerical analysis are validated by the full-scale experiments performed in a specially developed and modified hot box apparatus. The full-scale experiments are also conducted for the specially constructed perforated decks in which heat exchange surface increases compared to the standard flat decks. The decks with perforations are examined with regards to the amount of heat that could be stored during the typical day-night cycle of an office building with specially designed ventilation inlet slot diffuser.

Firstly, it was observed that the assumptions regarding the theoretical thermal properties stand out from the experimentally determined thermal properties of the PCM concrete. Consequently, the results obtained from the initial (theoretical) and updated (experimental) numerical models reflect significant discrepancy of the dynamic heat storage and cooling capacity of the developed decks. The experimentally determined thermal conductivity and specific heat capacity of PCM concrete are significantly lower than ones from the theoretical calculations, what in both cases result in poorer heat storage and cooling power performances than initially expected.

Results from the full-scale investigation of dynamic heat storage capacity of decks indicated that there is no substantial difference between decks with extended heat transfer surface and one with an ordinary flat surface. Moreover, no significant improvement was observed for decks with PCM with regards to their reference deck cast with ordinary mortar. On the other hand, an improvement in the heat storage was observed for all deck casts with specially designed tiles on the bottom with regards to standard concrete deck element. These results, however, were unexpected since the material properties of mortar used to cast tiles were determined to be worse than those of concrete material used to cast standard decks. 


\section{DANSK RESUMÉ}

Byggesektoren er ansvarlig for ca. $40 \%$ af verdenens totale primærenergiforbrug og hoveddelen af denne energi bliver brugt til at fastholde tilfredsstillende indeklimaforhold med opvarmning, afkøling og ventilation.

De traditionelle energikilder er derudover uigenkaldeligt ved at formindskes og prisen på energi og brændstof stiger gradvist. Oven i det har udledning af gasser i atmosfæren forårsaget langtidsvarige og skadelige forandringer i det globale klima. Som en reaktion på dette er lande startet med at indføre nye, mere krævende lovgivninger og standarder til fremtidig konstruktion og renovering af bygninger. For eksempel forudsætter de nye energirammer i Danmark en reduktion af primærenergiforbruget ved bygninger på forholdsvis 25 \% i 2010, 50 \% i 2015 og 75 \% i 2020 sammenlignet med tal fra 2006. Byggesektoren må, som en konsekvens heraf, udstyres med de nye teknologier, der muliggør overholdelse af de nye krav vedrørende de nye energirammer.

Konceptet, der præsenteres og udvikles i denne afhandling, fokuserer på energioptimering og potentiallet med det nye produkt, der kan udnytte lagring af høj termisk energi (TES) og termiskstyrede bygningssystemer (TABS). Afhandlingen undersøger potentialet ved at inkorporere mikroindkapslet faseskiftmateriale (PCM) i et betondækelement med hulkerne, for at øge kapaciteten for dynamisk varmelagring i den interne klimaskærm i fleretagesbygninger. Undersøgelsen udforsker ydermere afkølingskapaciteten og præstationsevnen for betondæk med PCM og integreret TABS, og fremhæver begrænsninger og udfordringer ved den nye teknologi.

Det fremlagte værk bruger adskillige metoder til at undersøge den dynamiske ydelsesevne for det nyudviklede produkt. Som følge deraf udvikles forsøgsopstillingerne og metodelæren først, for at bestemme de termiske egenskaber for det nye materiale, så som PCM-beton-kombinationen, og derefter for at undersøge ydelsesevnen for de udviklede dæk i en 1:1 skala.

Forskningen er planlagt som en iterativ proces, hvor den første numeriske undersøgelse af dækket med PCM udføres ved brug af de teoretiskbestemte termiske egenskaber for PCM-betonmaterialet. Årsagen til denne iterative forskning er manglen på forsøgsbestemte termiske egenskaber for dette relativt nye materiale. I det andet trin af denne forskning bestemmes de termiske egenskaber for PCM-betonen gennem forsøg og efterfølgende opdateres de første numeriske modeller med de målte termiske egenskaber for det nye kompositmateriale. Til sidst valideres resultaterne fra den numeriske analyse med fuldskalaforsøg, der udføres i et specialudviklet og modificeret hot box apparat. Fuldskalaforsøgene udføres også for de specialudviklede profileret dæk med reliefer, hvorpå varmeudvekslingsoverfladen forøges i forhold til standard flade dæk. De profilerere dæk undersøges med henblik på mængden af varme, der kan lagres i løbet af en typisk dag-nat cyklus i en kontorbygning med specialdesignede spelteindblæsning.

For og fremmest observeredes det, at antagelserne for de teoretiske termiske egenskaber skilte sig ud fra de forsøgsbestemte termiske egenskaber for PCM-beton. Resultaterne opnået fra de første (teoretiske) og opdaterede (forsøg) numeriske modeller reflekterer som følge deraf en væsentlig uoverensstemmelse i den dynamiske varmelagring og afkølingskapacitet for de udviklede dæk. Den forsøgsbestemte termiske ledningsevne og specifikke varmekapacitet for PCM-beton er væsentlig lavere end dem fra de teoretiske beregninger, hvilket i begge tilfælde resulterer i dårligere varmelagring og afkølingseffektpræstationer end oprindeligt forventet.

Resultaterne fra fuldskalaundersøgelsen af dynamisk varmelagring i dækkene indikerede, at der ikke er nogen betydelig forskel mellem dækkene med udvidet varmeudvekslingsoverflade og ét med en ordinær flad overflade. Derudover blev der ikke observeret nogen betydelig forbedring for dækkene med PCM i forhold til deres referencedæk med almindelig mørtelstøbning. Derimod blev en forbedring i varmelagringen observeret for alle dækstøbninger med specialdesignede tegl på bunden med hensyn til standard 
betondækelementer. Disse resultater var derimod uventede, da materialeegenskaberne for mørtelen, der blev brugt til at støbe tegl med, blev fastsat til at være ringere end dem for betonmaterialet, der blev brugt til at støbe standarddækkene. 
1 Introduction

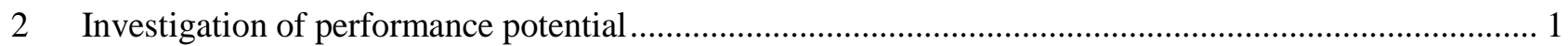

2.1 What is PCM, how does it work and what is its heat storage potential.......................................... 1

2.2 Thermally activated building system (TABS): investigation of capacity......................................... 3

2.3 Previous research on PCM concrete: state-of-the-art .................................................................... 6

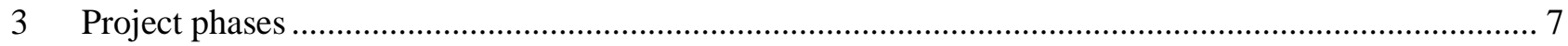

4 Initial numerical analysis of the heat storage and cooling power of the concrete deck with PCM and TABS

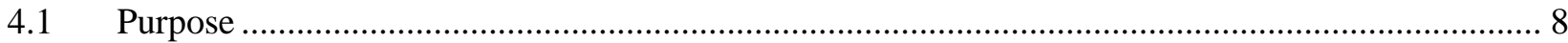

$4.2 \quad$ Methodology

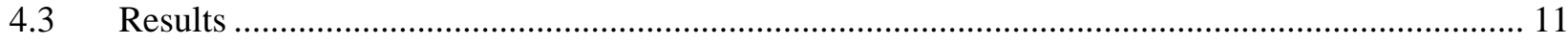

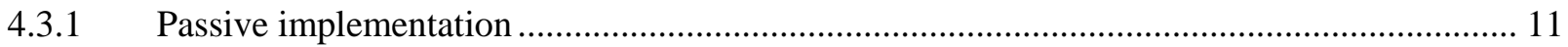

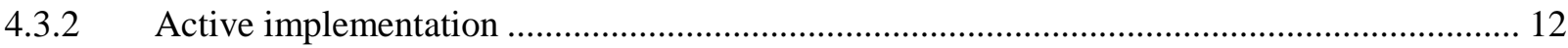

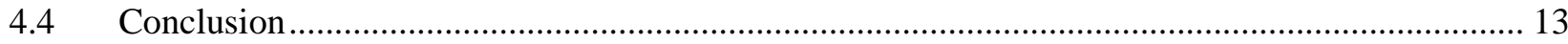

5 Experimental determination of thermal properties of PCM concrete ..................................................... 14

5.1 Thermal conductivity - experimental investigation ......................................................................... 14

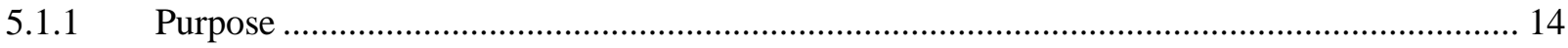

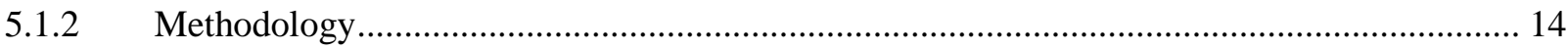

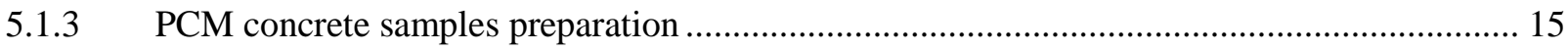

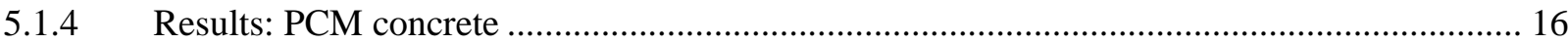

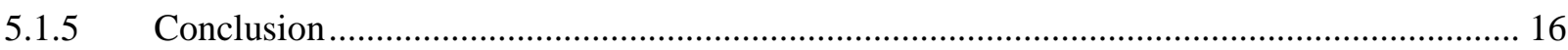

5.2 Specific heat capacity - experimental investigation ...................................................................... 17

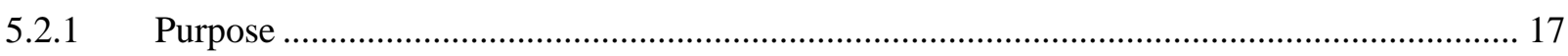

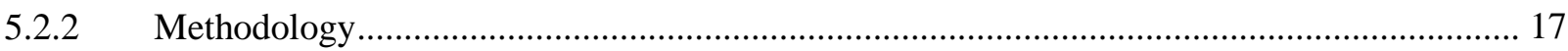

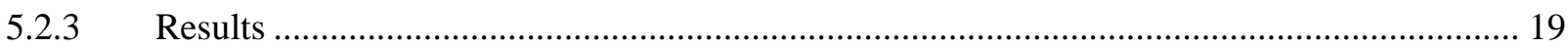

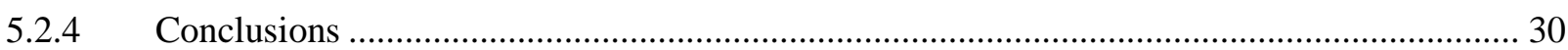

6 Experimental and numerical analysis of heat transfer in the inhomogeneous concrete deck.................. 31

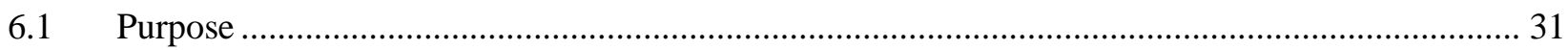

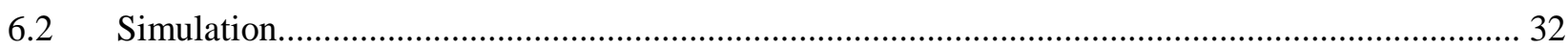

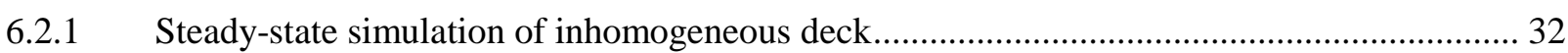

6.3 Experimental investigation of the thermal conductivity of the inhomogeneous deck..................... 32

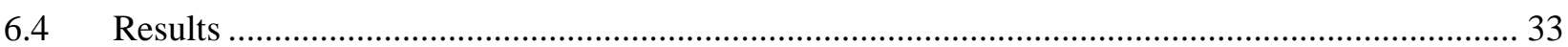

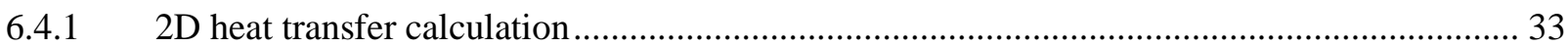

6.4.2 Experimental determination of the thermal conductivity of the hollow core deck element.... 34 
7 Updated numerical analysis of heat storage and cooling power of the concrete deck with PCM and TABS

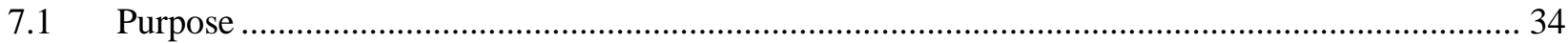

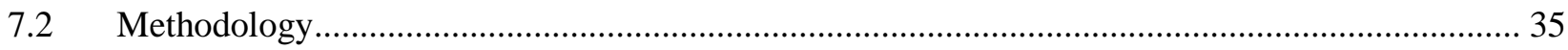

7.2.1 Sensitivity analysis of location and percentage of integrated PCM ….................................... 35

7.2.2 Thermal properties of the combined PCM and concrete material ......................................... 35

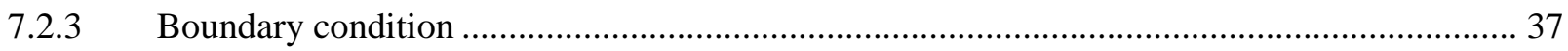

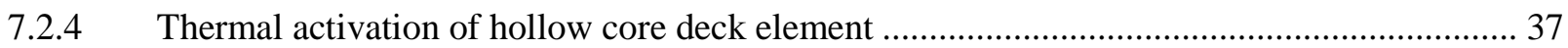

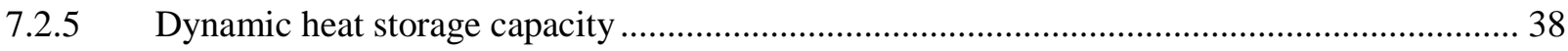

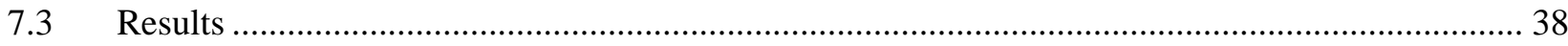

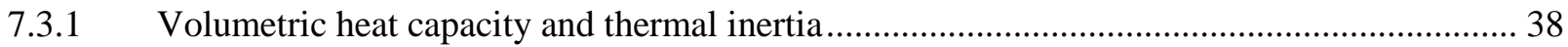

7.3.2 Passive approach: Calculated dynamic heat storage............................................................... 39

7.3.3 Active approach: Calculated cooling capacity ........................................................................... 40

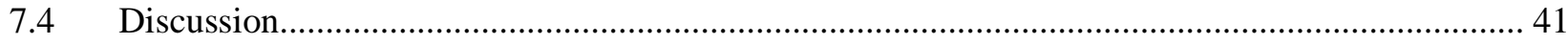

8 Full-scale experiment on various decks: heat storage and heat transfer enhancement investigation ...... 42

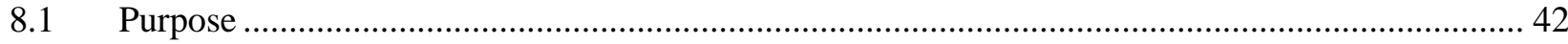

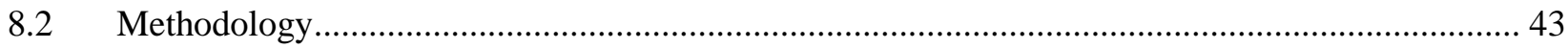

8.2.1 Numerical investigation of potential of extended bottom surface ............................................ 43

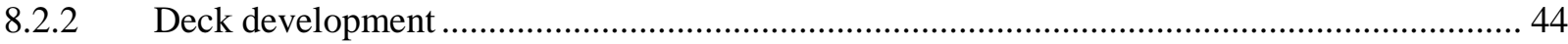

8.2.3 Modified hot box apparatus development ................................................................................ 45

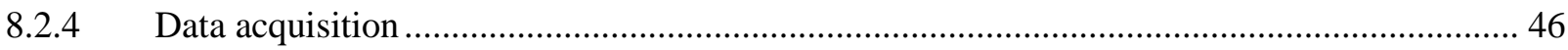

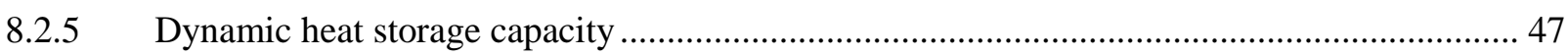

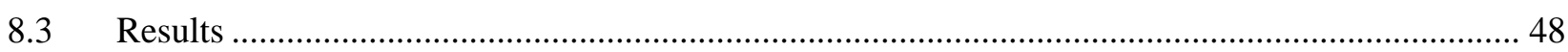

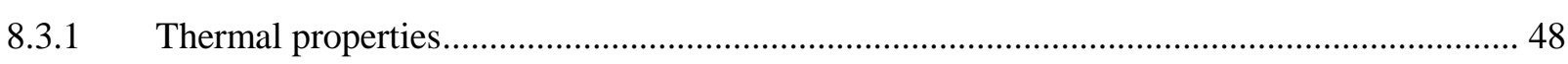

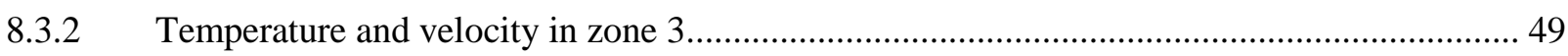

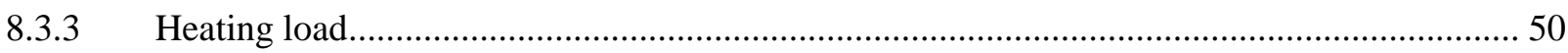

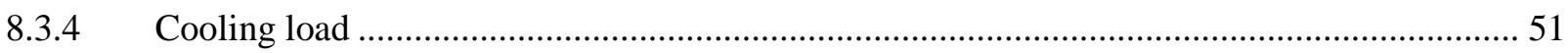

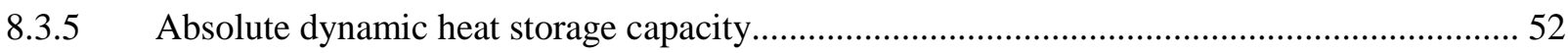

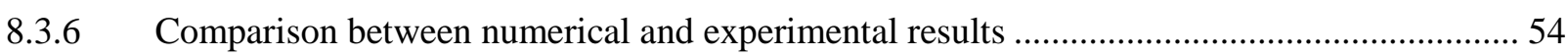

8.3.7 Correlation between dynamic heat storage capacity and weight .......................................... 56

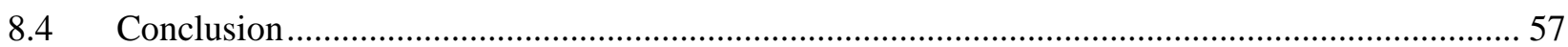

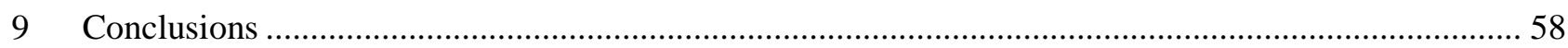

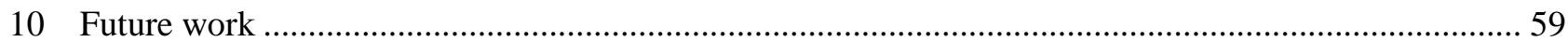


11 References 


\section{PREFACE}

This thesis represents a part of the fulfillment for acquiring the Ph.D. degree. The thesis will be presented at Aalborg University on January, 2013. This PhD project is part of the Energy Efficient Concrete project and was financed by The Danish National Advanced Technology Foundation.

The work has been supervised by Professor Per Heiselberg and Associate Professor Rasmus Lund Jensen. I would like to thank Per Heiselberg for his continuous guidance, inspiring and fruitful discussions and giving me opportunity to actively influence scope of the project. I think this allowed me to become a better and more independent researcher. Also, I would like to thank Rasmus Lund Jensen for helping make things happen and be able to finish within project time schedule. His guidance and point of view was very stimulating during last 3 years of our work together. Additionally, I would like to express my thanks to all my colleagues from the Indoor Environmental Engineering Research Group, and others at the Department of Civil Engineering.

I would like to thank my family and friends for asking "How is it going and when will you finish?" and for supporting me in difficult moments that turned up on the road once in a while.

Finally, I would like to thank my wife for being understanding and patient.

Michal Pomianowski

October 2012 


\section{Introduction}

In the coming years, the new legislations regarding significant reduction of the energy use in the building sector enforce a need to develop the new technologies and solutions that could help fulfill this plan. The preparation and activities can be observed across numerous disciplines connected with the building sector and energy production. The energy used in the building sector can be reduced by introducing improvements on various levels; starting from the power plants, through the grids and finishing with the building itself. The savings of the energy use at the building level can be obtained in two ways. The first way is to directly apply, to the buildings, the technologies that can produce heat / electricity from the renewable sources. In that way, the energy use is not reduced but the share of the fossil fuels and gas emissions in the energy production for the buildings is reduced. The second way is to improve buildings so that they become more efficient in operation, for example by using thicker and better insulation on external constructions, by operating high heat recovery ventilation and balanced ventilation and by ensuring tight envelopes. There is of course another possibility which combines the previous two approaches in order to obtain an economically sound solution and good indoor climate. On top of that, for example, the new Zero Energy Building (ZEB) concept investigates if and how the renewable energy production at each single house could be integrated on a bigger scale in order to obtain the global zero energy impact from the building sector [1].

The concept of the new technology presented in this thesis belongs to the second methodology where focus is put on the improvement of the energy efficiency of the building. The technology that is investigated is characterized by the high thermal energy storage (TES) and the thermally activated building system (TABS). The high TES is expected to be achieved by utilization of the microencapsulated phase change material (PCM) in the concrete construction element. TABS is introduced to the concrete construction element by pipes with circulating water. In this approach, the concrete construction element can gain two times; by increasing its passive heat storage capacity and by introducing the low temperature heating and high temperature cooling system that could maintain the thermal indoor comfort when the passive capacity is insufficient.

All in all, it is expected that the new deck could become a novel technology that could help reduce energy use in buildings.

\section{Investigation of performance potential}

\subsection{What is PCM, how does it work and what is its heat storage potential}

The properties of PCMs that allow them to store large amounts of heat have been known for many years. However, successful PCM implementation in building constructions did not start until the development of the microencapsulated PCMs. The microencapsulated PCMs have a spherical shape and a diameter varying from 1 to $100 \mu \mathrm{m}$, and they can be incorporated into various broadly used building materials. The capsule shell prevents direct contact between the incorporated PCM and matrix material, for example concrete. When PCM is bounded by the shell, it can melt and solidify almost isothermally and thereby charge and discharge heat without any destructive impact on the material matrix. Isothermal processes occur only in the close range around the specific melting temperature of the PCM. For building purposes, the melting point temperature is usually chosen within the average thermal comfort temperature range for an occupied space [2]. In Figure 1, the difference between the sensible heat and latent heat is presented. 


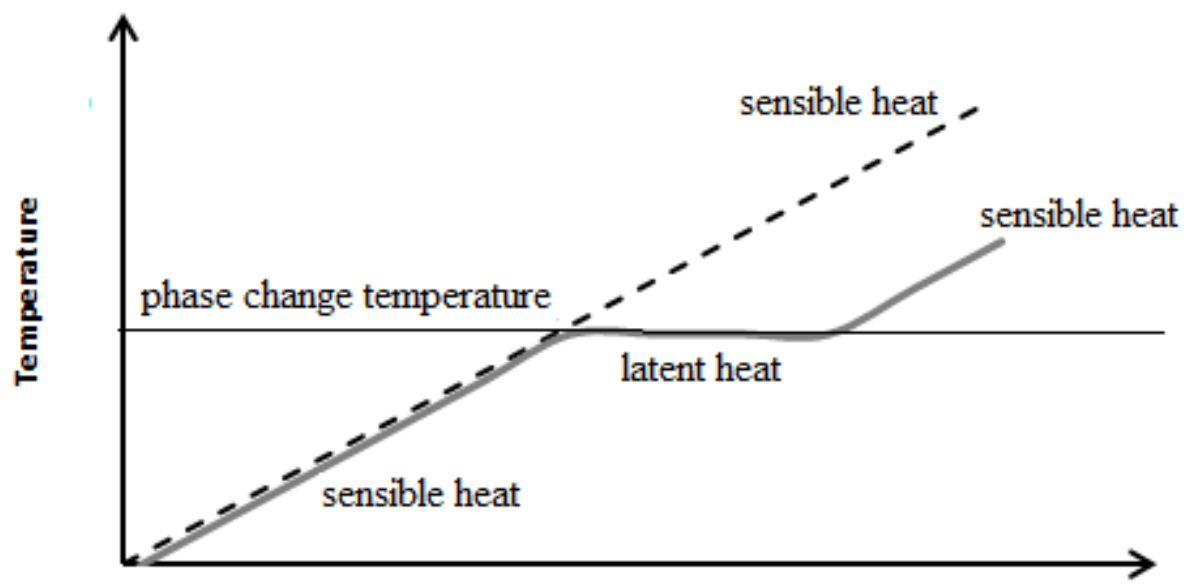

Heat stored

Figure 1. Heat storage as sensible and latent heat.

In sensible heat storage, the temperature of the heated medium increases due to the received heat. The temperature increase can be registered and therefore the heat stored in the medium is called sensible heat. If heat is stored as latent heat, a phase change of the storage material is used [3], and during the phase transition the temperature of the medium is approximately constant. In fact, as Figure 1 shows, PCM can store both sensible and latent heat. The sensible heat is stored for temperatures below and above phase transition range. In the PCM used in the investigation in this thesis, the phase change is considered only from solid to liquid and vice versa.

The significant potential of utilizing PCM as a heat storage buffer in buildings is presented in Table 1, where the heat storage of various common building materials is compared with each other and with pure microencapsulated PCM type DS 5040X from BASF that has melting point at $23^{\circ} \mathrm{C}$.

\begin{tabular}{|l|c|c|c|c|}
\cline { 2 - 5 } \multicolumn{1}{c|}{} & Density & $\begin{array}{c}\text { Specific heat } \\
\text { capacity }\end{array}$ & $\begin{array}{c}\text { Volumetric specific } \\
\text { heat capacity }\end{array}$ & Q/Vol for $\Delta \mathrm{T}=3 \mathrm{~K}$ \\
\cline { 2 - 5 } & {$\left[\mathrm{kg} / \mathrm{m}^{3}\right]$} & {$[\mathrm{kJ} /(\mathrm{kgK})]$} & {$\left[\mathrm{kJ} /\left(\mathrm{m}^{3} \mathrm{~K}\right)\right]$} & {$\left[\mathrm{MJ} / \mathrm{m}^{3}\right]$} \\
\hline Plaster & 1100 & 1.1 & 1.21 & 3.63 \\
\hline Concrete & 2300 & 0.9 & 2.07 & 6.21 \\
\hline Wood & 700 & 1.7 & 1.19 & 3.57 \\
\hline Mineral wool & 50 & 0.75 & 0.04 & 0.11 \\
\hline PCM $\left(22^{\circ} \mathrm{C}-24^{\circ} \mathrm{C}\right)$ & 750 & $/$ & $/$ & 59.32 \\
\hline
\end{tabular}

Table 1. Heat capacities and heat stored in various building material in $3 \mathrm{~K}$ temperature interval between 22 ${ }^{\circ} \mathrm{C}$ and $24{ }^{\circ} \mathrm{C}$.

For the proposed temperature interval between $22{ }^{\circ} \mathrm{C}$ and $24{ }^{\circ} \mathrm{C}$, concrete is observed to store almost double the amount of heat compared to plaster and wood. Moreover, the heat storage of e.g. mineral wool is so small that could be disregarded. On the contrary, the heat capacity of the PCM is almost 10 times higher than for concrete and almost 17 times higher than for plaster and wood. Consequently, if PCM is integrated in the concrete then the heat storage capacity of the concrete should increase in the phase change temperature of added PCM. The theoretical calculations according to weight average method for the combined standard 
concrete and various amount of microencapsulated PCM type DS 5040X were done, and results of these calculations are presented in Figure 2 and Table 2.

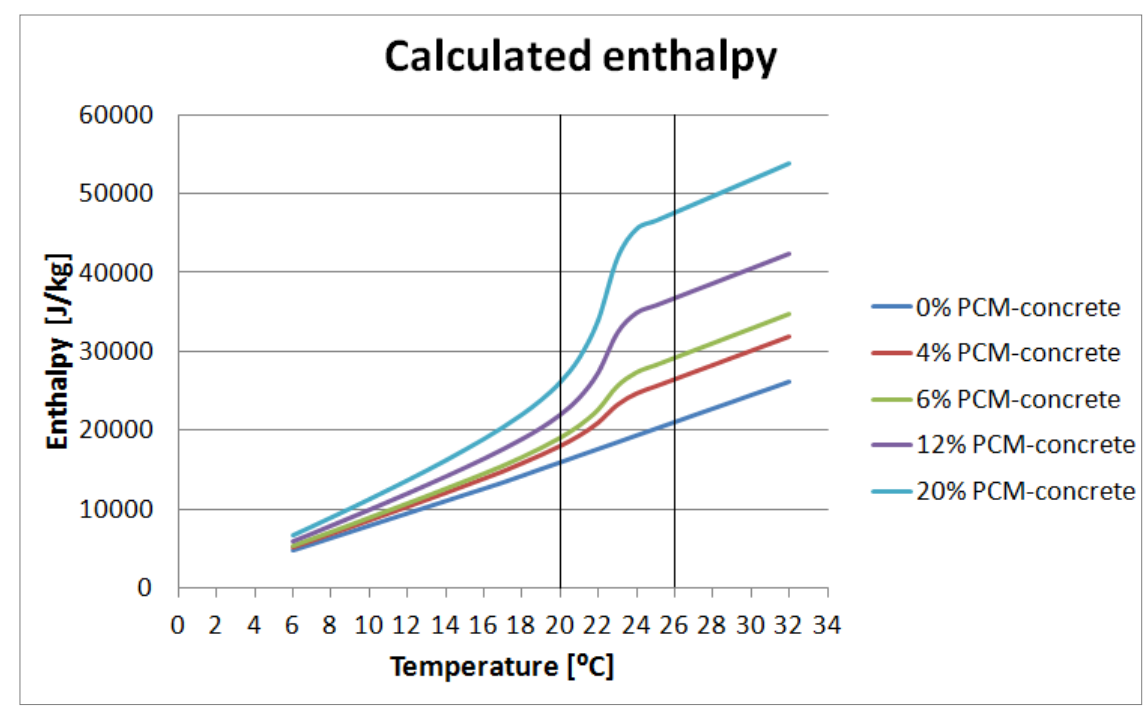

Figure 2. Theoretical calculation of enthalpy of combined PCM and concrete material

\begin{tabular}{|l|c|c|c|c|}
\cline { 2 - 4 } \multicolumn{1}{c|}{} & $\begin{array}{c}\text { Enthalpy from } \\
20 \text { to } 26\left[{ }^{\circ} \mathrm{C}\right]\end{array}$ & Density & $\begin{array}{c}\text { Thermal } \\
\text { mass }\end{array}$ & $\begin{array}{c}\text { Thermal mass increase with } \\
\text { regards to the reference } \\
\text { concrete }\end{array}$ \\
\cline { 2 - 5 } & {$[\mathrm{kJ} / \mathrm{kg}]$} & {$\left[\mathrm{kg} / \mathrm{m}^{3}\right]$} & {$\left[\mathrm{kJ} / \mathrm{m}^{3}\right]$} & {$[\%]$} \\
\hline $0 \%$ PCM concrete (reference) & 4.71 & 2300 & 10833 & $\#$ \\
\hline $4 \%$ PCM concrete & 8.07 & 2247 & 18137 & 67 \\
\hline $6 \%$ PCM concrete & 9.75 & 2221 & 21660 & 100 \\
\hline $12 \%$ PCM concrete & 14.79 & 2142 & 31684 & 192 \\
\hline $20 \%$ PCM concrete & 21.52 & 2036 & 43809 & 304 \\
\hline
\end{tabular}

Table 2. Thermal mass of combined PCM and concrete material based on theoretical weight average calculation of enthalpy of PCM concrete

In the calculations, it is assumed that the percentage of incorporated PCM in the concrete is by weight of PCM in the mixture. According to the theoretical calculations, the thermal mass of the reference concrete can be doubled within $20{ }^{\circ} \mathrm{C}$ to $26{ }^{\circ} \mathrm{C}$ by adding 6 (wt)\% of PCM to the concrete. It was also included in the calculations that the density of the concrete decreases the more PCM is integrated. The calculation of densities was also based on the weight average method.

\subsection{Thermally activated building system (TABS): investigation of capacity}

TABS concept started in the 1990s in Switzerland and involved an idea of activation of the thermal mass of the concrete slabs located between each storey of the building. As a result, when circulating hot or cold water in the concrete slabs, the building can be heated or cooled respectively. TABS were investigated in many theoretical studies and were implemented in a number of full-scale projects, as e.g. presented in [4]. Moreover, laboratory tests and theoretical studies have indicated that this technology could be energy efficient and has a significant potential of reducing operational costs for cooling/heating of buildings and provides an appreciated indoor thermal comfort [5]. 
In [C1] the recommendation of permissible surface temperatures is defined. From these recommendations, it can be concluded that the radiant cooling should be applied on the ceiling and walls and radiant heating on the floors and walls. What is more, [6] indicates that the total heat transfer coefficient (combined convection and radiation) is highest for the cooled ceiling and heated floors. It means that this particular mode and location of TABS in the building are advantageous and would result in the highest efficiency. Consequently, the ceiling has available sensible cooling capacity of up to $100 \mathrm{~W} / \mathrm{m}^{2}$ and sensible heating capacity of up to $40-50 \mathrm{~W} / \mathrm{m}^{2}$. A floor has the highest available sensible heating capacity of up to $100 \mathrm{~W} / \mathrm{m}^{2}$ and sensible cooling capacity of up to $40 \mathrm{~W} / \mathrm{m}^{2}$, except in the special case when there is substantial direct sun radiation on cooled flooring. In this case, cooling capacity may exceed $100 \mathrm{~W} / \mathrm{m}^{2}$.

Standards [C2] and [C3] provide the calculation methodology to estimate the cooling/heating capacity of the TABS system for steady-state condition.

The focus of this thesis is to investigate the performance of the TABS integrated in the hollow core concrete deck element with PCM. However, in order to simplify the problem and by that omit some unknown parameters, the performance of the deck with water pipes was initially investigated as ordinary concrete deck without hollow cores and PCM. What is more, the investigation was made only on the cooling performance, since this kind of deck is typically used in the office buildings where cooling needs are usually more dominant than heating needs. Furthermore, the initial simulations were performed for the transient model, since utilization of the latent heat provided with the PCM integrated in the deck, is only possible when the deck is under varying temperature load from the room. This also means that contrary to the steady-state calculations presented in standards [C2] and [C3], the initial calculations of TABS presented in this chapter are valid for the deck under the dynamic conditions.

The initial sensitivity analysis of some parameters: water temperature, total heat transfer coefficient on the top and bottom surface of the deck, distance of the pipe from the bottom of the deck $(L)$, distance between pipes $(S)$, was performed to estimate capacity of the deck and to investigate which parameter has a higher or lower influence on the capacity of the cooling performance. The parameters and their variation are presented in Table 3. The thickness of the deck $H$ is constant through the investigation and equals $270 \mathrm{~mm}$. The thermal properties of the concrete are defined as standard properties for this material: density $\rho=2300 \mathrm{~kg} / \mathrm{m}^{3}$, specific heat capacity $C p=1000 \mathrm{~J} /(\mathrm{kgK})$, thermal conductivity $\lambda=1,8 \mathrm{~W} /(\mathrm{mK})$. The diameter of the pipe was chosen to be $20 \mathrm{~mm}$. The one section of the deck that is modeled is presented in Figure 3.

A two dimensional representation of one section of concrete deck, see Figure 3, was created in COMSOL Multiphysics and dynamic heat transfer model was used. With regards to boundary condition it was assumed that on the top and bottom of the deck temperature fluctuates between $20^{\circ} \mathrm{C}$ and $26^{\circ} \mathrm{C}$ according to sin curve and heat transfer coefficient on these boundaries is calculated as total for convection and radiation and is parameterized as presented in Table 3. The sin curve and amplitude was chosen to imitate realistic indoor temperature swing. The boundary on the water pipe was simplified by temperature boundary condition and three different water temperatures were applied, see Table 3. Finally, the vertical boundary condition was described as adiabatic one since the neighboring section on the left and right is the same section as the one modeled. 


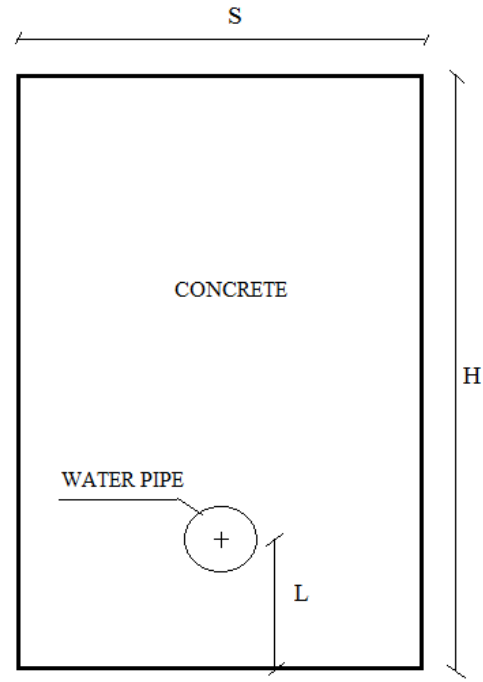

Figure 3. The section of the concrete deck with integrated TABS

\begin{tabular}{|c|c|c|c|}
\hline Distance between pipes & $\begin{array}{c}\text { Distance of the pipe } \\
\text { from the bottom of the } \\
\text { deck }\end{array}$ & Water temperature & $\begin{array}{c}\text { Total heat transfer } \\
\text { coefficient on the } \\
\text { surface of the deck }\end{array}$ \\
\hline$[\mathrm{cm}]$ & {$[\mathrm{cm}]$} & {$\left[{ }^{\circ} \mathrm{C}\right]$} & {$\left[\mathrm{W} /\left(\mathrm{m}^{2} \mathrm{~K}\right)\right]$} \\
\hline$S=10, S=15, S=20, S=30$ & $L=1$ to 5 (step1) & $T=16, T=18, T=20$ & $h=5, h=10, h=15$ \\
\hline
\end{tabular}

Table 3. The range of the varied parameters
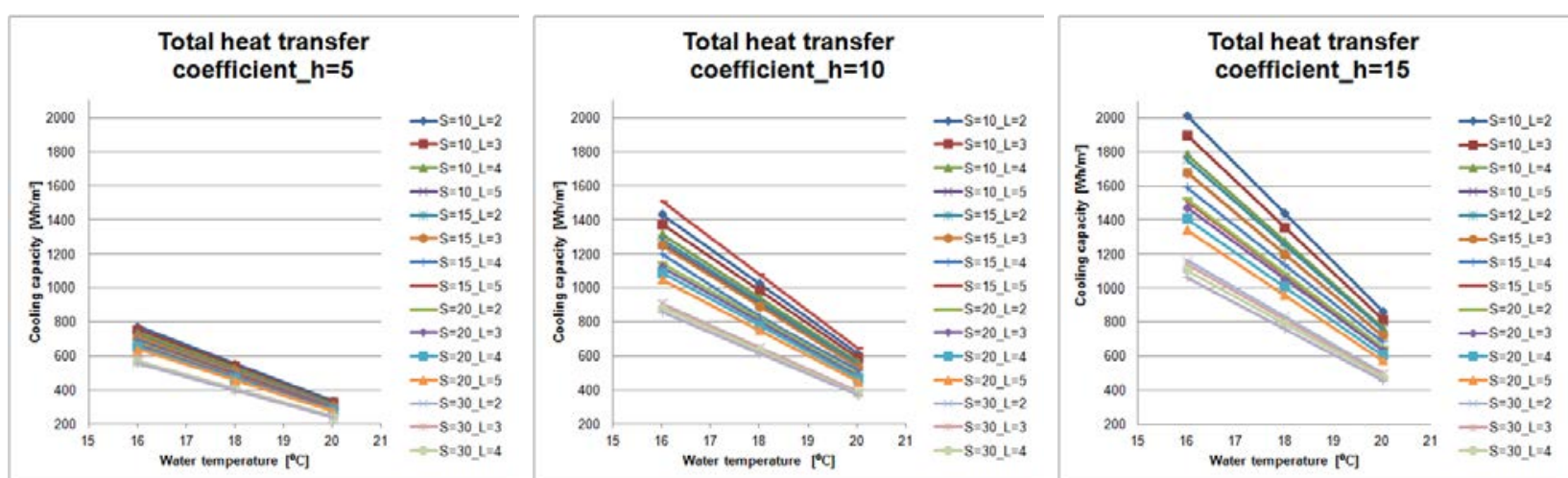

Figure 4. Cooling capacity of the deck grouped with regards to the heat transfer coefficient on the surface

Firstly, from Figure 4 it can be observed for example that the cooling capacity of deck is rather low for the low total heat transfer coefficient on the surface of the deck, when it equals $5 \mathrm{~W} /(\mathrm{mK})$,. Secondly, the spacing between the pipes and the depth of the pipes in the deck do not notably influence the cooling capacity. What is more, the temperature of the cooling water is significantly influencing the cooling capacity. Moreover, the higher the total heat transfer coefficient on the surface of the deck, the more significant the spacing between pipes, the depth of the pipes in the deck and the temperature of the water in the pipes becomes. Finally, it can be concluded that within the parameters investigated, the heat transfer coefficient on the surface is the dominant parameter that decides the performance of the deck.

To sum up, the maximum and minimum average cooling capacity of the deck with regards to 1 hour instead of one whole day and taking into consideration only the investigated parameters, the results are respectively at $83 \mathrm{Wh} / \mathrm{m}^{2}$ and $9 \mathrm{Wh} / \mathrm{m}^{2}$. This indicates that TABS systems should have sufficient capacity to maintain thermal comfort in standard office buildings where maximum heating loads usually do not exceed $30 \mathrm{~W} / \mathrm{m}^{2}$. 
Further on, the results presented in Figure 4 are transformed so that they are grouped relative to the distance between pipes. Some of the conclusions stated for Figure 4 are illustrated yet again in Figure 5 to better understand outcome of the performed initial sensitivity analysis.

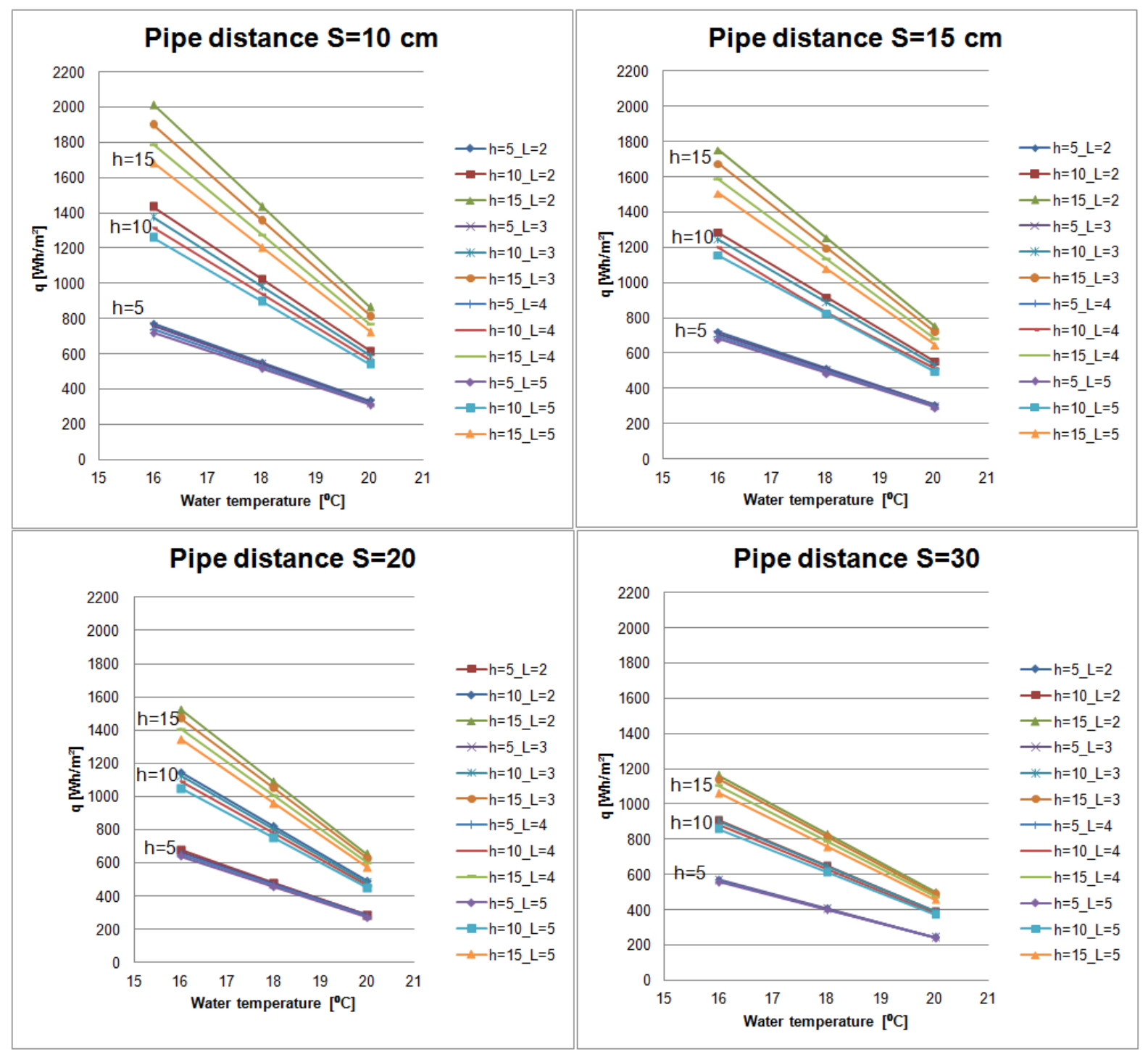

Figure 5. Cooling capacity of the deck grouped relative to the water pipe spacing.

\subsection{Previous research on PCM concrete: state-of-the-art}

On one hand, there is a substantial amount of research which focuses on PCM application in refurbished light weight buildings and light weight constructions in order to increase the thermal mass of the building; for example, [2],[7-10], and an extensive review on energy conservation in various wallboards with PCM; for example [11 - 12]. There are also numerous studies on the thermal properties of various PCMs but in the pure state [13-19].

On the other hand, only a few studies have been reported on implementation of PCM into concrete [20 - 22] and only [20] investigates the thermal properties of the material, whereas in [21-22] the focus is put on the performance of the PCM concrete material in the building rather than on determining the thermal properties of such a material. Further on, in [20] the investigation is made on the self-compacting concrete that is the type of the concrete that would vary a lot from the concrete used, for example, to cast prefabricated elements 
that are investigated in the scope of this project. Nevertheless, further discussion regarding methodology and results presented in [20] can be found in chapter 5.2.3.3.

The study presented in [21] investigates the potential of microencapsulated PCM incorporated in the concrete floors to help heat living rooms of houses located in a moderate climate. In the experimental set-up, PCM is incorporated in the floor and is activated only by direct solar irradiation through the window. In total, four boxes are used, where in two boxes PCM is added to the concrete floor and in the remaining two boxes ordinary concrete is used. Moreover, different insulation on the walls and different glazing in the windows is used in the boxes. Based on the results presented in the article, the authors claim that PCM can effectively store thermal energy. On the other hand, it is difficult to conclude if the reduction of the low temperatures is due to the presence of PCM or due to various insulations in the walls or various glazing in the windows. In addition, concrete floors are usually covered with various type of flooring and that would decrease the access of the direct solar heat to the PCM incorporated in the floor slabs.

The study presented in [22] investigates the two cubicles of the same size. One is made with panels made of conventional concrete and one of modified concrete panels with $5(\mathrm{wt}) \%$ of microencapsulated PCM that was directly admixed to the concrete. The research has indicated that PCM has insulating effect on the concrete walls. Moreover, temperature fluctuation of the wall with PCM was smaller than for the conventional concrete wall. The comparison of the indoor temperature in the conventional cubicle and PCM cubicle indicated a very small difference. However, the amplitude of the fluctuation was smaller in the cubicle made of concrete panels with PCM. What is more, no limitations on the lower and upper bound of the indoor temperature fluctuations are applied in the study. Therefore the indoor temperature fluctuates between $20{ }^{\circ} \mathrm{C}$ and up to $43{ }^{\circ} \mathrm{C}$ approximately during the day, and due to that the PCM incorporated in the panels can undergo full phase transition. On the other hand, in real buildings neither that big temperature fluctuations nor high indoor temperatures are permitted and appreciated. As a consequence of smaller temperature variations, the potential of the PCM concrete investigated would be significantly reduced. Investigations presented in [21-22] focus only on the passive performance of the concrete with PCM. In the literature no references can be found to the investigations into combined PCM concrete which can be thermally activated by the water based system at the same time. On the other hand, there are documented research works on the development of thermally activated PCM plaster products. For example, in [23] the developed panels are a composite of microencapsulated PCM mixed with gypsum. In these panels, the capillary tubes are integrated to circulate water and with that activate the deck/discharge the heat stores. The research presented in [23] starts with the conceptual design, continues with the numerical optimization of the model and finishes with the initial numerical and experimental investigation of the performance of the developed panel. The investigation highlighted that the panels need to integrate highly conductive aluminum fins in order to overcome the discovered low thermal conductivity of the new PCM gypsum composite and to be able to store a sufficient amount of heat. Moreover, although the paper presents the specific heat capacity in function of temperature of the new composite of the PCM gypsum, it does not explain how that property was determined. The outcome from the simulation presented in [23] indicated that for the typical summer week the developed panel can maintain indoor temperatures within comfort range of the standard office room. The experimental investigation indicated that panel was able to store $290 \mathrm{Wh} / \mathrm{m}^{2}$ during the $7.5 \mathrm{~h}$ of the melting process, which was less than expected $320 \mathrm{Wh} / \mathrm{m}^{2}$. The unexpected lower heat storage was explained by the lower quantity of incorporated paraffin than initially designed and by a not full control over the density of the new composite during the mixing and filling in the panel process.

Another example of developed panel for cooling and latent heat storage is patented by ILKATHERM. The sandwich panel consists of capillary tubes located in the PU foam, the aluminum sheet on the top and the plaster board with PCM on the bottom. However, the company publishes only very few technical information regarding the performance of the product.

\section{Project phases}

The literature review indicated that there are only a few research works dealing with the performance and thermal properties of PCM concrete, and no research has been done on the cooling potential of combined PCM concrete and thermally activated building system (TABS). Therefore, numerous activities have been 
scheduled in order to investigate the potential of this new technology. In the project, the following activities can be listed:

- Firstly, the project presents the initial investigation of the potential to increase the heat storage and to determine the cooling capacity of the hollow core concrete deck element with PCM concrete and with integrated pipes for TABS. The stage is called initial because the thermal properties of combined PCM and concrete are calculated according to the theoretical assumptions and are not validated with measurements yet.

- Secondly, the presented work indicates the experimental methodologies to determine the thermal conductivity of the new material such as combined microencapsulated PCM and concrete. Moreover, the thesis presents the newly developed methodology to determine the specific heat capacity of PCM concrete as a function of temperature $C p(T)$. What is more, various methods are proposed to calculate $C p(T)$ and the obtained results are discussed.

- Thirdly, the numerical and experimental investigation of the thermal conductivity of inhomogeneous hollow core deck element is presented. The outcome of that investigation indicates which method should be applied to describe heat transfer within the air hollow in the hollow core deck in order to obtain results that are close to the experimental results.

- Fourthly, the investigation will include updated numerical analysis of the performance of the concrete hollow core deck element with PCM and TABS. The updated decks are defined with experimentally determined thermal properties of combined PCM concrete material.

- Fifthly, the full-scale dynamic experimental analysis of five various decks is performed to investigate the potential for increase of the dynamic heat storage in the hollow core decks. The modified decks integrate microencapsulated PCM and their bottom surface area is extended in order to increase the heat transfer area and by that increase the diurnal dynamic heat storage capacity of the decks. The result of the investigation is the absolute average daily dynamic heat storage capacity of investigated decks.

\section{Initial numerical analysis of the heat storage and cooling power of the concrete deck with PCM and TABS}

\subsection{Purpose}

The purpose of the initial numerical study is to investigate the most advantageous design of concrete hollow core slab with regards to optimal location and amount of the PCM. The optimal location and amount of PCM should result in the increased thermal mass and at the same time optimal utilization of thermal mass capacity. Moreover, focus is also put on, how to establish possible heat storage and cooling power performance of the deck element within realistic dynamic thermal condition in the building. Due to the fact that PCM is expensive and its addition to the concrete element not necessarily has to improve thermal storage capacity of the hollow core deck element, it has to be precisely investigated, how, how much and where it should be integrated in the deck element to achieve a feasible and price competitive product.

Firstly, the development of the concept of the integrated PCM and TABS in the element of prefabricated hollow core slab will be presented. Secondly, developed concept is transferred to COMSOL Multihysics program, where various scenarios for variation of geometrical and thermal properties and boundary condition parameters are numerically calculated. Obtained results shall reveal which parameters are mostly important to utilize the thermal mass of the slab and where PCM shall be located. What is more, diurnal dynamic heat storage capacity for the passive approach of the deck is compared with diurnal cooling effect in the case when the deck is activated according to miscellaneous time schedules. Full investigation of initial numerical analysis presented in this chapter can be found in [24]. 


\subsection{Methodology}

In this study, the development and design of PCM and TABS concrete deck element was based on existing and already commercially introduced product, which is called ThermoMax, see Figure 6. Yet ThermoMax is produced as deck made of only concrete, in other words without PCM.

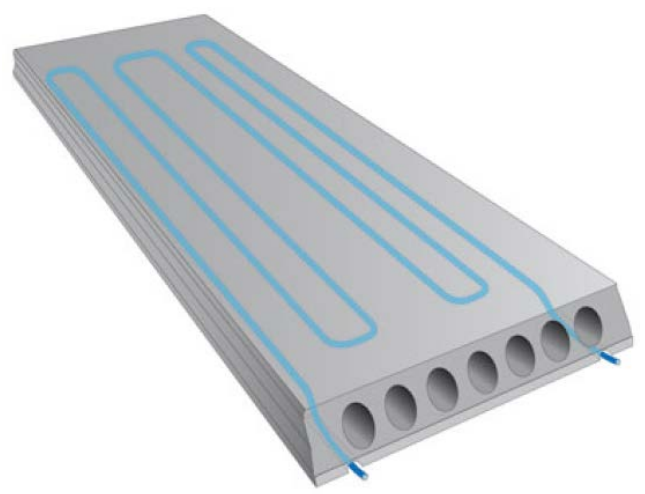

Figure 6. ThermoMax: Prefabricated concrete ceiling deck element with integrated water pipes.

In order to be able to calculate dynamic heat storage capacity of any material, three parameters have to be known. These parameters are: density- $\rho$, heat conductivity- $\lambda$ and specific heat capacity- $C p$.

Normal concrete has its well known and defined thermal properties. Thermal properties of different PCMs are known or can relatively easily be defined with use of Differential Scanning Calorimetry (DSC). The microencapsulated PCM that will be used in this research is produced by BASF and product name is 5040X. However, if concrete and PCM is combined into one material, then physical and thermal properties have to be specially defined for each of combination ratios. In the initial investigation that is presented in this section, density for combined concrete and PCM is calculated according to weight average calculation presented in Equation (1).

$\rho=\left(\mathrm{P} \_\right.$PCM $) * \rho_{\mathrm{pcm}}+\left(100-\mathrm{P} \_\mathrm{PCM}\right) * \rho_{\text {concrete }}$

Where:

$P \_P C M$ - is weight percentage of added PCM, [\%]

$\rho_{p c m}$ - is PCM density, $\left[\mathrm{kg} / \mathrm{m}^{3}\right]$

$\rho_{\text {concrete }}$ - is concrete density, $\left[\mathrm{kg} / \mathrm{m}^{3}\right]$

Heat conductivity of combined concrete and PCM is calculated according to the methodology for calculation of heat conductivity of inhomogeneous materials, which is presented in [C4]. After simplification, methodology adapts the same form as Equation (1), but density is replaced by respectively heat conductivity of PCM and concrete.

\begin{tabular}{|l|c|c|c|}
\hline & Density $\left[\mathrm{kg} / \mathrm{m}^{3}\right]$ & Conductivity $[\mathrm{W} /(\mathrm{mK})]$ & Specific heat capacity $[\mathrm{J} /(\mathrm{kgK})]$ \\
\hline PCM & 98 & 0,14 & - \\
\hline Concrete & 2300 & 1,8 & 1000 \\
\hline
\end{tabular}

Table 4. Thermal properties of concrete and PCM

Calculation of specific heat capacity for combined concrete and PCM is based on the results obtained from (DSC) of pure PCM. Due to the fact that PCM specific heat capacity varies with its temperature, analogically the same was assumed for combined concrete and PCM material.

In Figure 7 are presented calculated heat capacities for different weight percentage ratios with respect to temperature. Curves are valid for melting process and PCM with melting point at $23{ }^{\circ} \mathrm{C}$. 


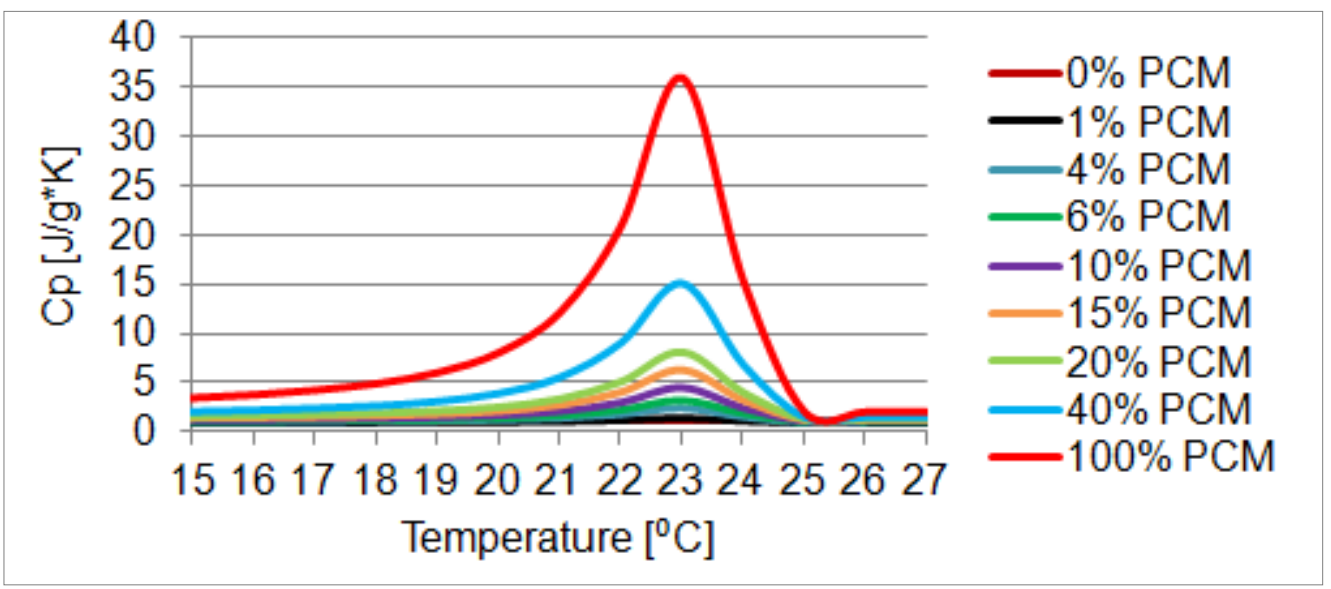

Figure 7. Calculated specific heat capacities for different ratios of PCM and concrete in function of temperature

The sensitivity analysis of location and amount of integrated PCM was performed based on simulation done in the COMSOL Multiphysics program.

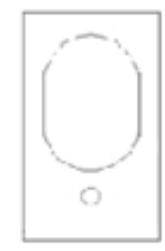

reference

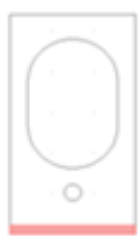

$1 \mathrm{~cm}$

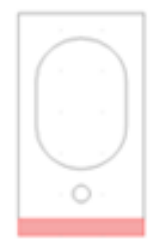

$2 \mathrm{~cm}$

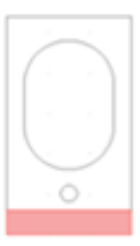

$3 \mathrm{~cm}$

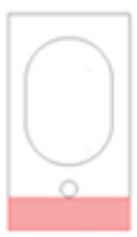

$4 \mathrm{~cm}$

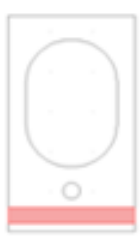

$2 \mathrm{~cm} \_1 \mathrm{~cm}$

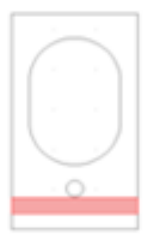

$2 \mathrm{~cm} \_2 \mathrm{~cm}$

Figure 8. COMSOL models: Model without PCM and with highlighted various location and thickness of layer with combined concrete and PCM

Several models with different percentage of the incorporated PCM and different location of combined PCM and concrete material were simulated in order to find which model has ability to store highest amount of heat. Improvement of ability to store heat was measured in comparative manner with respect to performance of the original deck made without PCM. COMSOL models can be simplified to the sections presented in Figure 8 due to the symmetry and geometric repeatability of the deck construction.

Due to the fact that in the real deck, vertical boundaries are facing almost the same sections, these boundaries are defined as adiabatic. Moreover, it is assumed that temperature on the upper and lower surface is fluctuating with diurnal sinusoidal pattern between $20^{\circ} \mathrm{C}$ and $26^{\circ} \mathrm{C}$ in order to imitate indoor temperature condition in the building. Moreover, on the upper and lower surface is applied combined heat transfer coefficient for convection and radiation, which in this study is varying between 2 and $30 \mathrm{~W} /\left(\mathrm{m}^{2} \mathrm{~K}\right)$. Furthermore, when diurnal dynamic heat storage capacity is calculated, which means that deck is passive, water in the pipe is only defined as material and none boundary is applied. However, when the deck is simulated as thermally activated, the pipe perimeter is defined as boundary condition and heat transfer coefficient on the internal surface of the pipe is defined at $15000 \mathrm{~W} /\left(\mathrm{m}^{2} \mathrm{~K}\right)$. In this study temperature of the water is defined for three scenarios: $16{ }^{\circ} \mathrm{C}, 18{ }^{\circ} \mathrm{C}$ and $20^{\circ} \mathrm{C}$. Finally, at this stage of the project the heat transfer within air void is simplified and the air void is presented as air chamber with standing still air and neither radiation nor convection within air hollow is considered. Since all boundary conditions are conserved for all simulated models and total size of the models is not changed the obtained results can be compared for all models.

Although TABS concept can be used for both heating and cooling, in this study focus is put only on its cooling performance, see also chapter 2.2. Respectively, investigation was carried out for carrier temperature of $16{ }^{\circ} \mathrm{C}, 18{ }^{\circ} \mathrm{C}$ and $20^{\circ} \mathrm{C}$ which is in all cases either below or equal to lowest assumed indoor temperature. 


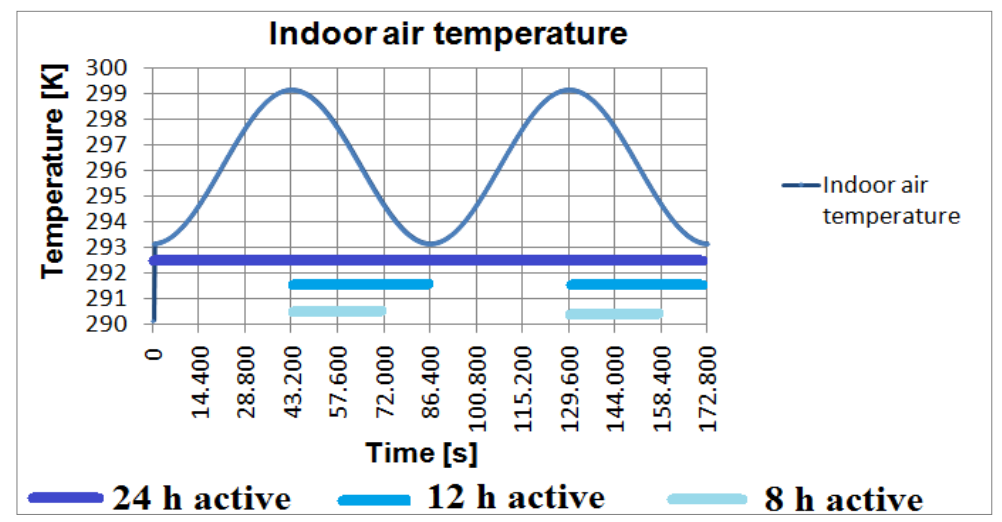

Figure 9. TABS thermal activation schedules with respect to indoor temperature fluctuation.

Moreover, in this study, are considered two different water pipe locations. First, where centre of the pipe is $50 \mathrm{~mm}$ and second, where centre of the pipe is $20 \mathrm{~mm}$ from the bottom surface of the hollow core slab. In both cases the diameter of the water pipe is set to be $20 \mathrm{~mm}$ and spacing between pipes is $150 \mathrm{~mm}$. Investigation is carried out for different control modes. Full time mode considers that TABS is in operation 24 hours/day, which means always. Secondly, investigation with shorter time mode is carried out, and respectively 12 and 8 hour mode is considered. For sake of cost efficiency of operated system and with efficient utilization of high heat storage capacity of the PCM, it would be recommended to operate activated system as presented in Figure 9.

\subsection{Results}

Obtained results are split into two parts. In the first part initial results will be present for passive performance of the hollow core deck element with PCM; water flow is deactivated. Respectively, second part will illustrate results for thermally activated hollow core deck element; water flow is activated.

\subsubsection{Passive implementation}

In Figure 10, are presented results for case where PCM layer thickness is variable and the layer is always attached to the bottom of the deck element. 


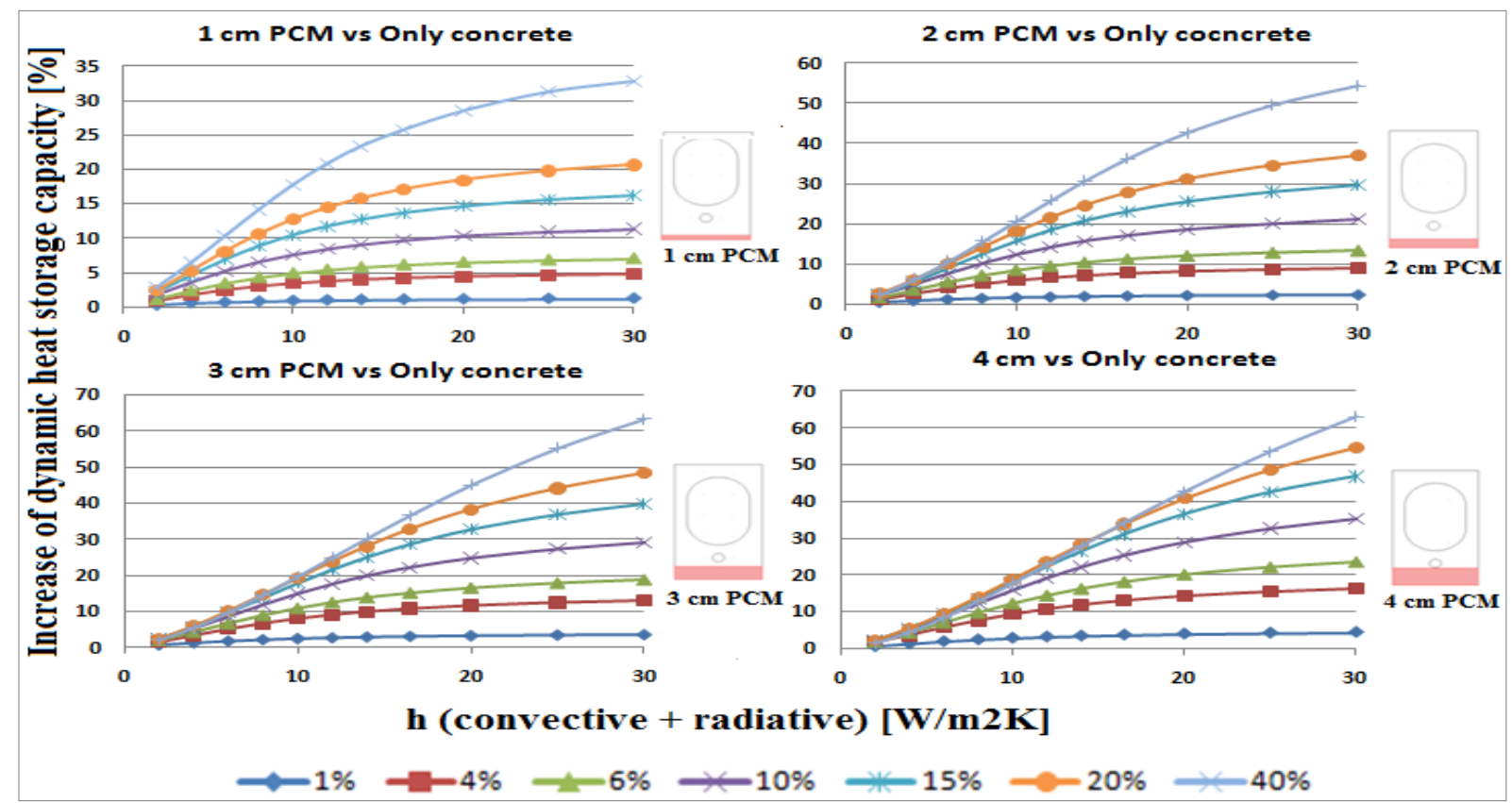

Figure 10. Increase of the dynamic heat storage capacity of the slab with PCM layer attached to the bottom of the deck.

In Figure 11, are presented results for case where PCM layer of constant thickness is moved towards the centre of the hollow core deck element.

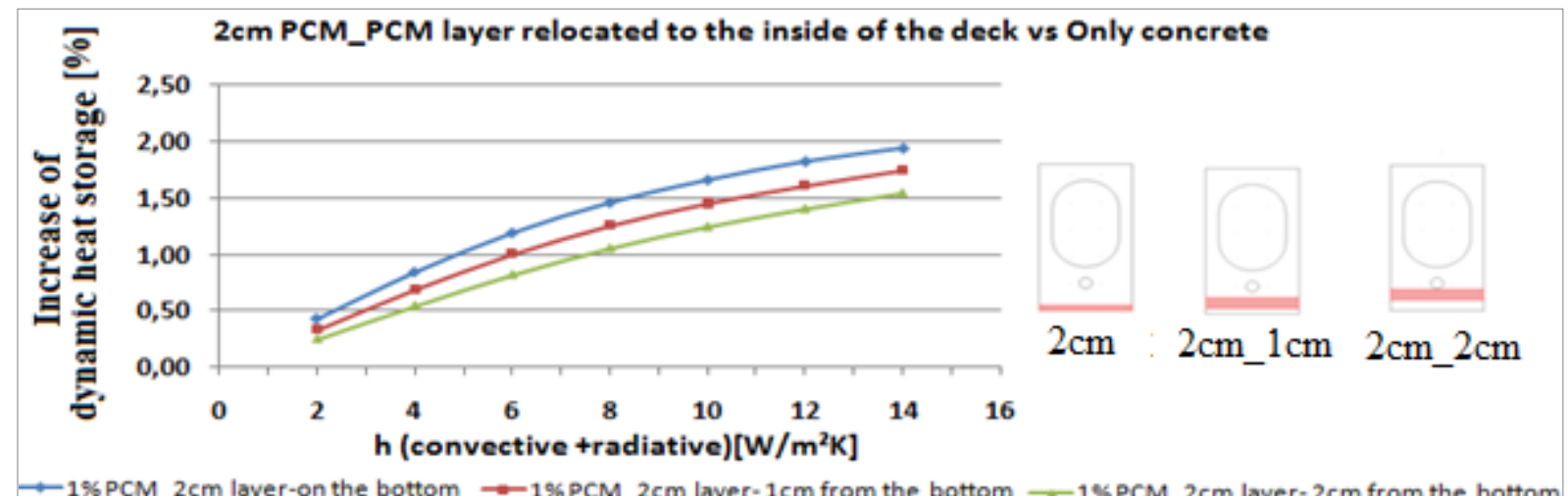

Figure 11. Increase of dynamic heat storage capacity for slab with PCM layer gradually relocated to the inside of the deck.

\subsubsection{Active implementation}

Results presented in Figure 12, for activated deck, are valid for the deck with 1cm thick layer with PCM that is attached to the bottom of the deck. 


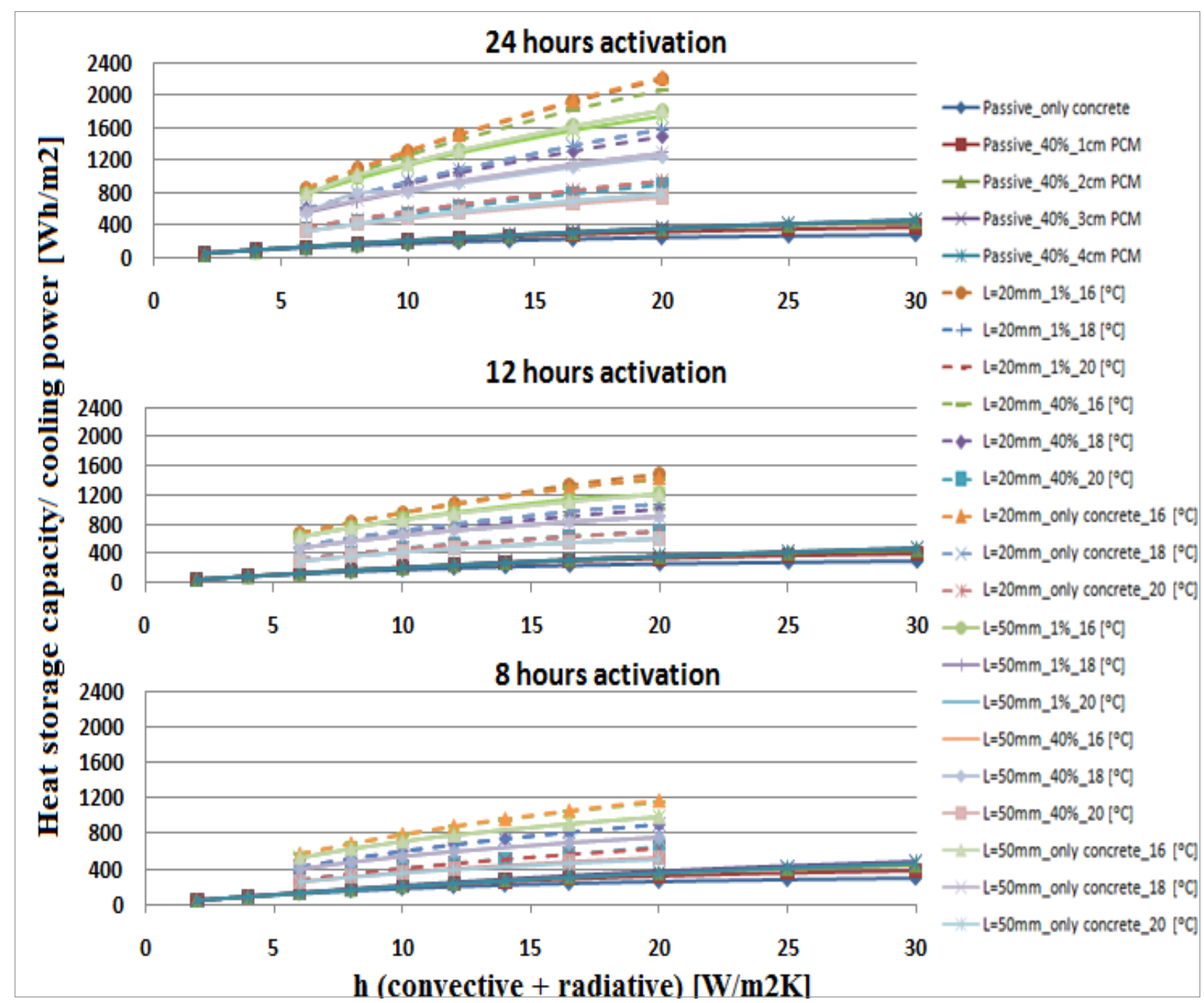

Figure 12. Calculated daily cooling power of thermally activated deck and heat storage capacity of passive deck for chosen deck configurations

\subsection{Conclusion}

In Figure 10 is presented calculated improvement of diurnal dynamic heat storage capacity of the hollow core deck element with different thicknesses of layer with PCM with respect to the deck made of only concrete. Results for different ratio of implemented PCM are presented as a function of combined heat transfer coefficient for radiation and convection. Results are valid for the decks with a layer of PCM attached to the bottom of the deck. At some point, it can be observed, that for the low percentage of PCM and high heat transfer coefficient there is no improvement. This means, that all thermal mass is utilized. On the other hand, for very high percentage of PCM it can be observed that not all thermal mass is utilized even for very high heat transfer coefficient. Moreover, in Figure 10, it can be noticed that improvement of the dynamic heat storage capacity between the deck with 1 and $2 \mathrm{~cm}$ is more significant than between the deck with 2 and $3 \mathrm{~cm}$ thick layer of PCM. Finally, improvement between deck with 3 and $4 \mathrm{~cm}$ thick layer of PCM is almost none for full range of PCM ratios. The reason for that kind of results is due to the fact that with increased amount of implemented PCM, decreases heat conductivity of the combined material. Low heat conductivity decreases heat penetration into the deck, which cause that a larger inner part of the deck is not activated. Although results presented in Figure 11 indicate that there is improvement in dynamic heat storage with respect to the deck made of only concrete, it can also be observed that the further layer is located from the bottom surface of the deck the lower becomes improvement. Based on results presented in Figure 10 and Figure 11 it can be concluded that layer with PCM should be always attached to the bottom surface of the 
hollow core deck element. Moreover, for the theoretically calculated thermal properties of the PCM concrete it is not recommended that the layer with PCM is thicker than $3 \mathrm{~cm}$. Finally, it can be noticed that the heat transfer coefficient on the surface has a dominant role in activating the thermal mass of the construction element.

In Figure 12 are depicted results of daily cooling power of the thermally activated deck element. In the same figure are depicted results of calculated heat storage capacity for chosen simulations with passive deck implementation. With regards to activated system, results are presented for three activation modes: 24 (correspond to 100\% diurnal cooling capacity), 12 (50\% of diurnal cooling capacity), and 8 hour (33\% of diurnal cooling capacity). Firstly, it can be noticed, that the longer the water flow is activated and the lower is the water temperature, the higher is the cooling performance. Secondly, for the deck with pipes located 20 $\mathrm{mm}$ from the bottom of the deck the cooling effect is higher than for the deck with pipes located $50 \mathrm{~mm}$ from the surface. Moreover, it can be observed that if there is a very high amount of PCM in the concrete then the layer of PCM concrete can have a damping effect on cooling performance of the thermally activated deck. Finally, in all three charts presented in the Figure 12, it can be noticed, that the cooling effect regardless of activation mode, water temperature and pipe location is much higher than the heat capacity that can be stored in the deck. This means that TABS system should be able to discharge even high heat loads from the building of approximately up to $55 \mathrm{~W} / \mathrm{m}^{2}$ within realistic heat transfer coefficient range of up to $10 \mathrm{~W} / \mathrm{m}^{2} \mathrm{~K}$.

The presented modeling study on combined PCM and TABS concept indicates possibly the best configuration with regards to the heat storage capacity of the hollow core deck. Still it has to be kept in mind that the obtained results are valid for theoretically calculated thermal properties of combined PCM and concrete.

\section{Experimental determination of thermal properties of PCM concrete}

Since the results presented in the section 4 are valid for the theoretically calculated thermal properties (thermal conductivity and specific heat capacity) the following step is to experimentally determine the thermal properties of the newly developed PCM concrete material and revise the initial assumptions. In the following subsections 5.1 and 5.2 methodologies will be presented respectively to measure thermal conductivity and specific heat capacity of PCM concrete material and obtained results from measurements.

\subsection{Thermal conductivity - experimental investigation}

A full investigation of thermal conductivity of PCM concrete presented in chapter 5.1 can be found in [25].

\subsubsection{Purpose}

Although thermal conductivity is known for the PCM and standard concrete when they are separate materials it is not certain that the thermal conductivity of the combination of them will be the same as the weight average thermal conductivity of both of them, as it was initially assumed in the calculations presented in section 4 . The purpose of the experimental study presented in this chapter is to determine the actual thermal conductivity of the combined PCM and concrete material. Likewise specific heat capacity and density the proper thermal conductivity has to be known in order to properly simulate thermal behavior of constructions under dynamic thermal conditions.

\subsubsection{Methodology}

Measurements were conducted with use of a hot plate apparatus type EP500 fabricated by Lambda Messtechnik. The apparatus was upgraded to a version which allows measurements of concrete samples of thermal conductivity of up to $2 \mathrm{~W} /(\mathrm{mK})$. More information regarding steady-state thermal conductivity 
measurements with use of hot plate apparatus can be found in standard according to which the apparatus is operating [C5], [C6], [C7], [C8].

Samples are inserted between a hot (upper) and a cold (lower) plate with dimension of $50 \mathrm{~cm} \mathrm{x} 50 \mathrm{~cm}$. Afterwards, the upper plate is lowered with the given pressure until the pressure set point is reached. Measuring area is the innermost square measuring $15 \mathrm{~cm} \mathrm{x} 15 \mathrm{~cm}$ and the rest is a frame made of a highly insulating material. During the experiments with concrete samples, it was discovered that the frame made of elastic foam gives the best repeatability. Additionally, the apparatus is equipped with perimeter zones surrounding the measured sample which control the temperature according to an embedded algorithm. Finally, a 1D heat flow is achieved, from the hot to the cold plate, within the measured sample. One set of experiments includes three measurements at three various mean temperatures. In this investigation, mean temperature of 10,20 and $40^{\circ} \mathrm{C}$ were chosen for measurements. Moreover, the temperature difference between the hot and the cold plate is set to $15^{\circ} \mathrm{C}$ in all the series of measurements. In that manner one measurement $\left(10^{\circ} \mathrm{C}\right)$ is done for the temperatures across the sample below PCM melting point, one measurement $\left(20^{\circ} \mathrm{C}\right)$ is done for the temperatures across sample within PCM melting point and one measurement $\left(40^{\circ} \mathrm{C}\right)$ is done for the temperatures across sample above PCM melting point.

In order to ensure a good attachment between the apparatus plates and the measured samples, a thin layer of ultrasound gel is used on tops of the samples. Moreover, it has to be stressed that to be able to compare results of measured thermal conductivity of various samples they all need to be dry. Based on the obtained results it can be concluded that firstly, the thermal conductivity of concrete containing moisture is higher than for the dry one and secondly, it is very long process to completely dry out concrete and cement paste samples.

\subsubsection{PCM concrete samples preparation}

A set of PCM concrete specimens was prepared with $0 \%, 1(\mathrm{wt}) \%, 4(\mathrm{wt}) \%$ and $6(\mathrm{wt}) \%$ by weight of incorporated PCM. Each specimen has area of $15 \times 15 \mathrm{~cm}$ and height of approximately $8 \mathrm{~cm}$. Specification of the concrete is given in Table 5 and properties of additives are given in Table 6 . When preparing mixtures the total volume for each of concrete mixtures was $0.025 \mathrm{~m}^{3}$.

\begin{tabular}{|l|c|c|c|c|c|c|}
\hline Sample & PCM & Cement & Sand(dry) & Stone(dry) & Water & Superplasticizer \\
\hline$[-]$ & {$[\mathrm{kg}]$} & {$[\mathrm{kg}]$} & {$[\mathrm{kg}]$} & {$[\mathrm{kg}]$} & {$[\mathrm{kg}]$} & {$[\mathrm{kg}]$} \\
\hline $0 \%$ & 0 & 7.63 & 20.72 & 25.42 & 4.72 & 0 \\
\hline $1(\mathrm{wt}) \%$ & 0.58 & 7.64 & 20.10 & 24.54 & 4.73 & 0 \\
\hline $4(\mathrm{wt}) \%$ & 2.19 & 7.63 & 18.01 & 22.10 & 4.63 & 0.13 \\
\hline $6(\mathrm{wt}) \%$ & 3.18 & 7.63 & 16.78 & 20.58 & 4.41 & 0.58 \\
\hline
\end{tabular}

Table 5. PCM concrete specification

\begin{tabular}{|l|c|c|c|c|}
\hline Material & Supplier & Brand & Density & Abs. /moist \\
\hline$[-]$ & {$[-]$} & {$[\mathrm{kg}]$} & {$\left[\mathrm{kg} / \mathrm{m}^{3}\right]$} & {$[\%]$} \\
\hline PCM & BASF & MicronalDS5040X & 970 & $/$ \\
\hline Cement & Aap & BASIS & 3100 & $/$ \\
\hline Sand $(0 / 4 \mathrm{~mm})$ & NCC & $/$ & 2640 & 0.2 \\
\hline Stone $(4 / 8 \mathrm{~mm})$ & NCC & $/$ & 2660 & 0.6 \\
\hline Superplasticizer & BASF & AC410 & 1060 & 77 \\
\hline Water & $/$ & $/$ & 998,2 & $/$ \\
\hline
\end{tabular}

Table 6.PCM concrete material properties

It can be observed that in the all PCM concrete specimens w/c ratio is equal 0.6. This parameter is kept at the same level because as it was indicated in reported research [26] thermal conductivity of concretes depends strongly on the w/c ratio. 
Before starting measurements, all the samples were dried at $60{ }^{\circ} \mathrm{C}$ in the oven until they reached constant weight. The constant weight signalized that all the water has evaporated from the sample and that the measured thermal conductivity is independent of moisture content in the samples.

\subsubsection{Results: PCM concrete}

Each of PCM concrete samples was measured 3 times. Results from these experiments are presented in Figure 13. Based on the results presented in Figure 13 (left) an arithmetic average thermal conductivity is then calculated for each sample and the mean measurement temperature, see graph Figure 13 (right). In Figure 13 (right) is also depicted theoretically calculated thermal conductivity that was used in initial numerical investigations on dynamic heat storage capacity presented in chapter 4 and in [24].

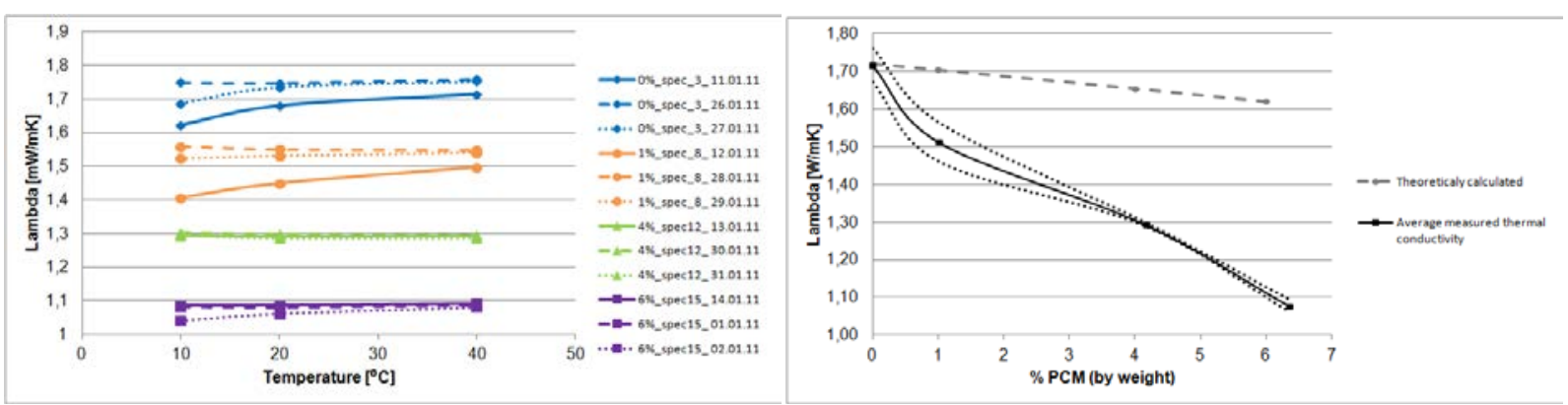

Figure 13. (left) Is presented the measured thermal conductivity of PCM concrete as a function of mean temperature, in the (right) is presented the average measured thermal conductivity of PCM concrete as a function of integrated PCM and theoretical thermal conductivity based on weight ratio.

The accuracy of each thermal conductivity measurement is set to $\pm 1.5 \%$ for at least 150 minutes what in other words means that the test will not be finished if thermal conductivity varies more than $1.5 \%$ from the mean value measured over 150 minutes. However, each time a new test is triggered a slightly different attachment between specimen and apparatus's plates are obtained and different surface resistances occur. The error due to different attachment between specimen and plates can be observes when comparing measurements of the same specimen with each other. Therefore the uncertainty of measured thermal conductivity strongly depends on number of tests of each specimen and the more measurements is performed the smaller uncertainty should be obtained.

To estimate uncertainty of thermal conductivity measurements a standard deviation calculations are proposed:

$m_{x}=\frac{x_{1}+x_{2}+x_{3}}{n}$

and standard deviation then is calculated from:

$s_{x}=\sqrt{\frac{\left(x_{1}-m_{\chi}\right)^{2}+\left(x_{2}-m_{\chi}\right)^{2}+\left(x_{3}-m_{\chi}\right)^{2}}{n-1}}$

The result of standard deviation for three tests performed on each sample is depicted in Figure 13 (right) as doted lines.

\subsubsection{Conclusion}

Results presented in this section indicate that integration of PCM, which itself has a low thermal conductivity, significantly influences the thermal conductivity of the entire concrete in which it is integrated. Although, the diameter of microencapsulated-PCM is of only couple $\mu \mathrm{m}$, the thermal conductivity of the cement paste in which it is integrated decreases significantly with increased amount of integrated PCM. In 
that manner heat cannot flow from aggregate to aggregate (stone to stone) for which the thermal properties are kept unchanged.

Furthermore, it can be observed that the lower the mean temperature of a measurement the lower is the repeatability of the thermal conductivity measurements. This can not entirely be explained but reason for the low repeatability of measurements could be due to condensation problem on the cold plate. It should be stressed that in order to obtain proper results and good repeatability of measurements the bottom and upper surface of the concrete samples have to be as flat as possible and attachment between plates and sample need to be insured.

It is concluded, that to increase the repeatability of measurements for the low mean temperatures whole hot plate apparatus should be located in the space where moisture in the air could be controlled.

With regards to the decreasing thermal conductivity with increased amount of PCM it can be concluded that this property will have negative impact on the thermal activation and energy storage within the PCM concrete building elements. It can be also expected that initial simulations, see chapter 4 and [24], with theoretically calculated thermal conductivity of PCM concrete overestimate dynamic heat storage of investigated decks. The performance of decks is re-analyzed at later stage in the project with respect to new measured thermal conductivities of PCM concrete and results of that analysis can be found in chapter 7 and in [34].

\subsection{Specific heat capacity - experimental investigation}

Specific heat capacity of PCM concrete materials is experimentally determined due to the same reason as for thermal conductivity, see chapter 5.1.1. However, the challenge to determine the specific heat capacity of PCM concrete is that there is no standard procedure for that type of measurements of inhomogeneous materials characterized by the latent heat storage capacity. For that reason and for the purposes of the project, a new methodology to determine the specific heat capacity of PCM concrete as a function of temperature has been developed. A full investigation of specific heat capacity of PCM concrete material presented in chapter 5.2 can be found in [27].

\subsubsection{Purpose}

The correct design of the building with integrated PCM concrete material requires correct knowledge of the thermal properties of PCM concrete material. The single data points, for example, phase change enthalpy at melting temperature or heat of fusion do not describe PCM properties with sufficient accuracy in order to perform dynamic simulation of the room or the whole building with the PCM concrete. The phase change occurs in a temperature range and not at a constant temperature level and therefore the specific heat capacity of this type of materials has to be known as a function of temperature.

Since the investigated material matrix (concrete) is always in solid state, the measurements of the thermal conductivity can be done according to standardized steady-state procedures, for example, with hot plate or hot box apparatus. On the contrary, the challenge is to define PCM concrete specific heat capacity, which as mentioned, has to be known as a function of temperature. The specific heat capacity of PCM concrete cannot be measured with the conventional transient methods because the representative samples of concrete materials are too big and are inhomogeneous. The sample of few milligrams normally tested, for example, by DSC method is not representative for concrete materials and therefore a new methodology for measurements of the specific heat capacity of PCM concrete bulk material has been developed and is presented in this section.

\subsubsection{Methodology}

\subsubsection{Modified hot plate apparatus}

The hot plate apparatus EP 500 presented in chapter 5.1.2, varies from the standard hot plate apparatus. In the standard apparatus only steady-state mode is available, which is used to measure thermal conductivity of 
various tested materials. For the purpose of the experiments presented in this chapter, the standard hot plate apparatus was modified in order to be able to conduct dynamic thermal experiments. The control system of the hot plate apparatus was upgraded with the new mode that enables to define a dynamic temperature load. Firstly, a steady temperature at $18{ }^{\circ} \mathrm{C}$ on upper and lower plate is defined in the dynamic mode. This steadystate is maintained for at least 5 hours in order to ensure that the whole sample reaches the same temperature. Afterwards, the sample is heated symmetrically by both the upper and the lower plate from $18^{\circ} \mathrm{C}$ to $32^{\circ} \mathrm{C}$ over a period of 10 hours after which temperature stabilizes at $32{ }^{\circ} \mathrm{C}$. For the designed temperature range and heating time the temperature change is only $0.023^{\circ} \mathrm{C} / \mathrm{min}$. It is worth to stress that during the heating up process the hot plate apparatus is programmed to maintain linear temperature increase.

\subsubsection{Temperature profile measurements}

The presented experiment is designed to measure vertical temperature profiles of specimens with thin K-type thermocouples. Due to the fact that the concrete material is not homogeneous and has various aggregate sizes, direct casting of thin and gentle thermocouples in the sample would be very difficult and the final location of the thermocouples in the sample might be different from the designed one. As a result, an incorrect temperature profile of the specimens would be obtained. Therefore, after the thermal conductivity measurements of specimens measuring $15 \mathrm{~cm}$ x $15 \mathrm{~cm} \mathrm{x} 8 \mathrm{~cm}$ are completed, see chapter 5.1.4, the samples are cut into two equal pieces $15 \mathrm{~cm} \times 7.5 \mathrm{~cm} \times 8 \mathrm{~cm}$ and the surfaces along the cut is carefully polished. Afterwards, 9 parallel grooves $0.3 \mathrm{~mm}$ deep and wide spaced $8 \mathrm{~mm}$ apart are cut into the concrete as presented in Figure 14. Calibrated thin thermocouples, type K, are inserted in the specially grooved PCM concrete specimens, see Figure 14. Then, the two parts of a previously cut specimens are assembled with inserted thermocouples in-between. Finally, visual check was performed to ensure that there are no air gaps along the joining line where the thermocouples are inserted and that the specimens fit well to each other. The procedure is repeated for all investigated samples.
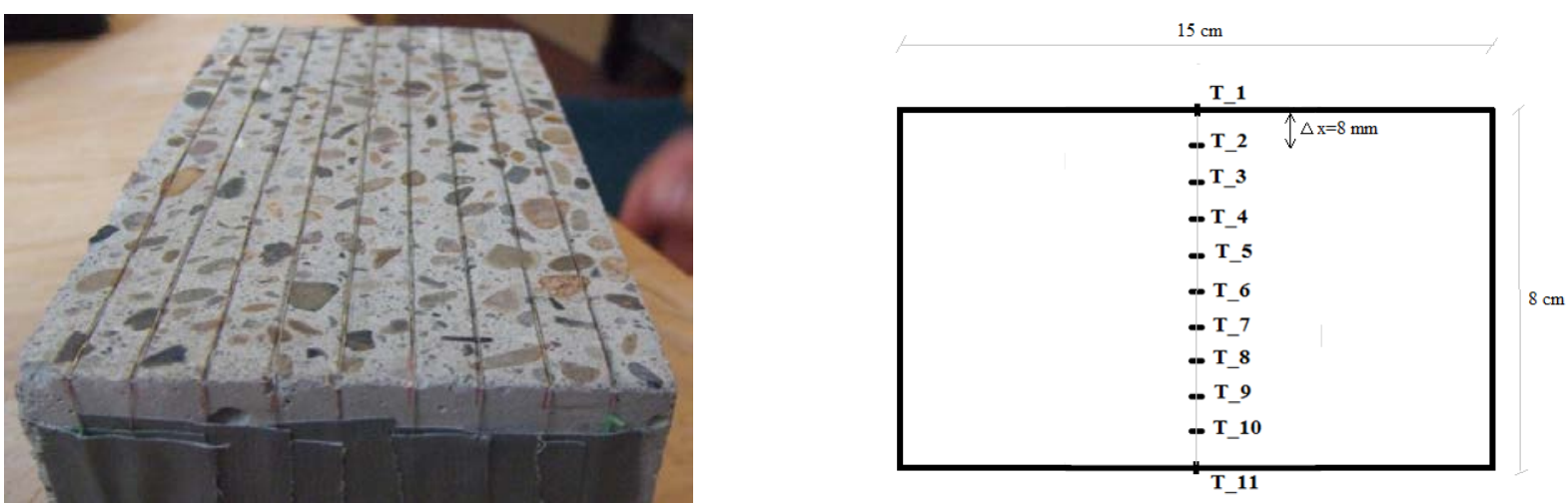

Figure 14. (left) Sample with special grooves for thermocouples, (right) location and number of the thermocouples in the sample.

\subsubsection{Methodology of heat flux measurement}

In the presented experimental investigation, it is necessary to measure the heat flux supplied from the plates of the apparatus to the PCM concrete specimen. Since the heating load from the hot plate apparatus is symmetric, the temperature of the bottom and top plate changes over time in the same manner. Thus it is sufficient to measure the heat flux only on one surface of the specimen which is attached to one of the plates of the apparatus. The heat flux is then measured either on the top or the bottom surface of the specimen. In this experiment, it is chosen to locate a heat flux film on the upper surface of the PCM concrete specimen. The dimension of the heat flux film located on the top surface of the PCM concrete specimen is specially chosen for the purposes of the dynamic experiment presented in this paper. Due to the dynamic nature of the experiment, the PCM concrete and the insulating frame is heated up at different rates. The difference of the 
temperature profile as a function of time in the concrete sample and in the surrounding insulating frame is due to the various thermal diffusivities of the two materials. As a result of temperature differences in the sample and the surrounding frame, the heat flux close to the edge of the concrete specimen is not onedimensional (1D), but is influenced by the frame temperature. In order to perform measurements of only 1D heat flux provided from the apparatus plates and free of side heat flux from the frame, the heat flux sensor has to have a smaller area than the total area of the specimen measuring $15 \mathrm{~cm} \times 15 \mathrm{~cm}$ and has to be located at the centre of the specimens, see Figure 15. In order to calculate the ratio between the side heat flux to the sample the heat flux applied from the hot plate apparatus, the numerical investigation is performed in the COMSOL Multiphysics program. The result from that investigation indicated that, if the heat flux film has a square size of $8 \mathrm{~cm} \mathrm{x} 8 \mathrm{~cm}$, then the side heat flux is at its maximum but constitutes only $0.6 \%$ of the total heat flux supplied from the bottom and top plate of the apparatus. It was assumed that the error at this level is within the acceptable range.

The heat flux film used in the experiment is a square heat flux sensor produced by Captec and has the sensitivity of $23.4 \mu \mathrm{V} /\left(\mathrm{W} / \mathrm{m}^{2}\right)$. The sensor is made of highly conductive copper and is only $0.3 \mathrm{~mm}$ thick.

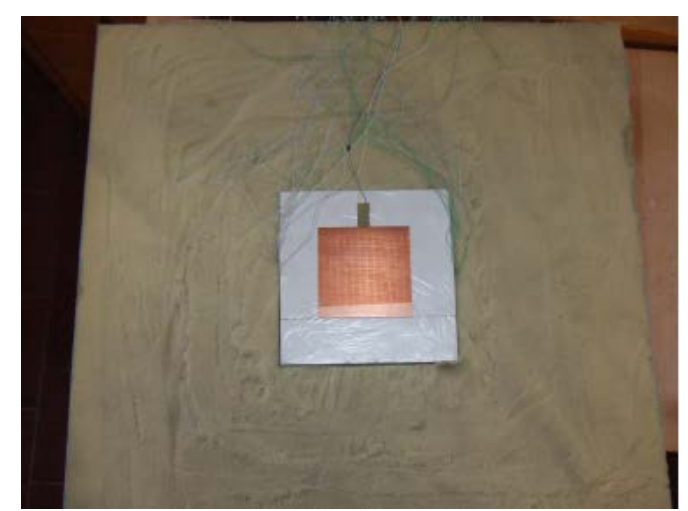

Figure 15. Concrete sample set in the insulating frame and with the heat flux film sensor on the top surface of the sample

\subsubsection{Sample set up in hot plate apparatus}

The specimen with the inserted thermocouples as described in section 5.2.2.2 is positioned in the hot plate apparatus in the centre of the lower plate. Afterwards, the attachment of the bottom of the specimen is checked for any irregularities. Then the top of the specimen is wrapped in a thin packing foil, and a thin layer of ultrasound gel is applied on the entire foil surface. The gel layer is covered with one more layer of thin foil. A thin square shaped heat flux film measuring $8 \mathrm{~cm} \times 8 \mathrm{~cm}$ manufactured by Captec is positioned in the middle of the top surface of the specimen and pressed into the gel layer. The prepared specimen is surrounded with elastic insulating frame and an upper "hot" plate is lowered until it reaches the top of the concrete specimen. The dynamic test is triggered after the last visual inspection is performed to verify if the specimen is attached well to both the lower and upper plate of the apparatus. At the same time, the logging process of signals from the thermocouples and the heat flux sensor film is started using the Helios Data logger type 2287A.

\subsubsection{Results}

The addition of the microencapsulated PCM in the concrete results in a development of the new material. The newly developed composite should be characterized by the new thermal properties that combine properties of the ordinary concrete and properties of PCM.

This chapter aims to present the outcome, temperature and heat flux results, measured during the experimental investigation. The outcomes from the experimental investigation are used to calculate the 
specific heat capacity as a function of the temperature of investigated PCM concrete samples. Subsequently, in the chapter are presented five different methodologies to calculate the specific heat capacity as a function of the temperature of PCM concrete composites.

Each method and its assumptions are described and representative results are illustrated. Finally, results obtained from the five methods are compared with each other and conclusions are drawn.

\subsubsection{Outcome of the dynamic experiment: temperature and heat flux}

This chapter presents the measured average heat flux and average temperature of the investigated specimens. Presented results are the average results of three series of measurements performed on each of the investigated samples. The average temperature presented in Figure 16 is calculated as the average temperature reading from all thermocouples inserted in the specimen and from all three series of measurements for each investigated specimen.
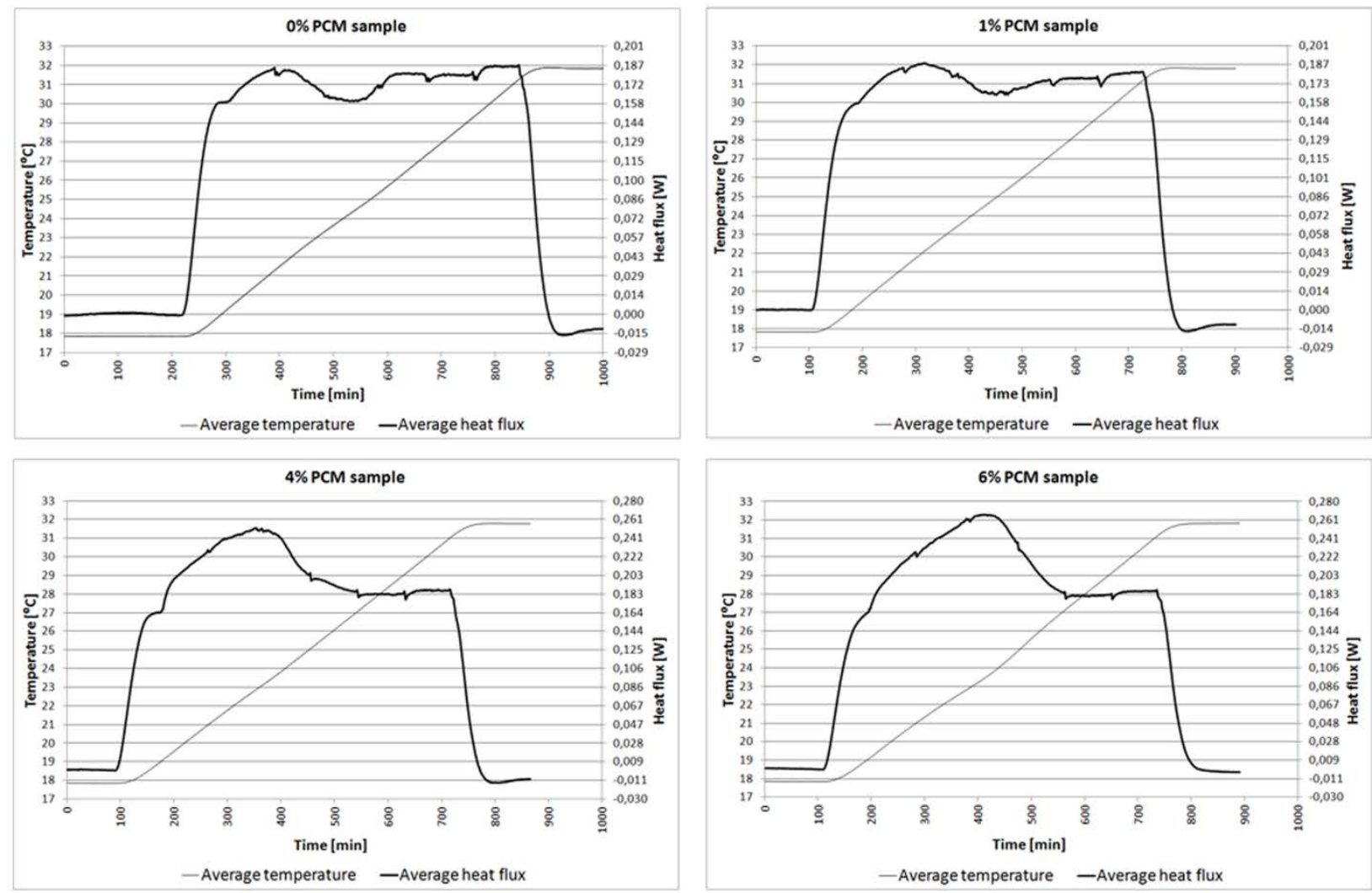

Figure 16. Temperature and heat flux results from the dynamic experiment.

As seen in Figure 16, the temperature of the sample stabilizes at approximately $18{ }^{\circ} \mathrm{C}$ and thereafter the specimen is linearly heated over 10 hours to approximately $32{ }^{\circ} \mathrm{C}$ when the temperature stabilizes again. For the concrete specimens with PCM, the hot plate apparatus needs to deliver more heat, see bold-faced curve, in the temperature range from approximately $19^{\circ} \mathrm{C}$ to $27^{\circ} \mathrm{C}$. This additional heat is necessary in order to overcome the melting process of the incorporated PCM in the specimen and to sustain a linear temperature increase predefined by the hot plate apparatus dynamic mode. The width of the measured heat flux peak indicates the melting range of the PCM. The highest peak of the heat flux occurs at approximately $23{ }^{\circ} \mathrm{C}$ which is also the melting point of the used PCM. The outputs of the experiment are the measured temperature profile in the sample and the heat flow to the specimen as a function of time. These outputs will be used to calculate the specific heat capacities of the PCM concrete specimens as a function of temperature. 


\subsubsection{Uncertainty of temperature and heat flux measurements}

In order to determine the minimal total errors of the measured and calculated heat flux and temperatures of various vertical directions, the relative weights of the object function can be determined by the error transfer function.

It is known that if there is a correlation between the indirectly measured parameter $\mathrm{N}$ and the directly measured parameters $x, y$ :

$Z=f(x, y)$

The error of indirectly measured parameter $Z$ can be described by the errors of directly measured parameter $x, y$ as follows:

$\Delta Z=\left|\frac{\partial f}{\partial x}\right| \Delta x+\left|\frac{\partial f}{\partial y}\right| \Delta y$

The uncertainty of measurements include: uncertainty of temperature measurements and uncertainty of heat flux measurements. The first one can be obtained from estimation of uncertainty of components used to measure temperature and these are given below:

- Voltage measurement of the data logger (maximum offset between different channels $\pm 0.075{ }^{\circ} \mathrm{C}$ ).

- Cell temperature of the ice point reference $\left( \pm 0.02^{\circ} \mathrm{C}\right)$.

- Composition of the thermocouple alloys $\left( \pm 0.023^{\circ} \mathrm{C}\right)$.

- Local changes of the alloys at the junction (minimized by cold joining).

The total uncertainty of temperature measurement is estimated by quadrature addition:

$\Delta T=\sqrt{0.075+0.02+0.023}=0.343{ }^{\circ} \mathrm{C}$

Regarding the accuracy of heat flux film sensor used in the measurements, it should be noticed that it was calibrated with use of hot plate apparatus. And therefore the uncertainty of thermal conductivity measurements obtained from hot plate apparatus have to be taken into consideration $( \pm 1.5 \%$ set in the single measurements test). In the calibration of heat flux film were also used additional thin thermocouples that were inserted on the top and bottom of sample materials used during calibration.

The sensitivity of flux sensor is $23.4 \mu \mathrm{V} / \mathrm{m}^{2}$, the area of the sensor is $0.0064 \mathrm{~m}^{2}$. The accuracy of data logger that logs voltage from heat flux (it was measured that $40 \mu \mathrm{V}$ corresponds to $1 \mathrm{~K}$ temperature difference). In order to minimize the contact thermal resistance, the flux measurement film with a thickness of $0.3 \mathrm{~mm}$ is pressed in the ultrasound (US) scanning gel with a pressure of about $1000 \mathrm{~Pa}$. The thermal conductivity of the ultrasound (US) scanning gel is $0.335 \mathrm{~W} /(\mathrm{m} \mathrm{K})$.

Considering the principle of hot plate apparatus, the error of heat flux measurement can be determined by following equations.

$q=\frac{T_{x=0}-T_{x=L}}{\frac{L}{k A}}=\frac{\left(T_{x=0}-T_{x=L}\right) k A}{L}$

$\frac{\Delta q}{q}=\left|\frac{\partial \ln q}{\partial k}\right| \Delta k+\left|\frac{\partial \ln q}{\partial T}\right| \Delta T=\frac{\Delta k}{k}+\frac{2 \Delta T}{T_{x=0}-T_{x=L}}$

Where:

$\mathrm{q}$ - heat flux, [W]

$\mathrm{k}$ - thermal conductivity, [W/(mK)]

A - Area, $\left[\mathrm{m}^{2}\right]$ 
L - Specimen height $[\mathrm{m}]$

It can be determined from the above error transfer function that the relative error of the heat flux measurement is $6.3 \%$.

\subsubsection{First $\mathrm{Cp}(\mathrm{T})$ calculation method: Theoretical method}

The theoretical method utilizes weight average equation for the specific heat of matrix material, for example, concrete and the pure PCM which is measured with use of DSC method, see Equation (9). The DSC measurements presented, are conducted by the producer of the PCM used in the presented investigation see Figure 17.

$C_{\text {composite }}=C_{P C M} * x_{P C M}+C_{\text {matrix }} *\left(1-x_{P C M}\right)$

Where:

$C_{\text {composite }}$ - Specific heat capacity of the composite, [J/(kgK)]

$C_{P C M}$ - Specific heat capacity of the PCM, [J/kgK]

$x_{P C M}$ - Weight ratio of the PCM in the composite

$C_{\text {matrix }}$ - Specific heat capacity of the matrix material, [J/kgK]

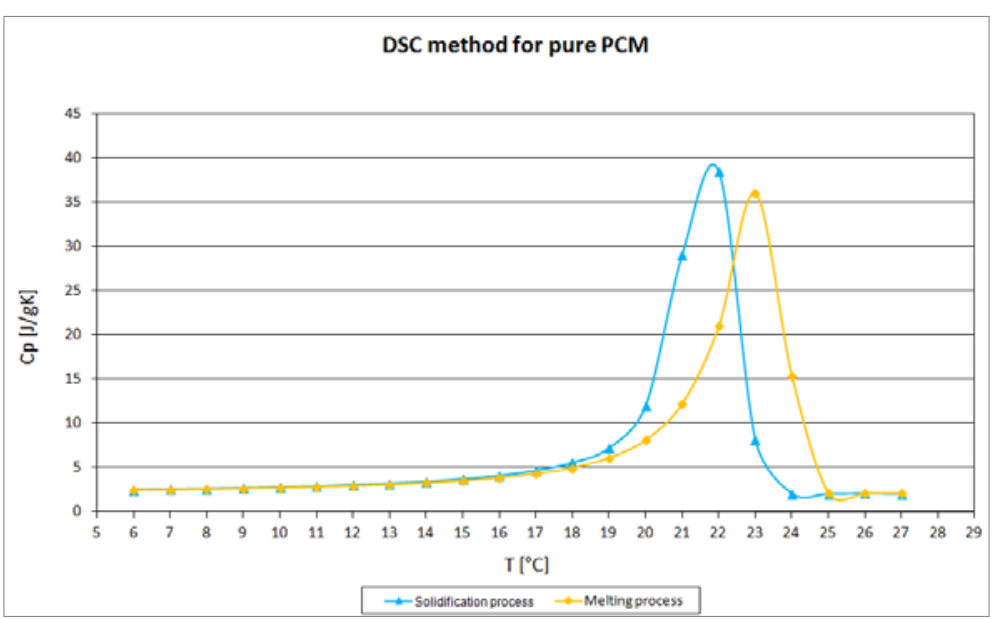

Figure 17. Result of DSC measurement of pure microencapsulated PCM

Then the results of 4(wt)\% and 6(wt)\% PCM concrete are as presented in Figure 18.

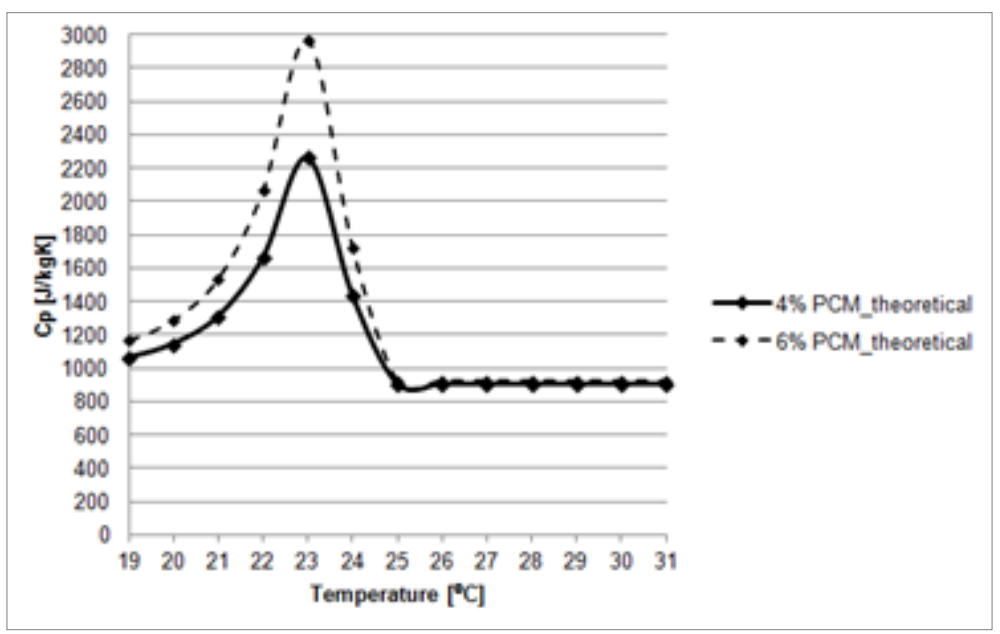


Figure 18.Theoretical Cp(T) for 4(wt)\% and 6(wt)\% PCM concrete only for melting.

It is worth highlighting that the calculations using the theoretical weight average method presented in this chapter did not utilize the results of the experimental outputs from the hot plate apparatus.

\subsubsection{Second $\mathrm{Cp}(\mathrm{T})$ calculation method: Simple method}

Calculation of the specific heat capacity of the material investigated in this research varies from the calculations of an ordinary material. The reason for this is the presence of PCM in the concrete. For normal solid materials, the specific heat capacity can be calculated using Equation (10) and Equation (11).

$C_{p}=\frac{\Delta Q}{m * d T}\left[\frac{J}{k g K}\right]$

and

$\Delta Q=\int_{T_{\text {start }}}^{T_{\text {end }}} \mathrm{q}(T) d T$

Where:

$\Delta Q$ - Internal energy increase of the sample, [J]

$m$ - Sample mass, [kg]

$C p$ - Specific heat capacity, [J/(kgK)]

$d T$ - Temperature difference between the beginning and the end of the sample heating process, [K]

This method makes it possible to find an average specific heat capacity in the defined temperature range. However, for the materials that change state, it is important to establish how enthalpy /specific heat capacity changes during the phase transition. Therefore, Equation (10) has to be modified in order to include the temperature gradient over time:

$C p(T)=\frac{A * q}{m * \frac{d T}{d t}}$

Where:

$A$ - Heated up sample area, $\left[\mathrm{m}^{2}\right]$

$q$ - Measured heat flux provided to the sample, $\left[\mathrm{W} / \mathrm{m}^{2}\right]$

$m$ - Mass of the sample, [kg]

$d T / d t$ - Increase of sample temperature in given time step, [K/s]

The method presented in Equation (12) was previously proposed by [20]. However, the method has its shortcoming. The heat flow used in the calculation is the one measured at the surface of the sample by the heat flux film sensor. In reality, the heat flux varies in the interior space of the sample due to the dynamic temperature at the specimen's top and bottom boundaries. As a consequence, Equation (12) overestimates the heat flux transferred to the sample with respect to the internal temperature gradient over time and therefore the calculated $C p(T)$ is also overestimated.

The calculated results for $0(\mathrm{wt}) \%, 1(\mathrm{wt}) \%, 4(\mathrm{wt}) \%$ and $6(\mathrm{wt}) \%$ PCM concrete specimens are illustrated in Figure 19. The results presented are the calculated average results of the specific heat capacity calculated for each of the thermocouples inserted in the specimen. The results for each of the measured specimen are presented separately for the three conducted measurement series. All three series of measurements were depicted in order to present that obtained results form a repeatable pattern. 


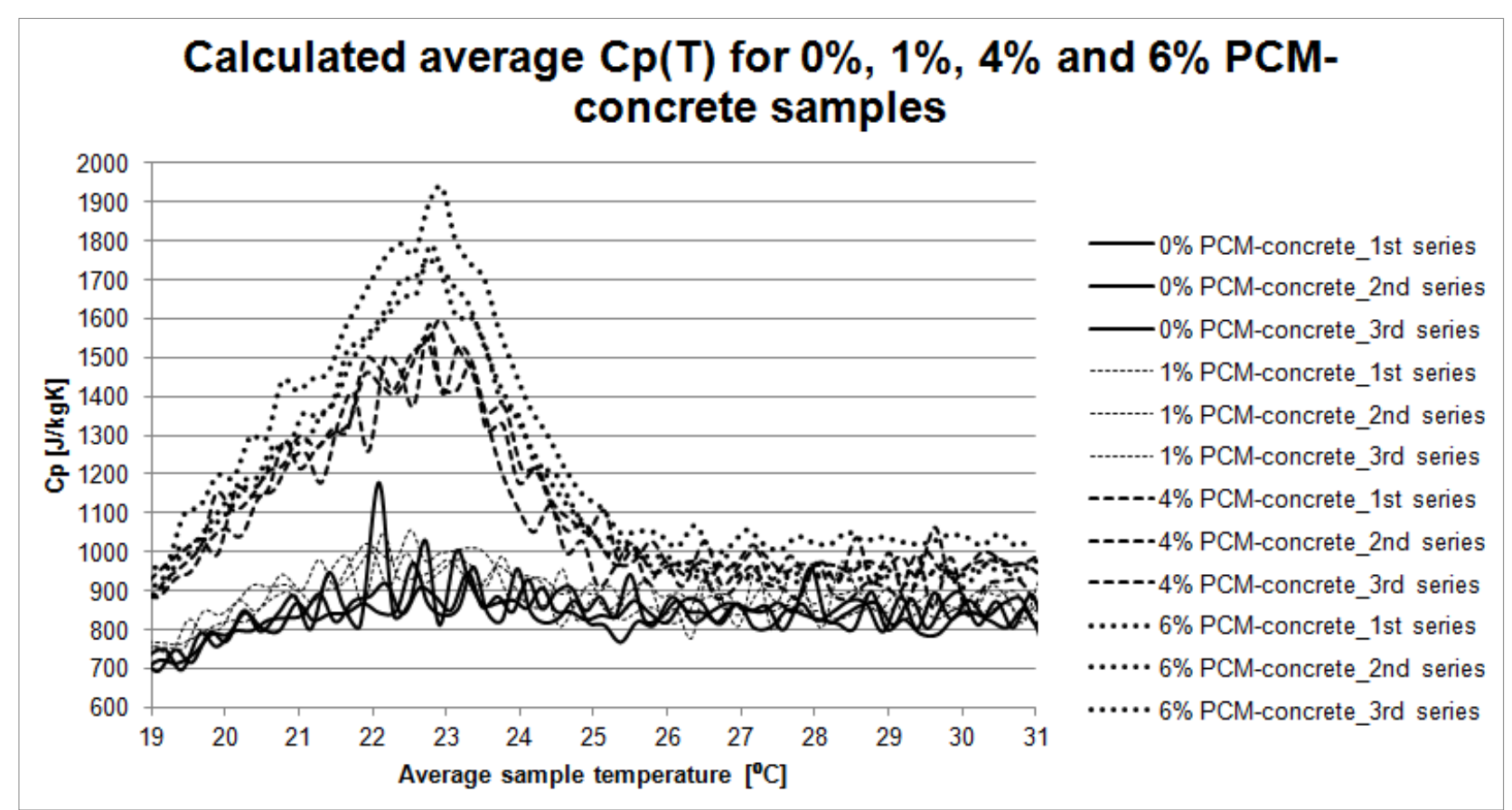

Figure 19. Calculated Cp(T) for various PCM concrete samples with use of "simple method”.

\subsubsection{Third Cp(T) calculation method: Moving enthalpy method}

The objective of the moving enthalpy method is to include in the calculation the variable heat flux in the interior of the PCM concrete sample that was disregarded in the simple method. The moving enthalpy method takes into consideration the fact that if the sample is under dynamic temperature load, it is not in thermal equilibrium, and the heat flux at various layers of the sample is varying due to the heat accumulation in the sample.

The method presented in this chapter utilizes the rule that the increase of enthalpy of the system equals the heating energy provided to the system under constant pressure. Taking into consideration that the temperature of the system is changing in time, the enthalpy increase can be written as:

$Q_{i, j}=\Delta H_{i, j}=A * \Delta x * \rho * C p\left(T_{i, j}\right) *\left(T_{i, j+1}-T_{i, j}\right)$

Where:

$Q_{i, j}$-Heat provided to the system to $\mathrm{i}^{\text {th }}$ node and in $\mathrm{j}^{\text {th }}$ time step, [J]

$\Delta H_{i, j}$ - Increase of the enthalpy of the system, [J]

$A$ - Surface area of the sample, $\left[\mathrm{m}^{2}\right]$

$\Delta x$ - Thickness of one layer between space steps where temperature is measured, [m]

$C p\left(T_{i, j}\right)$ - Specific heat capacity at temperature registered in space step i and time step j, [J/kgK]

$T_{i, j}$ - Temperature in space step i and time step j, [K]

Then on the surface of the sample it can be written:

$C p\left(T_{1, j}\right)=\frac{2 *\left(H_{1, j+1}-H_{1, j}\right) / 10}{A * \rho * \Delta x *\left(T_{1, j+1}-T_{1, j}\right)}$

$H_{i, j}=\int_{0}^{j} q_{1, j} d t$ 
$H_{i, j+1}=\int_{0}^{j+1} q_{1, j+1} d t$

Where:

$H_{i, j}$ - Total amount of energy provided in a unit of time, [J]

$q_{1, j}$ - Heat flow measured by the heat flux film on the surface of the sample, [W]

$d t$ - Time step between logging, [s]

In Equation (14) has been made an assumption that heat provided to the sample is divided equally between all 10 layers of the sample, see also Figure 14. Having calculated specific heat capacity in the $1^{\text {st }}$ point for all the time steps, it is possible to calculate the energy that reaches the second point in all of the time steps. This is done using Equation (17). The process can be repeated until $C p(T)$ is calculated for all of the layers where the thermocouples are located in the specimen

$H_{2, j}=H_{1, j}-C p\left(T_{1, j}\right) * A * \Delta x * \rho *\left(T_{1, j}-T_{2, j}\right)$

The results for one chosen measuring series of 6(wt)\% PCM concrete sample are presented in Figure 20.

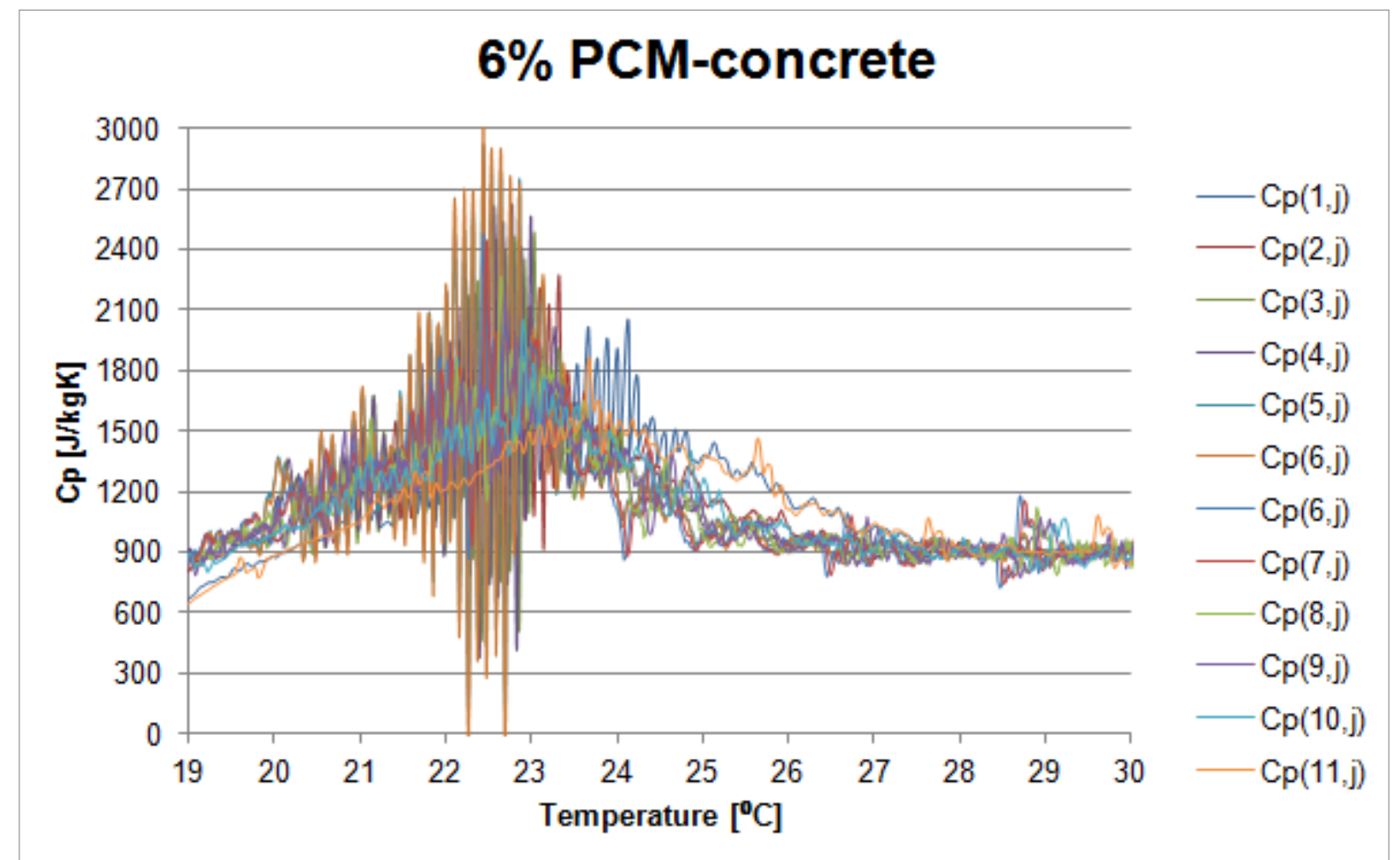

Figure 20. Calculated specific heat capacity from one measuring series of 6(wt)\% PCM concrete sample

Although the temperature in the sample was logged for each 10 seconds the time step used for the calculation presented in this chapter was chosen to be 10 minutes. The reason to take longer time step was to damp fluctuations in the calculated $C p$ that is dependent on the $T_{i, j+1}-T_{i, j}$. As can be observed in Figure 20, despite the longer time step the fluctuations of the $\mathrm{Cp}$ are still significant for some of the thermocouples. Due to high fluctuations it is difficult to comment on the obtained results. However, still the $C p$ peak can be distinguished at approximately $23^{\circ} \mathrm{C}$. 


\subsubsection{Fourth $\mathrm{Cp}(\mathrm{T})$ calculation method: Simple numerical method}

The "numerical simple method" for calculating $C p(T)$ presented in this chapter uses the explicit finite difference method for solving 1D unsteady heat conduction problem. The governing equation is:

$\frac{\partial T}{\partial t}=\alpha \frac{\partial^{2} T}{\partial x^{2}}$

Where:

$T$ - Temperature, $\left[{ }^{\circ} \mathrm{C}\right]$

$t$ - Time, [s]

$x$ - Space length, $[\mathrm{m}]$

$\alpha$ - Thermal diffusivity, $\left[\mathrm{m}^{2} / \mathrm{s}\right.$ ]

The boundary conditions for the numerical model are set to resemble the experimental conditions. The initial temperature of the specimen is defined as $18{ }^{\circ} \mathrm{C}$ and thereafter the temperature is symmetrically and linearly increased to $32{ }^{\circ} \mathrm{C}$ over 10 hours at the top and bottom surface of each sample. The height, density and thermal conductivity defined for the samples in the numerical model correspond to the measurements performed on the real samples. The number of nodes and time steps are dependent on the thermal properties of the samples. Therefore, the number of virtual nodes in the analyzed geometry is chosen so as to result in a good stability and convergence of the model [28].

In the developed numerical model, the specific heat capacity is linearly dependent on the temperature. The iterative procedure of finding a satisfactory linear approximation of the specific heat capacity is repeated until the difference between the calculated and the measured heat flux at the surface is acceptably small. As mentioned previously in this section, the experimental measurements are repeated three times for each specimen. In the numerical investigation presented in this subchapter the heat flux calculated from the model is compared with the average heat flux for all three measurements for $4(\mathrm{wt}) \%$ PCM concrete. The results of the investigation are presented in Figure 21. 

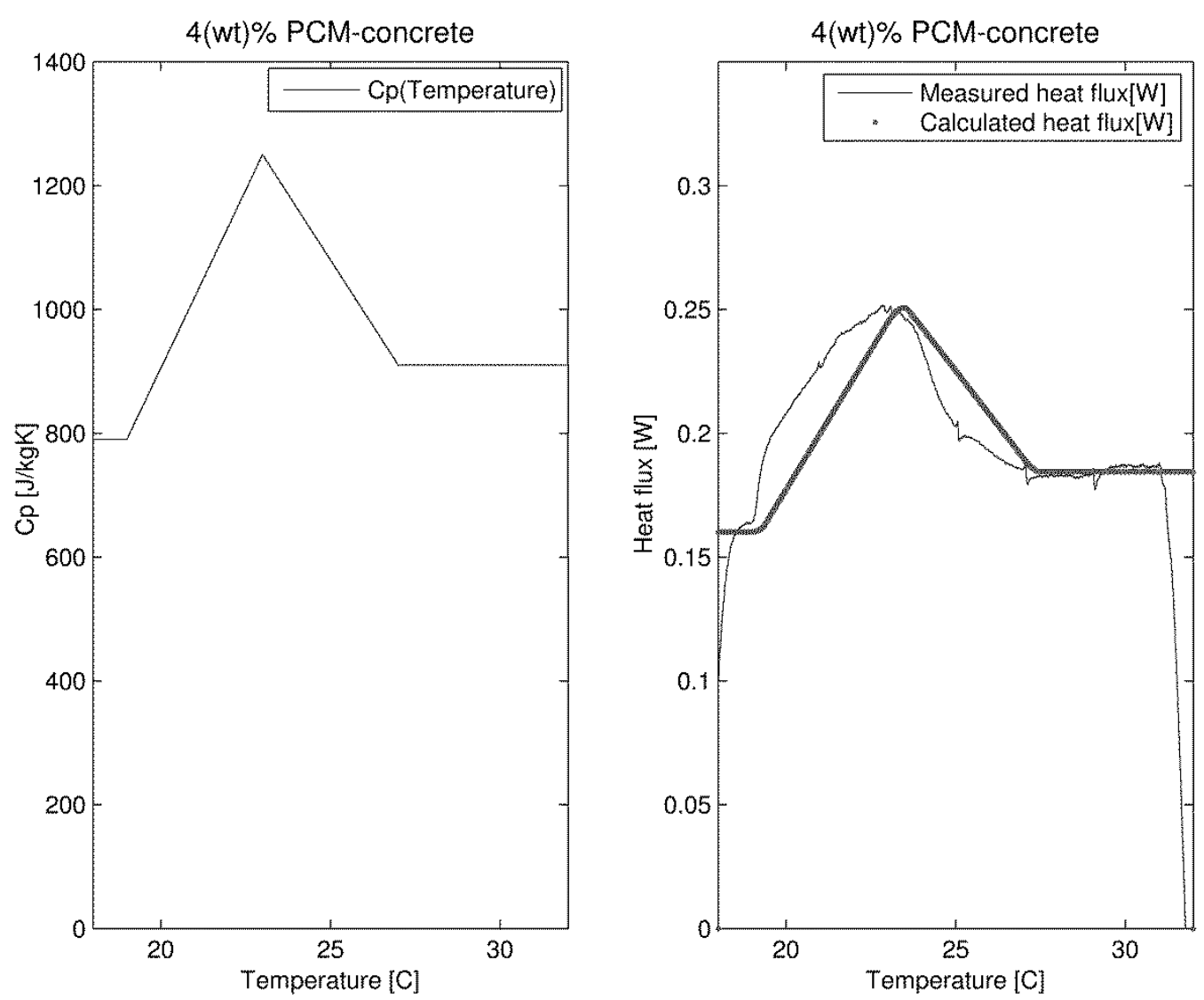

Figure 21. (left) Linear $C p$ representation in function of temperature, (right) measured and calculated heat flux on the sample surface: $4(\mathrm{wt}) \%$ PCM concrete.

As presented in Figure 21, a linear simplification of the $C p(T)$ gives a linear representation of the calculated heat flux at the surface. The correspondence between the measured heat flux and the calculated one is rather good. The heat flux between approximately $18{ }^{\circ} \mathrm{C}$ to $19{ }^{\circ} \mathrm{C}$ and $31{ }^{\circ} \mathrm{C}$ to $32{ }^{\circ} \mathrm{C}$ is not taken into account in the calculations of $C p(T)$ since these are the transition temperatures ranging respectively from steady-state to dynamic state and from dynamic to steady-state.

\subsubsection{Fifth $\mathrm{Cp}(\mathrm{T})$ calculation method: Inverse method}

In the "numerical simple method", the heat equation is solved by a traditional explicit finite difference method. The thermal properties: $\rho$-density, $\lambda$-thermal conductivity and $C p(T)$-specific heat capacity as a function of temperature and also temperature boundary conditions are given in order to solve the $1 \mathrm{D}$ unsteady heat conduction problem. However, the problem is non-linear and linearization of $C p(T)$ presented in "numerical simple method" is a simplification. Still the "ideal" value of $C p(T)$ can be obtained by using the inverse method that will be presented in this chapter. The method has been proposed by [29] in order to find the best thermal physical properties of the building that will result in the indoor thermal comfort and minimum energy use for heating and for cooling of that building.

The method proposed in this chapter utilizes the $\mathrm{N}$-segment method to obtain ideal $C p(T)_{i}, i=1, . ., N$. The temperature range in which the experiment is performed is divided into $\mathrm{N}$ equal temperature segments and $C p(T)^{i}, i=1, \ldots N$ is distributed in that $\mathrm{N}$ segments. Subsequently the $C p(T)^{i}, i=1, . ., N$ is adjusted to obtain minimum of the objective function which is given by the Equation (19), by using a non-linear constrained optimization method such as the Sequential Quadratic Programming (SQP) method [30-32]. In Equation (19) is given the objective function for the optimization problem.

$\operatorname{Min} f=\left|q_{\text {calculated } 1, j}-q_{\text {measured } 1, j}\right|$ 
Where:

$q_{\text {calculated } 1, j}$ - is the calculated heat flow to the sample on the sample surface [W]

$q_{\text {measured } 1, j}-$ is the measured heat flow to the sample on the sample surface [W]

Taking into consideration results obtained from the first to fourth method to calculate $C p(T)$, the upper and lower bound is chosen to be $0<C p(T)_{i}<2000 \mathrm{~J} /(\mathrm{kgK})$.

Due to the fact that, the temperature segment division may influence the accuracy of the results, the division should be adjusted until the relative error is acceptable. In the presented calculation the temperature segment has length of $0.5^{\circ} \mathrm{C}$. It should be kept in mind that the governing equation, see Equation (18), for the problem is as in "numerical simple method".

The results of the "inverse method" are presented for 4(wt)\% PCM concrete, but only for the chosen third measuring series.
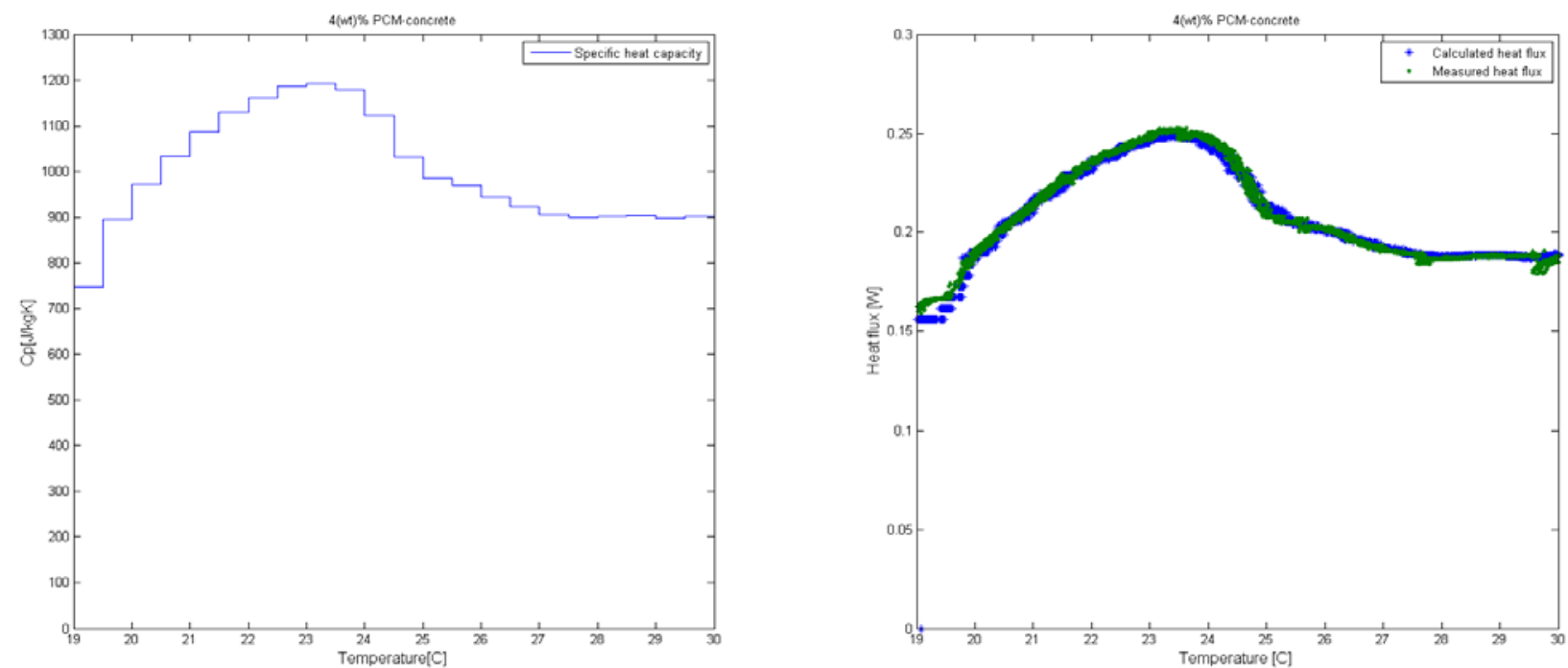

Figure 22. (left) Calculated optimized $C p$ in function of temperature, (right) measured and calculated heat flux on the sample surface: 4(wt)\% PCM concrete

To control the discrepancy between the measurements and calculations, the measured and calculated vertical temperature profile is compared and the total average relative error is calculated. As an example, the comparison between calculated and measured temperature profile is done for $4(\mathrm{wt}) \%$ PCM concrete sample, see Figure 23. The total average relative error at all time steps for 4(wt)\% PCM concrete is calculated at approximately $0.5 \%$. 


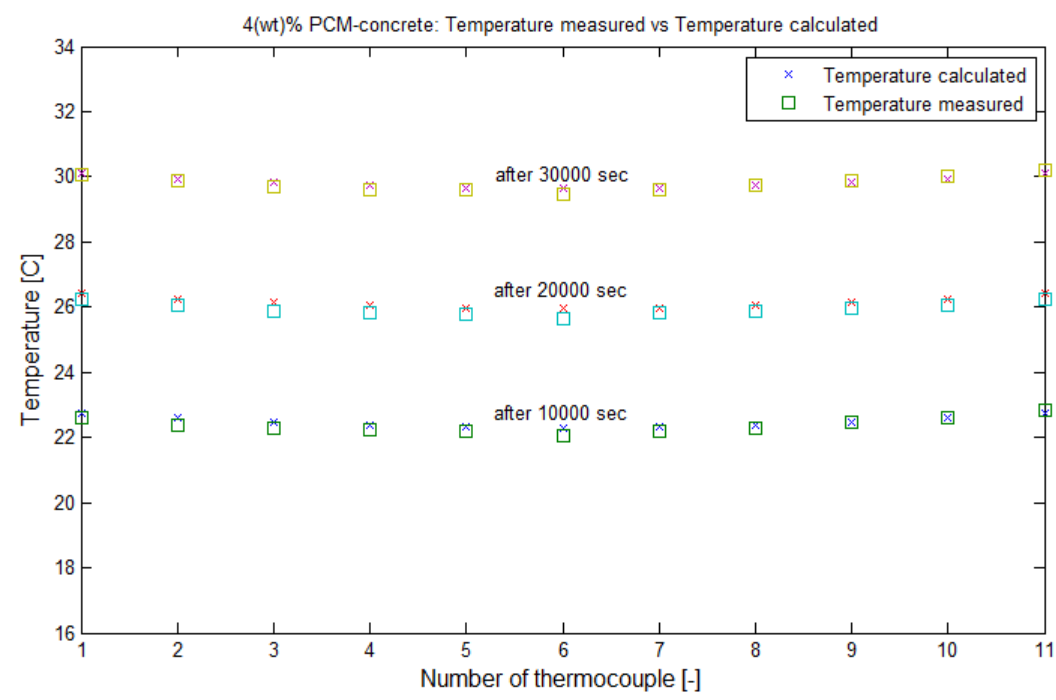

Figure 23. Comparison of measured and calculated vertical temperature profile at chosen time steps for 4(wt)\% PCM concrete sample.

\subsubsection{Comparison of methods}

In this chapter, results obtained from all presented methods are compared with each other. The third measuring series for the specimen containing 4(wt)\% of PCM is chosen for the comparison. For the moving enthalpy method the presented $C p(T)$ is calculated on the top surface of the sample.

In Figure 24 are depicted results obtained by using all methods presented in subsections from 5.2.3.2 to 5.2.3.6.

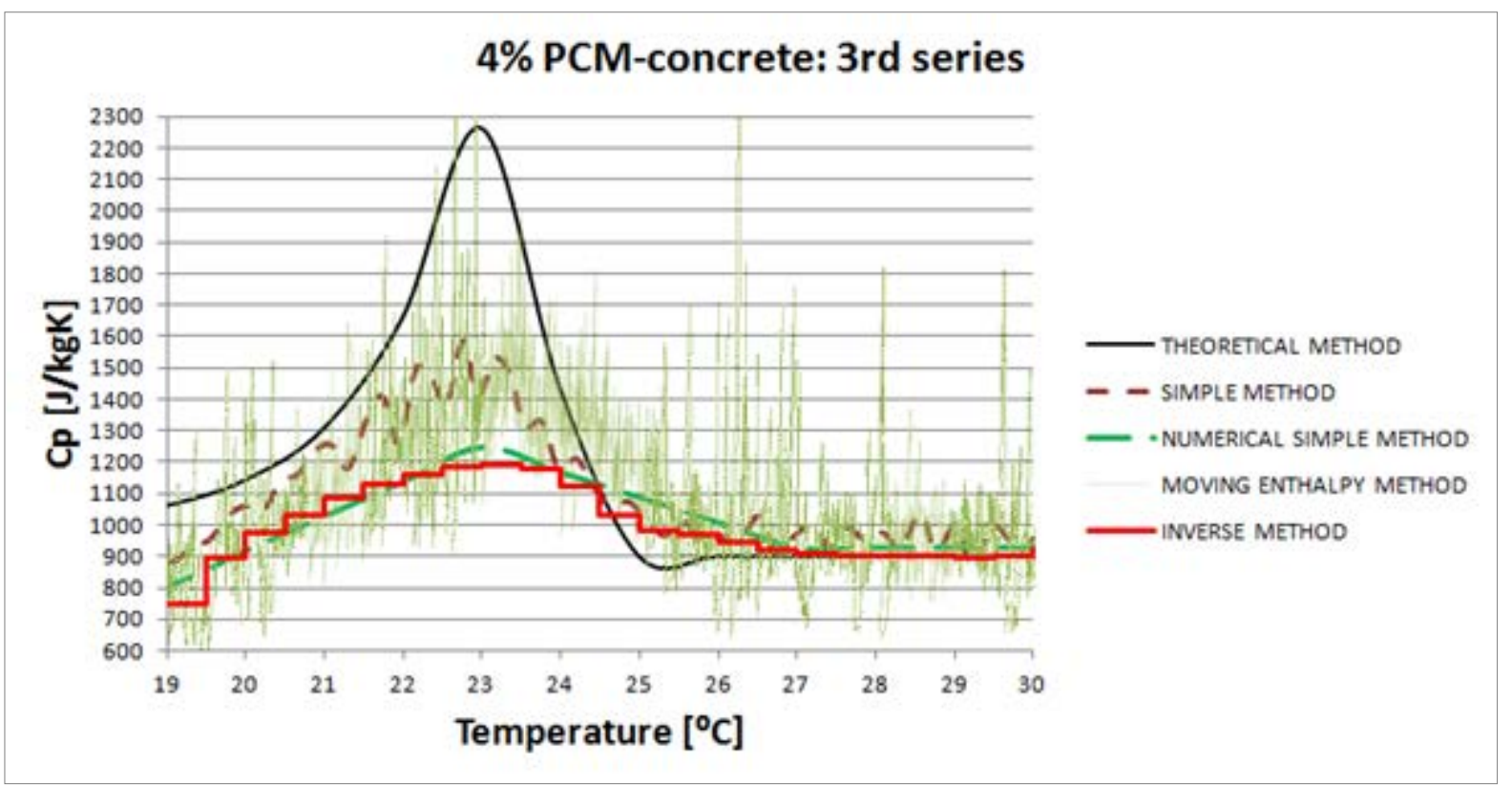

Figure 24. Comparison of results from various proposed calculation methods of $\mathrm{Cp}(\mathrm{T})$.

In Figure 24, it can be observed that various calculation methods lead to various results. Firstly, it is noticeable that the peak $C p$ obtained by the theoretical method is much higher than the peaks obtained from the methods utilizing experimental data. 
The peak obtained from the "simple method" is higher than the ones obtained from the "simple numerical method", "moving enthalpy method" and "inverse method", but as elaborated in chapter 5.2.3.3 this method is expected to give overestimated results. The results of calculated $C p(T)$ with use of moving enthalpy method characterize high fluctuation due to fluctuations in the temperature measurements, however, the shape of the peak can be still distinguished.

The curves of calculated $C p(T)$ from the "simple numerical method" and "inverse method" lie very close to each other, still the "inverse method" should give a more realistic representation of the $C p(T)$ since this method is based on optimization algorithm.

Moreover, due to the fact that problem is nonlinear the traditional solutions will always provide less accurate results than the "inverse method".

What is more, the peak of the calculated $C p(T)$ for all methods lies at approximately $23^{\circ} \mathrm{C}$, which is as expected.

\subsubsection{Conclusions}

The used experimental set-up presented in the chapter made it possible to activate the microencapsulated PCM directly integrated in the concrete mixture. Moreover, the size of the heat flux film was designed by using the finite element software: COMSOL Multiphysics. The proper design of the size of the flux film results in measurements of the $1 \mathrm{D}$ heat flow to the specimen. Furthermore, the methodology to insert thin thermocouples to the concrete specimen allowed to measure vertical temperature profile inside the specimen. The outcome from the experimental investigation indicates that in order to linearly heat up the specimen from $18{ }^{\circ} \mathrm{C}$ to $32{ }^{\circ} \mathrm{C}$, the hot plate apparatus has to provide more heat to the specimen with the PCM than to those without it.

The heat of fusion for temperatures ranging between $19{ }^{\circ} \mathrm{C}$ and $27^{\circ} \mathrm{C}$ can be distinctly observed for the specimens containing $4 \%$ and $6 \%$ of the microencapsulated-PCM. On the other hand, for the sample with $1 \%$ PCM, the measured heat flux does not increase substantially. The insignificant heat flux peak can be explained by the small amount of incorporated PCM. What is more, some of the capsules could have been damaged during the mixing process.

The problem of the heat flux stability can be observed for the reference specimen without PCM. The heat flux is expected to increase and stabilize at a certain level during the heating process. On the contrary, a small swing is observed and then an insignificant linear increase of the heat flux. It is concluded that the unstable heat flux is either due to temperature control problems of the dynamic mode in the hot plate apparatus or fluctuation in the temperature of the surroundings. Still, the instability of the heat flux is insignificant and the results can be considered as reliable.

Regarding the calculation of the specific heat capacity, various methods give various results. The "theoretical method" that uses the weight-average method results in the highest $C p$ values. On the contrary, the results based on the measurements generally indicate that the peak of the specific heat capacity is much lower and has a wider shape than the theoretically calculated one.

The second presented method called the "simple method" is indeed fast and simple, but it overestimates the actual specific heat capacity of the measured specimens. In Equation (12), the heat flux measured at the surface of the specimen is used for all temperature gradients $d T / d t$, even the ones measured in the interior of the specimen. In reality, the heat flux decreases in the direction of the centre of the specimen, and therefore the real specific heat capacity should be lower than the calculated one.

The third method, moving enthalpy method includes the variable heat flux in the sample, but it also bears a strong initial assumption regarding the heat distribution in the sample. Moreover, the logged values by some of the thermocouples are fluctuating. As a consequence, these fluctuations are transferred to calculations of the specific heat capacity.

The fourth method, the "numerical simple method" simplifies the problem by the linearization of the specific heat capacity as a function of temperature. The method is not too complex and at the same time provides acceptable accuracy. On the other hand, the weakness of the method is the manual iterative process for finding a satisfactory linear approximation of $C p(T)$. 
The fifth method, the "inverse method", is the most advanced of all of the presented methods. It uses a nonlinear constrained optimization method to calculate $C p(T)$. The calculated optimized results correspond very well with the measurements.

A general conclusion can be drawn that for the practical purposes, to be able to perform a simulation of an entire building and to calculate the indoor temperature and energy use of a room with PCM concrete elements, the third and fourth methods - the "numerical simple method" and "inverse method" - would probably be the most suitable ones. The reason is that the obtained $C p(T)$ is directly represented either by a function or a pair of points that can easily and conveniently be transferred to any building simulation program. The "simple method" could also be used, but as stated earlier the results obtained are considered to be overestimated and therefore the method will not be recommended. The results obtained from the moving enthalpy method are significantly fluctuating and therefore it would be very difficult to implement them in further applications.

The advantage of the experimental method presented in the paper is the very small heating rate of approximately $0.023 \mathrm{~K} / \mathrm{min}$, which can imitate the temperature increase in a real building construction element and thus simulate realistic thermal conditions at which the PCM concrete would be activated. The present development of the hardware used in the experiment allows to determine the $C p(T)$ but only for the melting process. An experiment, where the sample would be cooled down in order to define the $C p(T)$ of the solidification process, is also possible. However, due to the limited accuracy of the presently available hardware these experiments have not been performed.

The thermal activation of PCMs and their efficient application in buildings is strongly limited by their very low thermal conductivity. Therefore, in order to increase the thermal conductivity, pure PCMs have to be mixed with other highly conductive materials that could carry the heat to deeper layers over short time. It is expected that the experimental method for determining the heat capacity of a concrete material with PCM, proposed in this section, should also work for other inhomogeneous composites with PCM.

\section{Experimental and numerical analysis of heat transfer in the inhomogeneous concrete deck}

\subsection{Purpose}

In section 5 a careful investigation of thermal properties of a new material such as PCM concrete has been presented. This would be sufficient to describe the homogeneous construction element however the hollow core deck is an inhomogeneous element and more careful approach to determine heat transfer within the deck need to be done in order to properly estimate its heat storage capacity (passive application) or cooling capacity (active application with integrated TABS).

The purpose of the presented experimental investigation is to determine simple and accurate method to determine the heat transfer within the air void of the concrete hollow core deck element. As mentioned in section 2.2 and again in 4.2 in the initial numerical investigations the heat transfer within the air voids was either simplified by disregarding the heat transfer within the air hollows or by simplifying the deck to the deck without air hollows. However, both simplification were useful only for the initial analysis to study the potential of PCM and TABS and at the later stage it is required to determine real heat storage performance and cooling performance of the deck. In order to investigate the global thermal conductivity of the deck the 4 various 2D-models were developed in COMSOL Multiphysics program. In these 4 models the heat transfer within the air hollows is modeled according to various approaches. Along with numerically developed models an experimental set-up with a real hollow core located in the hot box apparatus was prepared. The 2 sets of steady-state measurements were conducted in order to determine the global thermal conductivity of the hollow core deck element. Finally, the intention is to define which of the numerical approaches to calculate the heat transfer within the air hollows gives the closest result of the global thermal conductivity of the entire inhomogeneous concrete deck element. Results presented in chapter 6 are fully presented in [33]. 


\subsection{Simulation}

The numerical model created in the COMSOL program was based on the real cast of the hollow-core concrete deck element which section view is presented in Figure 25.

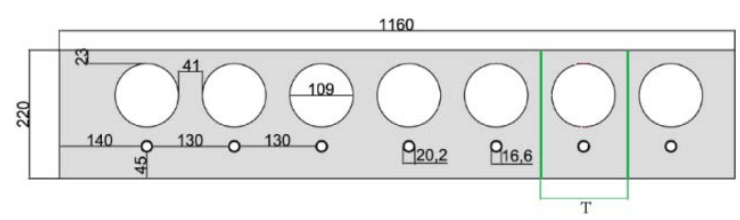

Figure 25. Section view of the hollow core concrete deck

Thermal properties of the concrete used in COMSOL are assumed to be as follows: thermal conductivity 1.8 $\mathrm{W} /\left(\mathrm{m}^{2} \mathrm{~K}\right)$, density $2300 \mathrm{~kg} / \mathrm{m}^{3}$ and specific heat capacity $1000 \mathrm{~J} /(\mathrm{kgK})$. In order to save simulation time and due to symmetry of the element, only one section "T" presented in Figure 25 is modeled. The small circular voids that can be seen on the bottom of the deck represent water pipes that were used in another experiment where the deck was thermally activated. Due to the small size of these pipes, they only have a minor importance on the experimental investigation of thermal conductivity. In the modeling part, they were not included in the model and substituted by the concrete material.

\subsubsection{Steady-state simulation of inhomogeneous deck}

For the steady-state models, the temperature on the upper and lower surface of the deck is presented as a constant temperature and the temperature on the bottom is different from the temperature on the top of the deck.

Heat transfer within the air void is modeled according to the following four various assumptions:

1. Air void is presented as an adiabatic boundary.

2. Air in the void is given real air thermal properties such as: density, thermal conductivity, specific heat capacity. However, air is standing still thus no convection is considered. In this model, radiation between surfaces is not considered.

3. Air void cavity is given radiation surface to surface boundary.

4. Air void is given equivalent thermal conductivity calculated based on norm [C9]. This thermal conductivity considers heat transfer by convection and radiation in the closed voids.

In this study, parameterization of the heat transfer within the air void is distributed along with 4 various assumptions presented above in this section. In the first model, the air void is excluded from the heat transfer through the slab with the air voids, in the second model, the air void is included in the heat transfer through the slab but neither convection nor radiation is considered. The third model considers only the heat transfer by radiation between the air void surfaces and in the fourth model, both radiation and convection in the air voids is included.

During the steady-state simulations, the 2D models were calculated as per assumption given in points 1 to 4 in this section.

\subsection{Experimental investigation of the thermal conductivity of the inhomogeneous deck}

The purpose of the experimental investigation of the thermal conductivity of the concrete hollow core deck element is to estimate which of the modelling assumption for the heat transfer within the air void is closest to the real life conditions.

To measure the thermal conductivity of the deck, a guarded hot box apparatus is used, see Figure 26. 
Presented in Figure 26 hot box apparatus has a sandwich wall construction made of: 10mm MDF plate, 300 $\mathrm{mm}$ EPS and again $10 \mathrm{~mm}$ MDF plate. Metering box has walls constructed as following: $10 \mathrm{~mm}$ MDF and $40 \mathrm{~mm}$ EPS.

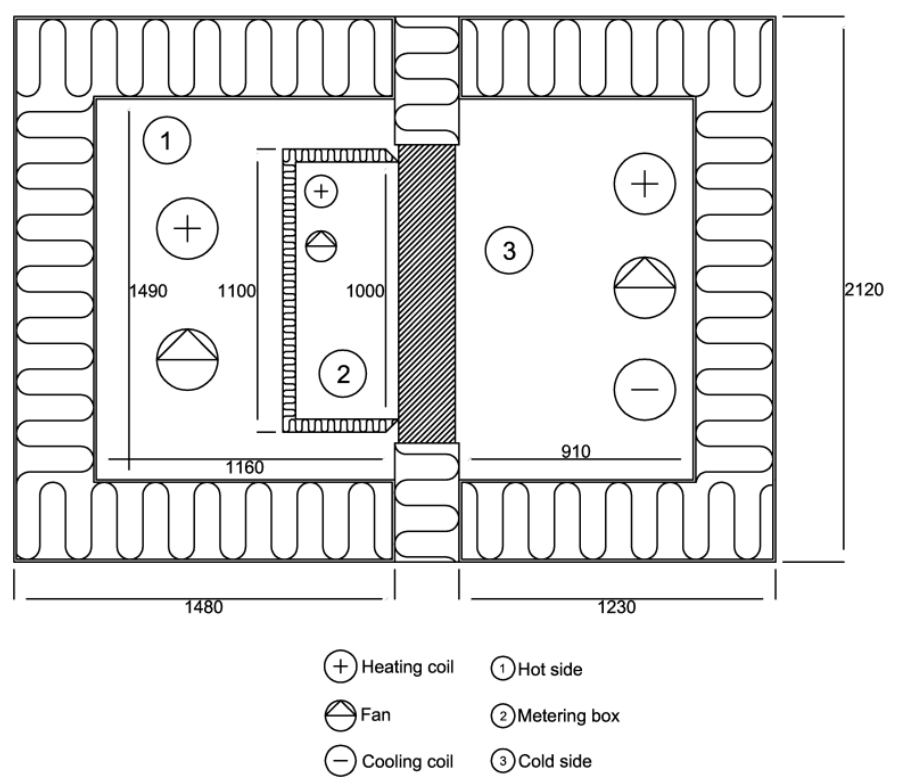

Figure 26. Set-up of the deck in the hot box, vertical section view

The concrete deck is inserted between the hot and cold side of the deck. Secondly, the air temperature on the hot and cold side is stabilized. Additionally, necessary time is taken until the air temperature between the hot side and the metering zone stabilizes and reaches equilibrium. If this happens, it is known that all energy, (which is measured), provided to the metering box is transferred through the deck to the lower temperature in the cold zone.

In order to calculate the thermal conductivity of the deck, a heat supply to the guarding box was measured by a wattmeter. Surface temperature of the deck on the hot and cold side was measured with 6 thermocouples type "K" on each side of the deck. Temperatures were logged by the data logger Fluke Helios Plus 2287A.

\subsection{Results}

\subsubsection{D heat transfer calculation}

In Table 7 are presented results of the obtained thermal conductivity of the 2D models from COMSOL simulations. Presented results are the average values for the entire deck.

\begin{tabular}{|l|c|}
\hline Heat transfer within air void: & $\lambda$ \\
\hline & {$[\mathrm{W} /(\mathrm{mK})]$} \\
\hline Air void: adiabatic & 0.982 \\
\hline Air void: standing still air & 1.002 \\
\hline Air void: radiation & 1.246 \\
\hline Air void: equivalent conductivity & 1.261 \\
\hline
\end{tabular}

Table 7. Overall heat transfer in the hollow core deck modeled as 2D model 


\subsubsection{Experimental determination of the thermal conductivity of the hollow core deck element}

The thermal conductivity was calculated after the temperatures had been stabilized in the hot box. Thermal conductivity was calculated for the two various temperature setups, see Table 8.

\begin{tabular}{|l|c|}
\hline Setup & Thermal conductivity \\
\hline$[-]$ & {$[\mathrm{W} /(\mathrm{mK})]$} \\
\hline 1st & 1.50 \\
\hline 2nd & 1.52 \\
\hline Average: & 1.51 \\
\hline
\end{tabular}

Table 8. Measured thermal conductivity of the hollow core concrete deck

\subsection{Conclusion}

Based on the results from COMSOL 2D steady-state simulations, it can be observed that for the first two cases, where the air void is represented by the adiabatic boundary and respectively air standing still, the obtained thermal conductivity is almost the same. These results are in agreement with expectations because standing still air has very poor thermal conductivity and it can be considered as a good insulator.

The following two cases, where heat transfer within air void in the first case is including surface to surface radiation and in the second equivalent thermal conductivity that includes convection and radiation, gave considerably higher thermal conductivity than the first two cases. These results and the fact that the model with equivalent conductivity gives highest thermal conductivity of the deck comply with the expectations. Finally, when comparing obtained thermal conductivity of the hollow core deck for various modeling assumptions regarding the heat transfer in the air void, it can be observed that the overall deck thermal conductivity varies from 0.98 to $1.26 \mathrm{~W} /(\mathrm{mK})$. This variation is rather substantial and indicates that proper modeling of the heat transfer within the hollow-core deck element might be crucial to properly calculate the heat storage in this type of building construction element.

To sum up, the discrepancy between measured and simulated thermal conductivity can not only be due to various approaches to modeling heat transfer within closed air void but also due to different thermal conductivity of bulk concrete that was assumed in the simulation models and that is in the deck used in the experiment. Moreover, the simulation model does not include steel reinforcement that is located in the deck and which should have an impact on the overall thermal conductivity as it has larger thermal conductivity than pure concrete. All in all, the model with equivalent thermal conductivity that considers convection and radiation within air void gives the closest result to the experimentally determined thermal conductivity and this approach will be used in the further investigations of the performance of the hollow core deck element with PCM and TABS.

\section{Updated numerical analysis of heat storage and cooling power of the concrete deck with PCM and TABS}

\subsection{Purpose}

In the presented study the initial numerical model of the hollow core concrete deck element was presented in section 4 and its diurnal dynamic heat storage potential (passive) and diurnal cooling capacity potential (activated with TABS) was investigated. The initial numerical model of the hollow core deck element is valid for theoretically determined thermal properties of PCM concrete composite. Afterwards, in section 5 is presented experimental methodology to measure thermal conductivity and newly developed methodology to determine specific heat capacity of new composite materials such as PCM concrete with integrated microencapsulated PCM. In section 5 are also presented obtained experimental results of thermal conductivity and specific heat capacity of PCM concrete. Results of the experimental investigation revealed 
that the theoretical calculations of the effective thermal conductivity that are based on a weight average method gives much higher results than the ones obtained from the experiments, both regarding thermal conductivity and heat storage capacity.

Although in section 5.2.3.7 it is presented that various methods to calculate heat capacity give various results the explanations are given that "numerical simple method" and "inverse method" should be considered as the most reliable and accurate methods. What is more, still the experimental results are always lower than theoretical results for heat capacity of PCM concrete.

Furthermore, based on conclusions made in subsection 5.2.4 it seems that the "inverse method" should provide most accurate results, but on the other hand, the "numerical simple method" is still accurate and provides results that could be implemented more easily in the numerical models developed in the study presented in this section. Therefore, in the research presented in this chapter, the results obtained from the "numerical simple method" will be used. Moreover, findings from the numerical study on the heat transfer in the inhomogeneous hollow core concrete deck elements presented in section 6 were taken into consideration for models developed in this section.

To sum up, the initially developed numerical model presented in section 4 is updated with findings from section 5 and 6 . The results of calculated heat storage capacity from the models utilizing theoretically determined thermal properties of the PCM concrete will be compared with the one utilizing experimentally determined thermal properties of the PCM concrete. As a consequence, the potential of the improvement of the heat storage of the decks with PCM will be presented and analyzed.

Finally, the objective of the study is to investigate how and if it is beneficial to combine TABS and PCM in a prefabricated concrete hollow core deck element.

A complete investigation illustrated in chapter 7 can be found in [34].

\subsection{Methodology}

\subsubsection{Sensitivity analysis of location and percentage of integrated PCM}

As presented in section 4, the best exploitation of the latent heat storage is when the layer of the PCM concrete material is located on the very bottom surface of the deck. As well, the initial investigation revealed that the layer with PCM concrete should not be thicker than approximately $3 \mathrm{~cm}$ else the PCM at the deeper layers is not sufficiently activated and cannot contribute to the heat storage of the concrete deck element. This thickness, however, has to be revised in this section since the theoretically determined thermal properties used in section 4 differ significantly from the experimentally determined ones that are presented in section 5 .

The advantage of casting the PCM concrete only in a thin layer on the bottom of the deck is that the strength and other physical properties of the deck will be kept unchanged since all the reinforcement and bearing properties would not be affected by the PCM presence in the concrete.

\subsubsection{Thermal properties of the combined PCM and concrete material}

The initial theoretical calculation of the thermal properties (thermal conductivity and specific heat capacity) of the new composite of the PCM concrete that are presented in section 4 are based on weight average calculation of the concrete and PCM. The results of that calculation are depicted respectively in Figure 28, Figure 29 and Figure 30. The calculation of the theoretical specific heat capacity for combined concrete and PCM is based on the results of $C p(T)$ obtained from Differential Scanning Calorimetry (DSC) of pure microencapsulated PCM type DS 5040X from BASF. Due to the fact that PCM specific heat capacity varies with its temperature, the same was assumed analogically for the combined concrete and PCM material.

To experimentally determine the thermal properties of the PCM concrete material, special samples with 0 (wt)\%, 1(wt)\%, 4(wt)\% and 6(wt)\% (by weight) of microencapsulated PCM type DS 5040X from BASF have been cast, see section 5.1.3. The procedure and design of the casts and as well the experimental 
methodology to determine thermal conductivity and specific heat capacity can be found in section 5 . The results of the experimentally determined thermal conductivity are presented in Figure 28 and experimentally determined specific heat capacity results (by the numerical simple method) are presented in Figures 29 and 30.

The densities of the samples are determined by the direct measurements of the cast specimens and are depicted in Figure 27.

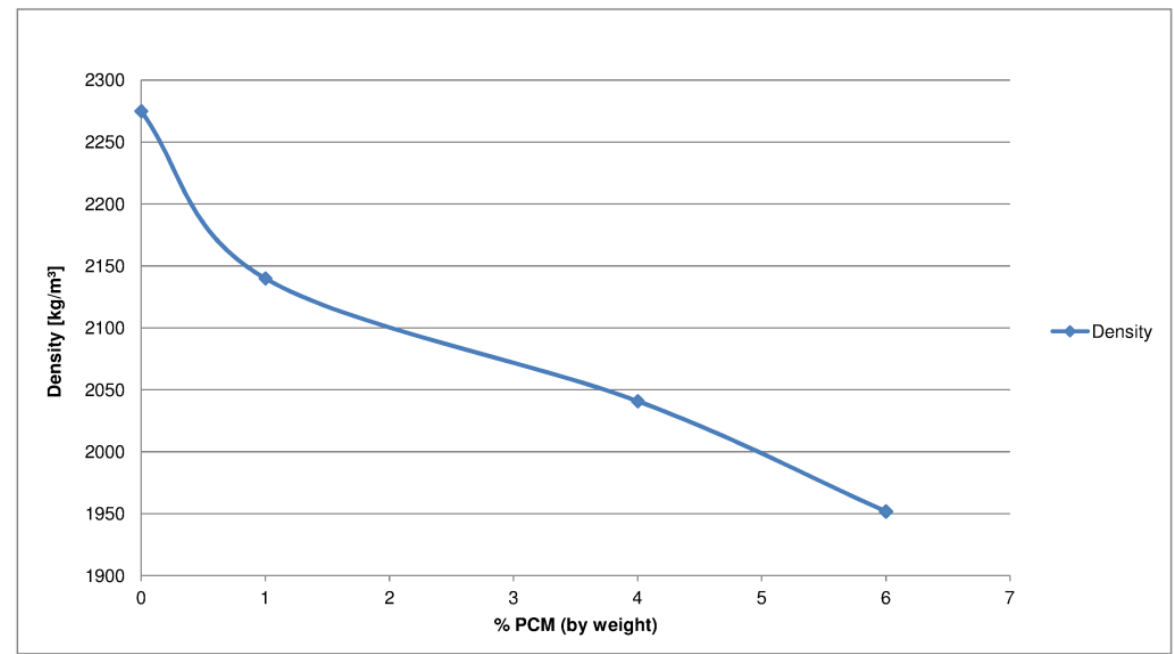

Figure 27. Measured density of the PCM concrete samples

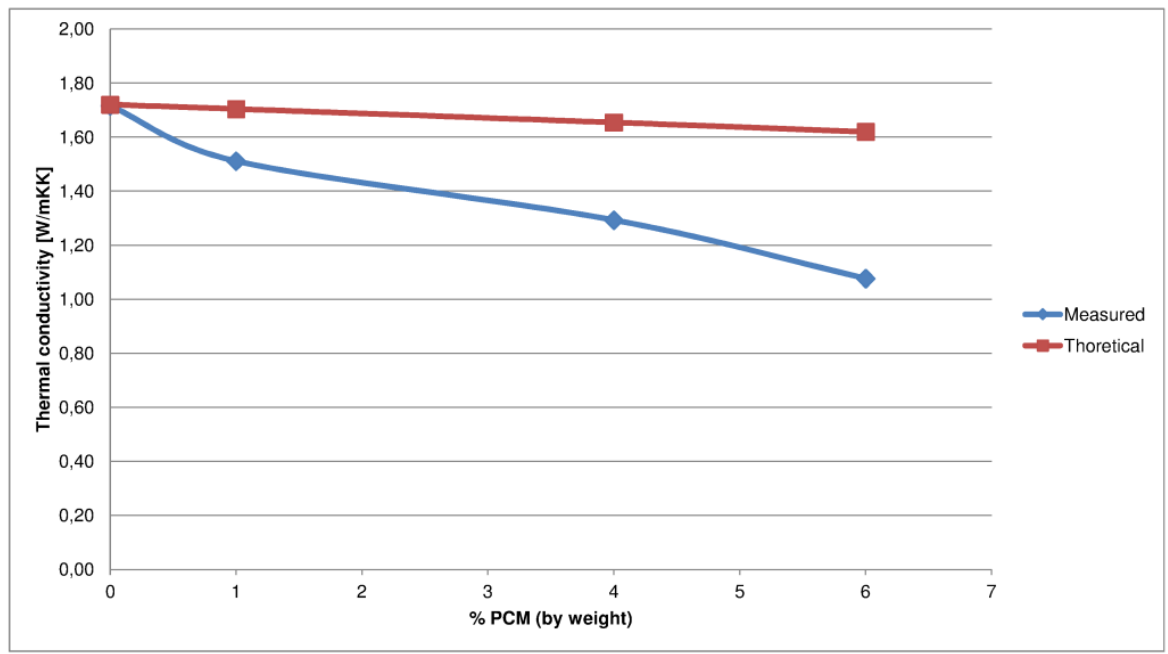

Figure 28. Theoretically and experimentally determined thermal conductivity of PCM concrete material 


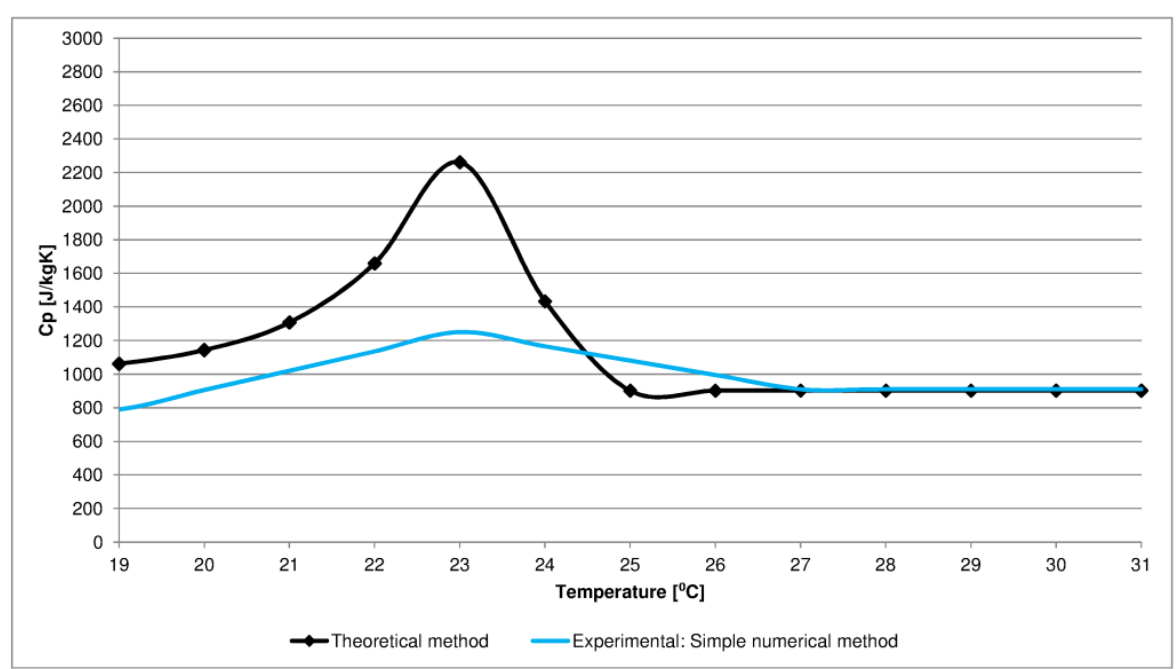

Figure 29. Theoretically and experimentally determined specific heat capacity of 4(wt)\% PCM concrete material

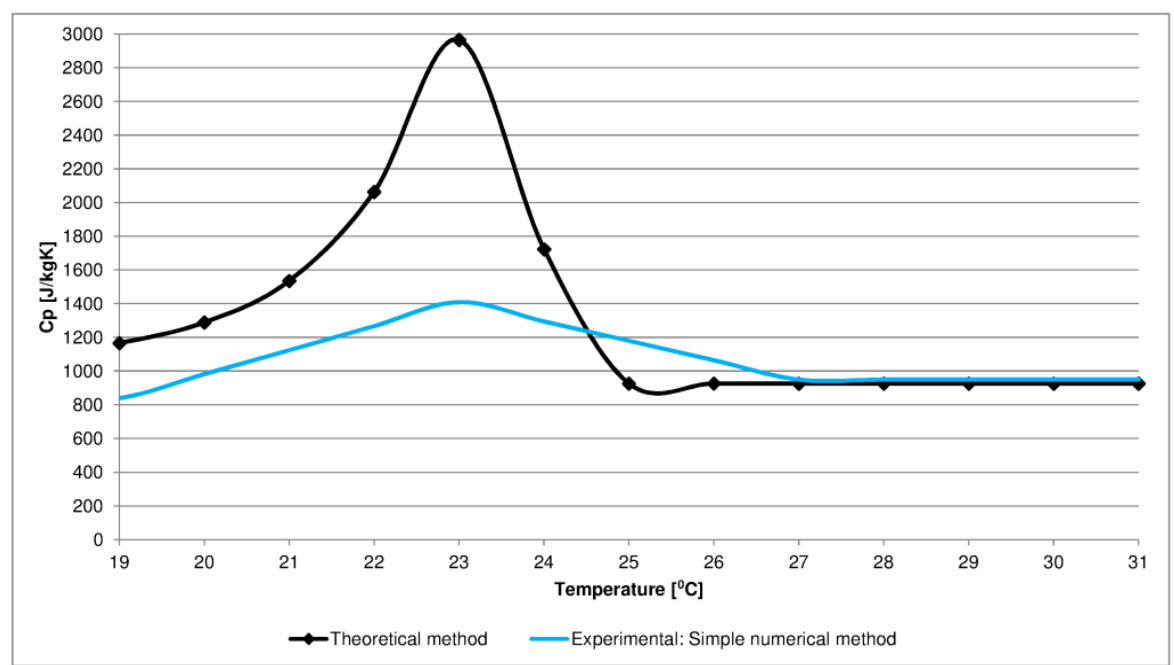

Figure 30. Theoretically and experimentally determined specific heat capacity of $6(\mathrm{wt}) \%$ of PCM concrete material

The specific heat capacity of the reference sample that does not contain PCM , which also means it only reflects sensible heat storage properties, was measured at approximately $785 \mathrm{~J} /(\mathrm{kgK})$.

\subsubsection{Boundary condition}

The boundary conditions for the model are preserved from the initial numerical analysis that is presented in chapter 4.2 with exception of the air void which was given equivalent thermal conductivity calculated according to methodology presented in chapter 6.

\subsubsection{Thermal activation of hollow core deck element}

Although TABS concept can be used for both heating and cooling, in this study focus is put solely on its cooling performance. The research on TABS presented in [35] indicated that the cooled ceiling temperatures are not an issue with respect to the normative requirements for the temperature asymmetry of the construction elements. However, the limit for cooled ceiling temperature is connected with the risk of condensation on the construction elements. The lowest permitted temperature of the cooling agent in the 
radiant systems depends on relative humidity of the indoor air but it usually do not drop below $16{ }^{\circ} \mathrm{C}$, which is the limit of surface temperature for buildings equipped with a dehumidification system.

Moreover, in this study, the centre of the pipe with water is $50 \mathrm{~mm}$ from the bottom surface of the hollow core slab. The diameter of the water pipe is set to $20 \mathrm{~mm}$ and spacing between pipes is $150 \mathrm{~mm}$.

The investigation is carried out for full-time control mode meaning TABS is in operation 24 hours a day, which is always. The purpose of the presented study was to investigate how the presence of the PCM in the deck will affect the maximum cooling capacity of the deck which is always in operation and in which the cooling agent temperature is close to the lowest possible.

\subsubsection{Dynamic heat storage capacity}

Due to the cyclic temperature on the boundary of the deck the model reaches periodic steady-state after a certain time. The length of this time depends on the geometry of the model, thermal properties of the model, amplitude and period of the cyclic boundary condition. When the model reaches the periodic steady-state it means that the amount of the energy transferred to the model during the charging period is equal to the amount of energy taken from the model during its discharging. The dynamic heat storage capacity is the energy/heat stored in the model during either charging or discharging period as defined in the European standard [C 10]. The dynamic heat storage capacity can be also calculated on the chosen boundary of the model. Then it is calculated as the total normal heat flux transferred to or from the model during either charging or discharging period but only through that chosen boundary.

In the developed model of the concrete hollow core deck element, the cyclic temperature that imitates the indoor temperature fluctuations is applied on the top and the bottom of the deck. However, it is only interesting to calculate the heat that is stored in the deck due to the heat transfer through the bottom surface of the deck. Firstly, the top surface of the deck would in practice be covered with various type of flooring resulting in various heat transfer to the deck on its top surface. Secondly, the construction of the deck is not changing on the top and the layer of the various PCM concrete is applied only on the bottom of the deck. This means that the total heat storage of the deck would vary only due to the various PCM concrete layer thickness and amount of PCM in that layer.

\subsection{Results}

\subsubsection{Volumetric heat capacity and thermal inertia}

In Figure 31 and Figure 32 is depicted respectively volumetric heat capacity and thermal inertia of standard (reference) concrete and the PCM concrete with 4(wt)\% and 6(wt)\% of microencapsulated - PCM.

The volumetric heat capacity is calculated according to the equation:

$V H C=\rho * C p$

Where:

$\rho$ - density, $\left[\mathrm{kg} / \mathrm{m}^{3}\right]$

$\mathrm{Cp}$ - specific heat capacity, [kJ/(kgK)]

and describes material ability to store energy in a given volume while undergoing a given temperature change. By using a volumetric heat capacity instead of directly using the specific heat capacity, results take also into consideration the material's density which is decreasing for PCM concrete with increasing content of PCM.

The thermal inertia is calculated according to the equation:

$I=\sqrt{\rho * C p * \lambda}$ 
Where:

$\lambda$ - thermal conductivity, $[\mathrm{W} /(\mathrm{mK})]$

and combines volumetric heat capacity with thermal conductivity of a bulk material. The high thermal inertia describes materials that characterize high thermal mass and high thermal conductivity. The higher thermal inertia the faster the material can be thermally activated and more thermal load can be stored during the dynamic thermal process.

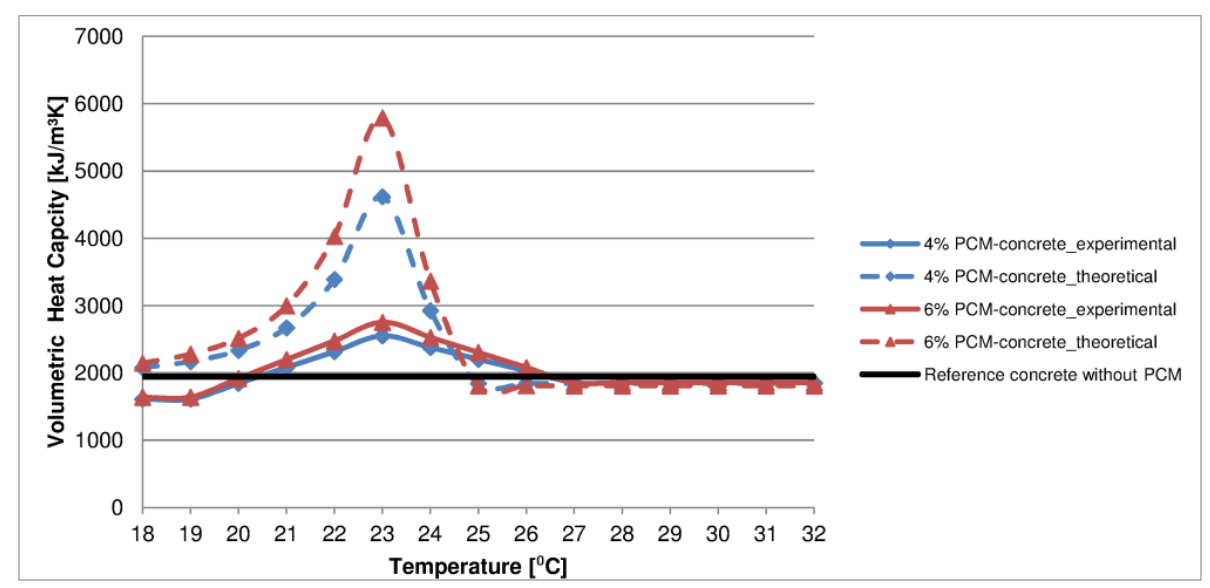

Figure 31. Volumetric heat capacity of 0\%, 4(wt)\% and 6(wt)\% PCM concrete

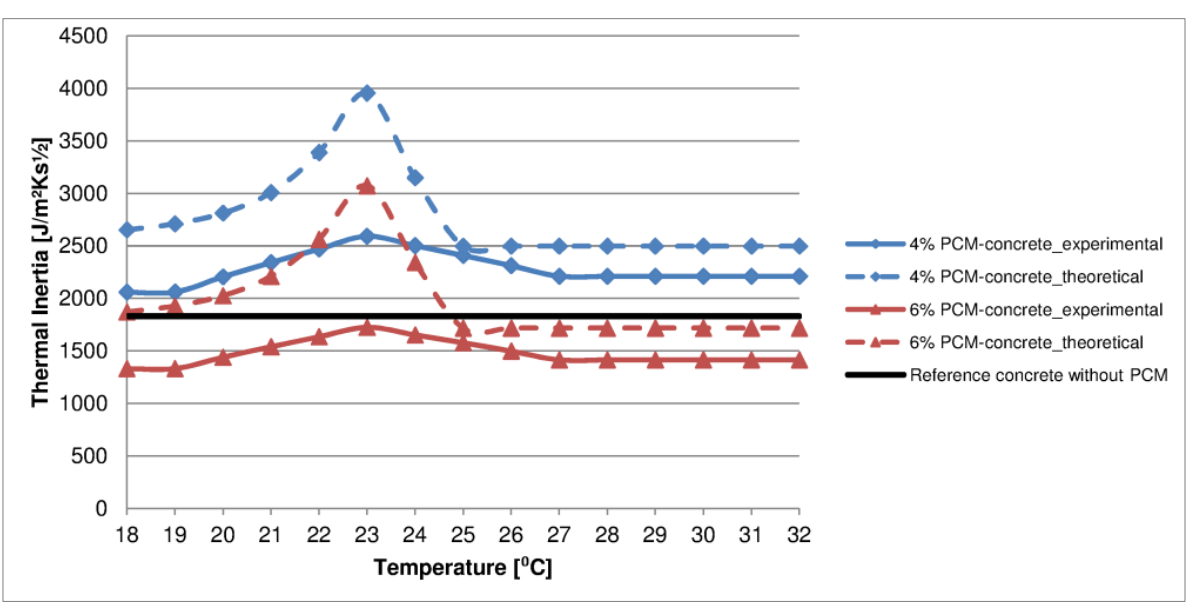

Figure 32. Thermal inertia of $0 \%, 4(w t) \%$ and $6(w t) \%$ PCM concrete

\subsubsection{Passive approach: Calculated dynamic heat storage}

In Figure 33 and Figure 34 can be found calculated improvement of diurnal dynamic heat storage of respectively decks with $4(\mathrm{wt}) \%$ and $6(\mathrm{wt}) \%$ PCM in the concrete and the improvement is calculated with regards to the reference deck made of standard concrete (no PCM). The calculated results are for the deck with the PCM concrete layer with a thickness from $1 \mathrm{~cm}$ up to $4 \mathrm{~cm}$. Moreover, results are presented as function of the total heat transfer coefficient that is combining convective and radiative heat transfer and was parameterized in the ranges from 4 up to $30 \mathrm{~W} /\left(\mathrm{m}^{2} \mathrm{~K}\right)$. The continuous curves represent results obtained from the models where the PCM concrete properties were calculated according to the theoretical weight average method that deploys the thermal properties determined for the separated standard concrete and pure PCM. The dashed lines represent the results obtained from the models where the PCM concrete properties were 
obtained from experimental investigations where measurements were conducted on the PCM and concrete combined into one material.

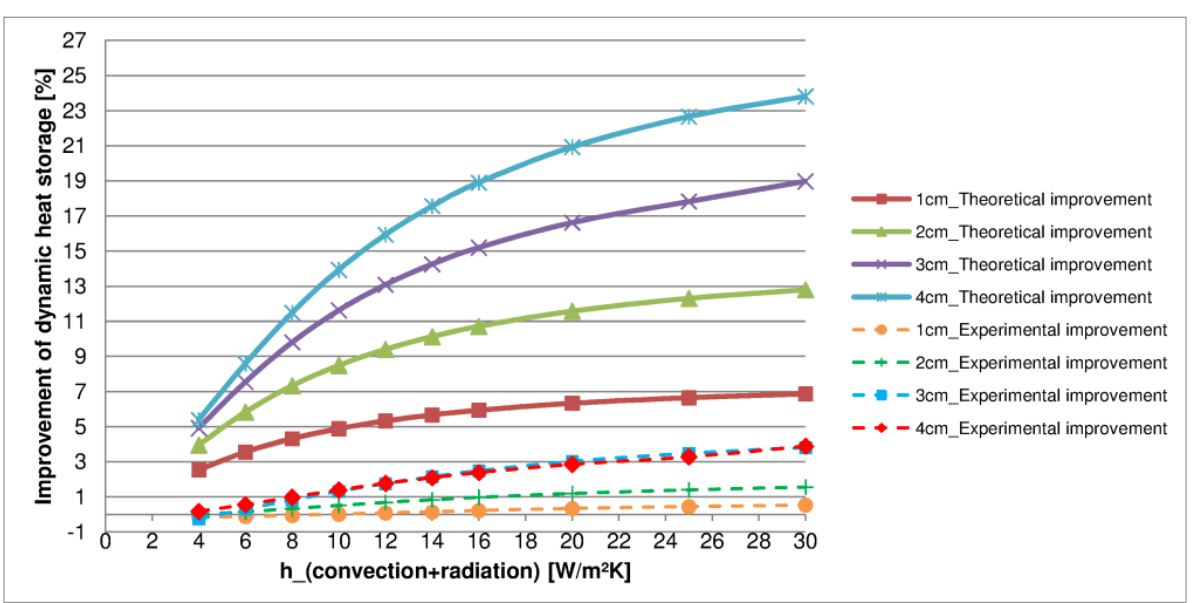

Figure 33. Calculated improvement of the dynamic heat storage of deck with theoretically/experimentally determined 4(wt) \% PCM concrete with regards to the deck without PCM

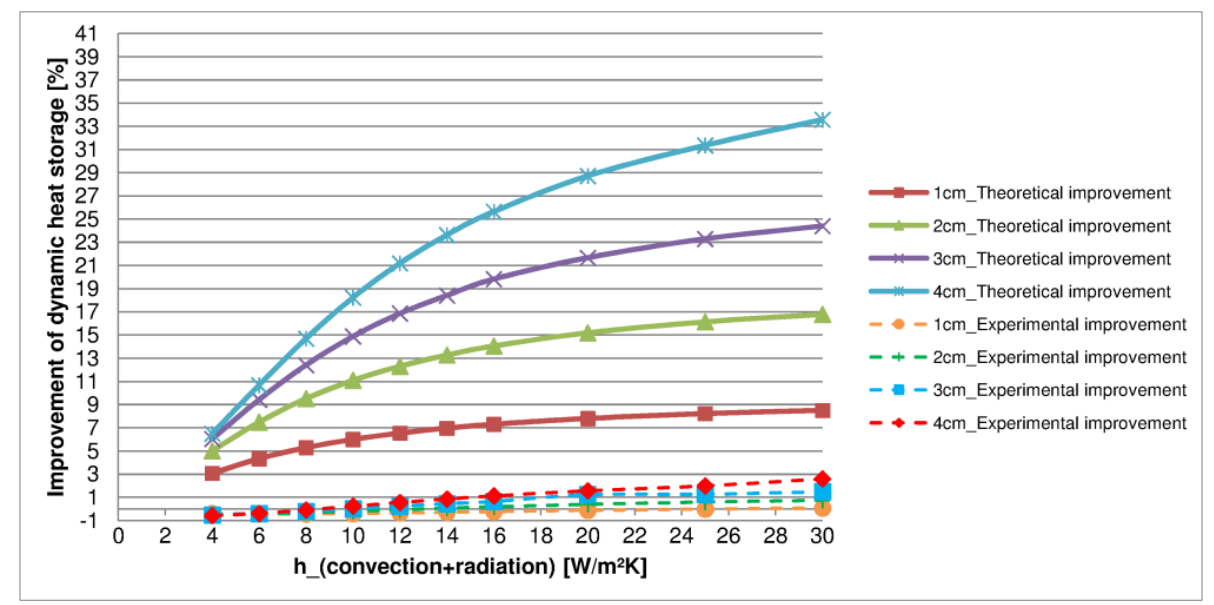

Figure 34. Calculated improvement of the dynamic heat storage of deck with theoretically/experimentally determined 6(wt) \% PCM concrete with regards to the deck without PCM

\subsubsection{Active approach: Calculated cooling capacity}

The results presented in Figure 35 and Figure 36 illustrate the diurnal cooling capacity of the decks with respectively $0 \%$ (reference), 4 (wt) \% PCM in the concrete and water in the decks circulates $24 \mathrm{~h} /$ day (always). As in the passive approach, the performance of the decks is calculated with the PCM concrete layer that has a thickness from 1 up to $4 \mathrm{~cm}$, and the total heat transfer coefficient on the surface is a parameter varying from 4 up to $30 \mathrm{~W} /\left(\mathrm{m}^{2} \mathrm{~K}\right)$. 


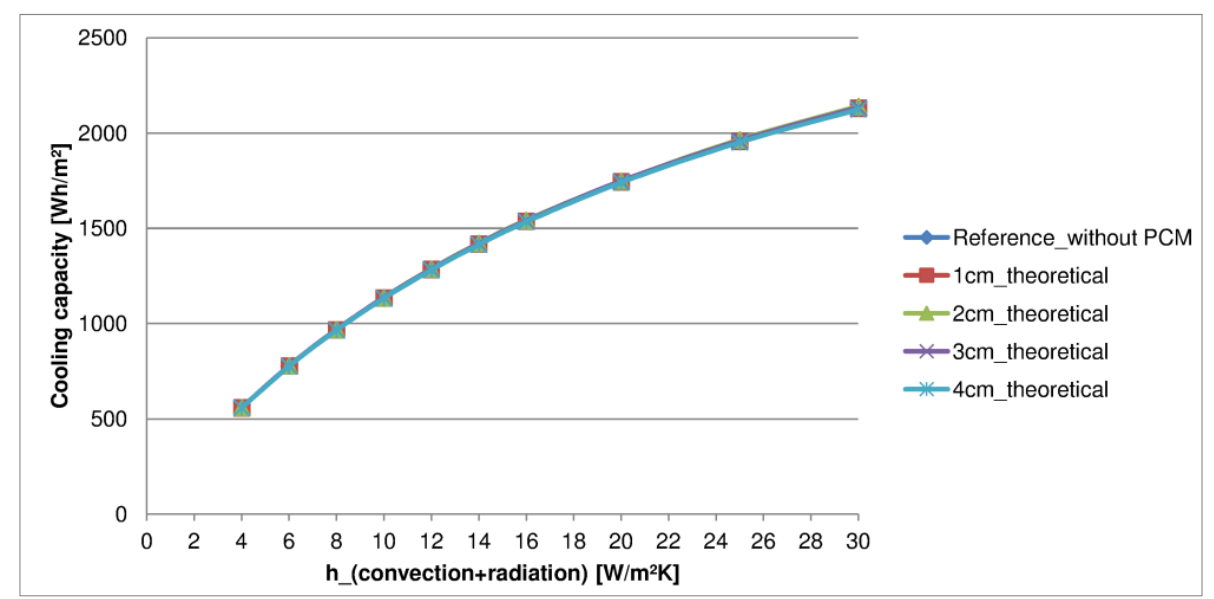

Figure 35. Daily cooling capacity of the deck with reference concrete and theoretically determined 4(wt) \% PCM concrete

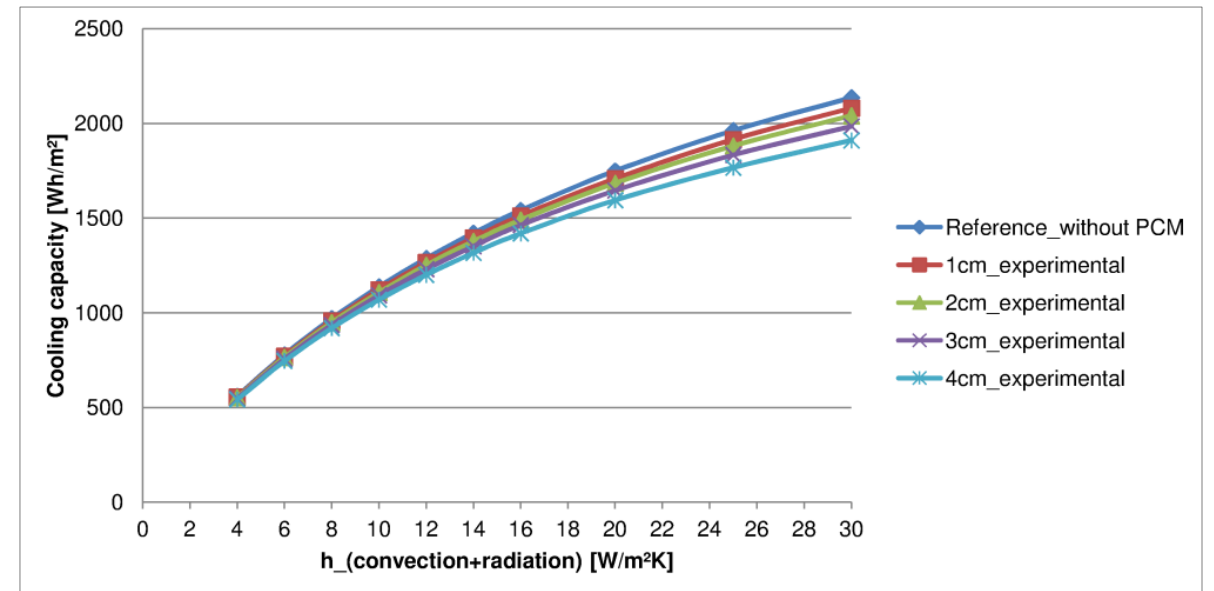

Figure 36. Daily cooling capacity of the deck with reference concrete and experimentally determined 4(wt) \% PCM concrete.

\subsection{Discussion}

As seen in Figure 31, volumetric heat capacity calculated based on weight average (theoretical) calculations give much higher results than the experimentally determined ones. Furthermore, the left side of the peak of the volumetric heat capacity in function of temperature has comparable width for the theoretical and experimental data where, on the other hand, the right side of the peak is much shorter for the theoretical data than for the experimentally determined results. Moreover, the difference between the volumetric heat capacity of the $4(\mathrm{wt}) \%$ and $6(\mathrm{wt}) \%$ PCM concrete is quite insignificant. This can be explained by the decreasing density with the increasing content of PCM in the concrete.

Results of thermal inertia presented in Figure 32 indicate that this thermal parameter is lower for the experimentally determined 6(wt)\% PCM concrete than for the reference concrete. The low thermal inertia of the $6(\mathrm{wt}) \%$ PCM concrete is the reason for the negative or almost neutral heat storage capacity improvement with regards to the reference deck presented in Figure 34. Due to its significantly higher thermal conductivity than the experimental 6(wt)\% PCM concrete, the experimental 4(wt)\% PCM concrete has higher thermal inertia than the reference concrete and therefore the heat storage improvement is also higher with regards to the deck made only of reference concrete.

The thermal inertia for the theoretically calculated thermal properties of the $4(\mathrm{wt}) \%$ and $6(\mathrm{wt}) \%$ PCM concrete is significantly higher than the thermal inertia of the reference concrete but only within the melting 
range where the specific heat capacity is high. Above the melting range the theoretical 6(wt)\% PCM concrete has slightly lower thermal inertia than the reference concrete.

The conclusion is therefore that when using the PCM concrete in buildings, it has to be ensured that the indoor temperature swing is fluctuating within the melting range of the PCM, or that the used PCM has a melting range that covers expected and acceptable temperature swing in the building. In this manner the latent heat of fusion will be utilized most efficiently. Moreover for both theoretical and experimental parameters, the thermal inertia of the 4(wt)\% PCM concrete is correspondingly higher than the thermal inertia of the $6(\mathrm{wt}) \%$ PCM concrete.This can be explained by the increasing specific heat capacity and decreasing thermal conductivity and density while the percentage of the incorporated PCM is increasing. As stated, the drop of the density and thermal conductivity of the concrete effectively counteract the increase of the specific heat capacity due to the latent heat available within the melting range of PCM.

In Figure 33 and Figure 34, the increase of the dynamic heat storage in the decks with PCM with respect to the reference deck without PCM becomes more distinct the higher the heat transfer coefficient on the surface is. Also, the curves representing dynamic heat storage are continuously rising with the increased heat transfer coefficients, which is the indication that the thermal mass in any decks is not fully utilized.

Contrary to the results obtained based on the theoretical assumptions for the thermal properties of the combined PCM and concrete, the improvement of the heat storage of the deck with the experimentally determined properties is not exceeding $5 \%$ even for a quite high heat transfer coefficient that reaches 30 $\mathrm{W} /\left(\mathrm{m}^{2} \mathrm{~K}\right)$. As seen in Figure 33 and Figure 34, the improvement is not higher than $1 \%$ for the total heat transfer coefficient that is lower than $10\left(\mathrm{~W} / \mathrm{m}^{2} \mathrm{~K}\right)$. What is more, the performance of the $4(\mathrm{wt}) \%$ PCM concrete is surprisingly better than the performance of the $6(\mathrm{wt}) \%$ PCM concrete and the explanation for that is given in Figure 31 and Figure 32.

Regarding the cooling capacity of the thermally activated decks presented in Figure 35, the results are overlapping each other regardless of the amount of PCM and the thickness of the layer with PCM for the theoretically determined thermal properties of the PCM concrete. The reason for that is the calculated insignificant drop in the thermal conductivity with the increase of the amount of PCM in the concrete. Contrary to that, the cooling capacities obtained from the decks with the experimentally determined properties of the PCM concrete, see Figure 36, are considerably lower with regards to the reference deck. This is because of the drastic drop in the measured thermal conductivity discovered during the experimental investigation on the new PCM concrete material.

\section{Full-scale experiment on various decks: heat storage and heat transfer enhancement investigation}

Methodology, results and conclusions of full scale experimental analysis presented in chapter 8 are fully elucidated in [36].

\subsection{Purpose}

The purpose of the investigation is to compare heat storage of various concrete hollow core decks that are located in the interior of the building and are thermally activated only by temperature fluctuations of the indoor air. The investigation is conducted on five different deck elements:

- DECK_1: Hollow core concrete deck with grooved PCM mortar tiles on the bottom

- DECK_2: Hollow core concrete deck with flat PCM mortar tiles on the bottom

- DECK_3: Hollow core concrete deck with grooved mortar tiles on the bottom

- DECK_4: Hollow core concrete deck with flat mortar tiles on the bottom

- DECK_5: Reference standard hollow core concrete deck with flat bottom surface

The modification with regards to standard deck is either due to addition of microencapsulated PCM or due to extension of the bottom surface by special triangular grooves on the bottom of the decks or by both of the 
two mentioned measures. The addition of PCM introduces latent heat capacity to the concrete deck. The grooves on the bottom surface of the deck extend the surface and with that should result in higher heat transfer to the deck and higher diurnal dynamic heat storage capacity of the decks. The extended surface of the bottom the deck were done because the heat transfer coefficient on the surface is the key parameter deciding how much energy can be stored in the concrete deck during diurnal charging/discharging condition as presented in chapters 4 and 7 . The higher heat transfer coefficient is due to convection and radiation on the surface, the higher the dynamic heat storage capacity of the construction element.

\subsection{Methodology}

\subsubsection{Numerical investigation of potential of extended bottom surface}

Investigation of potential to increase dynamic heat storage capacity of concrete deck elements due to extension of the bottom area of the decks was studied in COMSOL Multiphysics using dynamic heat transfer model. The geometry of the two dimensional models developed in COMSOL are presented in Figure 37. In the models all the assumptions regarding the boundary condition are preserved from models presented in chapter 4.2 with exception of the air void which was given equivalent thermal conductivity calculated according to methodology presented in chapter 6 . Since the hollow core deck has repetitious construction it is allowed to simplify model to only one section of the deck. The models presented in Figure 37 have increased bottom surface area by factor of 2 (left) and factor of 3 (right) with respect to ordinary deck with flat bottom surface.
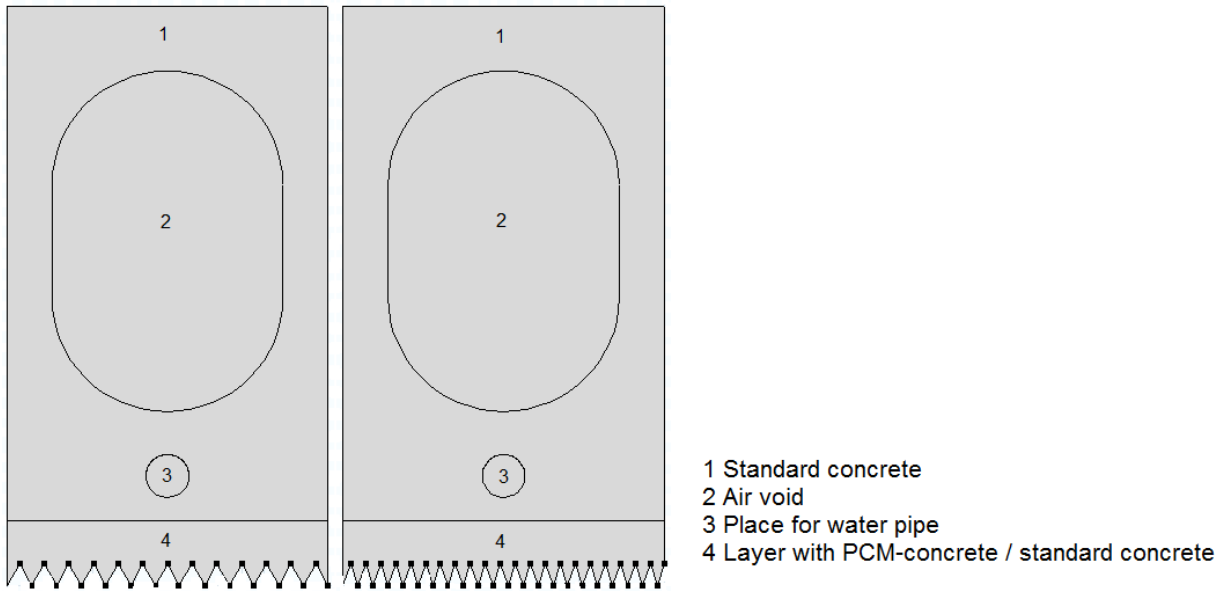

Figure 37. COMSOL 2D models of the hollow core deck with extended bottom surface by factor 2 and 3.

The dynamic heat storage capacity of decks has been calculated only due to heat transfer on the bottom surface of the decks. Results obtained from the numerical analysis indicated that increased surface area might have a potential to help thermally activate thermal mass only due to diurnal indoor temperature fluctuations in the room, see Figure 38. On the contrary, numerical prediction did not indicate any significant improvement of dynamic heat storage capacity due to addition of PCM to concrete. 


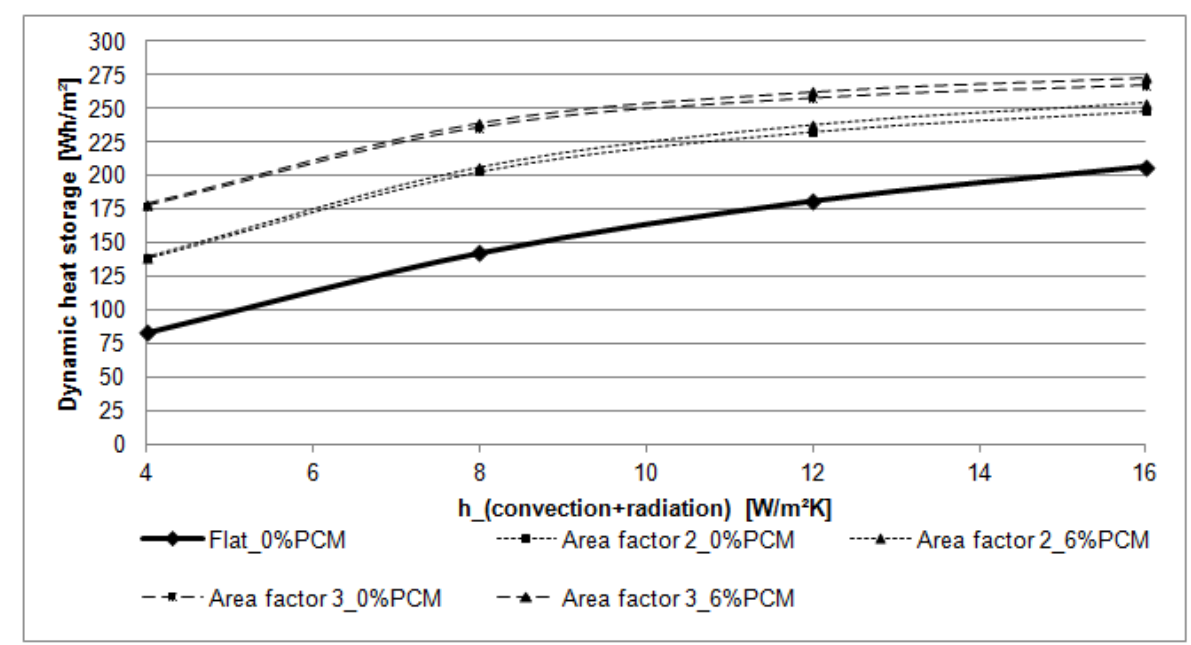

Figure 38. Dynamic heat storage capacity for flat and grooved decks.

\subsubsection{Deck development}

Five various decks are investigated in the presented research. In Figure 39, drawings of cast hollow core decks are presented. The reference hollow core deck is made of standard ordinary concrete. The four remaining hollow core decks integrate mortar tiles with and without PCM. Each deck has in total 6 tiles of one type integrated, next to each other, and they cover almost the whole bottom surface of the hollow core deck.

The tiles are cast in specially prepared moulds prior to cast of prefabricated hollow cores. Consequently, tiles are demoulded and the necessary time is taken for the tiles to obtain their required strength before they are cast in the bigger moulds, where the big hollow cores are cast. The tiles are located at the bottom of the big mould, and the reinforcement of the tiles is connected to the reinforcement prepared for the big hollow cores. Afterwards, concrete is poured in the moulds in the same manner as for the standard hollow core deck. This way, specially designed tiles become an integral part of the big hollow core concrete deck element. For the profiled mould on the bottom, triangular wooden elements were located which gave the tiles a designed surface. The triangular profile was designed to be $10 \mathrm{~mm}$ high and $8 \mathrm{~mm}$ width at the base. This triangular profile on the surface increases the original flat surface by factor 2.7. At the present moment, surface increase factor of 2.7 was the highest possible at which demoulding of tiles was still possible without damaging the surface of the tiles.

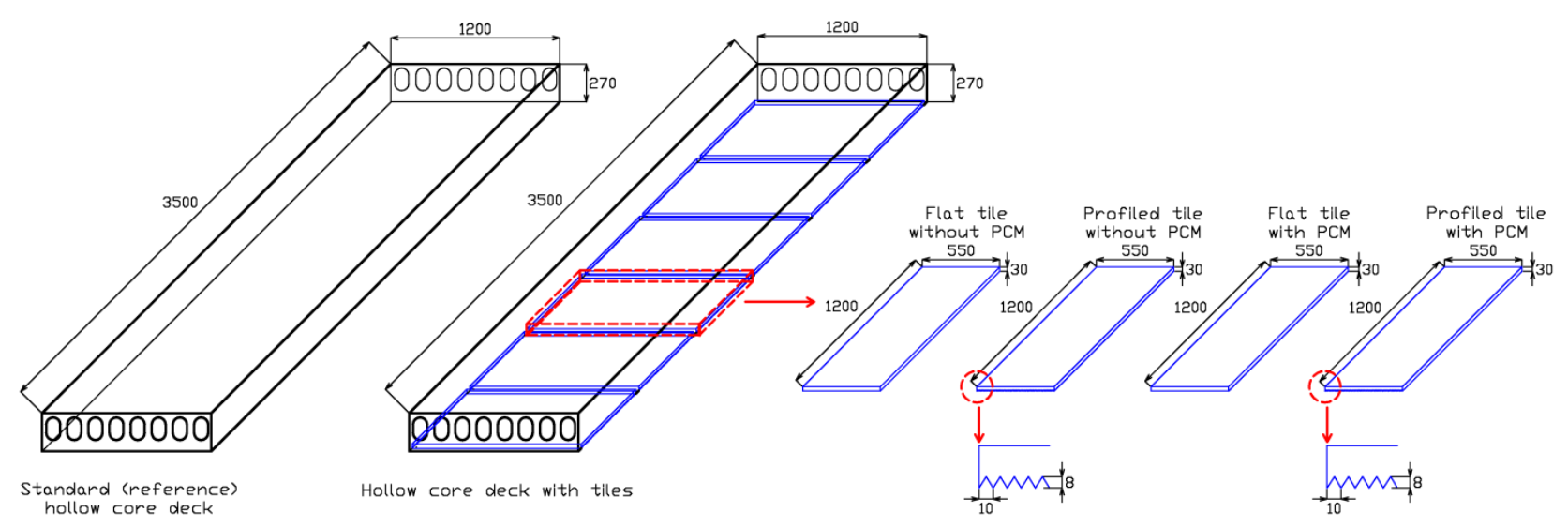

Figure 39. Design of five various types of hollow core deck elements. 
The tiles were cast with special mortar without stones. If they were cast with concrete with stone aggregate, then the profiled shapes would be damaged while demoulding. Finally, in total two decks of each kind were cast, and in total 10 full-scale decks measuring $3.5 \times 1.2 \times 0.32$ were cast.

It is worth to stress that all hollow cores were cast at the same time and were stored in the same indoor condition. Therefore, it is assumed that moisture content in all the decks is at a similar level.

\subsubsection{Modified hot box apparatus development}

The standard hot box apparatuses are usually operated in order to maintain steady-state conditions and measure the overall heat transfer through large, homogenous or inhomogeneous structures and from that thermal conductivity of elements can be determined. According to [C11], two types of hot box apparatus can be distinguished: guarded hot box (GHB) and calibrated hot box (CHB). In the presented research, the constructed hot box was developed based on the GHB concept. However, the purpose of the presented experimental analysis is not to determine the overall thermal conductivity, but to determine and compare thermal performance (dynamic heat storage capacity) of the investigated various decks under the periodic steady-state temperature conditions.

The vertical section view of the developed modified hot box apparatus is presented in Figure 40. Four zones can be distinguished in the hot box. In each zone, air is re-circulated through the air handling unit (AHU) that can provide cold and heat to the individual zone depending on the predefined temperature profile.

Zones 2 and 3 directly influence the two hollow core decks mounted in the hot box. In zones 2 and 3, air temperature profile is designed to vary daily between $20^{\circ} \mathrm{C}$ and $26{ }^{\circ} \mathrm{C}$ according to a sine curve. Thus, the chosen temperature range would be close to the recommended design values of the indoor operative temperature for design of buildings and HVAC systems in office buildings according to [C12] and would almost entirely cover the melting temperature range of used PCM which was determined to be between 19 ${ }^{\circ} \mathrm{C}$ and $27{ }^{\circ} \mathrm{C}$ with melting point at $23^{\circ} \mathrm{C}$, see section 5.2.3.7.

In the presented hot box, the guarding zones for zones 2 and 3 are zones 1 and 4 . The set temperature in zones 1 and 4 is identical to zones 2 and 3. In this way, it can be assumed that no heat is gained or lost due to the temperature differences between zones 2 and 3 and the air in the surrounding laboratory. In zone 4, the air circulates around zones 2 and 3 in specially designed chambers of height of $120 \mathrm{~mm}$ and width of 600 $\mathrm{mm}$.

Additionally, the zones are separated from each other with thick layers of thermal insulation to minimize the risk of any uncontrolled heat gains or losses, as presented in Figure 40. For example, zones 2 and 3 are separated from each other with $150 \mathrm{~mm}$ of mineral wool, zones 2 and 3 are separated from guarding zone 4 with $25 \mathrm{~mm}$ of expanded polystyrene, and from guarding zone 1 with $100 \mathrm{~mm}$ of mineral wool. Additionally, zone 4 was separated from the surrounding laboratory with $150 \mathrm{~mm}$ expanded polystyrene, and distribution boxes and ventilation channels were insulated with $50 \mathrm{~mm}$ of mineral wool. Moreover, special focus was put on ensuring that all zones were air tight and that there was no uncontrolled air exchange between zones. Zone 1 presented in Figure 40 is designed on wheels and can be moved forth and back in order to close or open zone 2 and 3. During tests, the chamber 1 is clamped tightly against an insulated frame that surrounds chambers 2 and 3. 


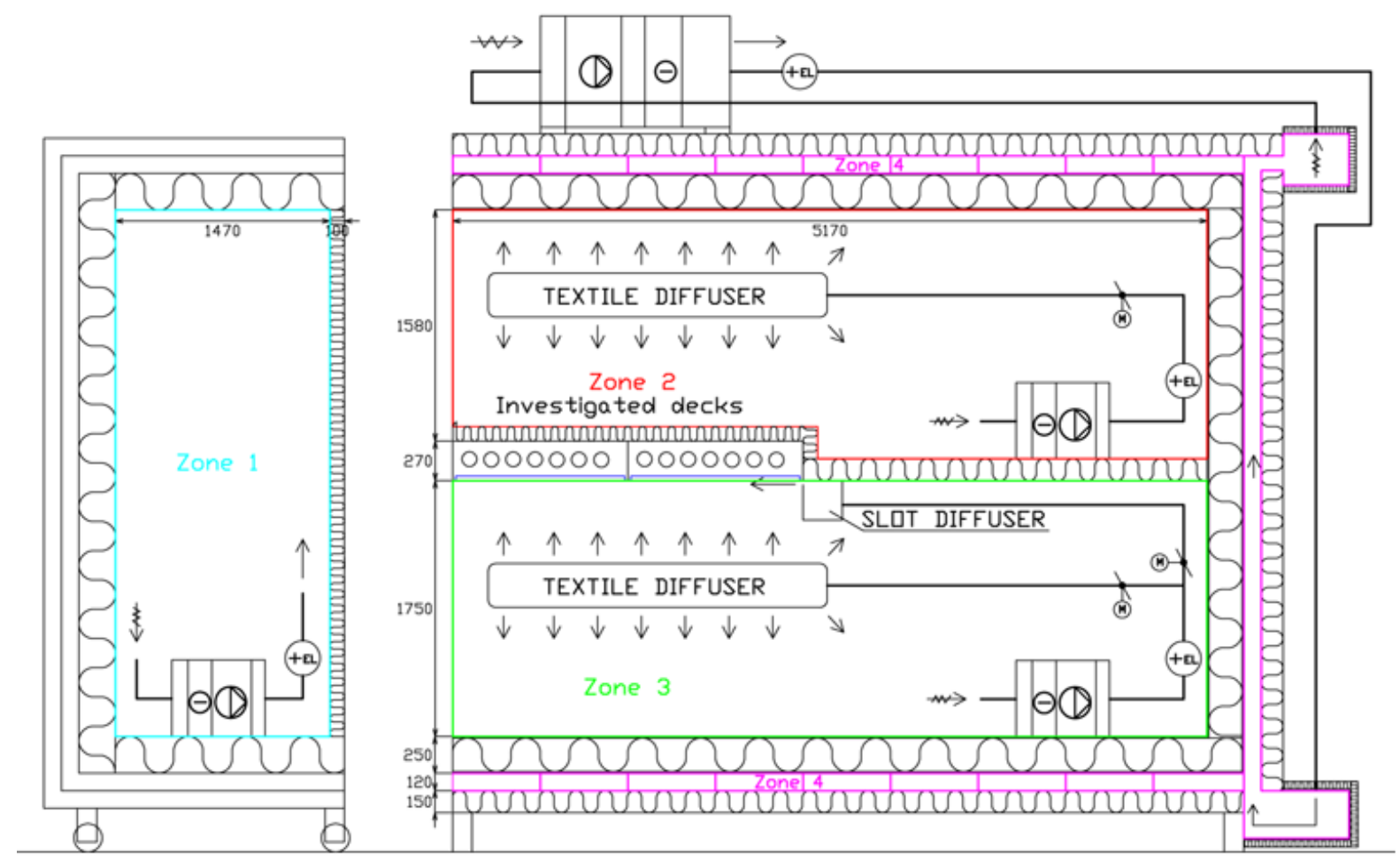

Figure 40. Vertical section view of developed modified hot box apparatus with distinguished thermal zones, dimensions are given in $\mathrm{mm}$.

As presented in Figure 40, the only difference between zones 2 and 3 is the air distribution system. In zone 2, air is distributed by the circular low impulse diffuser and air is fully mixed. In zone 3 , two various air distribution systems are available. The textile one is the same as in zone 2, and the other one is from the slot diffuser that is blowing air just under the two investigated decks. The inlet air can be directed by the mounted motor throttles either to the textile diffuser or to the slot diffuser or to both of them. In both designed distribution cases, air in zone 3 is fully mixed, but the air velocities close to the bottom of the investigated decks are expected to be different. All experiments presented in this paper were conducted with use of only the ventilation slot diffuser in zone 3 . The slot diffuser is $3.6 \mathrm{~m}$ long (covers all length of the decks) and the opening has height of $3 \mathrm{~cm}$. Moreover, ventilation aggregate is set to operate at its maximum capacity which results in air change rate (ACR) approximately at $351 /$ h. Here, air velocity in the inlet slot diffuser is approximately $5 \mathrm{~m} / \mathrm{s}$. Consequently, the convective heat transfer coefficient is as high as possible for the available ventilation system, and therefore the thermal mass of the deck should be sufficiently activated.

\subsubsection{Data acquisition}

Data acquisition system includes following measurements: air temperature, cooling water temperature, air velocity under decks, cold water flow, heat provided to the electrical components (fans, pumps, heaters) and deck weight.

Regarding temperature measurements, beside PT 100 sensors located in each zone to control temperature there are in total $86 \mathrm{~K}$ type calibrated thermocouples to monitor the temperature. Thermocouples are scanned every 10 seconds, and temperatures are logged by the Helios Fluke data logger type 2287A. Thermocouples are used to measure vertical air temperature profiles, horizontal air temperature profile under the investigated decks, hot box internal walls, temperature, ceiling and floor temperatures, temperature on the bottom and top surface of the investigated decks and in the investigated concrete decks, cold water inlet and outlet to cooling coils in zones 2 and 3. 
Air velocity measurements are done with use of three-dimensional thermal anemometers. In total 16 anemometers are used, and they are all located in two axes. Each axis is placed $5 \mathrm{~cm}$ from the bottom of the investigated decks. Each anemometer is scanned every $30 \mathrm{sec}$ and velocity is measured as mean value from 10 sec. Velocities are logged by Dantec multichannel flow analyzer type 54N10.

Electrical power measurements to all components located in zones 2 and 3 are measured at transformer type GP-1from Noratel and logged through the special LabVIEW script.

Cooling effect provided to zones 2 and 3 is calculated from water flow registered by Brunata energy meter type HGQ1and thermocouples located at the inlet and outlet to zone 2 and zone 3 . The water flow is logged through special LabVIEW script and at the same time temperature from thermocouples is scanned every 10 second.

Weight of each deck is measured by four force transducers type S9/5 manufactured by HBM mounted to the carriage supporting the decks in the hot box. Measured data is amplified by the Spider 8 amplifier from HBM. Data acquisition is done by Catman professional software.

\subsubsection{Dynamic heat storage capacity}

The test specimen behavior under dynamic temperature conditions can be described by various coefficients, for example the thermal lag, reduction in heat flux/temperature amplitude, total heat flow ratio or decrement factor presented, as seen in some former investigations [37 - 38]. These parameters however are usually derived for a construction where one side is in steady-state condition and the other is in dynamic thermal condition. For example a simplified model of external wall where external temperature is varying and internal temperature is assumed constant.

The purpose of the investigation presented in this article is to determine dynamic heat storage capacity of concrete decks. Also, to be able to compare this heat storage for various concrete hollow core decks located under the condition that imitate interior of the building and which thermal mass is activated only by the temperature fluctuations of the indoor air.

The dynamic heat storage capacity of each deck element, but only with respect to the heat transfer through the bottom surface of the deck, can be derived from known energy balance in zone 3 in the modified hot box apparatus. The dynamic heat storage capacity of zone 3 would be then a half of the difference of the cumulative electric (heating) energy provided to zone 3 during charging period and discharging period decreased by the cooling load provided to zone 3 . To calculate absolute dynamic heat storage capacity of only concrete deck elements excluding the heat capacity of the hot box construction and all components in zone 3 (ventilation aggregate, ventilation channels, pump and fittings, two steel carriages to support decks) one experiment was conducted for hot box apparatus where instead of two concrete decks a ceiling built of a very light extruded polystyrene (EPS ceiling) was mounted. The thermal mass of such ceiling can be neglected, and the absolute dynamic heat storage capacity of zone 3 without concrete decks can be calculated in the same manner as for zone 3 with concrete decks. Then the difference of absolute dynamic heat storage capacity of zone 3 with concrete decks and absolute dynamic heat storage capacity of zone 3 without concrete decks (but with all other components kept in zone 3), results in absolute dynamic heat storage capacity of each pair of decks investigated.

A comparison between different decks can be assessed based on energy balance in zone 3, because the only variable parameter in the whole set-up is the finish on the bottom surface of the deck facing zone 3 . The reference deck for the investigation is standard deck made of concrete (DECK_5). The comparison of absolute dynamic heat storage capacity of decks can be done, since in all experiments and for all types of investigated decks, the same dynamic temperature profile in zones 2 and 3 is maintained, the same control technique is implemented and the same air distribution system is preserved.

In the charging period (when temperature is varying from $23^{\circ} \mathrm{C}$ to $26^{\circ} \mathrm{C}$ ), the more heat that has to be provided to zone 3 , the higher the heat storage capacity of particular deck element will be. Conversely, in the 
discharging period (when temperature is varying from $23^{\circ} \mathrm{C}$ to $20^{\circ} \mathrm{C}$ ), the less heating that has to be provided to zone 3 , the higher the heat storage capacity of particular deck element will be.

Periodic temperature cycles are repeated until the quasi steady-state situation is obtained. As stated in [37], such repetition is typically attained within two days for lightweight frame walls systems and four days for heavy masonry wall system. In the conducted experiments, each deck was exposed to $24 \mathrm{~h}$ periodic steadystate cycles over seven days, where the first two days are considered as the stabilization period and the five remaining days are taken into consideration for calculation of dynamic heat storage capacity of the decks.

\subsection{Results}

\subsubsection{Thermal properties}

Along with full-scale experiments conducted in the modified hot box apparatus, an experimental investigation of thermal properties of concrete, mortar and PCM mortar used in hollow core deck elements was performed using a modified hot plate apparatus.

Small specimens of concrete, mortar and PCM mortar measuring $15 \mathrm{~cm}$ x $15 \mathrm{~cm}$ x $8 \mathrm{~cm}$ were cast aside fullsize hollow core deck elements to determine their thermal properties. Firstly, a thermal conductivity of materials was measured. The methodology and the experimental set-up to measure a thermal conductivity of concretes and mortars with use of the hot plate apparatus can be found in section 5.1. Measurements were conducted for three mean temperatures of each specimen: $10^{\circ} \mathrm{C}, 20^{\circ} \mathrm{C}$ and $40^{\circ} \mathrm{C}$ respectively, and in all measurements the temperature difference between hot and cold plate was at $15^{\circ} \mathrm{C}$. Measurements were repeated three times for each specimen and average thermal conductivity for each mean temperature was calculated. Results of the measurements are depicted in Figure 41. Moreover, the repeatability of results was very satisfactory, see also standard deviation for previously conducted measurements of thermal conductivity which are depicted in Figure 13. As can be observed, thermal conductivity of investigated materials is almost independent of temperature within which measurements were conducted. Therefore, an average thermal conductivity for three mean temperatures was calculated and results are presented in Table 9.

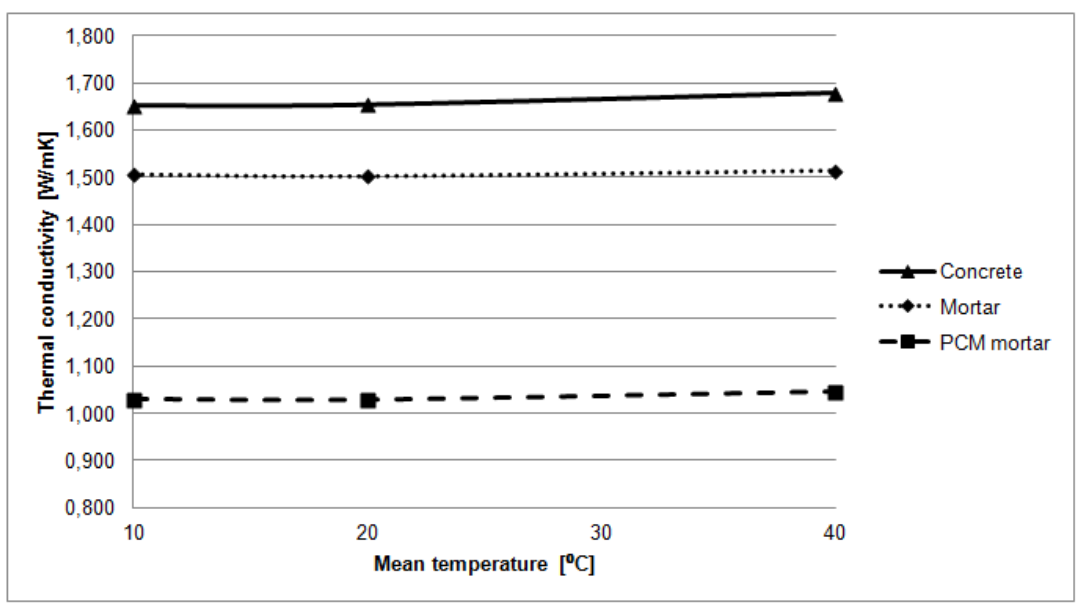

Figure 41. Measured thermal conductivity of concrete, mortar and PCM mortar used to cast decks and tiles.

Secondly, the same specimens were used to experimentally determine their specific heat capacity. A new method to determine specific heat capacity of inhomogeneous concrete and mortar materials with PCM was used. The specific heat capacity of the samples was determined as an inverse problem, and sequential quadratic programming (SQP) algorithm was used. A detailed description of the calculation methodology with SQP algorithm, experimental set-up and specimen preparation can be found in section 5.2.3.6 and in [27]. Results of specific heat capacity of the PCM mortar sample which is dependent on temperature are presented in Figure 42, and specific heat capacity of mortar and concrete is presented in Table 9. Each 
specimen was measured 3 times in order to control repeatability of results, and they were concluded to be satisfactory. In Table 9, mean average values from three measurements of each specimen are given.

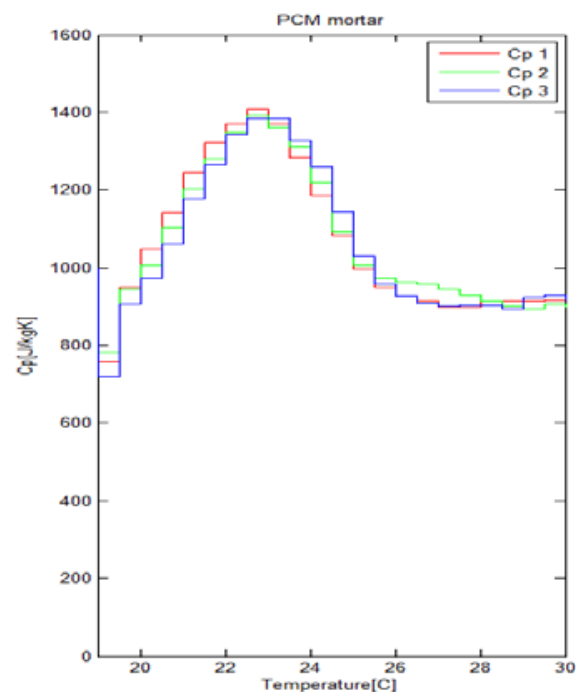

Figure 42. Measured specific heat capacity (latent and sensible) of PCM mortar as a function of temperature

\begin{tabular}{|l|c|c|c|}
\hline \multicolumn{1}{|c|}{ Material } & Thermal conductivity & Density & Specific heat capacity \\
\hline \multicolumn{1}{|c|}{$[-]$} & {$[\mathrm{W} /(\mathrm{mK})]$} & {$\left[\mathrm{kg} / \mathrm{m}^{3}\right]$} & {$[\mathrm{J} /(\mathrm{kgK})]$} \\
\hline Concrete & 1.661 & 2283 & 755 \\
\hline Mortar & 1.507 & 2090 & 797 \\
\hline PCM mortar & 1.035 & 1848 & - \\
\hline
\end{tabular}

Table 9. Thermal properties: thermal conductivity, density and specific heat capacity of concrete, mortar and PCM mortar used to cast full-scale hollow core decks.

Knowing thermal properties of materials, a volumetric heat capacity (VHC) and thermal inertia (TI) can be calculated using Equation (20) and Equation (21) respectively, presented previously in section 7.3.1.
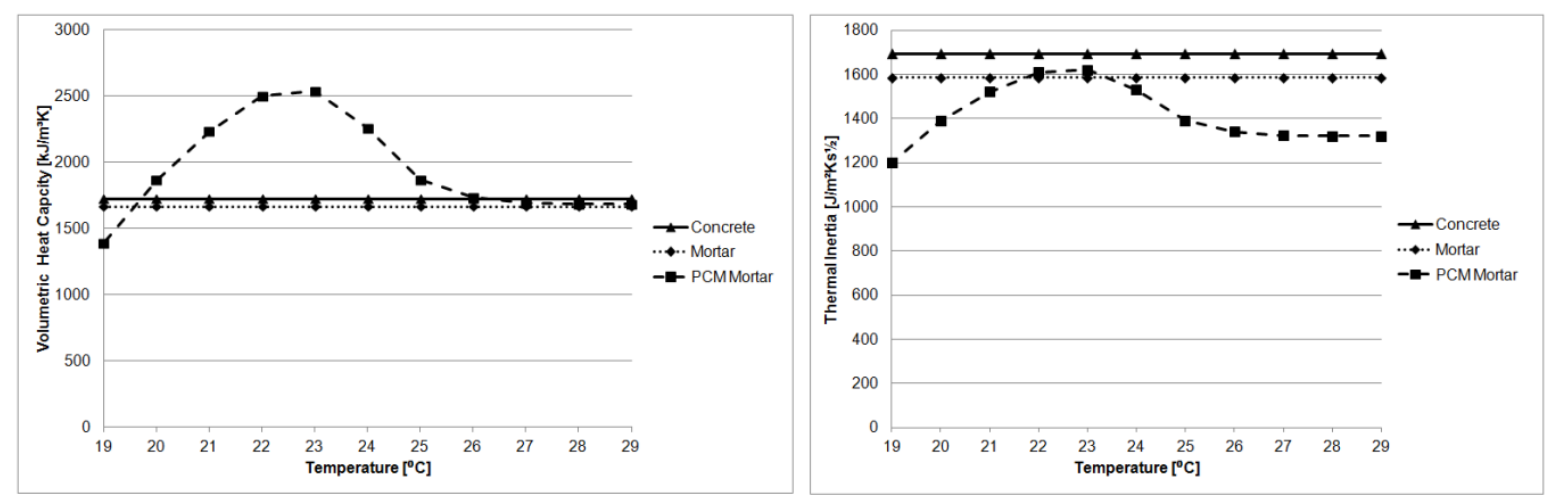

Figure 43. (left) Volumetric heat capacity, (right) thermal inertia of concrete, mortar and PCM mortar used to cast decks and tiles.

\subsubsection{Temperature and velocity in zone 3}

Temperature of the air in each zone is the parameter that is controlled during the experiments with different decks. To be able to compare and measure dynamic heat storage capacity of the decks, the same temperature has to be maintained from experiment to experiment. In this section, chosen temperatures are presented and these illustrate that thermal condition in the hot box were periodically steady-state and repeated from 
experiment to experiment and from day to day, see Figure 44. The location of thermocouples can be found in [36].
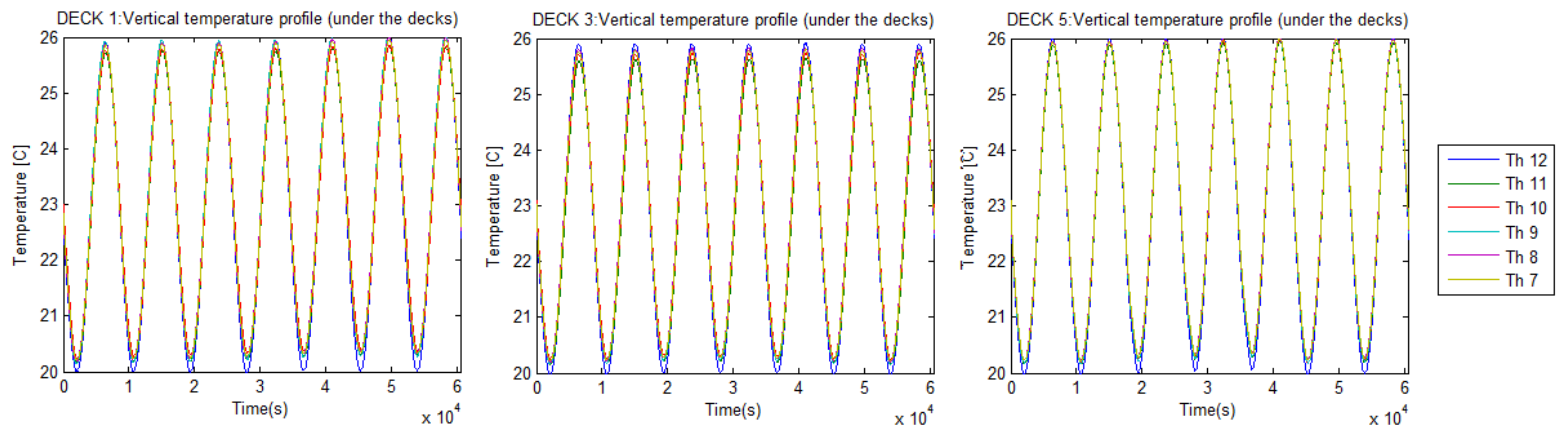

Figure 44. Measured vertical air temperature profile for chosen deck experiments

As seen in Figure 44, air is very well mixed and no temperature gradient can be noticed (logged temperatures at different heights in zone 3 overlap each other). Moreover, from experiment to experiment the same temperature amplitude and period can be observed.
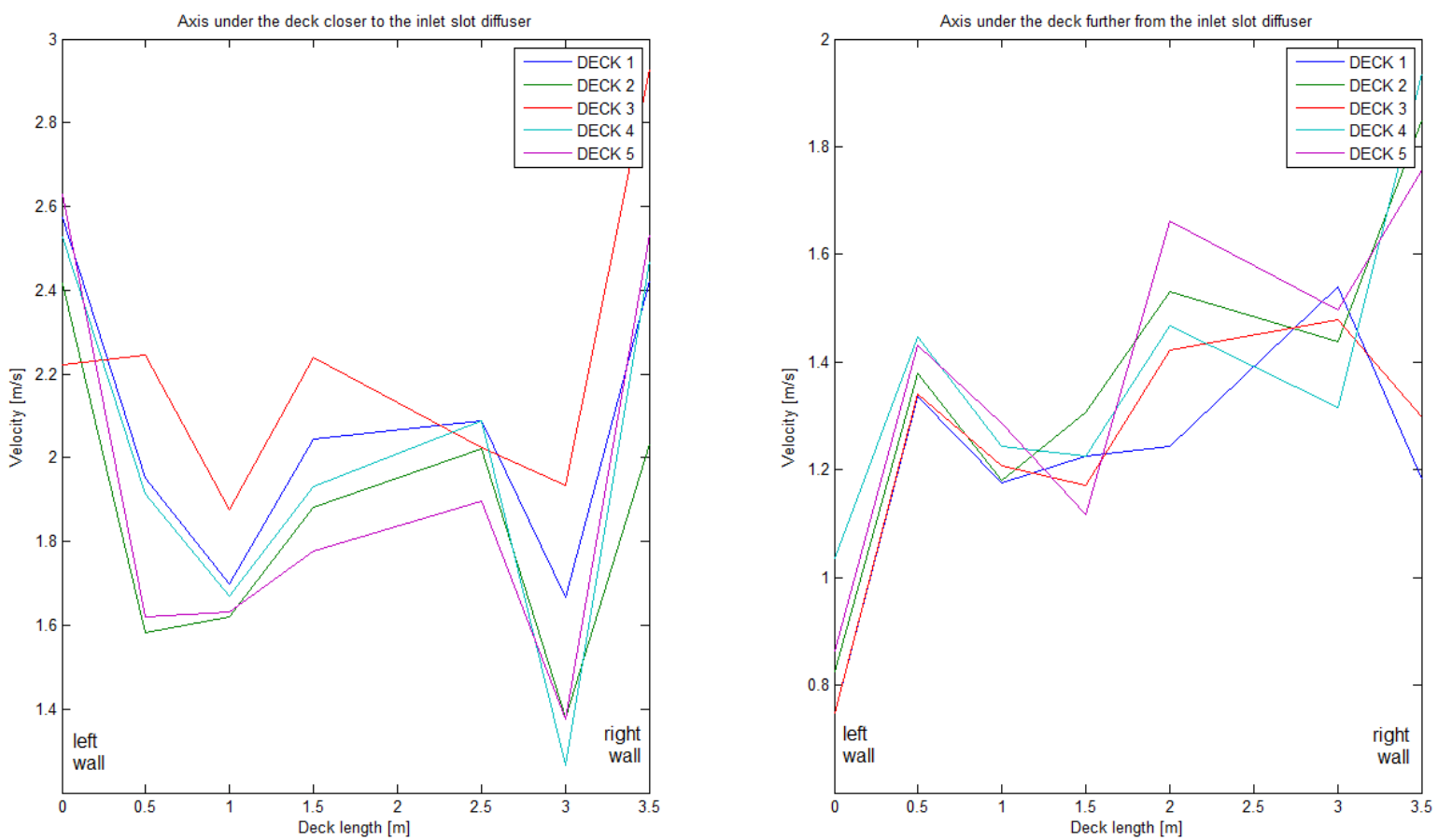

Figure 45. Mean air velocities under investigated decks

As seen in Figure 45, velocities in the axis closer to the inlet slot diffuser are highest closest to the walls, and in the axis further from the inlet slot diffuser, air jet attaches to one of the sides. In the conducted measurements, it was always the right side wall. Moreover, air velocity range and air velocity profiles follow very similar patterns for all conducted experiments. What is more, air velocities are generally higher under the decks located closer to the inlet slot diffuser than velocities under the decks further from the inlet slot diffuser. The location of anemometers used to measure air velocities can be found in [36].

\subsubsection{Heating load}

Heating load to zone 2 and zone 3 is provided by the following components: electric heater (modulated), fans, pumps, 3-way valves and P-line controllers. Heating load was measured at transformers and logged 
each 1 second. A graphical presentation of logged heating load during measurements of all decks as a function of time is presented in Figure 46.

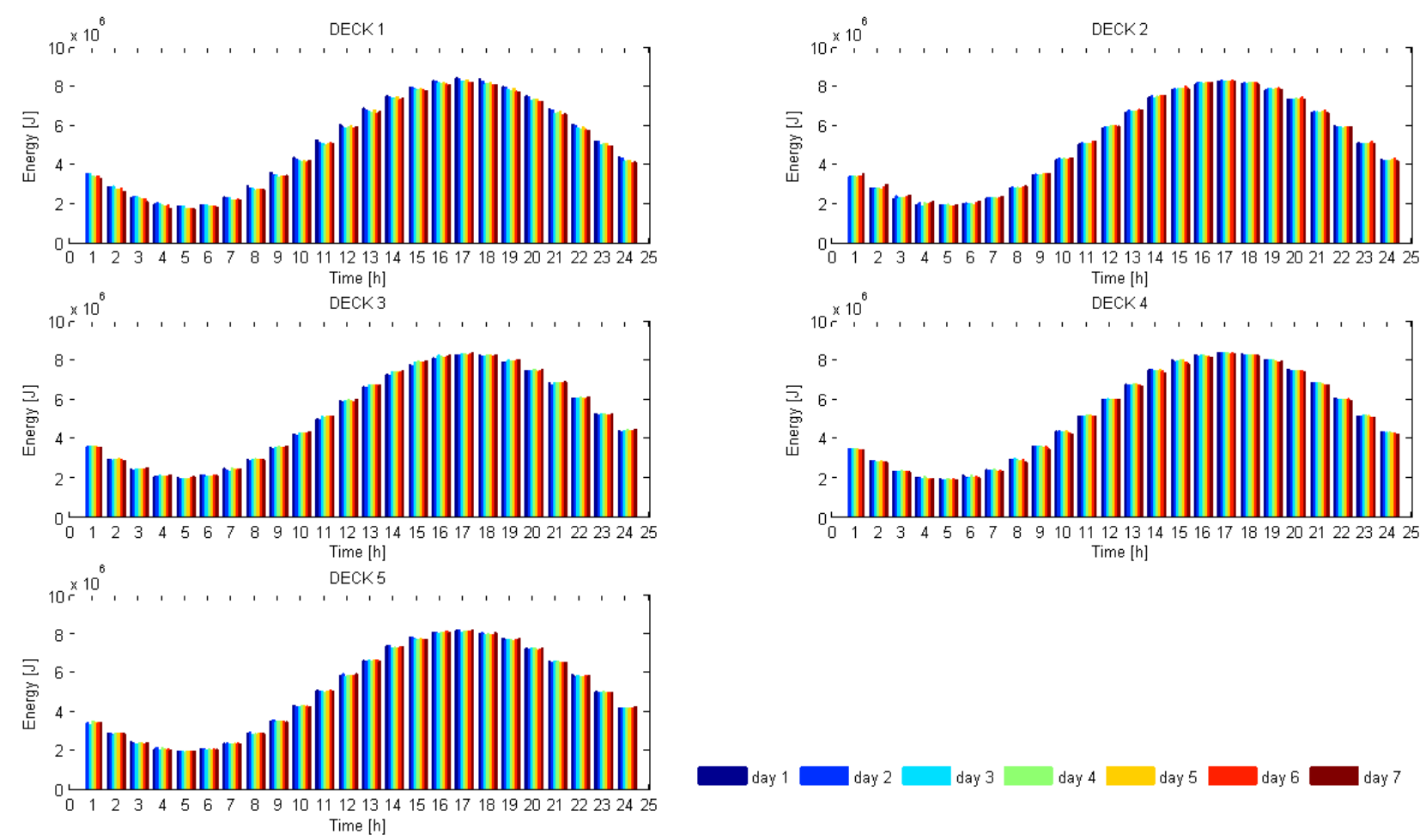

Figure 46. Hourly integrated heating load delivered to zone 3 for 7 measuring days of each investigated deck.

Figure 46 presents results which indicate satisfactory repeatability of hourly and daily heating load to zone 3 suggesting that periodic steady-state is obtained for each deck element.

\subsubsection{Cooling load}

Although mass flow of cooling water to the cooling coil is measured at a constant rate, see Figure 47, the temperature of cold water entering zones 3 and 2 was fluctuating insignificantly from experiment to experiment. Any water temperature fluctuations from experiment to experiment caused by air temperature variations that influenced the piping installation between the chiller and the hot box were taken into consideration in the cooling load calculations. As mentioned in data acquisition section, water temperature at the inlet and outlet to/from zone 2 and zone 3 was logged with a step of each 10 seconds. Using Equation 22 the cooling load to each zone as a function of time can be calculated.

$Q_{c}=m * \rho * C p *\left(\right.$ Tout $_{i}-$ Tin $\left._{i}\right)$

Where:

$\mathrm{Q}_{\mathrm{c}}$ - cooling energy, [W]

$\mathrm{m}$ - water mass flow, $\left[\mathrm{m}^{3} / \mathrm{s}\right]$

$\rho$ - water density, $\left[\mathrm{kg} / \mathrm{m}^{3}\right]$

$\mathrm{C}_{\mathrm{p}}$ - water specific heat capacity, $[\mathrm{J} / \mathrm{kgK}]$

$\mathrm{T}_{\text {out i }}-$ outlet water temperature measured in time, $[\square \mathrm{C}]$

$\mathrm{T}_{\text {in } \mathrm{i}}$ - outlet water temperature measured in time, [ $\left.\square \mathrm{C}\right]$ 


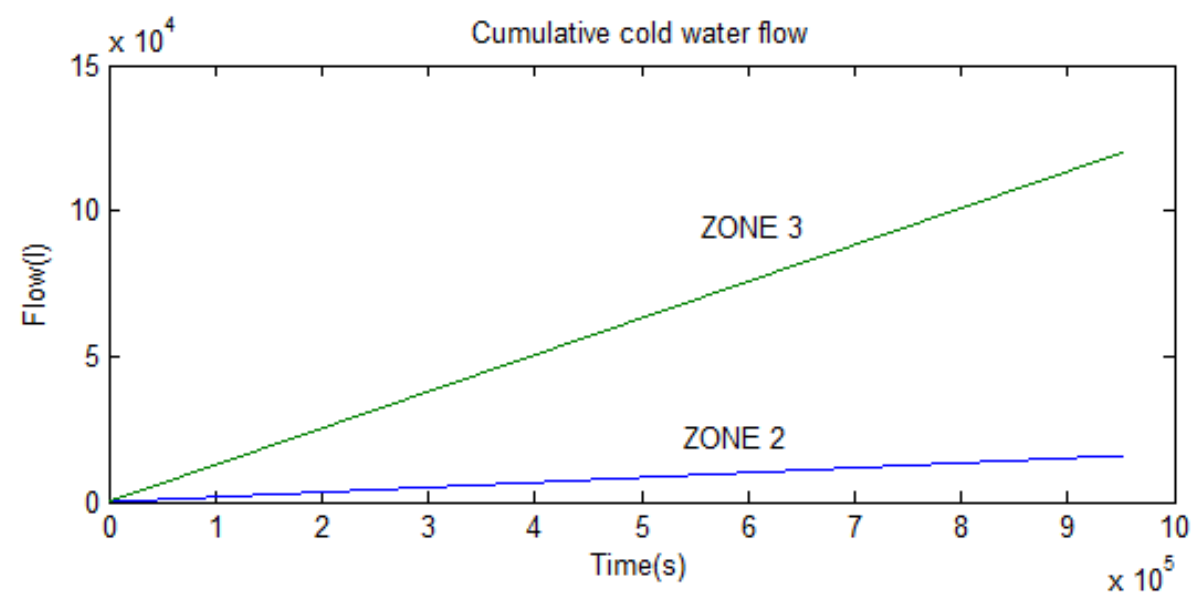

Figure 47. Cumulative water flow to zone 3 and zone 2.

\subsubsection{Absolute dynamic heat storage capacity}

Absolute dynamic heat storage capacity of concrete elements can be determined with use of Equation (23).

$$
\begin{array}{r}
\mathrm{Q}=\left(\int_{12}^{24}\left(Q_{\square-\text { deck }}(t)-Q_{c-\text { deck }}(t)-Q_{\square-\square o t-b o x}(t)-Q_{c-\square o t-b o x}(t)\right)-\right. \\
\int_{0}^{12}\left(Q_{\square-\text { deck }}(t)-Q_{c-\text { deck }}(t)-Q_{\square-\square o t-b o x}(t)-Q_{c-\square o t-}(t)\right) / 2
\end{array}
$$

Where:

$Q$ - Dynamic heat storage capacity of concrete deck

$Q_{h \text {-deck }}(t)$ - Heating energy provided to zone 3 in hot box with decks

$Q_{c-d e c k}(t)$ - Cooling energy provided to zone 3 in hot box with decks

$Q_{h \text {-hot-box }}(t)$ - Heating energy provided to zone 3 in hot box without decks (EPS ceiling)

$Q_{c-h o t-b o x}(t)$ - Cooling energy provided to zone 3 in hot box without decks (EPS ceiling)

The calculation in Equation (23) can be done for each day which means for each consecutive 24-hour period. An example of absolute charging and discharging energy is presented for DECK_3 (deck with grooved mortar tiles) as a function of time, see Figure 48. 


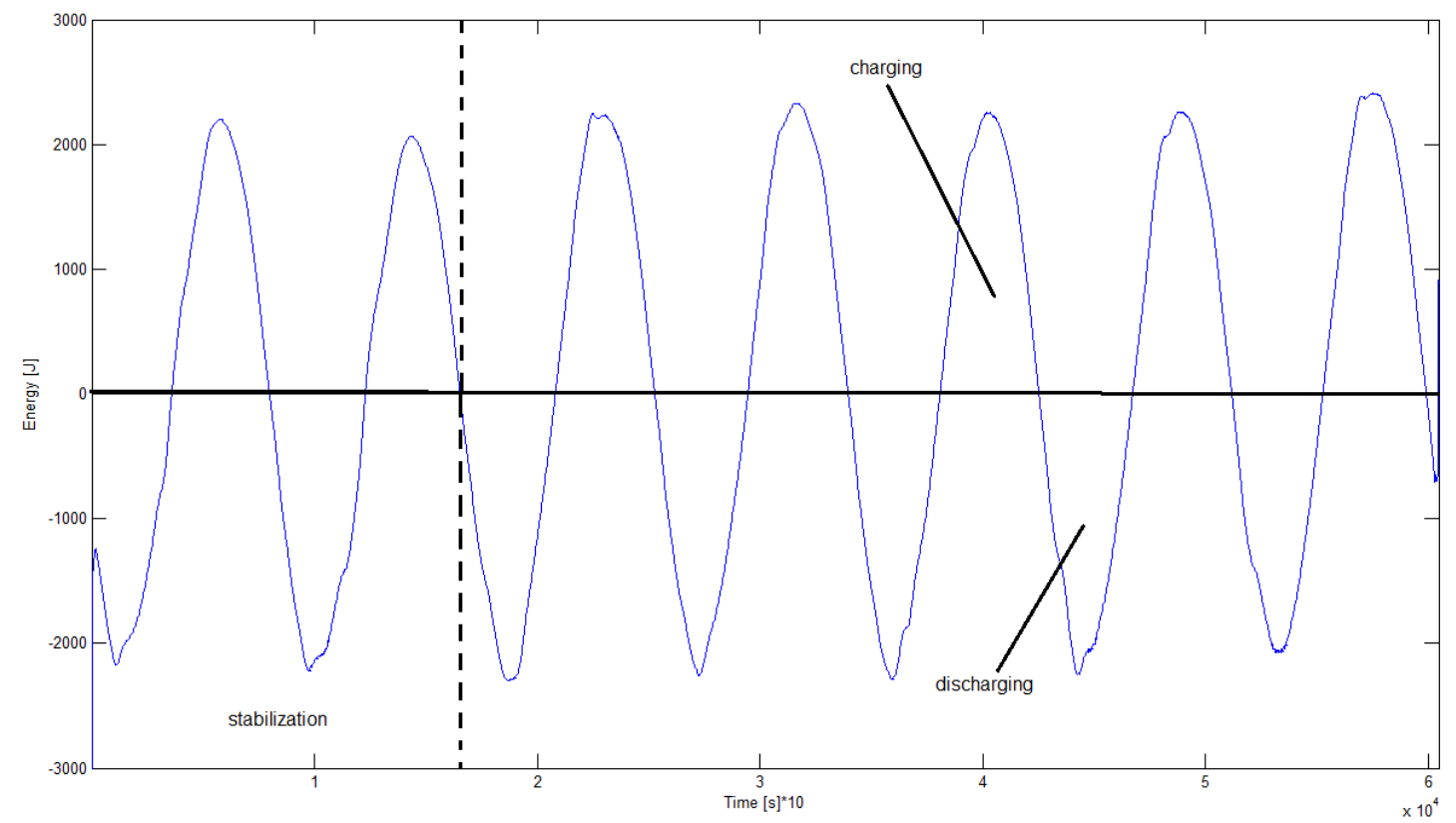

Figure 48. Absolute energy delivered to zone 3 during seven consecutive days of charging and discharging of DECK_3 ( perforated mortar tiles).

An absolute dynamic heat storage of each type of the deck is calculated as a half of difference of energy integrated over charging cycle and discharging cycle. In a graphical manner, the dynamic heat storage is a sum of the area between the curve and zero axis for the charging and discharging period which is then divided by two, see Figure 48.

In the calculations, the last five days of measurements, when the system reaches periodic steady-state condition, are taken into consideration. Results of absolute dynamic heat storage capacity are gathered and presented in Table 10. Results from the first two days are highlighted in red and taken in brackets.

\begin{tabular}{|c|c|c|c|c|c|}
\hline & $\begin{array}{c}\text { DECK_1 } \\
\text { (Grooved PCM } \\
\text { mortar) }\end{array}$ & $\begin{array}{c}\text { DECK_2 } \\
\text { (Flat PCM } \\
\text { mortar) }\end{array}$ & $\begin{array}{c}\text { DECK_3 } \\
\text { (Grooved mortar) }\end{array}$ & $\begin{array}{c}\text { DECK_4 } \\
\text { (Flat mortar) }\end{array}$ & $\begin{array}{c}\text { DECK_5 } \\
\text { (Reference: } \\
\text { conrete) }\end{array}$ \\
\hline Day & \multicolumn{5}{|c|}{ Average hourly heat capacity } \\
\hline$[-]$ & \multicolumn{5}{|c|}{$\left[\mathrm{Wh} / \mathrm{m}^{2}\right]$} \\
\hline$(1)$ & $(176)$ & $(168)$ & $(166)$ & $(177)$ & $(139)$ \\
\hline$(2)$ & $(176)$ & $(161)$ & $(166)$ & $(173)$ & $(151)$ \\
\hline 3 & 160 & 168 & 174 & 177 & 148 \\
\hline 4 & 170 & 162 & 175 & 171 & 138 \\
\hline 5 & 177 & 172 & 170 & 173 & 143 \\
\hline 6 & 157 & 170 & 171 & 170 & 152 \\
\hline 7 & 168 & 145 & 175 & 173 & 149 \\
\hline $\begin{array}{l}\text { Average } \\
\text { (standard } \\
\text { deviation) }\end{array}$ & $166( \pm 6.5 \%)$ & $163( \pm 6.1 \%)$ & $173( \pm 1.8 \%)$ & $173( \pm 2.9 \%)$ & $145( \pm 6.3 \%)$ \\
\hline
\end{tabular}

Table 10. Calculated average daily dynamic heat storage capacity of investigated concrete decks

Calculated average daily dynamic heat storage capacities of investigated decks presented in Table 10 are also depicted in the chart presented in Figure 49. 


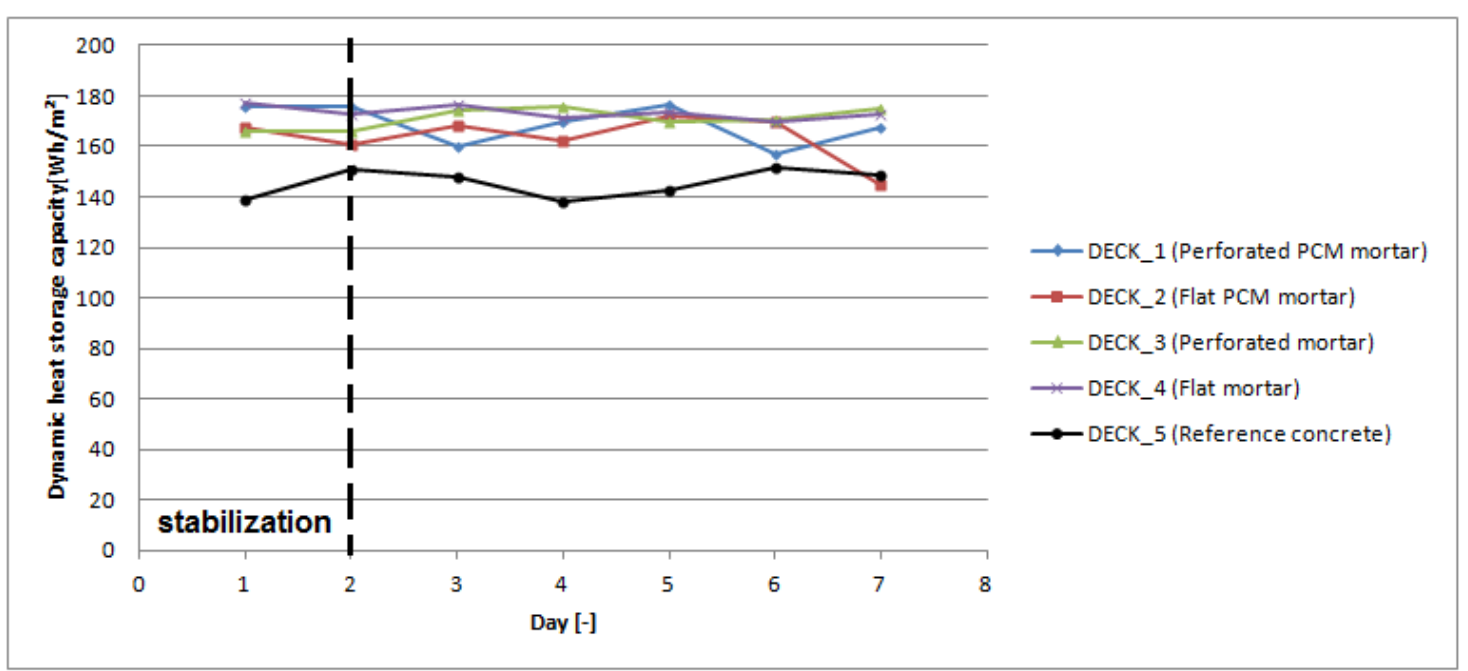

Figure 49.Average daily dynamic heat storage capacity of investigated concrete decks

The estimation of uncertainty of measurements in the hot box apparatus can be studied based on the absolute energy balance calculated for each deck type. The design of the experiment assumes that all thermal mass within zone 2 and 3 reaches quasi steady-state which means that in ideal condition for each charging and discharging period the absolute energy transfer to/from, for example, concrete decks is the same. However, in Figure 48 it can be observed that, for example, DECK_3 does not reach ideal quasi steady-state condition (the areas under the curve for charging periods are not exactly equal to areas under the curve for discharging periods for consecutive days). The discrepancy from quasi steady-state is used to estimate inaccuracy of results obtained from modified hot box apparatus. The reference dynamic heat storage capacity of each type of concrete deck is assumed as average dynamic heat storage capacity from last 5 days of measurements (see Equation (24) and standard deviation for each deck is then calculated with use of Equation (25). Results of measurements uncertainty are presented in Table 10.

$m_{x}=\frac{x_{1}+x_{2}+x_{3}}{n}$

and standard deviation then is calculated from:

$S_{x}=\sqrt{\frac{\left(x_{1}-m_{x}\right)^{2}+\left(x_{2}-m_{\chi}\right)^{2}+\left(x_{3}-m_{\chi}\right)^{2}}{n-1}}$

\subsubsection{Comparison between numerical and experimental results}

Comparison of numerical and experimental results is done for reference concrete deck with flat bottom surface finish: DECK_5. In order to be able to compare the dynamic heat storage from experiments to numerical results it is necessary to calculate radiative and convective heat transfer coefficients during measurements.

The radiative heat transfer coefficient on the bottom of the concrete deck can be calculated because temperature on the inner surfaces in zone 3 was logged during each experiment, see [36]. Knowing temperatures and geometry of zone 3 it is possible to calculate radiative heat transfer coefficient on the bottom of the decks. Radiative heat transfer coefficient was calculated using Equation (26) proposed in [39] to calculate radiative heat transfer between two enclosures and Equation (27) which takes into consideration view factors between enclosures. Simplification of radiative heat transfer to only two enclosures was possible because all constructions in zone 3 except bottom surface of the concrete decks have the same thermal properties and the same finish and their temperatures are almost the same. In that manner heat due to radiation is only transfer between surfaces of zone 3 construction and bottom of the concrete decks. Result of 
calculated heat transfer coefficient on the bottom of the DECK_5 is presented in Figure 50 for last 5 days of measurements.

$$
\begin{aligned}
& q_{\text {rad }}=\frac{\sigma\left(T_{1}^{4}-T_{2}^{4}\right)}{\frac{1-\varepsilon_{1}}{\varepsilon_{1} A_{1}}+\frac{1}{A_{1} F_{12}}+\frac{1-\varepsilon_{2}}{\varepsilon_{2} A_{2}}} \\
& \square_{\text {rad }}=\frac{q_{\text {rad }}}{T_{\text {ceiling }}-A U S T}
\end{aligned}
$$

Where:

$\sigma$ - Stefan-Boltzman constant: $5.67 * 10^{-8},\left[\mathrm{~W} /\left(\mathrm{m}^{2} \mathrm{~K}^{4}\right)\right]$

$T$ - Temperature, $[\mathrm{K}]$

$\varepsilon$ - Emissivity [-]

$A-$ Area, $\left[\mathrm{m}^{2}\right]$

$F$ - view factor, [-]

AUST - average unheated surface temperature, [K]

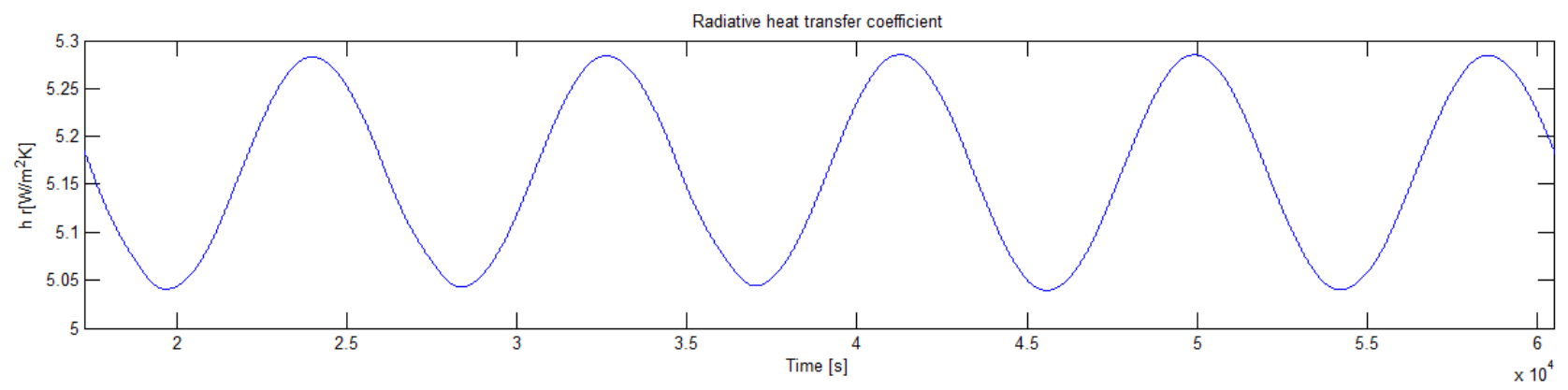

Figure 50. Radiative heat transfer coefficient on the bottom of DECK_5 as a function of time.

Presented in Figure 50 calculated heat transfer fluctuates due to temperature periodic steady-state fluctuations in the hot box. For further analysis an average radiative heat transfer coefficient is used $h_{\text {rad }}=5.16 \mathrm{~W} /\left(\mathrm{m}^{2} \mathrm{~K}\right)$.

Knowing radiative heat transfer coefficient $h_{\text {rad }}=5.16 \mathrm{~W} /\left(\mathrm{m}^{2} \mathrm{~K}\right)$ and measured dynamic heat storage capacity of DECK_5 Q=145 Wh/m $\mathrm{m}^{2}$ it is possible to estimate average convective heat transfer with use of numerical results from COMSOL Multiphysics program. From that approach average convective heat transfer coefficient on the bottom of DECK_5 is approximately $h_{\text {conv }}=3 \mathrm{~W} /\left(\mathrm{m}^{2} \mathrm{~K}\right)$, see Figure 51. 


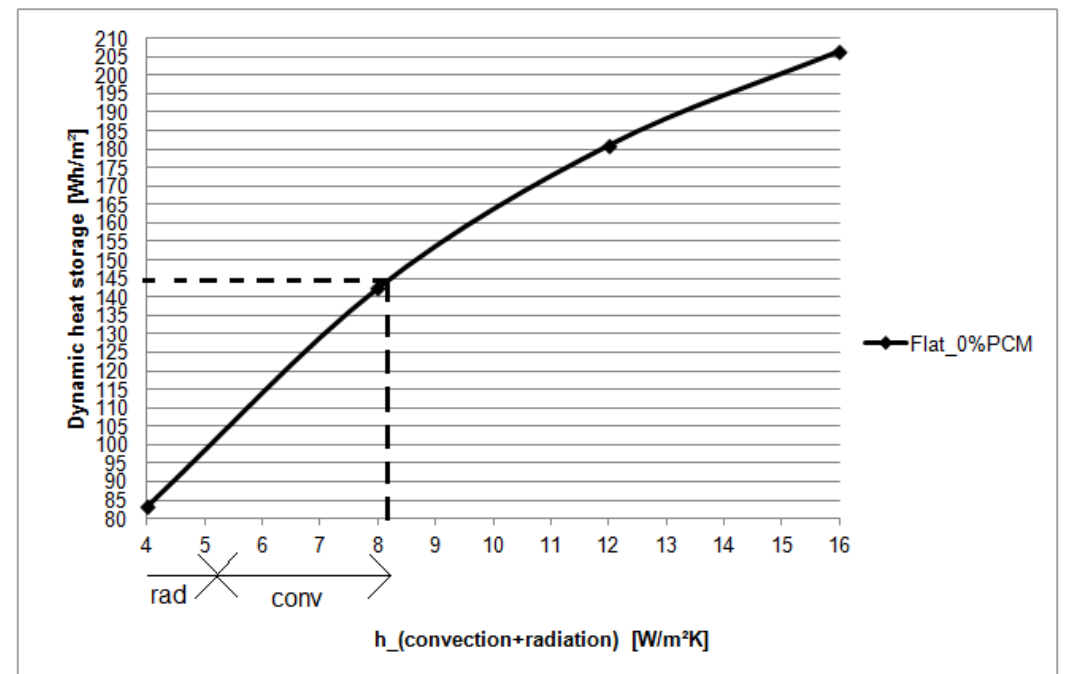

Figure 51. Determination of convective heat transfer coefficient from numerical COMSOL model.

Having measured velocities under the decks it is also possible to estimate average convective heat transfer coefficient on the bottom of the decks by using analytical approach (valid only for flat surfaces).

Calculations are presented only for DECK_5 (reference deck). The analytical approach proposed in [40] is used for laminar flow (because $\operatorname{Re}<10^{5}$ ) and forced convection case on flat surfaces. The convective heat transfer coefficient is calculated using Equation (28).

$\square_{c o n v}=\frac{\lambda * 0.664 * R e^{0.5} * P^{0.33}}{L}$

Where:

$\lambda$ - Thermal conductivity, [W/(mK)]

$R e$ - Reynold's number, [-]

$\mathrm{Pr}$ - Prandtl's number, [-]

$L$ - characteristic length (in this case it is length of decks along air flow), [m]

Based on analytical calculations average heat transfer coefficient on the bottom of DECK_5 is equal $h_{\text {conv }}=2.18 \mathrm{~W} /\left(\mathrm{m}^{2} \mathrm{~K}\right)$ which is very close to estimation based on numerical model from COMSOL.

\subsubsection{Correlation between dynamic heat storage capacity and weight}

During measurements, the weight of concrete decks located in the modified hot box apparatus was also monitored. As stated earlier in the paper, each deck was located on four force transducers. During measurements, it was observed that decks had a tendency to decrease in weight (except DECK_5). The fluctuations of dynamic heat storage capacity could be caused by a moisture release from the concrete decks to the air and then after to outside of the hot box apparatus. This could also explain deck weight decrease. Correlation of measured weight and average daily dynamic heat storage capacity is presented in Figure 52. 

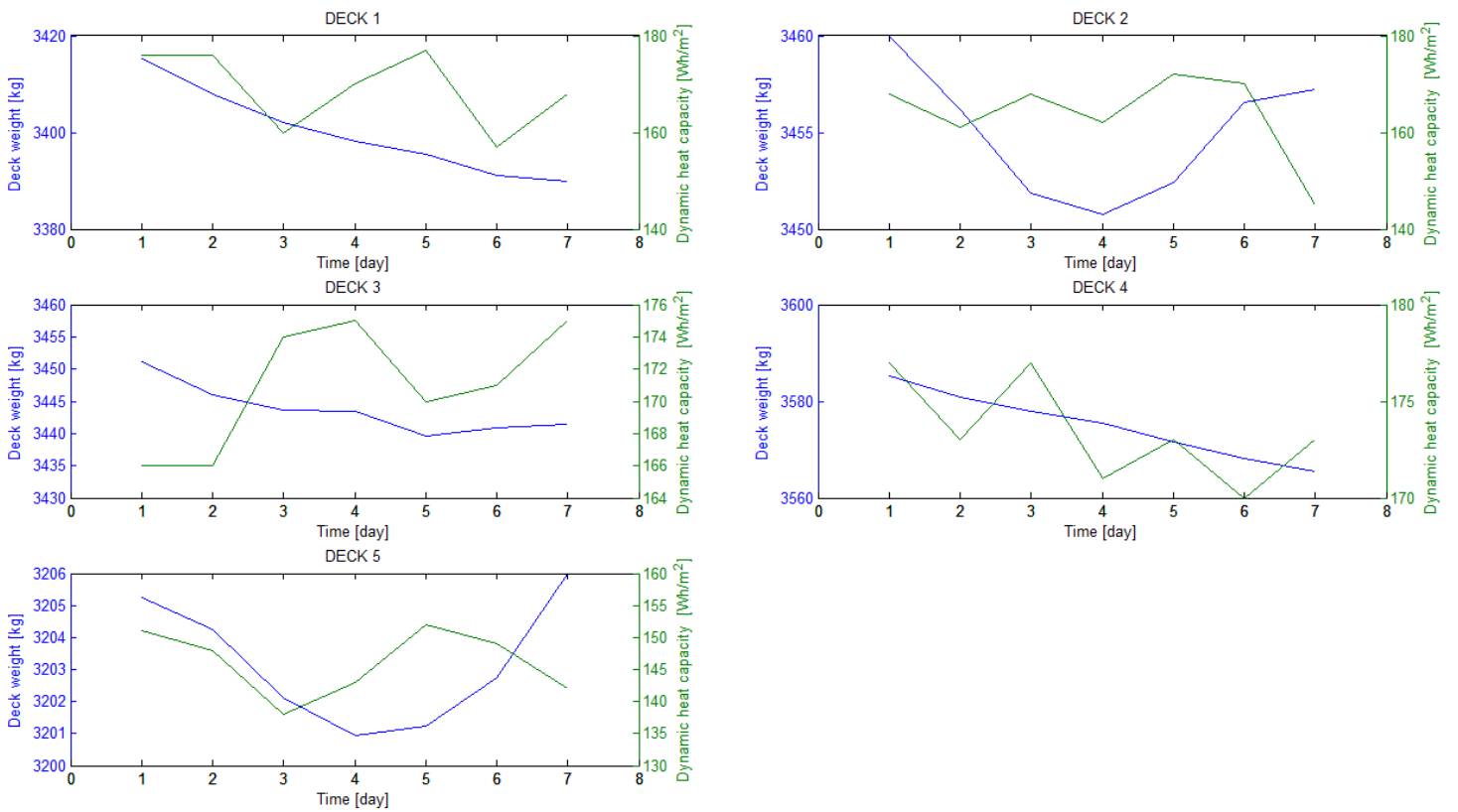

Figure 52. Correlation between deck weight and dynamic heat storage capacity of investigated decks.

\subsection{Conclusion}

Investigation of thermal properties of material used to cast deck elements (concrete, mortar and PCM mortar) indicated that, on one hand, PCM can increase heat storage of the mortar material / concrete within PCM melting solidification temperature range. On the other hand, thermal conductivity of such material drastically drops due to addition of low thermally conductive microencapsulated PCM. These properties were illustrated using VHC and TI in Figure 43. Moreover, it was discovered that the VHC of concrete is comparable to VHC of mortar. However, the TI of concrete was measured to be higher than for mortar, and this is due to the higher thermal conductivity of concrete than of mortar, see Table 9. Results of thermal properties of samples from the full-scale hollow core deck elements presented in section 8 confirm again the observation presented in section 5 .

Regarding periodic steady-state experiments conducted in the specially developed modified hot box apparatus, the repeatability of periodic condition was found to be satisfactory. Designed temperature profiles were found to be repeated with sufficient accuracy. The measured velocity profiles and ranges under the decks resemble each other, and the repeatability can be concluded as satisfactory, see Figure 45 . Finally, measured heating loads for different decks presented in Figure 46 indicate a good repeatability and stability of the system. However, the calculated absolute average daily dynamic heat storage capacity of different decks, presented in Table 10 and depicted in Figure 49, indicate that results vary from day to day. The very small differences in energy delivered to zone 3 for respective hours from day to day, see Figure 46, built up when the total energy is integrated over a 24-hour period. Final discrepancy of results from day to day is observed to be significant, approximately $\pm 10 \mathrm{Wh} / \mathrm{m}^{2}$. The fluctuation of the obtained dynamic heat storage capacity over the days makes it almost impossible to compare results for the different decks. The only heat storage that is observed to be significantly smaller from the rest of the decks is for reference deck, DECK_5, which is made of ordinary concrete. This result, however, is surprising since VHC and TI of concrete material is measured to be higher than e.g. mortar material used to cast DECK_3 and DECK_4. In that sense, it can be concluded that expectation based on measured material properties does not correlate with full-scale experimental results, and these results should be analyzed in further investigations. What is more, due to fluctuation of measured dynamic heat storage capacity, it is also impossible to draw a conclusion if the extended surface area of the bottom of the decks (DECK_1 and DECK_3) has a positive influence on heat transfer enhancement. 
The comparison between numerical modeling and experimental results is presented for DECK_5 (reference) with flat bottom and results are with good agreement. Comparison of grooved decks is not presented due to challenge of calculating radiative heat transfer on the profiled bottom area. What is more, simplified COMSOL modeling do not include view factors and real radiative heat transfer that occurs between profiled surface of concrete decks and surrounding walls in zone 3 of modified hot box in the experimental set-up. Figure 52 presents the correlation between deck weight and dynamic heat storage which indicate that, during the experiments, the challenge to obtain very stable results could be made difficult due to moisture release from the decks. It could be assumed that moisture released from the decks penetrates through the hot box apparatus walls to the surrounding laboratory, in which the air temperature for most of the time is below the temperature maintained in the hot box. What is more, in Figure 52 it can be observed that some of the decks are heavier than others, for example DECK_4. The difference in weight is because, in some of the decks, the concrete used to cast the layer with air voids was too dry and could not carry the load of the layer of concrete located above the air voids during the casting process. It was necessary to fill in air voids with concrete in these places to keep the shape of the decks. However, this additional concrete in some places in the air void layer should not be of significant importance for overall heat storage capacity of the decks, since the inner layer (air void layer) of concrete decks does not participate as significantly in thermal mass activation as external layers.

\section{Conclusions}

- The presented work combines numerical and experimental investigation of the new combined material that consists of standard concrete and microencapsulated-PCM.

- Initial numerical analysis based on the theoretically determined thermal properties of the new mixture of PCM concrete indicated that there is a potential of increasing the heat storage of the deck. At the same time, the cooling performance of the TABS system that could be integrated in the deck will be unchanged. It can be concluded that the most important parameter that influences the heat storage capacity of the construction the most is the surface heat transfer coefficient due to radiation and convection.

- The experimental steady-state measurements of thermal conductivity of PCM concrete have been accomplished with use of guarded hot plate apparatus. The experimentally determined thermal conductivity is much lower than the one theoretically calculated. Moreover, an analytical model to calculate thermal conductivity of PCM concrete up to $6(\mathrm{wt}) \%$ of integrated microencapsulated PCM was developed, see [25].

- A new experimental methodology to measure specific heat capacity of inhomogeneous materials with PCM, such as PCM concrete, was developed. Along with the experimental set-up, four methods to calculate the specific heat capacity, as a function of temperature of inhomogeneous bulk material with PCM, were developed and the obtained results were compared. Due to nonlinearity of the problem, the "inverse method" was discovered to be the most appropriate solution to calculate specific heat capacity as a function of temperature. Experimentally determined results of specific heat capacity are significantly lower than the ones obtained with initially proposed theoretical weight-average calculations.

- The experimental and numerical analysis of heat transfer within the air void of the concrete hollow core deck was performed. It was concluded that radiation and convection within the air void should be included in the dynamic modeling of the concrete decks.

- The updated numerical models of hollow core deck elements with the experimentally determined thermal properties of PCM concrete material indicate that the increase of the heat storage potential due to PCM presence in the concrete is very insignificant. The reason for that is the dramatically decreased thermal conductivity and a not as high as expected specific heat capacity. What is more, by adding PCM to concrete, the density will be decreased as well.

- Moreover, it was discovered that due to the low thermal conductivity of PCM concrete, the cooling effect of TABS integrated in the prefabricated hollow deck would be limited and the efficiency of TABS would be significantly decreased. 
- Experimental results from full-scale investigation indicated that neither presence of latent heat (due to implementation of PCM) nor heat transfer enhancement due to extended heat transfer surface area has a significant positive influence on the increase of dynamic heat storage of concrete elements, such as hollow core concrete deck elements.

- A full-scale modified hot box was developed to perform periodic steady-state and steady-state fullscale experiments in order to determine thermal properties of homogeneous and inhomogeneous construction materials.

\section{Future work}

The results presented in the study are valid for a relatively small number and variety of specimens of PCM concrete. Therefore, one of the future investigations should be focused on experimental study of additional specimens of various PCM and concrete mixes. Moreover, more specimens should be cast with various highly conductive additives, such as copper, steel fiber or graphite, and the thermal properties of these new materials should be defined.

Moreover, it is still undefined what fraction of microcapsules is broken and what fraction stays tight after the mixing process of concrete. Therefore, it is pending to develop a method that could allow this investigation.

The new methodology to measure and calculate specific heat capacity of inhomogeneous materials with PCM developed during this project should allow measurements of other inhomogeneous materials with PCM. An interesting concept could be to measure heat capacity of porous, highly conductive material such as copper foam or graphite foam that is filled with microencapsulated PCM.

As discovered in this project, the parameter that seems to have the largest influence on the diurnal heat storage of the deck is the convective and radiative heat transfer coefficient on the surface of the construction. Therefore, more detailed experimental studies should be accomplished in order to determine this heat transfer coefficient on the ceiling in the room with various ventilation distribution systems, various air change rates and various thermal mass of other construction elements. Also a closer look should be done on local convection on the convective cooled and heated ceilings.

The potential of TABS in the concrete deck with experimentally determined thermal properties of PCM was only numerically investigated with regards to maximum cooling capacity of TABS. This means that TABS in numerical models is always activated, PCM cannot undergo phase change and low thermal conductivity can have predominant effect on TABS performance. Therefore, complete analysis of TABS activation with various activation schedules and water temperatures should be performed to indicate if there is optimal activation time and temperature with regards to specific indoor temperature variations and PCM melting points.

Further research should be focused on investigating the potential of very high conductive construction materials and composites of high conductive materials and PCM. This could entail metal foams with PCM or graphite composites with PCM with an extended surface area since concrete and mortars could not have sufficiently high thermal conductivity to efficiently transfer a significant amount of energy from the air to the deeper layer of construction element available in the buildings diurnal temperature air fluctuations. 


\section{References}

[1] Lund H., Marszal A., Heiselberg P., Zero energy buildings and mismatch compensation factor, Energy and Buildings, 43, 2011, pp. 1646-1656.

[2] Kuznik, F., Virgone, J., Experimental investigation of wallboard containing phase change material: data for validation of numerical modelling, Energy and Buildings, 41 (5), 2009, pp. 561-570.

[3] Mehling H., Cabeza L.F., Mayinger F., Mewes D., Heat and cold storage with PCM: An up to date introduction into basics and applications, 2008, Springer.

[4] Meierhans, R., Olesen, B.W., Art museum in Bregenz - soft HVAC for strong architecture, ASHRAE Transactions 108 PART 2, 2002, pp. 708-713.

[5] Lehmann, B., Dorer, V., Koschenz, M., Application range of thermally activated building systems tabs, Energy and Buildings, 39 (5), 2007, pp. 593-598.

[6] Babiak J., Doctoral Thesis: Low temperature heating and high temperature cooling- Thermally activated building system, 2007, Bratislava.

[7] Kuznik, F., Virgone, J., Experimental assessment of phase change material for wall building use, Applied Energy, 86 (10), 2009, pp. 2038-2046.

[8] Schossig, P., Henning, H.-M., Gschwander, S., Haussmann, T., Micro-encapsulated phase-change materials integrated into construction materials, Solar Energy Materials and Solar Cells, 89 (2-3), 2005, pp. 297-306.

[9] Xiao W., Wang X., Zhang Y., Analytical optimization of interior PCM for energy storage in a lightweight passive solar room, Applied Energy, 86, 2009, pp. 2013 - 2018.

[10] Voelker C., Kornadt O., Ostry M., Temperature reduction due to the application of phase change materials, Energy and Buildings, 40, 2008, pp. 937 - 944.

[11] Khudhair A. M., Farid M. M., 2004, A review on energy conservation in building applications with thermal storage by latent heat using phase change materials, Energy Conservation and Management, 45, pp. $263-275$.

[12] Sharma A. Tyagi V.V., Chen C.R., Buddhi D., Review on thermal energy storage with phase change materials and applications, Renewable and Sustainable Energy Reviews, 13 (2), 2009, pp. 318-345.

[13] Günther E., Hiebler S., Mehling H., Redlich R., Enthalpy of Phase Change Materials as a Function of Temperature: Required Accuracy and Suitable Measurement Method, International Journal of Thermophysics, 30, 2009, pp. 1257- 1269.

[14] Yinping Z., Jiang Y., A simple method, the T-history method, of determining the heat of fusion, specific heat and thermal conductivity of phase change materials, Measurement Science and Technology, 10, 1999, pp. 201-205.

[15] Lázaro A., Günther E., Mehling H., Hiebler S., Martin M. J., Zalba B., Verification of T-history installation to measure enthalpy versus temperature curves of phase change materials, Meas. Sci, Technol., 17, 2006, pp. 2168 - 2174.

[16] Marin J.M., Zalba B., Cabeza L.F., Determination of enthalpy -temperature curves of phase change materials with the temperature-history method: improvement to temperature dependent properties, Measurement Science and Technology, 14, 2002, pp. 184-189.

[17] Castellón C, Günther E., Mehling H., Cabeza L.F., Determination of the enthalpy of PCM as afunction of temperature using a heat -flux DSC-A study of different measurement procedures and their accuracy, International Journal of Energy Research, 32, 2008, pp. 1258-1265. 
[18] Mehling H., Hiebler S., Günther E., New method to evaluate the heat storage density in latent heat storage for arbitrary temnperature ranges, Applied Thermal Engineering, 30, 2010, pp. 2652-2657.

[19] Zhang X., Hendro W., Fujii M., Tomimura T., Imaishi N., Measurements of the Thermal Conductivity and Thermal Diffusivity of Polymer Melts with the Short-Hot-Wire Method, International Journal of Thermopysics, 23, 2002, pp. 1077-1090.

[20]Hunger, M., Entrop, A.G., Mandilaras, I., Brouwers, H.J.H., Founti, M., The behavior of self-compacting concrete containing micro-encapsulated Phase Change Materials, 31, Cement and Concrete Composites,31, 2009, pp. 731-743

[21] Entrop A.G., Brouwers H.J.H, Reinders A.H.M.E., Experimental research on the use of microencapsulated Phase Change Materials to store solar energy in concrete floors and to save energy in Dutch houses, Solar Energy, 85, 2011, pp. 1007-1020.

[22] Cabeza L.F, Castellón C., Nogués M., Medrano M., Leppers R., Zubillaga O., Use of microencapsulated PCM in concrete walls for energy savings, Energy and Buildings, 39, 2007, pp. 113119.

[23] Koschenz M., Lehmann B., Development of a thermally activated ceiling panel with PCM for application in lightweight and retrofitted buildings, Energy and Buildings, 36, 2004, pp. 567-578.

[24] Pomianowski M., Heiselberg P., Lund Jensen R., Initial development of a combined PCM and TABS solution for heat storage and cooling, Proceedings of $9^{\text {th }}$ Nordic Symposium on Buildings Physics, Finland, Tampre, 2011, pp. 483-490

[25] Pomianowski M., Heiselberg P., Lund Jensen R., Experimental investigation of thermal conductivity of concrete containing micro-encapsulated Phase Change Material, Proceedings of $7^{\text {th }}$ International Symposium on Heating, Ventilation and Air-Conditioning, China, Shanghai, 2011, pp. 185-191.

[26] Kook-Han K., Sang-Eun J., Jin-Keun K., Sungchul Y., An experimental study on thermal conductivity of concrete, Cement and Concrete Research, 33, 2002, pp. 363-371.

[27] Pomianowski M., Heiselberg P., Lund Jensen R.,Cheng R., Zhang Y., A new experimental method to determine specific heat capacity of inhomogeneous concrete material with incorporated microencapsulated-PCM, Submitted to Cement and Concrete Research.

[28] E.Lund, T. Condra, Notes and Exercises for Numerical Methods, Aalborg University, Denmark.

[29] Zeng, R. Wang, X. Di, H. Jiang, F. Zhang, Y., New concept and approach for developing energy efficient buildings: ideal specific heat for building internal thermal mass. Energy and Buildings, 43 (5), 2011, pp.1081-1090.

[30] Gill, P.E. Murray, W. Saunders, M.A., Procedures for Optimization Problems with a Mixture of Bounds and General Linear Constraints. ACM Transactions on Mathematical Software, 10, 1984, pp. 282-298.

[31] Gill, P.E., Murray, W., Wright, M.H., 1991, Numerical Linear Algebra and Optimization.

[32] Han, S.P., Globally convergent method for nonlinear-programming. Journal of Optimization Theory and Application, 22 (3), 1977, pp. 297-309.

[33] Pomianowski M., Heiselberg P., Lund Jensen R., Johra H. Numerical analysis of heat storage and heat conductivity in the concrete hollow core deck element, Building Simulation conference, Australia, Sydney, 2011.

[34] Pomianowski M. Heiselberg P., Lund Jensen R., Dynamic heat storage and cooling capacity of a concrete deck with PCM and thermally activated building system, Energy and Buildings, 53, 2012, pp. 96-107.

[35] J. Babiak, Doctoral Thesis: Low temperature heating and high temperature cooling- Thermally activated building system, 2007, Bratislava. 
[36] Pomianowski M. Heiselberg P., Lund Jensen R., Full scale investigation of the dynamic heat storage of concrete decks with phase change material and enhanced heat transfer surface area, Submitted to Energy and Buildings.

[37] M. G. Van Geem, Measuring thermal performance of wall assemblies under dynamic temperature conditions, Journal of Testing and Evaluation, 15 (3), 1987, 178-187.

[38] H. Asan, Y. S. Sancaktar, Effect of wall's thermophysical properties on time lag and decrement factor, Energy and Buildings, 28, 1998, pp. 159-166.

[39] F. P. Incropera, D. P. Dewitt, T. L. Bergman, A. S. Lavine, Fundamentals of heat and mass transfersixth edition, 2007.

[40] ASHRAE fundamental handbook, Part 1, Chapter 4: Heat transfer, 2009.

\section{$\underline{\text { Related codes and standards }}$}

C1. CEN Report CR 1752, 1998: Ventilation for buildings-Design criteria for the Indoor environment. CEN , Brussels, Belgium, 1998.

C2. prEN 1264-2: Water based surface embedded heating and cooling systems- Floor heating - Part 2: Prove methods for the determination of the thermal output of floor heating systems using calculations and test methods, CEN, Brussels, Belgium

C3. EN 15377-1, 2007: Design of embedded water based surface heating and cooling systems:- Part 1: Determination of the design heating and cooling capacity , CEN, Brussels, 2007.

C4. DS 418, 2005: Calculation of heat loss from buildings.

C5. DIN 56212: Thermal insulation- Determination of steady-state thermal resistance and related propertiesGuarded hot plate apparatus

C7. DIN EN 1946-2: Thermal performance of building products and components - Specific criteria for the assessment of laboratories measuring heat transfer properties - Part 2: Measurements by the guarded hot plate method

C8. DIN EN 12667: Thermal performance of building materials and products- Determination of thermal resistance by means of guarded hot plate and heat flow meter method- Products of high and medium thermal resistance

C9. DS EN ISO 10077-2, 2004: Thermal performance of windows, doors and shutters - Calculation of thermal transmittance - Part 2: Numerical method for frames

C10. EN ISO 13786: Thermal performance of building components - Dynamic thermal characteristic Calculation methods

C11. EN ISO 8990, 1994, Thermal insulation - Determination of steady-state thermal transmission properties - Calibrated and guarded hot box 
C12. DS/EN 15251, 2007, Indoor environmental input parameters for design and assessment of energy performance of buildings addressing indoor air quality, thermal environment, lighting and acoustics 


\title{
Initial development of a combined PCM and TABS solution for heat storage and cooling
}

\author{
Michal Pomianowski, M.Sc. \\ Per Heiselberg, Professor \\ Rasmus Lund Jensen, Associate Professor \\ Aalborg University, Denmark
}

KEYWORDS: Phase change material, thermally activated building system, thermal mass, dynamic heat storage capacity, cooling.

\section{SUMMARY:}

This paper investigates heat storage and cooling concept that utilizes both phase change material $(P C M)$ and a thermal active building system (TABS) implemented in a hollow core concrete deck element.

PCMs are promising materials for improving the heat storage capacity of a building due to their significant thermal energy storage capabilities. The TABS has a potential for increasing the exploitation of the thermal mass of the building, which is rarely exposed for heat transfer.The main objective of this study is to optimize the location and amount of PCM in a hollow core deck in order to optimize heat storage capacity. A series of simulations were conducted using the COMSOL program to obtain knowledge regarding the dynamic heat storage capacity of the investigated hollow core deck element as a function of the amount and location of PCM. Furthermore, the dynamic heat storage capacity of a passive deck element and the possible cooling power of the thermally activated deck element were predicted and then compared. Finally, results obtained from precise numerical simulations in COMSOL Multiphysics were compared with results calculated in the whole building simulation software BSim. Initial results indicate that the best location of the PCM in the hollow core concrete deck element is close to the surface that is facing to the room. Moreover, the heat transfer coefficient on the surface of the deck has a very significant impact on the heat storage capacity of the concrete deck element.

\section{Introduction}

The study presented in this paper demonstrates a new technology that can be competitive compared to existing cooling by air-conditioning in buildings. The technology combines phase change material (PCM) and thermal activated building system (TABS) that are integrated in the element of prefabricated concrete hollow core deck. This technology has a potential to decrease energy use for cooling and heating in buildings and thus reduce $\mathrm{CO}_{2}$ emission to the atmosphere. Moreover, the concept presented in this paper considers flattening demand for cooling and shifting peak energy use from day time to night time. Furthermore, measurements conducted in the real buildings with integrated TABS indicated that this technology can provide and sustain acceptable indoor thermal environment (De Carli 2002).

The properties of PCM that allow it to store large amount of heat have been known for many years. However, successful PCM implementation into building constructions did not start until the development of the microencapsulated PCMs. The microencapsulated PCMs have spherical shape of only a few micrometers, and they can be incorporated into various broadly used building materials. The capsule shell prevents direct contact between the incorporated paraffin wax/PCM and matrix material, for example, concrete. When paraffin is bounded by the shell, it can melt and solidify almost 
isothermally and thereby charge and discharge heat without any destructive impact on the material matrix. Isothermal processes occur only in the close range around the specific melting temperature of the PCM. For building purposes melting point temperature is usually chosen within the average thermal comfort temperature range for an occupied space (Kuznik 2009).

On one hand, there is a substantial amount of research which focuses on PCM application in the refurbished light weight buildings and light weight constructions in order to increase thermal mass of the building (Kuznik 2009a) and (Schossig 2005). On the other hand, only a few studies have been made on implementation of PCM into concrete (Hunger 2009).

Parallel to PCM development has been conducted works on TABS technology. The TABS concept started in the 1990s in Switzerland and involved an idea of activation of the thermal mass of concrete slabs that are located between each storey in the building. As a consequence, when circulating hot or cold water in the slabs, building can be respectively heated up or cooled down. TABS were investigated in many theoretical studies and were implemented in a number of full scale projects for example presented in (Meierhans 2005). Additionally, laboratory tests and theoretical studies have indicated that this technology can be energy efficient and has a significant potential to reduce operational costs for the cooling/heating of buildings and provide appreciated indoor thermal comfort (Lehmann 2007).

The purpose of study that is presented in the paper is to investigate the most advantages design of concrete hollow core slab with regards to optimal location and amount of the PCM. The optimal location and amount of PCM should result in increased thermal mass and at the same time optimal utilization of thermal mass capacity. Moreover, focus is also put on, how to establish possible heat storage and cooling power performance of the deck element within realistic dynamic thermal condition in the building. Due to the fact that PCM is expensive and its addition to the concrete element not necessarily has to improve thermal storage capacity of the hollow core deck element, it has to be precisely investigated, how, how much and where it should be integrated in the deck element to achieve feasible and price competitive product.

First, in this paper is presented development of concept for integrated PCM and TABS in the element of prefabricated hollow core slab. Secondly, developed concept is transferred to the COMSOL Multihysics program, where various scenarios for variation of geometrical and thermal properties and boundary condition parameters are calculated. Obtained results reveal which parameters are of most importance to utilize thermal mass of the slab and where PCM shall be located. What is more, diurnal dynamic heat storage capacity for the passive approach of the deck is compared with diurnal cooling effect in case when the deck is activated according to miscellaneous time schedules. Finally, results obtained from the precise finite element simulations in COMSOL Multihysics are used to validate module for calculation of heat storage capacity and module for implementation of PCM in a whole building simulation program (BSim).

\section{Materials and methods}

\subsection{Development of specification of PCM and TABS-deck element}

In this study, the development and design of PCM and TABS concrete deck element was based on existing and already commercially introduced product, which is called ThermoMax, see Fig. 1. Yet ThermoMax is produced as deck made of only concrete, in other words without PCM.

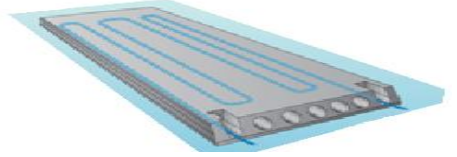

Fig. 1. ThermoMax: Prefabricated concrete ceiling deck element with integrated water pipes. 


\subsection{Thermal properties of combined PCM and concrete material}

In order to be able to calculate dynamic heat storage capacity of any material, three parameters have to be known. These parameters are: density- $\rho$, heat conductivity- $\lambda$ and specific heat capacity-Cp.

Normal concrete has its well known and defined thermal properties. Thermal properties of different PCMs are known or can relatively easily be defined with use of differential scanning calorimetry, see Table 1. However, if concrete and PCM is combined into one material, then physical and thermal properties have to be specially defined for each of combination ratios. In this investigation, density for combined concrete and PCM is calculated according to simple Eq. 1.

$$
\rho=\left(\mathrm{P} \_ \text {PCM }\right) * \rho_{\text {pcm }}+\left(100-P_{-} \text {PCM }\right) * \rho_{\text {concrete }}
$$

Where: $\quad$ P_PCM- is weight percentage of added PCM [\%]

$\rho_{\mathrm{pcm}}$ - is PCM density $\left[\mathrm{kg} / \mathrm{m}^{3}\right]$

$\rho_{\text {concrete }}$ - is concrete density $\left[\mathrm{kg} / \mathrm{m}^{3}\right]$

Heat conductivity of combined concrete and PCM is calculated according to methodology for calculation of heat conductivity for inhomogeneous materials, which is presented in DS 418(Calculation of heat loss from buildings.) After simplification, methodology adapts the same form as Eq. 1, but density is replaced by respectively heat conductivity of PCM and concrete.

TABLE 1. Thermal properties of concrete and PCM.

\begin{tabular}{lccc}
\hline & Density $\left[\mathrm{kg} / \mathrm{m}^{3}\right]$ & Conductivity $[\mathrm{W} / \mathrm{mK}]$ & Specific heat capacity $[\mathrm{J} / \mathrm{kgK}]$ \\
\hline PCM & 98 & 0,14 & - \\
Concrete & 2300 & 1,8 & 1000 \\
\hline
\end{tabular}

Calculation of specific heat capacity for combined concrete and PCM is based on the results obtained from (DSC) for pure PCM. Due to the fact that PCM specific heat capacity varies with its temperature, analogically the same can be assumed for combined concrete and PCM material.

In Fig. 4, are presented calculated heat capacities for different weight percentage ratios with respect to temperature. Curves are valid for melting process and PCM with melting point at $23\left[{ }^{\circ} \mathrm{C}\right]$.

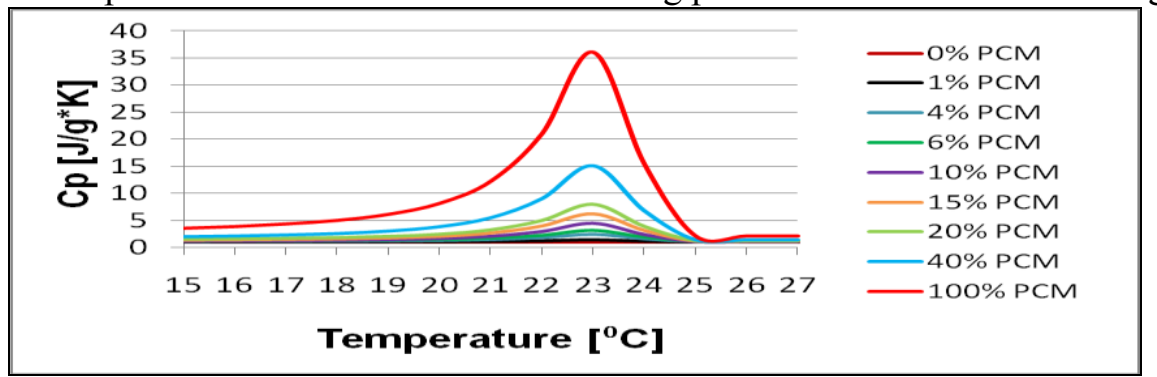

Fig. 4. Calculated specific heat capacities for different ratios of PCM and concrete as a function of temperature

\subsection{Sensitivity analysis of location and percentage of integrated PCM}

The sensitivity analysis of location and amount of integrated PCM was performed based on simulation done in the COMSOL Multiphysics program.
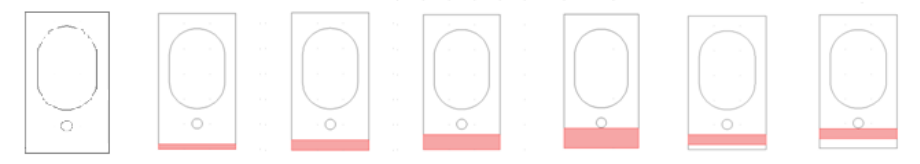

Fig. 5. COMSOL models: Model without PCM and with highlighted various location and thickness of layer with combined concrete and PCM. 
Several models with different percentage of the incorporated PCM and different location of combined PCM and concrete material were simulated in order to find which model has ability to store highest amount of heat. Improvement of ability to store heat was measured in comparative manner with respect to performance of the original deck made without PCM. Due to the symmetry and geometric repeatability of the deck construction COMSOL models could have been simplified to the sections presented in Fig.5.

\subsection{Boundary condition}

For the purposes of this study, the hollow core deck that is simulated in the COMSOL Multiphysics is simplified to 2D model and one section with pipe and air hollow core, see Fig. 5. Due to the fact that in the real model, vertical boundaries are facing almost the same sections, these boundaries are defined as symmetric. Secondly, it is assumed that temperature on the upper and lower surface is fluctuating with diurnal sinusoidal pattern between 20 and 26 degrees in order to imitate indoor temperature condition in the building. Moreover, on the upper and lower surface is applied combined heat transfer coefficient for convection and radiation, which in this study is varying between 2 and 30 $\left[\mathrm{W} / \mathrm{m}^{2} \mathrm{~K}\right]$. Thirdly, when diurnal dynamic heat storage capacity is calculated, which means that deck is passive, water in the pipe is only defined as material and none boundary is applied. However, when deck is simulated as thermally activated, pipe perimeter is defined as boundary condition and heat transfer coefficient on the internal surface of the pipe is defined at $15000\left[\mathrm{~W} / \mathrm{m}^{2} \mathrm{~K}\right]$. In this study temperature of the water is defined for three scenarios: 16,18 and $20^{\circ} \mathrm{C}$. Finally, the air void is simplified to air chamber with standing still air and without radiation. Boundary conditions are conserved for all simulated models. This allows comparison of results between models.

\subsection{Thermal activation of hollow core deck element}

Although TABS concept can be used for both heating and cooling, in this study focus is put only on its cooling performance. Respectively, investigation was carried out for carrier temperature of 16, 18 and $20{ }^{\circ} \mathrm{C}$ which is in all cases either below or equal to lowest assumed indoor temperature. Research on TABS, which were presented in (Babiak 2007), indicated that low cooled ceiling temperatures are not an issue with respect to normative requirements for temperature asymmetry of construction elements. However, in number of publication limit for cooled ceiling temperature is connected with risk of condensation on the construction elements.

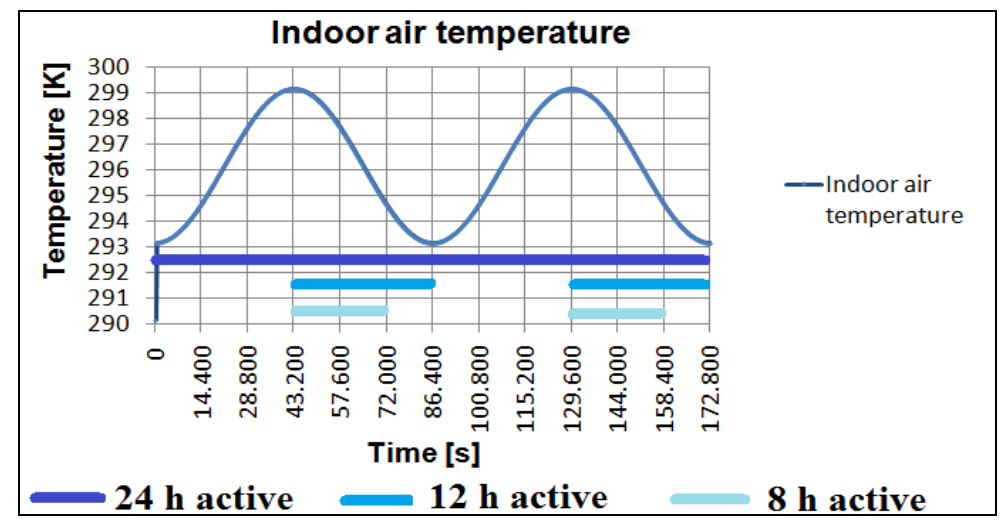

Fig. 7. Thermal activation periods with respect to indoor temperature fluctuation.

Moreover, in this study, are considered two different water pipe locations. First, where centre of the pipe is $50 \mathrm{~mm}$ and second, where centre of the pipe is $20 \mathrm{~mm}$ from the bottom surface of the hollow core slab. In both cases the diameter of water pipe is set to be $20 \mathrm{~mm}$ and spacing between pipes is $150 \mathrm{~mm}$. 
Investigation is carried out for different control mode. Full time mode considers that TABS is in operation 24 hours a day, which means always. Secondly, investigation with shorter time mode is carried out, and respectively 12 and 8 hour mode is considered. For sake of cost efficiency of operated system and with efficient utilization of high heat storage capacity of the PCM, it would be recommended to operate activated system as presented in the Fig. 7.

\section{Results}

Due to the fact that investigation presented in this paper is focused on two possible implementation of the hollow core deck element with PCM and thermally activated system, these results are split into two parts. First one will present results for passive implementation of hollow core deck element with PCM; water flow is deactivated. Respectively, second part will illustrate results for thermally activated hollow core deck element; water flow is activated. Finally, results for validation of BSim calculation with regards to heat storage calculation and PCM implementation are presented.

\subsection{Results from passive implementation}

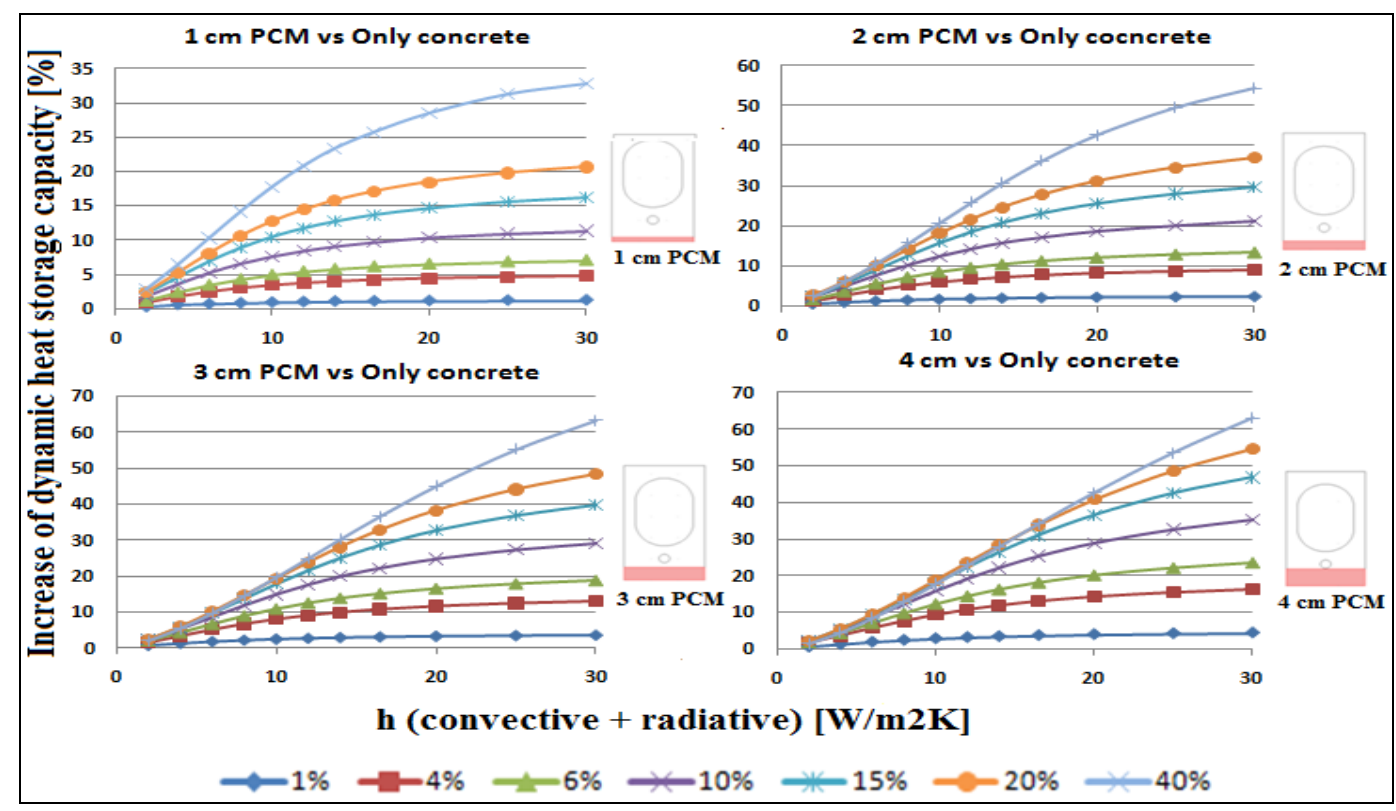

Fig. 8. Increase of dynamic heat storage capacity for slab with PCM layer attached to the bottom of the deck.

In the Fig. 9, are presented results for case where PCM layer of constant thickness is moved towards the centre of the hollow core deck element.

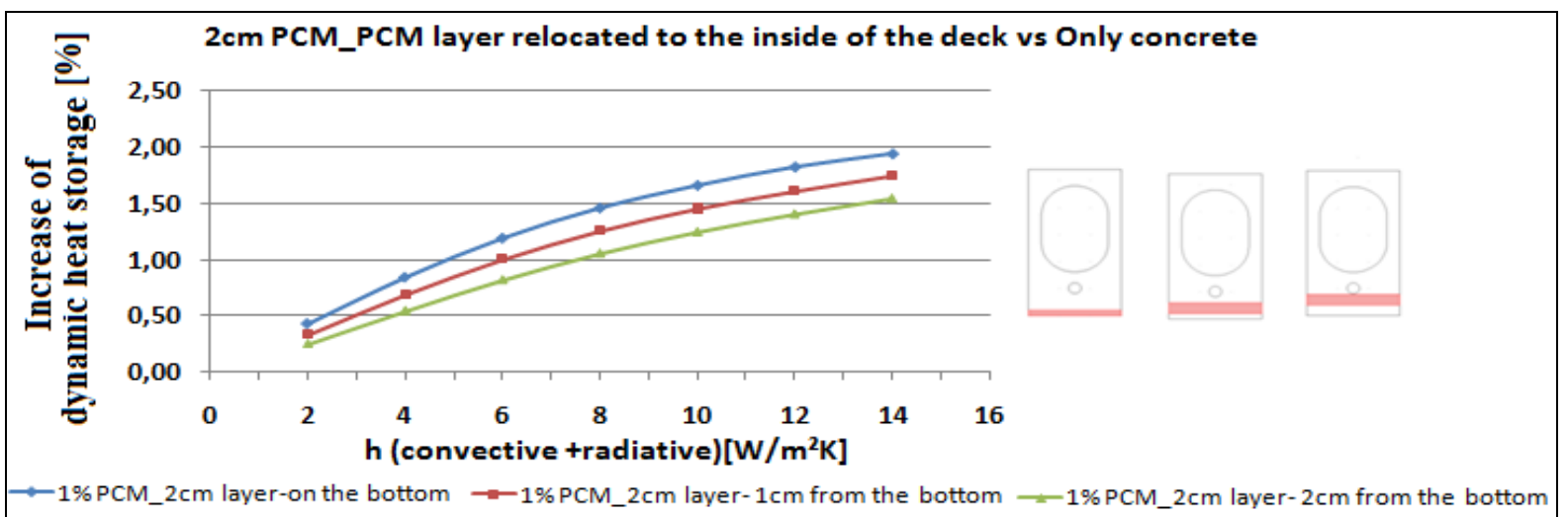


Fig. 9. Increase of dynamic heat storage capacity for slab with PCM layer gradually relocated to the inside of the deck.

\subsection{Results from active implementation}

Results presented in the Fig. 10, for activated deck, are valid for the deck with $1 \mathrm{~cm}$ thick layer with PCM that is attached to the bottom of the deck.

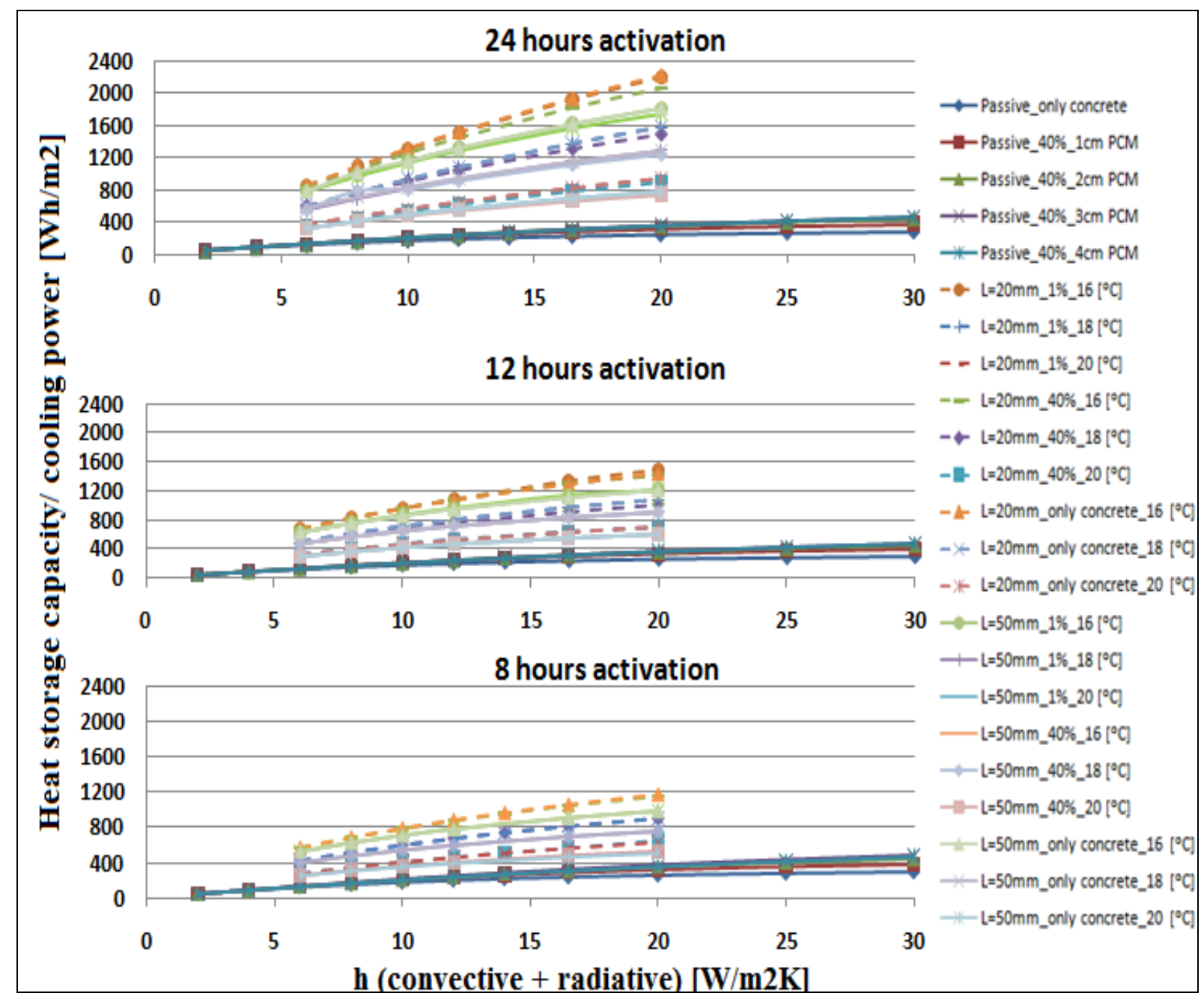

Fig. 10. Calculated daily cooling power of thermally activated deck and heat storage capacity of passive deck for chosen deck configurations.

\subsection{Validation of heat storage calculation in BSim}

BSim is whole building simulation program for calculating and analyzing indoor climate condition, power demand and energy consumption in the building. Calculations are performed based on hourly values of attached weather data. Heat transfer within construction elements is simplified to 1D problem and calculation engine is based on control volume method. Each construction element consists of one or more homogeneous layer. Each zone in BSim is presented as only one nodal point. It is assumed that the air in the zone is fully mixed.Whereas BSim is dedicated for simplified but time efficient whole building energy simulations, COMSOL Multiphysics program is more suitable for solving dynamic problems in smaller domains but with much higher accuracy. In COMSOL it is possible to solve dynamic problems within $1 \mathrm{D}, 2 \mathrm{D}$ or $3 \mathrm{D}$ geometry. This geometry can then be 
divided into very small domains by defining mesh type, accuracy and distribution. For a chosen domain, can be defined boundary conditions that represent miscellaneous physics. For transient simulations, time step for solving the model can be defined individually depending on required accuracy.In this investigation, in BSim was created a simple model that was made of two rooms. Between these two rooms is located internal floor which has the same geometrical and thermal properties as the model created in COMSOL and that is representing homogeneous concrete deck element. Boundary properties on the upper and lower surface of the deck are varied but are always the same as in the COMSOL program. Therefore, comparison of results from both programs is possible and is presented in Fig. 11.

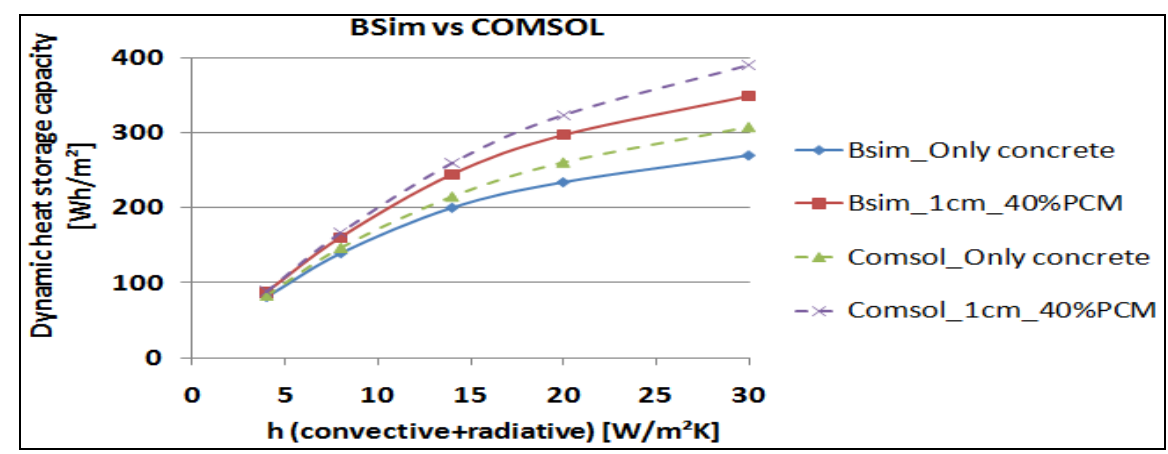

Fig. 11. Calculated in BSim and in COMSOL diurnal dynamic heat storage capacity for both, homogeneous construction deck made of only concrete and for deck with $1 \mathrm{~cm}$ layer with PCM that is located on the bottom of the deck.

\section{Discussion}

In the Fig. 8 is presented calculated improvement of diurnal dynamic heat storage capacity for the hollow core deck element with different thickness of layer with PCM with respect to deck made of only concrete. Results for different ratio of implemented PCM are presented as a function of combined heat transfer coefficient for radiation and convection. Results are valid for the decks with a layer of PCM attached to the bottom of the deck. At some point, it can be observed, that for low percentage of PCM and high heat transfer coefficient there is no improvement. This means, that all thermal mass is utilized. On the other hand, for very high percentage of PCM it can be observed that not all thermal mass is utilized even for very high heat transfer coefficient. Moreover in the Fig. 8, it can be noticed that improvement of the dynamic heat storage capacity between the deck with 1 and 2 $\mathrm{cm}$ is more significant than between the deck with 2 and $3 \mathrm{~cm}$ thick layer of PCM. Finally, improvement between deck with 3 and $4 \mathrm{~cm}$ thick layer of PCM is almost none for full range of PCM ratios. The reason for that kind of results is due to the fact that with increased amount of implemented PCM, decreases heat conductivity of the combined material. Low heat conductivity number decreases heat penetration into the deck, which cause that bigger part of the deck is not activated.

In the Fig. 9, is used the same approach for presenting the results as in Fig. 8. In Fig. 9, results are valid for the deck with layer with PCM of constant thickness of $2 \mathrm{~cm}$. In this investigation layer is relocated with step of $1 \mathrm{~cm}$ to the inside of the deck element. Although results presented in the Fig.9, indicate that there is improvement in dynamic heat storage with respect to the deck made of only concrete, it can also be observed that the further layer is located from the bottom surface of the deck the lower becomes improvement. Based on results presented in Fig. 8 and Fig. 9, it can be concluded that layer with PCM should be always attached to the bottom surface of the hollow core deck element. Moreover, it is not recommended that layer with PCM is thicker than $3 \mathrm{~cm}$. Finally, it can be noticed that heat transfer coefficient on the surface has a dominant role in activating the thermal mass of the construction element. 
In the Fig. 10, are depicted results of daily cooling power of the thermally activated deck element. In the same figure are depicted results of calculated heat storage capacity for chosen simulations with passive deck implementation. With regards to activated system, results are presented for three activation modes: 24 (correspond to 100\% cooling capacity), 12 (50\% cooling capacity), and 8 hour (33\% cooling capacity). Firstly, it can be noticed, that the longer the water flow is activated and the lower is the water temperature, the higher is the cooling performance. Secondly, for the deck with pipes located $20 \mathrm{~mm}$ from the bottom of the deck cooling effect is higher than for the deck with pipes located $50 \mathrm{~mm}$ from the surface. Moreover, it can be observed that layer of PCM can have damping effect on cooling performance of the thermally activated deck. Finally, in all three charts presented in the Fig. 10, it can be noticed, that cooling effect regardless of activation mode, water temperature and pipe location is much higher than the heat capacity that can be stored in the deck. This means that TABS system should be able to discharge even high heat loads from the building of approximately up to $55[\mathrm{~W} / \mathrm{m} 2]$ within realistic heat transfer coefficient range of up to $10[\mathrm{~W} / \mathrm{m} 2 \mathrm{~K}]$.

Fig. 11 shows calculated in BSim and COMSOL results of the heat storage capacity in function of heat transfer coefficient. One comparison is made for the deck element, which is made of only concrete and another is for the same element but with $1 \mathrm{~cm}$ layer of $40 \%$ PCM in the bottom of the deck. The discrepancy in results from these two programs is increasing with rising heat transfer coefficient. Moreover, discrepancies for both types of slabs are almost the same which indicate that error appear not due to calculation module for PCM implemented in BSim program. Results calculated by BSim are underestimated with regards to the one obtained from precise calculation in COMSOL.

\section{Conclusion}

The presented results of simulation study on combined PCM and TABS concept indicate possibly best configuration with regards to heat storage capacity. The results also indicate feasible performance range within investigated factors variation.

It has to be kept in mind that the obtained results are valid for theoretically calculated thermal properties of combined PCM and concrete. In the future scheduled activities, it is foreseen to update existing simulation models with experimentally determined thermal properties for various PCM and concrete ratios.

\section{References}

De Carli, M., Olesen, B.W., 2002, Field measurements of operative temperatures in buildings heated or cooled by embedded water-based radiant systems ,ASHRAE Transactions 108 PART 2, pp. 714-725.

Kuznik, F., Virgone, J., 2009, Experimental investigation of wallboard containing phase change material: data for validation of numerical modeling, 41 (5), Energy and Buildings, pp. 561-570.

Kuznik, F., Virgone, J., 2009a, Experimental assessment of phase change material for wall building use , 86 (10), Applied Energy, pp. 2038-2046.

Hunger, M., Entrop, A.G., Mandilaras, I., Brouwers, H.J.H., Founti, M., 2009, The behaviour of self-compacting concrete containing micro-encapsulated phase change material, 31, Cement and Concrete Composites, , pp. 731-743.

Lehmann, B., Dorer, V., Koschenz, M., 2007, Application range of thermally activated building systems tabs , 39 (5), Energy and Buildings, pp. 593-598.

Meierhans, R., Olesen, B.W., 2002, Art museum in Bregenz - soft HVAC for strong architecture, ASHRAE Transactions 108 PART 2, pp. 708-713.

Schossig, P., Henning, H.-M., Gschwander, S., Haussmann, T., 2005, Micro-encapsulated phase-change materials integrated into construction materials, 89 (2-3), Solar Energy Materials and Solar Cells, pp. 297-306. 


\title{
Experimental investigation of thermal conductivity of concrete containing micro-encapsulated Phase Change Materials
}

\author{
M.Z.Pomianowski ${ }^{1, *}$, P. Heiselberg ${ }^{1}$ and R. L. Jensen ${ }^{1}$ \\ ${ }^{1}$ Department of Civil Engineering, Aalborg University, Aalborg 9000, Denmark
}

\begin{abstract}
The aim of increasing the building internal heat storage capacity is to be able to store excessive heat gains and by that reduce indoor high temperature peaks and at the same time shift high heat loads to the low heat loads hours and to decrease cooling energy need. The concept presented in this article utilizes integration of the concrete and the microencapsulated Phase Change Material (PCM). PCM has ability to absorb and release significant amount of heat at a specific temperature range. As a consequence of admixing PCM to the concrete a new thermal properties like thermal conductivity and specific heat capacity have to be defined. This paper presents results from the measurements of the thermal conductivity of various microencapsulated PCM-concrete and PCM-cement-paste mixes.

It was discovered that increase of the amount of PCM decreases the thermal conductivity of the concrete PCM mixture. Finally, a theoretical calculation methodology of thermal conductivity for PCM-concrete mixes is developed.
\end{abstract}

\section{KEYWORDS}

Phase change material, thermal conductivity measurements, hot plate, concrete.

\section{INTRODUCTION}

The concept of using building materials for heat storage has been known for thousands of years. High thermal mass of internal building construction elements such as masonry walls, floors and ceilings has been exploited through ages. Then, in 1940`s, research in the field of latent heat storage in the buildings has begun with use of materials that change their state within the indoor temperature comfort zone. These materials, when melting or solidifying, respectively, absorb or release heat in the process and are known as phase change materials (PCM) (Hawes et al. 1989).

The properties of PCM that allow it to store large amount of heat have been known for many years. However, successful PCM implementation into the building constructions did not start until the development of the microencapsulated PCMs. The microencapsulated PCMs have spherical shape of only a few micrometers, and they can be incorporated into various broadly used building materials. The capsule shell prevents direct contact between the incorporated paraffin and the matrix material, for example, concrete. When paraffin is bounded by the shell, it can melt and solidify almost isothermally and thereby charge and discharge heat without any destructive impact on the material matrix (Pomianowski et al. 2011). Isothermal processes occur only in the close range around the specific melting temperature of the PCM. For building purposes the melting point temperature is usually chosen within the average thermal comfort temperature range for an occupied space (Kuznik 2009).

Another issue that is critical when introducing PCM in the concrete is the manner the PCM is incorporated to the building element. In the previous investigations it can be found that PCM

\footnotetext{
* Corresponding author email: ishvac2011 map@civil.aau.dk
} 
used to be directly incorporated to the mix or if not encapsulated also immersed Hawes (1989). In the study presented in this paper, PCM used for casting the concrete elements is the microencapsulated PCM type DS 5040X from BASF with melting temperature of $23^{\circ} \mathrm{C}$. This type of PCM is fed into the mix in encapsulated form and blended with the rest of the concrete additives. In that manner there is no risk that wax will leak from the construction after even lot of melting/solidifying cycles and will not interfere with a hydration process.

The purpose of the experimental study presented in this paper is to determine the thermal conductivity of combined PCM and concrete material. Likewise specific heat capacity or enthalpy thermal conductivity of PCM concrete must be known in order to properly simulate the constructions heat storage properties. Consequently, based on the results for the samples of PCM-concrete it was observed that the thermal conductivity decreases significantly with the increased amount of incorporated PCM. This observation triggered new series of measurements however this time with focus on the thermal conductivity of PCM-cementpaste.

\section{RESEARCH METHODS}

Measurements presented in this paper are conducted with use of a hot plate apparatus type EP500 fabricated by Lambda Messtechnik. The apparatus was equipped to an upgrade version which allows measuring concrete samples of thermal conductivity of up to 2 [W/mK].

Samples being measured are inserted between a hot (upper plate) and a cold (lower plate) of dimension of $50 \times 50 \mathrm{~cm}$. Afterwards the upper plate is lowered with the given pressure until the pressure set point is reached. Measuring area is only the most internal square of dimension $15 \times 15 \mathrm{~cm}$ and the rest is a frame which should be of highly insulating material. In the experiments with concrete samples it was discovered that the frame made of elastic foam gives the best repeatability of results. Additionally, the apparatus is equipped with perimeter zones which surround the measured sample and which control the temperature according to an embedded algorithm. Finally, is achieved a 1D heat flow, from the hot to the cold plate, within the measured sample. One set of experiments includes three measurements at three various mean temperatures. In this investigation it was chosen to measure for a mean temperature of 10, 20 and $40^{\circ} \mathrm{C}$. Moreover, the temperature difference between the hot and the cold plate is chosen to be $15^{\circ} \mathrm{C}$ for all the series of measurements. In that manner one measurement $\left(10^{\circ} \mathrm{C}\right)$ is done for the temperatures across the sample that are below PCM melting point, one measurement $\left(20^{\circ} \mathrm{C}\right)$ is done for the temperatures across sample that are within PCM melting point and one measurement $\left(40^{\circ} \mathrm{C}\right)$ is done for the temperatures across sample that are above PCM melting point.

In order to insure good attachment between apparatus plates and measured samples a thin layer of ultrasound gel is used on tops of the samples. The bottoms of the all investigated samples are very flat and smooth thanks to casting mold and therefore application of the gel was not necessary on the bottoms.

Moreover, it has to be stressed that to be able to compare results of measured thermal conductivity of various samples they all need to be dry. It is not presented in this paper but along drying process of samples a number of thermal conductivity measurements were conducted. Based on the obtained results it can be concluded that firstly, the thermal conductivity of concrete containing moisture is higher than for the dry one and secondly it is very long process to completely dry concrete and cement paste samples.

\section{Samples preparation (concrete and cement paste)}

A set of PCM-concrete samples was prepared with $0 \%, 1 \%, 4 \%$ and $6 \%$ by weight of incorporated PCM. Each sample has area of $15 \times 15 \mathrm{~cm}$ and height of approximately $8 \mathrm{~cm}$. 
Specification of the concrete is given in the Table 1 and properties of additives are given in the Table 2. When preparing mixtures the total volume for each of concrete mixtures was $0,025 \mathrm{~m}^{3}$.

Table 1.PCM-concrete specification

\begin{tabular}{ccccccc}
\hline Sample & $P C M$ & Cement & Sand (dry) & Stone (dry) & Water & SP \\
\hline$[-]$ & {$[\mathrm{kg}]$} & {$[\mathrm{kg}]$} & {$[\mathrm{kg}]$} & {$[\mathrm{kg}]$} & {$[\mathrm{kg}]$} & {$[\mathrm{kg}]$} \\
\hline $0 \%$ & 0 & 7,63 & 20,72 & 25,42 & 4,72 & 0 \\
\hline $1 \%$ & 0,58 & 7,64 & 20,10 & 24,54 & 4,73 & 0 \\
\hline $4 \%$ & 2,19 & 7,63 & 18,01 & 22,10 & 4,63 & 0,13 \\
\hline $6 \%$ & 3,18 & 7,63 & 16,78 & 20,58 & 4,41 & 0,58 \\
\hline
\end{tabular}

Table 2.PCM-concrete material properties

\begin{tabular}{lcccc}
\hline \multicolumn{1}{c}{ Material } & Supplier & Brand & Density & Abs. /moist \\
\hline \multicolumn{1}{c}{$[-]$} & {$[-]$} & {$[\mathrm{kg}]$} & {$\left[\mathrm{kg} / \mathrm{m}^{3}\right]$} & {$[\%]$} \\
\hline PCM & BASF & MicronalDS5040X & 970 & \\
\hline Cement & Aap & BASIS & 3100 & \\
\hline Sand $(0 / 4 \mathrm{~mm})$ & NCC & & 2640 & 0,2 \\
\hline Stone $(4 / 8 \mathrm{~mm})$ & NCC & & 2660 & 0,6 \\
\hline SP & BASF & AC410 & 1060 & 77 \\
\hline Water & & & 998,2 & \\
\hline
\end{tabular}

Secondly, a set of four PCM-cement-paste samples was prepared. In these samples no stone aggregate and sand was used. In that manner weight percentage has changed, see Table 3, but with regards to the only cement paste (concrete without stones and sand) in concrete samples was kept unchanged.

It can be observed that in the all PCM-concrete and PCM-cement-paste samples w/c ratio is equal 0,6. This parameter is kept at the same level because as it was indicated in previous reported research (Kook Han Kim et al. 2002) the thermal conductivity depends strongly on the $\mathrm{w} / \mathrm{c}$ ratio.

Before measurements, all the samples were dried at $60^{\circ} \mathrm{C}$ in the oven until they reached constant weight. The constant weight signalized that all the water has evaporated from the sample and that the measured thermal conductivity is independent of moisture content in the samples.

Table 3. Weighted percent of incorporated PCM in concrete / cement paste

\begin{tabular}{cc}
\hline PCM-concrete & $P C M$-cement-paste \\
\hline$[\%] \mathrm{wt}$ & {$[\%] \mathrm{wt}$} \\
\hline 0 & 0 \\
\hline 1 & 5 \\
\hline 4 & 15 \\
\hline 6 & 21 \\
\hline
\end{tabular}

In the Table 4 is given the recipe for PCM-cement-paste samples. Total volume for each of mixtures is $0,002 \mathrm{~m}^{3}$.

Table 4. Weighted percent of incorporated PCM in cement paste

\begin{tabular}{lcccc}
\hline & $0 \% w t$ & $1 \% w t$ & $4 \% w t$ & $6 \% w t$ \\
\hline Material & {$[\mathrm{kg}]$} & {$[\mathrm{kg}]$} & {$[\mathrm{kg}]$} & {$[\mathrm{kg}]$} \\
\hline Cement & 2,288 & 1,986 & 1,679 & 1,373 \\
\hline PCM & $0(0 \%)$ & $0,150(5 \%)$ & $0,481(15 \%)$ & $0,572(21 \%)$ \\
\hline Water & 1373 & 1,191 & 0,995 & 0,772 \\
\hline ACE 410 & 0 & 0 & 0,016 & 0,068 \\
\hline
\end{tabular}




\section{One dimensional heat transfer model for PCM-concrete}

Accurate calculation of the thermal conductivity of PCM-concrete is not simple due to its complexity and randomness. Therefore, an approximation of the heat transfer needs to be done. Heat transfer through an inhomogeneous material can be presented by parallel and series model (Wong et al. 2007).

Average thermal conductivity $\bar{\lambda}$ for series and parallel multiphase material can be given by respectively Equations (1) and (2):

Series: $\bar{\lambda}=\phi_{1} \lambda_{1}+\phi_{2} \lambda_{2}+\cdots \phi_{n} \lambda_{n}$

Parallel: $\bar{\lambda}=\frac{\lambda_{1} \lambda_{2} \cdots \lambda_{n}}{\phi_{1} \lambda_{2} \lambda_{3} \cdots \lambda_{n}+\phi_{2} \lambda_{1} \lambda_{3} \cdots \lambda_{n}+\phi_{n} \lambda_{1} \lambda_{2} \cdots \lambda_{n-1}}$

Where: $\phi_{\mathrm{i}}$ is the volume fraction of a particular component and $\lambda_{\mathrm{i}}$ is the thermal conductivity of a component material.

However, material distribution in a concrete is neither series nor parallel. Approach presented by Wong (2007) which is valid for the air permeable concrete was an inspiration for development of the calculation methodology for thermal conductivity of PCM-concrete.

With help of the methodology presented by Wong (2007) it can be written that the combined thermal conductivity of micro air pockets, aggregate and PCM-cement-paste is as in Eq. 3.

$$
\lambda_{\text {composite }}=\left(\phi_{a}+\phi_{c}-\phi_{\text {air }}\right) *\left\{\frac{\lambda_{a} \lambda_{c p}}{\phi_{c p} \lambda_{a} \lambda_{c p}+\phi_{a} \lambda_{a} \lambda_{c p}}+\left(\phi_{c p} \lambda_{c p}+\phi_{a} \lambda_{a}\right)\right\}
$$

where $\phi_{\mathrm{a}}$ is the volume fraction of aggregate, $\phi_{\mathrm{cp}}$ is the volume fraction of cement paste, $\phi_{\text {air }}$ is the volume fraction of micro air pockets in the concrete sample, $\lambda_{\mathrm{a}}$ is the thermal conductivity of aggregate, $\lambda_{\mathrm{cp}}$ is the thermal conductivity of cement paste, $\lambda_{\text {composite }}$ is the thermal conductivity of PCM-concrete composite.

\section{RESULTS}

The results presented in this section are divided into the three sections. The first group of the results presents measured thermal conductivity of PCM-concrete, the second group of the results includes the outcome of the thermal conductivity for PCM-cement-paste. Finally, the last section is focused on the comparison between the results obtained with use of the developed calculation methodology for thermal conductivity and the measured results of thermal conductivity of PCM-concrete.

\section{PCM-concrete results}

Each of the PCM concrete samples was set for 3 sets of measurements. Results from these experiments are presented in Fig. 1.

Based on the results presented in the Fig 1. a) an arithmetic average thermal conductivity is then calculated for each sample and the mean measurement temperature, see graph Fig. 1 b). 
a)

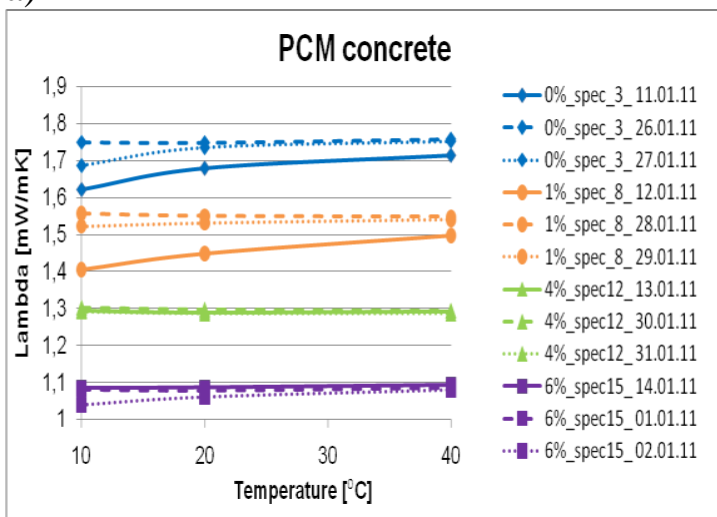

b)

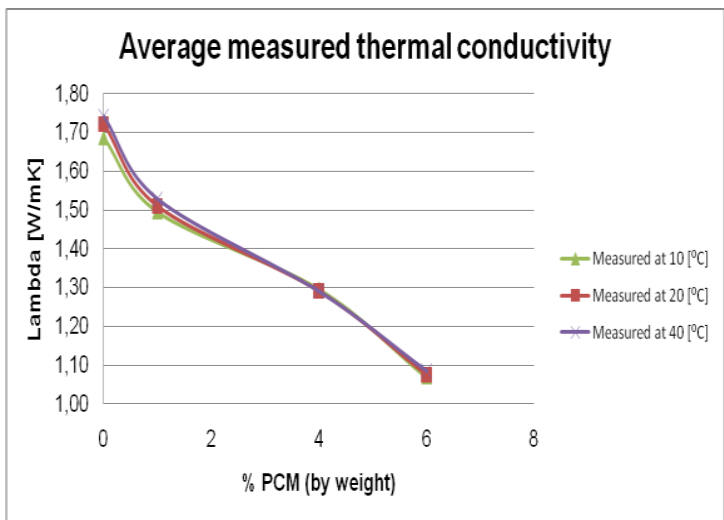

Figure 1. In the a) is presented the measured thermal conductivity of PCM-concrete in function of mean temperature, in the $b$ ) is presented the average thermal conductivity of $P C M$-concrete in function of integrated PCM.

\section{PCM-cement-paste results}

Three sets of measurements were performed for PCM-cement-paste samples and arithmetic average thermal conductivity for the each sample is calculated as in Fig 1. Results of these measurements are presented in the Fig. 2. It was detected that air percentage in the PCMcement-paste is on very high level, where respectively for $0 \mathrm{wt} \%, 1 \mathrm{wt} \%$, $4 \mathrm{wt} \%$ and $6 \mathrm{wt} \%$ of the incorporated PCM air content was calculated of 22,8\%, 27\%, 34,5\%, 23,9\% of the sample volume. Due to that, thermal conductivity of only PCM-cement-paste without air was calculated according to Eq.4. This thermal conductivity is depicted in the Fig. 2 as $\lambda_{\text {corrected }}$ and afterwards $\lambda_{\text {corrected }}$ is used to calculate thermal conductivity of PCM-concrete.

$$
\lambda_{\text {corrected }}=\frac{\lambda_{e}-\phi_{a} * \lambda_{a}}{\phi_{s}}
$$

Where $\lambda_{\text {corrected }}$ is the calculated thermal conductivity of PCM-cement-paste without air, $\lambda_{\mathrm{e}}$ is the measured thermal conductivity of PCM-cement-paste, $\lambda_{\mathrm{a}}$ is the air thermal conductivity of $0,025[\mathrm{~W} / \mathrm{mK}]$ at standard atmosphere, $\phi_{\mathrm{a}}$ is the volume fraction of air in the sample and $\phi_{\mathrm{s}}$ is volume fraction of cement paste.

a)

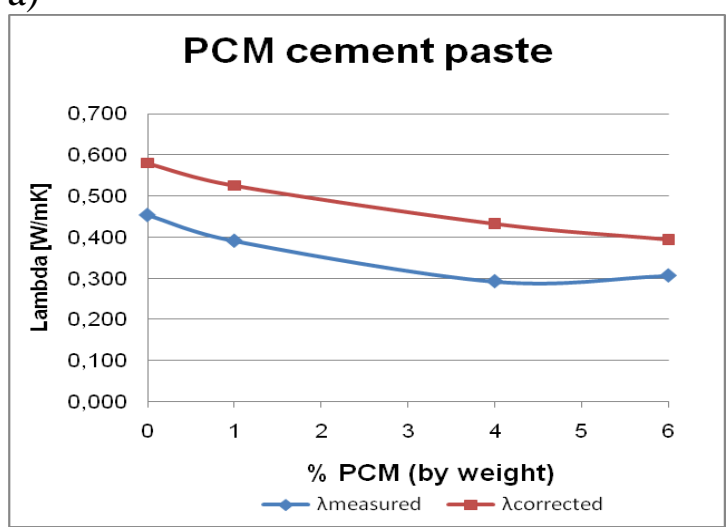

b)

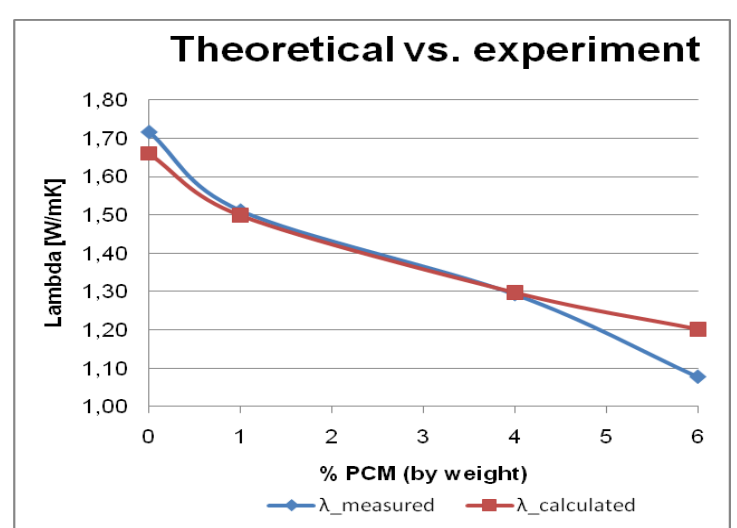

Figure 2. In the a) is presented measured thermal conductivity of PCM-cement paste and corrected thermal conductivity of PCM-cement paste with respect to air content in function of amount of integrated PCM, in the $b$ ) is presented measured and calculated thermal conductivity of PCM-concrete in function of integrated PCM. 


\section{PCM-concrete: new methodology for calculation of thermal conductivity}

The calculated thermal conductivity of PCM-concrete is obtained with use of Eq. 3 and calculated results are depicted together with the measured thermal conductivity in Fig. $2 \mathrm{~b}$.

\section{Conclusion}

The results presented in this paper indicate that integration of PCM, which itself has a low thermal conductivity, significantly influences the thermal conductivity of the entire concrete in which it is integrated. Although, the diameter of microencapsulated PCM is of only $5 \mu \mathrm{m}$, the thermal conductivity of the cement paste in which it is integrated decreases significantly with increased amount of integrated PCM. In that manner heat cannot flow from aggregate to aggregate (stone to stone) for which the thermal properties is kept unchanged.

Furthermore, it can be observed that the lower is the mean temperature of a measurement the lower is the repeatability of the thermal conductivity measurements. This can not entirely be explained but reason for the low repeatability of measurements could be due to condensation problem on the cold plate. For the mean measurement temperature of $10{ }^{\circ} \mathrm{C}$ and temperature difference of $15^{\circ} \mathrm{C}$ the cold plate temperature is only of $2,5^{\circ} \mathrm{C}$. On top of that, the frame made of flexible foam that was used in the experiments can easily infiltrate air from the surroundings. As a result, condensation appears and can influence the measured thermal conductivity of the concrete sample.

It should be stressed that in order to obtain proper results and good repeatability of measurements the bottom and upper surface of the concrete samples have to be as flat as possible and attachment between plates and sample need to be insured.

It is concluded that to increase the repeatability of measurements for the low mean temperatures whole hot plate apparatus should be located in the space where moisture in the air could be controlled.

With regards to the decreasing thermal conductivity with increased amount of PCM it can be concluded that this property will have negative impact on the thermal activation and energy storage within the PCM-concrete building elements. Further study will focus on casting samples below and above melting point and as well casting samples with metal fibers. These activities should highlight if the thermal conductivity of PCM-concrete can be increased.

\section{ACKNOWLEDGEMENTS}

The authors would like to acknowledge the great support and cooperation of Danish Technological Institute, BASF and Spæncom. The financial support from Danish National Advanced Technology Foundation is gratefully acknowledged.

\section{REFERENCES}

Hawes D.W, Banu D and Feldman D. 1989. Latent heat storage in concrete, Solar Energy Materials 19 (335-348).

Kook-Han K. Sang-Eun J, Jin-Keun K, Sungchul Y. 2002. An experimental study on thermal conductivity of concrete, Cement and Concrete Research 33 (363-371).

Kuznik F, Virgone J. 2009. Experimental investigation of wallboard containing phase change material: Data for validation of numerical modeling, Energy and Buildings 41 ( 561-570).

Pomianowski M. Z, Heiselberg P, Jensen L.R, 2011, Initial development of a combined PCM and TABS for heat storage and cooling, 9th Nordic Symposium of Building Physics, Finland. 
$7^{\text {th }}$ International Symposium on Heating, Ventilation and Air Conditioning - Proceedings of ISHVAC 2011

Wong J.M, Glasser F.P, Imbabi M.S. 2007. Evaluation of thermal conductivity in air permeable concrete for dynamic breathing wall construction. Cement and Concrete Composites 29 (647-655). 


\title{
A new experimental method to determine specific heat capacity of inhomogeneous concrete material with incorporated microencapsulated-PCM
}

\author{
Michal Pomianowski ${ }^{\mathrm{a}, *}$, Per Heiselberg ${ }^{\mathrm{a}}$, Rasmus Lund Jensen ${ }^{\mathrm{a}}$, Rui Cheng ${ }^{\mathrm{b}}$, Yinping Zhang ${ }^{\mathrm{b}}$ \\ a Department of Civil Engineering, Aalborg University, Sohngaardsholmsvej 57, 9000 Aalborg, Denmark \\ b Department of Building Science, Tsinghua University, Haidian District, Beijing 100084, China
}

\section{A R T I C L E I N F O}

\section{Article history:}

Received 15 March 2012

Accepted 23 September 2013

Available online $\mathrm{xxxx}$

\section{Keywords:}

Thermal analysis (B)

Concrete (E)

Composite (E)

PCM

$\operatorname{SEM}(B)$

\begin{abstract}
A B S T R A C T
The study presented in this paper focuses on an experimental investigation of the specific heat capacity as a function of the temperature $C p(T)$ of concrete mixed with various amounts of phase change material (PCM). The tested specimens are prepared by directly mixing concrete and microencapsulated PCM. This paper describes the development of the new material and the experimental set-up to determine the specific heat capacity of the PCM concrete material. Moreover, various methods are proposed and compared to calculate the specific heat capacity of the PCM concrete. Finally, it is hoped that this work can be used as an inspiration and guidance to perform measurements on the various composite materials containing PCM.
\end{abstract}

C 2013 Published by Elsevier Ltd.

\section{Introduction}

The thermal properties of a phase change material (PCM) reflect its abilities to absorb and release significant amounts of thermal energy in specific temperature ranges, also called melting/solidification ranges or temperature transition ranges. The middle of this range holds the melting temperature point, which characterizes the temperature for the best utilization of a particular PCM. This melting temperature point may differ from PCM to PCM, but for PCM application in buildings it is most beneficial when it lies in the indoor thermal comfort range [1]. PCMs reflect sensible heat storage capacity and latent heat storage capacity. The sensible heat storage reflects the temperature increase of the heated medium caused by the received heat. The temperature increase can be registered, and so the stored heat in the medium is called sensible heat. If heat is stored as latent heat, a phase change of the storage material occurs, and during the phase transition the temperature of the medium is relatively constant. In PCMs, the sensible heat is stored for temperatures below and above the phase transition range. In this paper, the specific heat capacity refers to both the latent and sensible heat capacity of PCM.

The combination of the high latent heat capacity of PCM and the high density of heavy weight concrete could result in a new technology for storing heat and in energy savings for heating and cooling of buildings,

\footnotetext{
* Corresponding author.

E-mail addresses: map@civil.aau.dk (M. Pomianowski), ph@civil.aau.dk (P. Heiselberg), rlj@civil.aau.dk (R. Jensen), chengrui928@gmail.com (R. Cheng), zhangyp@mail.tsinghua.edu.cn (Y. Zhang).
}

but only on the condition that such a material would be sufficiently exposed to convective and radiative heat transfer [2,3]. Moreover, the high heat storage capacity of a building helps decrease peaks of the indoor temperature and, at the same time, helps move these peaks to the hours when the building is either not in use or when the electricity tariffs are cheaper. As a result, financial benefits and energy saving should be observed both regarding the energy use for cooling and heating.

What is more, if the thermal mass is activated only by the indoor temperature fluctuation and no external driving power is used, then activation of the thermal mass should be treated as a passive technology [4].

The research on the use of PCMs in buildings is rather extensive and has been reviewed and gathered by Zalba and Marin and Zhu et al. [5,6]. However, for building application the majority of studies are focused on integrating PCMs in lightweight materials, such as plasters or porous light weight aggregates [7-9], and little attention is given to heavy materials such as concretes.

On the other hand, extensive research has been done on the thermal properties of various pure PCMs. As stated in Reference [10], the methods available to determine thermal properties, such as heat of fusion, latent heat and melting point of PCM materials can be classified into three groups: conventional calorimetry methods, differential thermal analysis (DTA) and differential scanning calorimetry (DSC) methods. The listed methods are well-developed, but the samples tested have to be homogeneous and of a very small size (1-10 mg). These limitations might lead to differences in thermal properties between the tested samples and the bulk materials used in practice. Another 
method, the T-history method, has been proposed in Reference [10]. This method has been improved later in References [11,12]. The Thistory method proposed in Reference [10] has the following advantages: a large sample size of organic, inorganic, encapsulated or composed PCM which can be measured, ranges of heating and cooling rates and temperatures are sufficiently large for various PCM applications, the instrumentation and finally the experimental set-up is simple and inexpensive. Still, although all the methods are well-developed, they share the same shortcomings: the sample tested has to be homogeneous. Therefore, none of them are applicable for determining the specific heat capacity as a function of temperature $C p(T)$ of such a material as concrete mixed with microencapsulated PCM, due to the inhomogeneity of the material.

The development of the technique for microencapsulation of paraffin, which allows direct integration into building materials such as concrete or plaster, is a relatively new technology that has not received much attention yet. Although investigations on full-scale performance of PCM concrete set-ups are being carried out $[13,14]$, there is almost no research available on determining the thermal and physical properties of concrete and microencapsulated PCM mixtures. The research presented by Hunger and Entrop [15] takes into account the challenge of measuring the specific heat capacity of self-compacting PCM concrete. However, the proposed calculation method simplifies the problem, and the experimental set-up disregards the influence of the surrounding temperature on the heat transfer within the sample. Both problems will be discussed further in Sections 3.2 and 4 of this paper.

The PCM type used in the experiments presented here is the commercially available powder, Micronal type DS5040X with a melting temperature of $23^{\circ} \mathrm{C}$. The paraffin in the microencapsulated PCM is enclosed in droplets measuring approximately $5 \mu \mathrm{m}$ in diameter. The droplet shell is made of a resistant acrylic polymer. This way, the paraffin has no direct contact with the material matrix in which it is incorporated. What is more, as long as the polymer shell remains sealed there is no risk of liquid paraffin leaking into the matrix holder or even out of the material matrix. Moreover, the paraffin enclosed in the polymeric shells can melt and solidify without any destructive influence to the material.

The correct design of a building with integrated PCM concrete materials requires a correct knowledge of the thermal properties of the $\mathrm{PCM}$ concrete material. For example, the single data points, the phase change enthalpy at the melting temperature or the heat of fusion does not describe the PCM properties with sufficient accuracy to perform dynamic simulations of a room or a whole building containing PCM concrete. The phase change occurs at a certain temperature range and not at a constant temperature level. Therefore, the specific heat capacity of this type of material has to be known as a function of temperature.

Since the investigated material matrix is always in the solid state, measurements of the thermal conductivity can be performed according to standardized steady-state procedures, e.g. with a hot plate or a hot box apparatus. However, the challenge is to define the specific heat capacity of the PCM concrete, which as mentioned before has to be known as a function of temperature. The specific heat capacity of the PCM concrete cannot be measured with conventional transient methods listed previously in this section, because the representative samples of concrete materials are too big and inhomogeneous. For example, the sample of a few milligrammes normally tested by the DSC method is not representative for concrete materials. Therefore, a new method for measuring the specific heat capacity of PCM concrete applied in bulk materials is developed and presented in this paper.

Firstly, the paper presents the preparation procedure of the $0,1,4$ and $6 \%$ (by weight) PCM concrete samples. Secondly, the assumptions and methodology of the experimental set-up and its design are described in order to calculate the specific heat capacity of PCM concrete specimens. Afterwards, four various methods to calculate the specific heat capacity as a function of temperature of the PCM concrete are presented. Each method is discussed, and the obtained results are compared. The paper is finalised with a discussion on the obtained results and conclusions regarding the measurements of thermal properties of PCM concretes.

\section{Methodology}

As stated in References [12,15,16], the specimens with PCM have to be of a substantial size in order to represent the bulk material used in practice. The PCM concrete specimens investigated in the research presented in this paper contain aggregate particles of sizes up to $8 \mathrm{~mm}$. This means that in case of concrete materials it is the aggregate size that determines whether or not a sample is representative. Concrete samples of only a few milligrammes have to be considered as inhomogeneous materials firstly and secondly as non-representative samples, and therefore neither the DTA nor DSC method can be used. Even the T-history method that allows measuring bigger cylindrical samples is not applicable. The T-history method was proposed by Zhang [10] to determine the enthalpy and the specific heat of the phase change from the solid to the liquid phase of PCM. In the method, the temperature evolution of the PCM sample and a reference sample when cooled against an ambient temperature is compared. The reference sample should be a material of well-defined thermal properties. It is important that the investigated sample and the reference sample are in the same container (usually of a cylindrical shape) so the heat transfer coefficients in both cases can be considered the same. Firstly, in order to treat a concrete sample as semi-homogeneous, the diameter of this cylindrical sample would have to be at least a couple of centimetres. Secondly, in order to fulfil the criterion of Biot number $(B i)<0.1$, the sample would have to be quite long. This makes the set-up unfeasible. The form for $B i$ is presented in Eq. (1).

$B i(=h R / 2 k)$

where:

$\begin{array}{ll}R & \text { Radius of the cylinder }[\mathrm{m}] \\ k & \text { Thermal conductivity of the PCM }[\mathrm{W} /(\mathrm{mK})] \\ h & \text { Natural convective heat transfer coefficient of air outside the } \\ \text { cylinder }\left[\mathrm{W} /\left(\mathrm{m}^{2} \mathrm{~K}\right)\right] .\end{array}$

If $B i$ is less than 0.1, the temperature distribution can be considered uniform, and a lumped capacitance method can be used. Consequently, if the diameter of the sample was smaller, the measured temperature at the vertical axis of the cylinder would be highly influenced by the distribution of the aggregate. Nevertheless, if a sample is tested by the DSC method or any other method in order to define the specific heat capacity of the material, focus has to be put on the accurate temperature and heat flow measurements. To ensure reliable results, it is also crucial to correctly prepare samples of representative dimensions in order to overcome the challenge of inhomogeneity. Moreover, the measured samples have to be exposed to a dynamic temperature load and the heat flux delivered to the sample and the temperature of the samples have to be registered in due time.

This section will present a new experimental method for determining the specific heat capacity as a function of temperature of inhomogeneous concrete materials with PCM. The experimental set-up consists of a modified hot plate apparatus and specially prepared concrete specimens with PCM. Moreover, this section will elaborate on the preparation of the PCM concrete design mixture and the sample casting procedure. This section also includes the thermal properties of the used microencapsulated PCM and other concrete additives. In addition, a scanning electron microscope (SEM) investigation of the casted PCM concrete samples will be presented in order to ensure that microcapsules with PCM are not destroyed during the mixing process and to see if the capsule distribution in the concrete is uniform. Furthermore, a detailed preparation of the specimens for the dynamic experiment will be described and explained later in this section, including the 
thermocouples insertion methodology, its validation, the heat flux sensor location, and flux sensor dimensioning procedures. Finally, the whole set-up of the specimens in the modified hot plate apparatus and the dynamic experiment mode will be presented and elucidated.

\subsection{Modified hot plate apparatus}

The commercially available hot plate apparatus type EP 500 manufactured by Lambda Messtechnik consists of a lower "cold" plate and an upper "hot" plate. The tested sample is inserted between the lower and upper plates, see schematic drawing in Fig. 1. The dimensions of the plates are $50 \mathrm{~cm} \times 50 \mathrm{~cm}$; however, the measurements of the samples are performed on a core square of $15 \mathrm{~cm} \times 15 \mathrm{~cm}$ only. The difference between the measuring area and the total area of plates is the guarding zone that surrounds the tested specimen and protects it from the influence of the surrounding temperature. The guarding area around the sample must be filled with highly insulating material. The guarding zone contains guarding rings, which can cool and heat and by that reduce the thermal influence of the ambient temperature on the tested sample. The isotherms visible on Fig. (1) which go through the test specimen are parallel to the hot and cold plates of the apparatus, and this indicates that the entire heat flux is transferred from the hot to the cold plates without heat losses.

The hot plate apparatus presented and used in this experiment is different from the standard hot plate apparatus. In the standard apparatus, only the steady-state mode is available, which is used to measure thermal conductivity of various tested materials. More information regarding steady-state thermal conductivity measurements with use of hot plate apparatus can be found in Reference [17] and in the following standards according to which the apparatus is operating: DIN 56212, ISO 8302, DIN EN 1946-2, and DIN EN 12667. The standard hot plate apparatus was modified for the purpose of the presented investigation in order to be able to conduct dynamic thermal experiments. The control system of the hot plate apparatus was upgraded with the new mode that allows definition of a dynamic temperature load. Firstly, a steady temperature at $18{ }^{\circ} \mathrm{C}$ on the upper and lower plates is defined in the dynamic mode. This steady state is maintained for at least $5 \mathrm{~h}$ in order to ensure that the whole sample reaches the same temperature. Afterwards, the sample is heated symmetrically by both the upper and

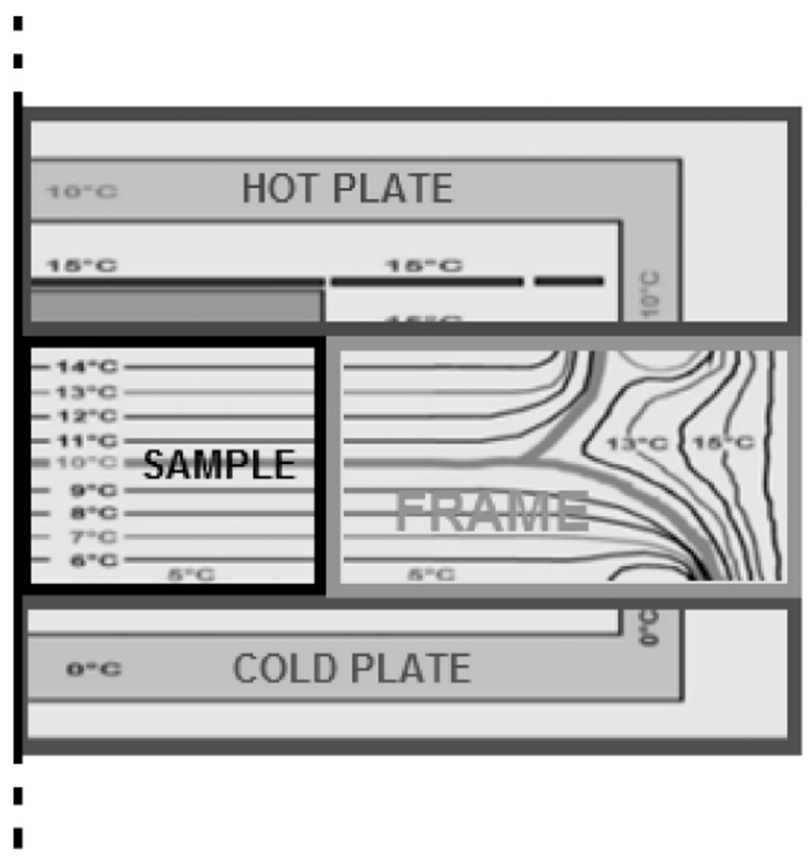

Fig. 1. Schematic section view through the half of the hot plate apparatus with sample and protecting frame. the lower plates from $18{ }^{\circ} \mathrm{C}$ to $32{ }^{\circ} \mathrm{C}$ over a period of $10 \mathrm{~h}$ after which the temperature is stabilised at $32{ }^{\circ} \mathrm{C}$. The temperature change during the heating time for the designed temperature range is only $0.023^{\circ} \mathrm{C} / \mathrm{min}$.

\subsection{PCM concrete mixture design and PCM properties}

The total volume of each mixture was 251 with $0,1,4$ and 6 (wt.\%) of PCM included. The specification of each mixture is given in Table 1. The type of the additives and their properties are presented in Table 2. All concrete mixtures have a water to cement ratio of $\approx 0.6$.

According to the product description, the Micronal type DS5040X used as one of the concrete additives has the following properties:

- $0.6 \mathrm{~kg} / \mathrm{l}-$ density of the powder

- $100 \mathrm{~kJ} / \mathrm{kg}$ - latent heat of fusion

$-23{ }^{\circ} \mathrm{C}-$ melting temperature point.

The $0,1,4$ and 6\% PCM concrete specimens of dimensions $15 \mathrm{~cm} \times 15 \mathrm{~cm} \times 15 \mathrm{~cm}$ were cast in moulds and left to harden at room temperature. Afterwards, the specimens were taken out of the moulds and cut to the desired dimensions of $15 \mathrm{~cm} \times 15 \mathrm{~cm} \times 8 \mathrm{~cm}$ (Table 3).

\subsection{CRYO-SEM analysis}

A concrete sample with PCM capsules was analysed using the CRYOSEM technique. The sample was taken from a concrete core cast at $5{ }^{\circ} \mathrm{C}$ in the following way: the core was cooled to about $-5{ }^{\circ} \mathrm{C}$, and a small piece was broken off. The piece was mounted in the SEM Zeiss 1540 CrossBeam (Zeiss XB-1540) equipped with the CRYO device Gatan ALTO 2500 and cooled to approximately $-200{ }^{\circ} \mathrm{C}$. The temperature of the sample did not at any point exceed $0{ }^{\circ} \mathrm{C}$. The sample was coated with platinum and then analysed in a high vacuum.

The fracture surface on the concrete sample was investigated in the CRYO SEM.

For PCM capsules in the fracture, the observation was that they were all broken, see Fig. 2 . This is not because the capsules were defective, but merely a consequence of the fracture cutting its way through the capsules because of their weaker strength when compared to the surrounding concrete. It is, however, noteworthy that the crack did not run in the attachment zone between the capsules and the surrounding cement paste. In fact, the connection between the capsules and the cement paste appeared to be quite good, and only very few interstices around the capsules were observed. Moreover, the distribution of the capsules was rather uniform, and no bigger packs or layers of grouped capsules could be found.

Moreover, the CRYO SEM analysis indicated that the solid paraffin inside the shell was influenced by the fact that capsules were enclosed in concrete. There were large interstices between the shell and the paraffin inside the shell. The paraffin was often layered, and porosities could have been identified in the paraffin core, see Fig. 3. However, the CRYO SEM analysis cannot be used to investigate whether the capsules were damaged during the process of mixing the concrete and the microencapsulated PCM. The capsules are easily damaged when taking smaller samples from the bulk material, and so it cannot be concluded if some of them were damaged during the mixing process.

Table 1

PCM concrete design mix specification.

\begin{tabular}{lllllll}
\hline Sample & PCM & Cement & Sand (dry) & Stone (dry) & Water & Super plasticizer \\
\hline$[$ wt.\%] & {$[\mathrm{kg}]$} & {$[\mathrm{kg}]$} & {$[\mathrm{kg}]$} & {$[\mathrm{kg}]$} & {$[\mathrm{kg}]$} & {$[\mathrm{kg}]$} \\
0 & 0 & 7.63 & 20.72 & 25.42 & 4.72 & 0 \\
1 & 0.58 & 7.64 & 20.10 & 24.54 & 4.73 & 0 \\
4 & 2.19 & 7.63 & 18.01 & 22.10 & 4.63 & 0.13 \\
6 & 3.18 & 7.63 & 16.78 & 20.58 & 4.41 & 0.58 \\
\hline
\end{tabular}


Table 2

PCM concrete material properties.

\begin{tabular}{lllcl}
\hline Material & Supplier & Brand & Density & Abs./moist \\
\hline$[-]$ & {$[-]$} & {$[\mathrm{kg}]$} & {$\left[\mathrm{kg} / \mathrm{m}^{3}\right]$} & {$[\%]$} \\
PCM & BASF & Micronal DS5040X & 970 & $/$ \\
Cement & Aalborg Portland & BASIS & 3100 & $/$ \\
Sand $(0 / 4 \mathrm{~mm})$ & NCC & $/$ & 2640 & 0.2 \\
Stone $(4 / 8 \mathrm{~mm})$ & NCC & $/$ & 2660 & 0.6 \\
Super plasticizer & BASF & AC410 & 1060 & 77 \\
Water & $/$ & $/$ & 998.2 & $/$ \\
\hline
\end{tabular}

\subsection{Steady state experiment: thermal conductivity measurements}

The $0,1,4$ and 6 (wt.\%) PCM concrete specimens measuring $15 \mathrm{~cm} \times 15 \mathrm{~cm} \times 8 \mathrm{~cm}$ were dried in an oven at $65{ }^{\circ} \mathrm{C}-70{ }^{\circ} \mathrm{C}$ until all moisture evaporated and they ceased changing weight. Drying the specimens was necessary in order to obtain repeatability of the thermal conductivity measurements. Afterwards, each sample was tested in the hot plate apparatus with regard to its thermal conductivity. The complete description of the methodology and results can be found in Reference [17]. Consequently, the obtained results of thermal conductivity were used to calculate the specific heat capacity of the specimens.

The specimens were tested for thermal conductivity approximately 5 months after they had been cast.

\subsection{Dynamic experiment: samples preparation}

The $0,1,4$ and 6 (wt.\%) PCM concrete specimens measuring $15 \mathrm{~cm} \times 15 \mathrm{~cm} \times 8 \mathrm{~cm}$ are big enough to be treated as homogeneous or semi-homogeneous materials. In other words, this means that they can be considered as representative samples of a bigger bulk concrete material. This subsection presents the method for measuring the temperature profile in the sample and the heat flux supplied to the samples during the heating process.

The samples are tested for heat storage capacity approximately 10 months after they have been cast.

\subsubsection{Methodology of temperature profile measurements}

The presented experiment is designed to measure vertical temperature profiles of specimens with thin K-type thermocouples. Due to the fact that the concrete material is not homogeneous and has various aggregate sizes, direct casting of thin and weak thermocouples in the specimens would be very difficult, and the final location of the thermocouples in the specimens might be different from the designed one. As a result, an incorrect temperature profile of the specimens would be obtained. Therefore, after the thermal conductivity measurements of specimens measuring $15 \mathrm{~cm} \times 15 \mathrm{~cm} \times 8 \mathrm{~cm}$ are completed (see Section 2.4), the specimens are cut into two equal pieces of $15 \mathrm{~cm} \times 7.5 \mathrm{~cm} \times 8 \mathrm{~cm}$, and the surface along the cut is carefully polished. Afterwards, nine parallel grooves $0.3 \mathrm{~mm}$ deep and wide spaced $8 \mathrm{~mm}$ apart are cut into the concrete as presented in Fig. 4 . Calibrated thin thermocouples, type $\mathrm{K}$, are inserted in the specially grooved PCM concrete specimens, see Fig. 4 . Then, the two parts of a previously cut specimen are assembled with inserted thermocouples inbetween. Finally, visual check is performed to ensure that there are no air gaps along the joining line where the thermocouples are inserted and that the specimens fit well to each other. The procedure is repeated

Table 3

PCM concrete properties.

\begin{tabular}{llll}
\hline PCM [wt.\%] & Slump [mm] & Air [\%] & Density $\left[\mathrm{kg} / \mathrm{m}^{3}\right]$ \\
\hline 0 & 140 & 1.4 & 2363 \\
1 & 140 & 4.9 & 2229 \\
4 & $480(\mathrm{SF})$ & 4.6 & 2140 \\
6 & 230 & 3.8 & 2073 \\
\hline
\end{tabular}

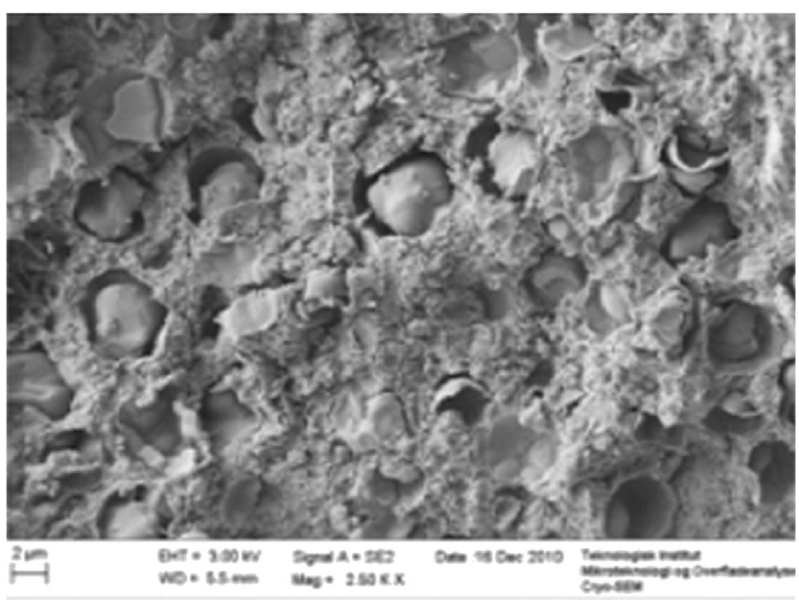

Fig. 2. Broken capsules lying in the fracture surface of the concrete sample.

for all investigated samples. Furthermore, the method of inserting thermocouples in the concrete specimen used in the presented experiment is validated by the use of a plaster specimen.

Contrary to concrete materials, the plaster material is easy to form and cast, and thus thermocouples can easily be casted in the sample unlike in the case of the concrete specimen. Consequently, it is possible to cast thermocouples and insert them in one specimen in predefined locations. The thermocouples are placed with $10 \mathrm{~mm}$ apart. Each cast thermocouple is paired up with inserted thermocouple, and all thermocouple locations in the specimen are known. The specimen with the thermocouples is inserted in the hot plate apparatus, and a predefined, symmetric, dynamic and steady-state temperature load is applied on the top and the bottom of the sample from the plates of the apparatus. The calculated relative error resulting from various logged voltage of the two thermocouples is almost always lower than $0.5 \%$. The highest calculated error observed for thermocouples is approximately of $1 \%$. This means that the method for inserting the thermocouples into the concrete specimens instead of casting them directly should be sufficiently accurate to measure the temperature profile in the concrete specimens.

\subsubsection{Method of heat flux measurement}

In the presented experimental investigation, it is necessary to measure the heat flux supplied from the plates of the apparatus to the PCM concrete specimen. Since the heating load from the hot plate apparatus is symmetric, the temperature of the bottom and top plates changes over time in the same manner. Thus it is sufficient to measure the heat flux only on one surface of the specimen which is attached to

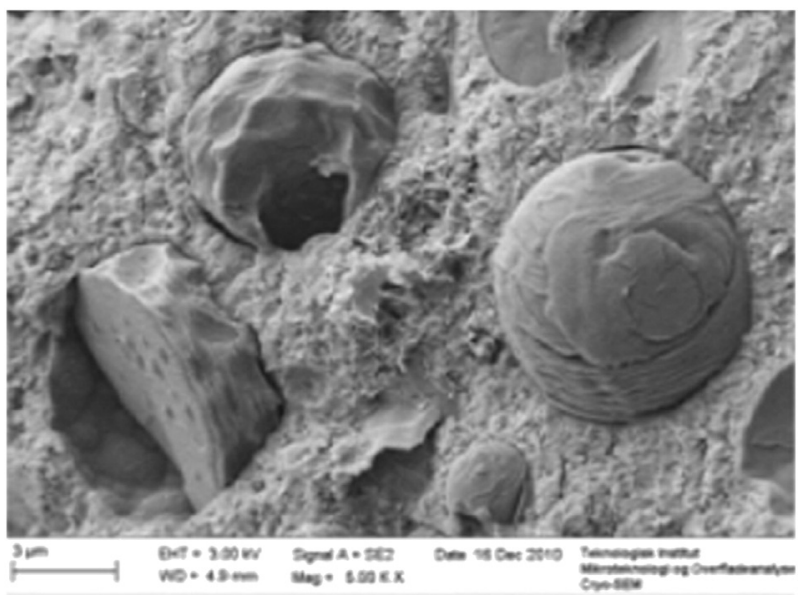

Fig. 3. Broken capsules where layered porosities are visible in the paraffin bodies. 

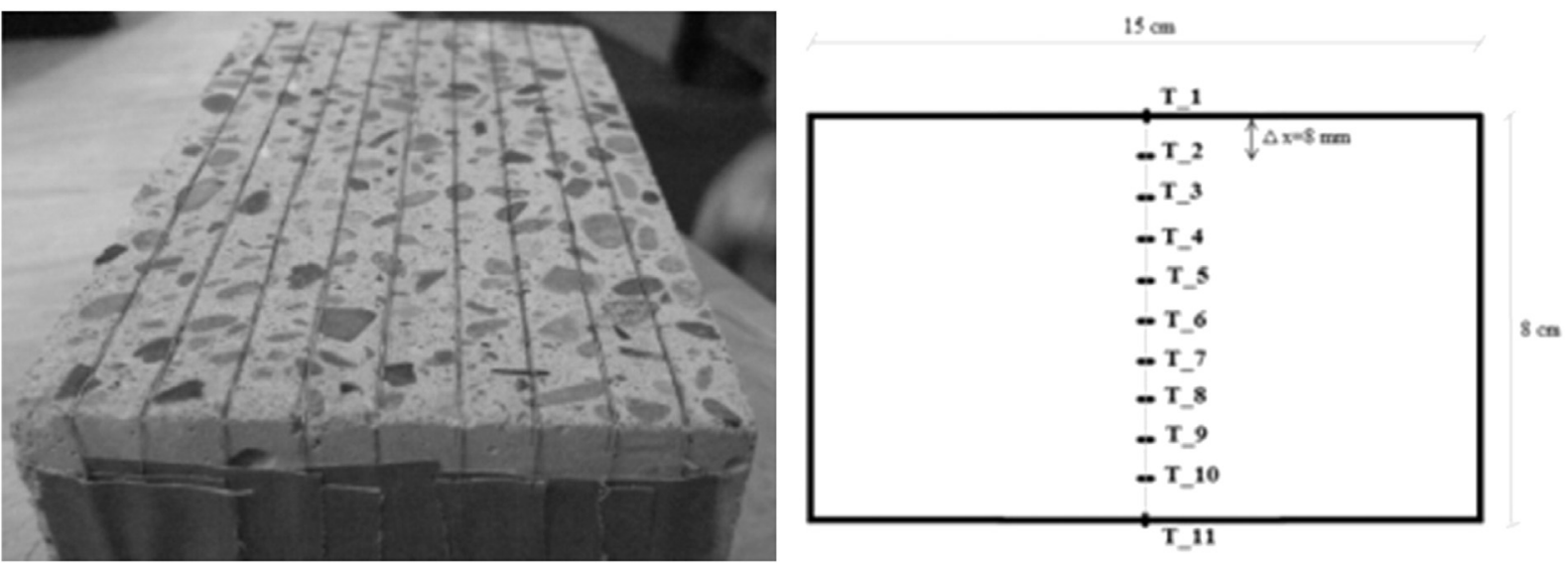

Fig. 4. (left) Specimen with special grooves for thermocouples, (right) location and number of the thermocouples in the specimen.

one of the plates of the apparatus. The heat flux is then measured either on the top or the bottom surface of the specimen. In this experiment, it is chosen to locate a heat flux film on the upper surface of the PCM concrete specimen.

The dimension of the heat flux film located on the top surface of the PCM concrete specimen is specifically chosen for the purposes of the dynamic experiment presented in this paper. Due to the dynamic nature of the experiment, the PCM concrete and the insulating frame are heated up at different rates. The difference of the temperature profile as a function of time in the concrete sample and in the surrounding insulating frame is due to the various thermal diffusivities of the two materials. As a result of temperature differences in the sample and the surrounding frame, the heat flux close to the edge of the concrete specimen is not one-dimensional (1D) but is influenced by the frame temperature. In order to perform measurements of only 1D heat flux provided from the apparatus plates and free of side heat flux from the frame, the heat flux sensor has to have a smaller area than the total area of the specimen measuring $15 \mathrm{~cm} \times 15 \mathrm{~cm}$ and has to be located at the centre of the specimens. In order to calculate the ratio between the side heat flux to the sample the heat flux applied from the hot plate apparatus, the numerical investigation is performed in the COMSOL Multiphysics program. The result from that investigation indicated that if the heat flux film has a square size of $8 \mathrm{~cm} \times 8 \mathrm{~cm}$, then the side heat flux is at its maximum but only constitutes $0.6 \%$ of the total heat flux supplied from the bottom and top plates of the apparatus. It was assumed that the error at this level is within the acceptable range.

The heat flux film used in the experiment is a square heat flux sensor produced by Captec and has the sensitivity of $23.4 \mu \mathrm{V} /\left(\mathrm{W} / \mathrm{m}^{2}\right)$. The sensor is made of highly conductive copper and is only $0.3 \mathrm{~mm}$ thick.

\subsubsection{Sample set-up in the hot plate apparatus}

The specimen with the inserted thermocouples as described in Section 2.5.1 is positioned in the hot plate apparatus in the centre of the lower plate. Afterwards, the attachment of the bottom of the specimen is checked for any irregularities. Then the top of the specimen is wrapped in a thin packing foil, and a thin layer of ultrasound gel is applied on the entire foil surface. The gel layer is covered with one more layer of thin foil. A thin square shaped heat flux film measuring $8 \mathrm{~cm} \times 8 \mathrm{~cm}$ manufactured by Captec is positioned in the middle of the top surface of the specimen and pressed into the gel layer. The prepared specimen is surrounded with an elastic insulating frame, and an upper "hot" plate is lowered until it reaches the top of the concrete specimen. The dynamic test is triggered after the last visual inspection is performed to verify if the specimen is attached well to both the lower and upper plates of the apparatus. At the same time, the logging process of signals from the thermocouples and the heat flux sensor film is started using the Helios Data logger type 2287A.

\section{Results}

This section aims to present the outcome, temperature and heat flux results, obtained during the experimental investigation presented in this paper. The outcome of the experimental investigation is used to calculate the specific heat capacity as a function of the temperature of the investigated PCM concrete specimens. Subsequently, four various methods for calculating specific heat capacity as a function of the temperature of the PCM concrete composite are presented.

Each method and its assumptions are described and representative results are illustrated. Finally, results obtained from the four methods are compared with each other and conclusions are drawn.

\subsection{Control of the repeatability of the measurements}

The addition of the microencapsulated PCM in the concrete results in a development of a new material. The newly developed composite should be characterized by new thermal properties that combine the properties of ordinary concrete and those of PCM.

In order to check if the experimental results are repeatable, each of the investigated specimens is measured three times. During each of the experiments, the temperature measurements from all nine thermocouples and the heat flux to the specimen are logged. The chosen results are presented for PCM concrete specimens with 4 (wt.\%) and 6 (wt.\%) of PCM.

As seen in Fig. 5, the calculated average temperatures of the 4 (wt.\%) and 6 (wt.\%) PCM concrete specimens for three various series of measurements are very close to each other as a function of time. They even overlap each other and, therefore, it is difficult to see three separate data series in Fig. (5). The maximum relative error of the temperature average for a fully developed dynamic temperature ranges from $19{ }^{\circ} \mathrm{C}$ to $31{ }^{\circ} \mathrm{C}$ for the 4 (wt.\%) and 6 (wt.\%) PCM concrete is approximately $1.5 \%$ and $0.5 \%$ respectively. With regard to the heat flux measurements, some discrepancy between the three series can be seen, but the measurements are still reliable. The maximum average relative error for the calculated heat flux for a fully developed dynamic temperature ranges from $19{ }^{\circ} \mathrm{C}$ to $31{ }^{\circ} \mathrm{C}$ for 4 (wt.\%) and 6 (wt.\%) PCM concrete is approximately $6.5 \%$ and $9.5 \%$ respectively.

\subsection{Output from the dynamic experiment: temperature and heat flux}

This section presents the measured average heat flux and average temperature of the investigated specimens. Presented results are the average of three series of measurements performed on each of the investigated samples. The average temperature presented in Fig. 6 is calculated as the average temperature reading from all thermocouples inserted in the specimen and from all three series of measurements for each investigated specimen. 


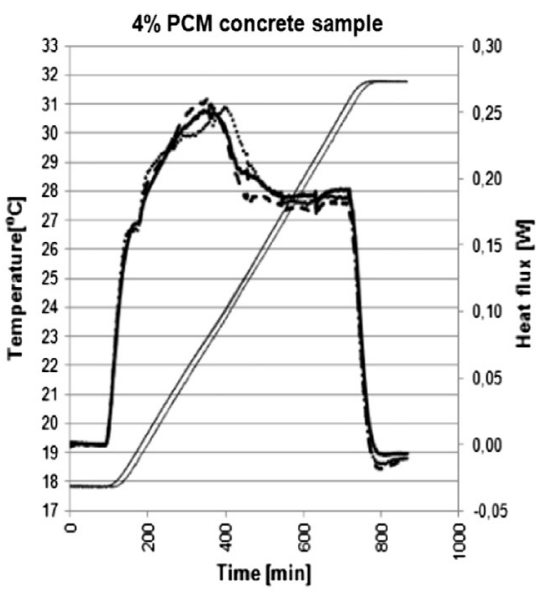

$\begin{array}{cc}\text { - Average temperature_1st series } & \text {...... Heat flux_1st series } \\ \text { - Average temperature_2nd series } & -- \text { Heat flux_2nd series } \\ \text { Average temperature_3rd series } & - \text { Heat flux_3rd series }\end{array}$

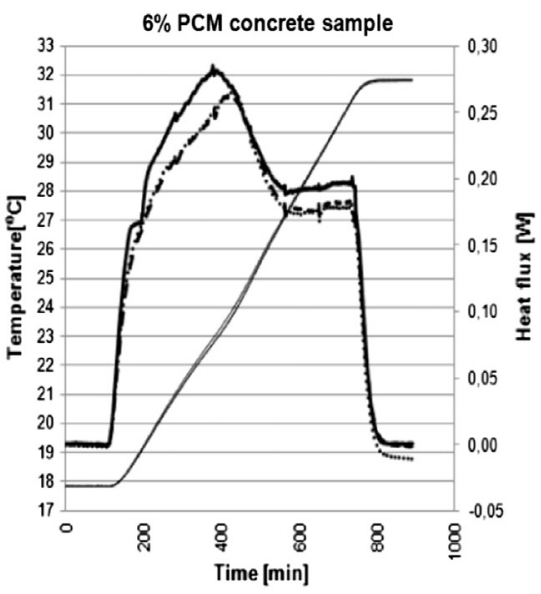

\begin{tabular}{cc} 
- Average temperature_1st series & ....... Heat_flux_1st series \\
\hline Average temperature_2nd series & -- Heat flux_2nd series \\
Average temperature_3rd series & - Heat flux_3rd series
\end{tabular}

Fig. 5. Logged temperature and heat flux results for three separate series of measurements of $4 \%$ and $6 \%$ PCM concrete specimens.

As seen in Fig. 6, the temperature of the specimen stabilizes at approximately $18{ }^{\circ} \mathrm{C}$, and thereafter the specimen is linearly heated over $10 \mathrm{~h}$ to approximately $32{ }^{\circ} \mathrm{C}$ when the temperature stabilizes again. For the concrete specimens with $\mathrm{PCM}$, the hot plate apparatus needs to deliver more heat (see bold-faced curve) in the temperature range from approximately $19{ }^{\circ} \mathrm{C}$ to $27^{\circ} \mathrm{C}$. This additional heat is necessary in order to overcome the melting process of the incorporated PCM in the specimen and to sustain a linear temperature increase predefined by the hot plate apparatus dynamic mode. The width of the measured heat flux peak indicates the melting range of the PCM. The highest peak of the heat flux occurs at approximately $23{ }^{\circ} \mathrm{C}$ which is also the melting point of the used PCM. The outputs of the experiment are the measured temperature profile in the sample and the heat flow to the specimen as a function of time. These outputs will be used to calculate the specific heat capacities of the PCM concrete specimens as a function of temperature.

\subsection{First $C p(T)$ calculation method: the theoretical method}

The theoretical method utilizes the weight average equation for the specific heat of the matrix material, e.g. concrete and the pure PCM, which is measured according to the DSC method, see Eq. (2). The DSC
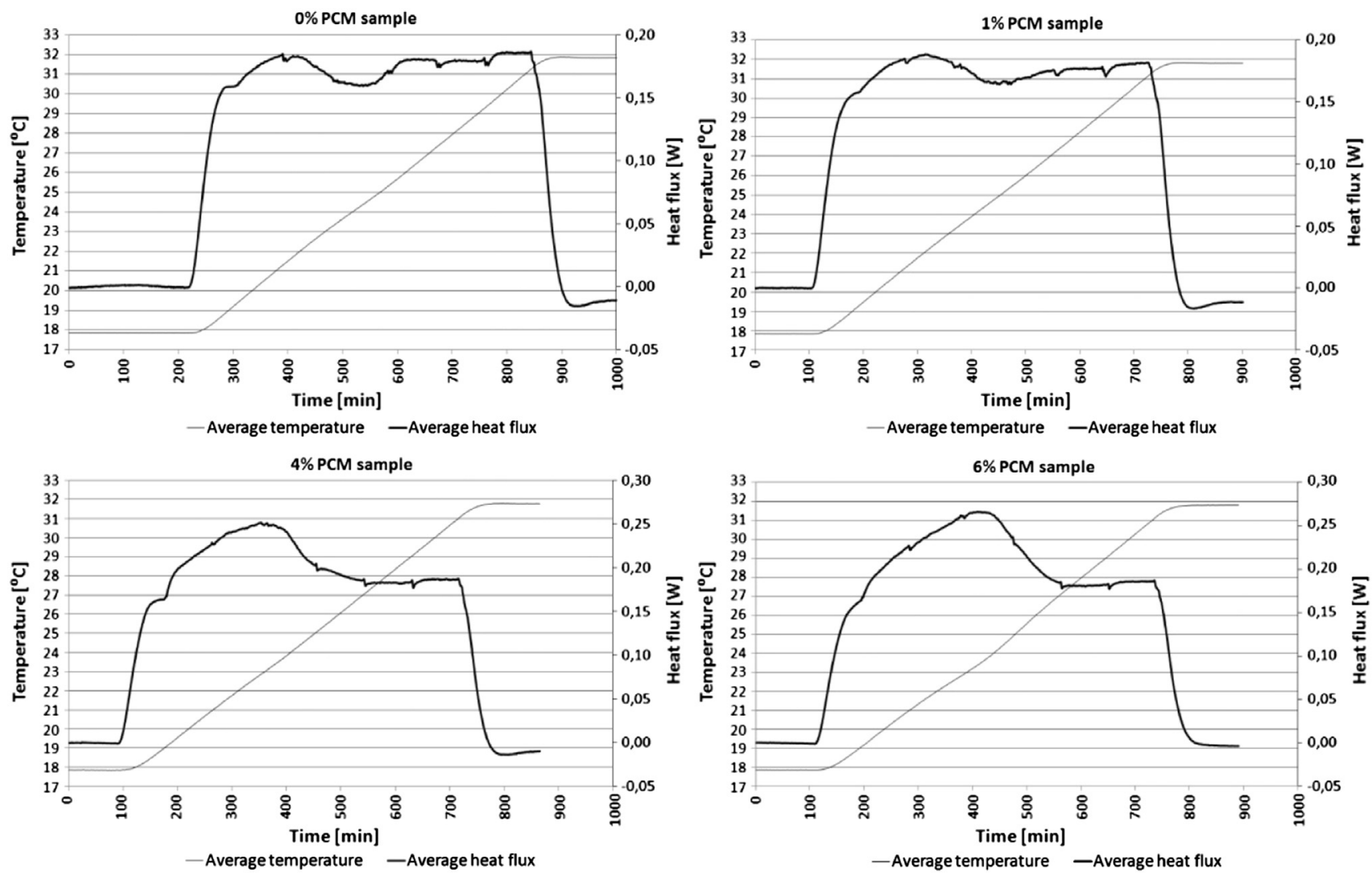

Fig. 6. Temperature and heat flux results from the dynamic experiment. 
measurements presented, see Fig. 7, are conducted by the producer of the PCM used in this study.

$C_{\text {composite }}=C_{\mathrm{PCM}} * X_{\mathrm{PCM}}+C_{\text {matrix }} *\left(1-X_{\mathrm{PCM}}\right)$

where:

$C_{\text {composite }}$ Specific heat capacity of the composite, $\mathrm{J} / \mathrm{kgK}$

$C_{\mathrm{PCM}} \quad$ Specific heat capacity of the PCM, J/kgK

$X_{\mathrm{PCM}} \quad$ Weight ratio of the PCM to the composite

$C_{\text {matrix }} \quad$ Specific heat capacity of the matrix material, $\mathrm{J} / \mathrm{kgK}$.

The results for $4 \%$ and 6\% PCM concrete are as presented in Fig. 8 .

It is worth highlighting that the calculations using the theoretical weight average method presented in this section did not utilize the results of the experimental outputs from the hot plate apparatus.

\subsection{Second $C p(T)$ calculation method: the simple method}

The calculation of the specific heat capacity of the material investigated in this research varies from the calculations of an ordinary material. The reason for this is the presence of PCM in the concrete. For normal solid materials, the specific heat capacity can be calculated from the equation:

$C_{p}=\frac{\Delta Q}{m * d T}$

and

$\Delta Q=\int_{T_{\text {start }}}^{T_{\text {end }}} q(T) d T$

where:

$\Delta Q \quad$ Internal energy increase of the sample, J

$m \quad$ Sample mass, $\mathrm{kg}$

Cp Specific heat capacity, $\mathrm{J} / \mathrm{kgK}$

$d T \quad$ Temperature difference between the beginning and the end of the sample heating process, $\mathrm{K}$.

This method makes it possible to find an average specific heat capacity in the defined temperature range. However, for the materials that change state it is important to establish how enthalpy/specific

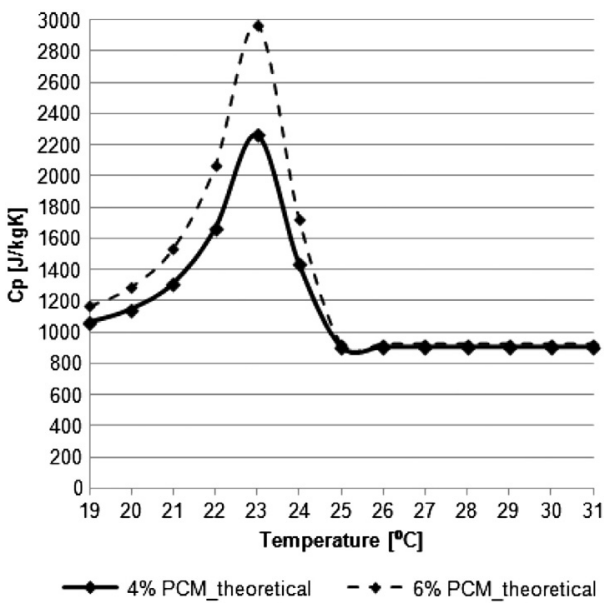

Fig. 8. Theoretical $C p(T)$ for $4 \%$ and $6 \%$ PCM concrete, only for melting process.

heat capacity changes during the phase transition. Therefore, Eq. (2) has to be modified in order to include the temperature gradient over time:

$$
C p(T)=\frac{A * q}{m * \frac{d T}{d t}}
$$

where:
A Heated sample area, $\mathrm{m}^{2}$
$q \quad$ Measured heat flux supplied to the sample, $\mathrm{W} / \mathrm{m}^{2}$
$m \quad$ Mass of the sample, $\mathrm{kg}$
$d T$ / $d t \quad$ Increase of sample temperature in a given time step, $\mathrm{K} / \mathrm{s}$.

The method presented in Eq. (5) was previously proposed in Reference [15] to calculate heat capacity of concrete containing PCM. However, the method has its shortcomings. The heat flow used in the calculation is the one measured at the surface of the sample by the heat flux film sensor. In reality, the heat flux varies in the interior space of the sample due to the dynamic temperature at the top and bottom boundaries of the specimen. As a consequence, Eq. (5) overestimates the heat flux transferred to the sample with respect to the internal temperature gradient over time, and so the calculated $C p(T)$ is also overestimated.

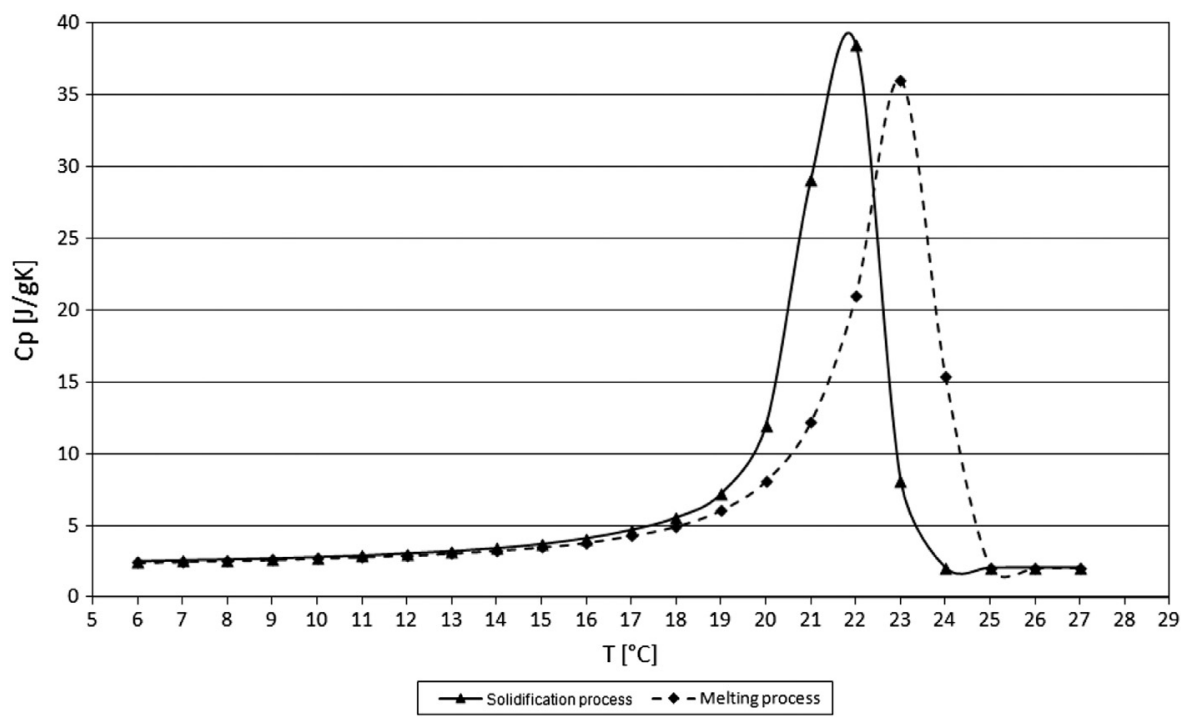

Fig. 7. Result of DSC measurement of pure microencapsulated PCM. 
The calculated results for 0, 1, 4 and 6 (wt.\%) PCM concrete specimens are illustrated in Fig. 9. The results presented in the paper are the calculated average results of the specific heat capacity calculated for each of the thermocouples inserted in the specimen. The results for each of the measured specimens are presented separately for the three conducted measurement series. All three series of measurements were depicted in order to show that the obtained results form a repeatable pattern.

\subsection{Third $C p(T)$ calculation method: the numerical simple method}

The "numerical simple method" for calculating $C p(T)$ presented in this section uses the explicit finite difference method for solving 1D unsteady heat conduction problem. The governing equation is as follows:

$\frac{\partial T}{\partial t}=\alpha \frac{\partial^{z} T}{\partial x^{z}}$

where:

$\begin{array}{ll}T & \text { Temperature, }{ }^{\circ} \mathrm{C} \\ t & \text { Time, } \mathrm{s} \\ x & \text { Length, } \mathrm{m} \\ \alpha & \text { Thermal diffusivity, } \mathrm{m}^{2} / \mathrm{s} .\end{array}$

The boundary conditions for the numerical model are set to resemble the experimental conditions. The initial temperature of the specimen is defined as $18{ }^{\circ} \mathrm{C}$, and thereafter the temperature is symmetrically and linearly increased to $32{ }^{\circ} \mathrm{C}$ over $10 \mathrm{~h}$ at the top and bottom surface of each sample. The height, density and thermal conductivity defined for the samples in the numerical model correspond to the measurements performed on the real samples. The number of nodes and time steps are dependent on the thermal properties of the samples. Therefore, the number of virtual nodes in the analysed geometry is chosen so as to result in a good stability and convergence of the model [18].

In the developed numerical model, the specific heat capacity is linearly dependent on the temperature. The iterative procedure of finding a satisfactory linear approximation of the specific heat capacity is repeated until the difference between the calculated and the measured heat flux at the surface is acceptably small. As mentioned previously, the experimental measurements are repeated three times for each specimen. In the numerical investigation presented in this subsection, the heat flux calculated in the model is compared to the average heat flux for all three measurement series, for $4 \%$ and 6\% PCM concrete respectively. The results of the investigation are presented in Figs. 10 and 11.

As shown in Figs. 10 and 11, the linear simplification of the $C p(T)$ gives a linear representation of the calculated heat flux at the surface. The correspondence between the measured heat flux and the calculated one is rather good. The heat flux between approximately $18{ }^{\circ} \mathrm{C}-19{ }^{\circ} \mathrm{C}$ and $31{ }^{\circ} \mathrm{C}-32{ }^{\circ} \mathrm{C}$ is not taken into account in the calculations of $\mathrm{Cp}(T)$ since these are the transition temperatures ranging respectively from steady-state to dynamic state and from dynamic to steady-state.

\subsection{Fourth $\mathrm{Cp}(T)$ calculation method: the inverse method}

In the "numerical simple method" presented in Section 3.5, the heat equation is solved by the traditional explicit finite difference method. The thermal properties: $\rho$ - density, $\lambda-$ thermal conductivity and $C p(T)$ - specific heat capacity as a function of temperature and also the temperature boundary conditions are given in order to solve the 1D unsteady heat conduction problem. However, the problem is nonlinear, and the linearization of $C p(T)$ presented in "numerical simple method" is a simplification.

For the materials whose thermal properties are temperaturedependent and unknown and for which the temperature profile and boundary conditions are known, an inverse analysis method could be applied.

The inverse analysis method has been used by many researchers to determine the temperature-dependent thermal conductivity and specific heat capacity of materials, in which only the interior temperature field and initial and boundary conditions were known. As stated in Reference [19], inverse methods were developed in two directions. The first one was devoted to estimating the initial boundary conditions leading to a desired temperature field. The second direction was focus on estimating the thermal parameters, such as diffusivity, thermal conductivity and heat capacity, from a measured temperature field.

For example, the inverse method utilizing the conjugate gradient method was presented in Reference [20] to simultaneously determine

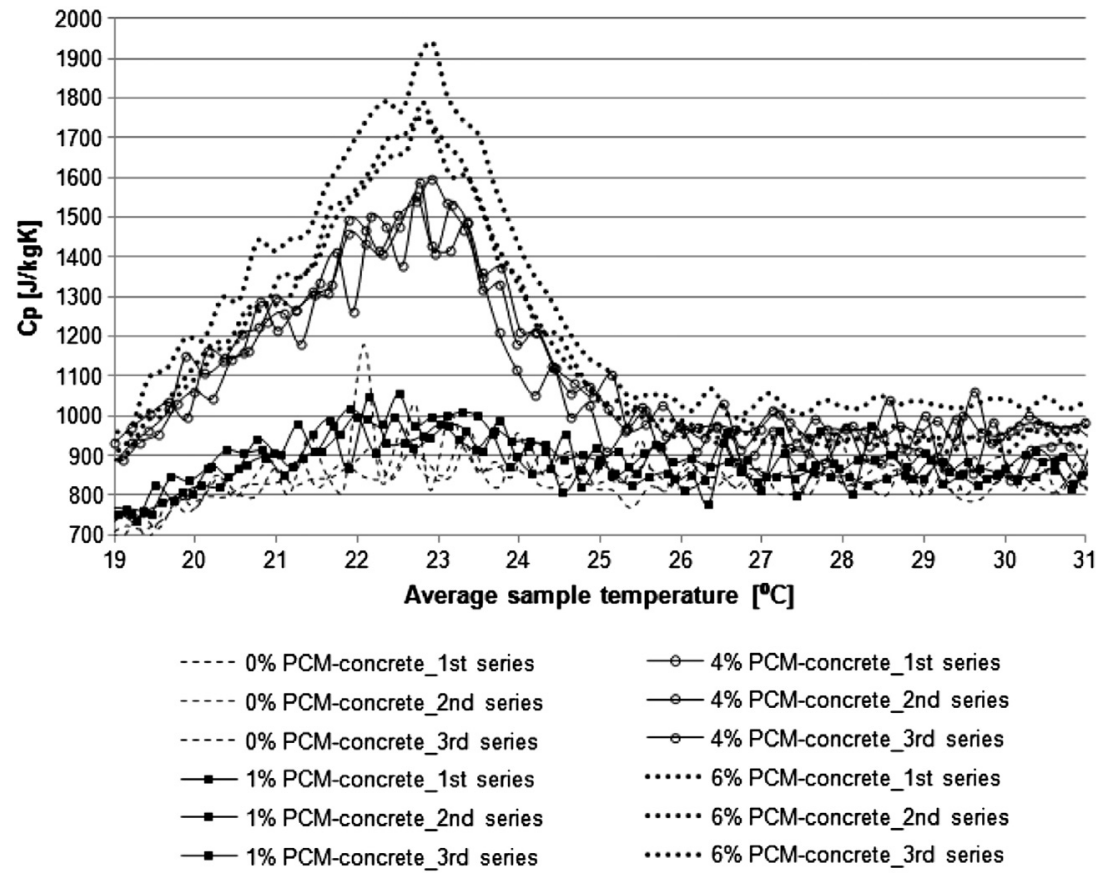

Fig. 9. Calculated $C p(T)$ for various PCM concrete specimens with use of "simple method". 

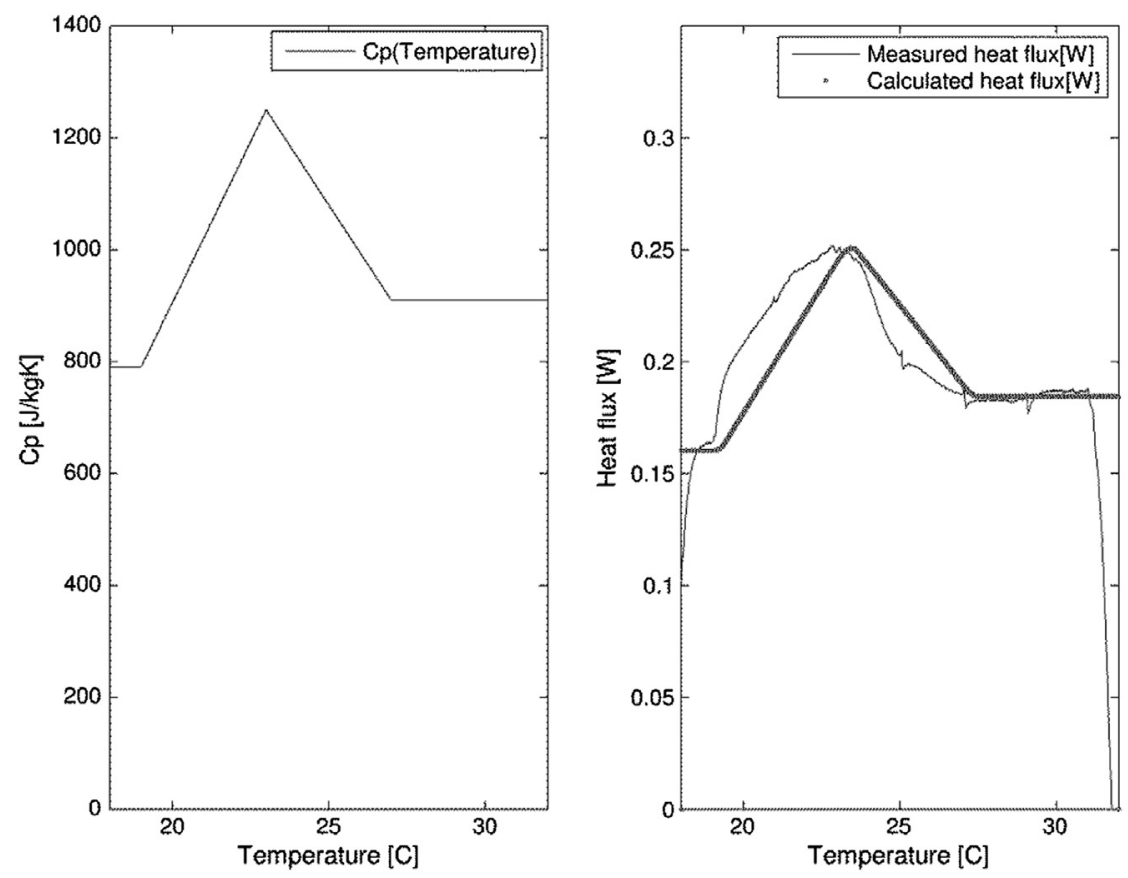

Fig. 10. (left) Linear $C p$ representation in function of temperature, (right) measured and calculated heat flux on the specimen surface: $4 \%$ PCM concrete.

the temperature-dependent thermal conductivity and heat capacity per unit volume of the material. Reference [21] presents a linear inverse model for determining temperature-dependent thermal conductivity in one-dimensional inverse conduction problems. The author also claims that the method is applicable to other kinds of inverse problems such as estimating the heat capacity and the convective heat transfer coefficient in one-dimensional or multidimensional heat conduction problems.

Reference [19] presents an inverse analysis based on the onedimensional finite element method case to simultaneously identify the constant thermal conductivity and heat capacity per unit volume of chosen polymers.

In this section, an inverse analysis based on the one-dimensional finite difference method is applied to identify the temperature-dependent specific heat capacity $C p(T)$ of PCM concrete composites. The thermal conductivity in the analysis is regarded as a constant within the investigated temperature range $(18<T<32)$ and was determined through steady state measurements (see also [17]) and therefore not regarded as unknown in the inverse problem investigation. What is more, to determine the thermal properties of PCM concrete, instead of using measured
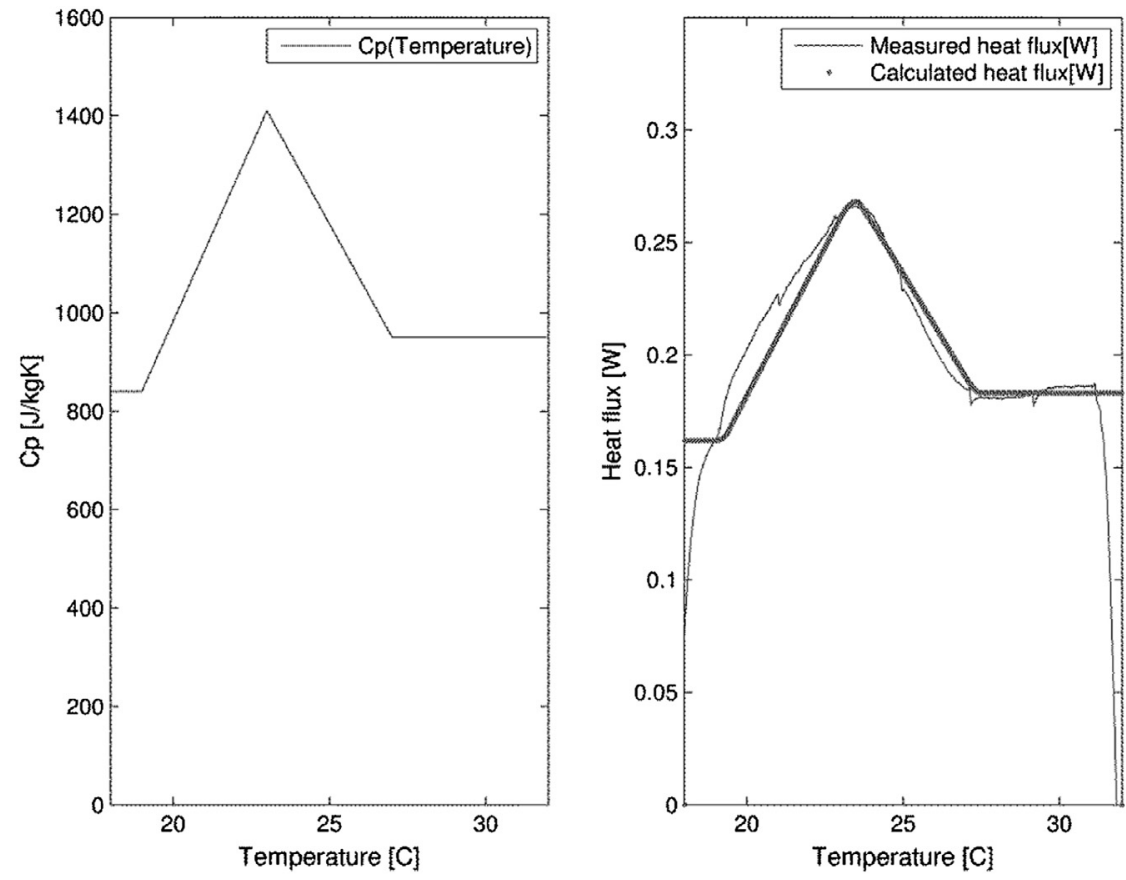

Fig. 11. (left) Linear $C p$ representation in function of temperature, (right) measured and calculated heat flux on the specimen surface: $6 \%$ PCM concrete. 
temperature profiles in the PCM concrete sample a measured heat flux at the surface of the sample is used. Finally, the measured and the calculated temperature profiles are compared.

Nonlinear programming problems arise quite often and not just in engineering fields. Over the past years, several numerical methods have been proposed to solve such problems. These methods include e.g.: interior point methods, gradient projection methods, trust region techniques and the sequential quadratic programming (SQP) method. In this paper, the SQP method has been chosen to solve the inverse problem. An overview of the SQP method can be found in References [22-25]; only a general problem description is presented in this section.

The objective of the optimization technique is to find a set of design parameters, $x=\left\{x_{1}, x_{2}, \ldots, x_{n}\right\}$, that can in some way be defined as optimal. For example, in advanced formulation the objective function, $f(x)$, to be minimized or maximized might be subject to constraints in the form of equality and inequality constraints and/or parameter boundaries (lower and upper boundaries). A general optimization problem can be stated as:

minimize $\quad f(x), x \in R$

subject to

equality constrain $g(x)=0$

inequality constrain $g(x) \leq 0$

boundaries $\quad l b \leq x \leq u b$

where:

$f(x) \quad$ Linear or nonlinear objective function

$c(x) \quad$ Vector

$x \quad$ Searched parameter

lb Lower boundary

$u b \quad$ Upper boundary.

Vector $c(x)$ contains the values of equality and inequality constraints evaluated at $x$. Quadratic programming (QP) deals with the minimization or maximization of a quadratic objective function that is linearly constrained. The idea of the SQP methods is to solve the nonlinearly constrained problem using a sequence of quadratic programming (QP) sub-problems. The constraints of each QP sub-problem are linearizations of the constraints of the original problem, and the objective function of the sub-problem is a quadratic approximation to the Lagrangian function also known as the Kuhn-Tucker condition:

$L(x, \lambda)=f(x)+\sum_{i=1}^{m} \lambda_{i} * g_{i}(x)$

where:

$\lambda \quad$ Lagrange multiplier vector.

Here, the QP sub-problem is obtained by the linearization of nonlinear constraints.

Traditional SQP seeks to improve an estimated parameter $(x)$ of the Lagrangian function by finding the correction $(\Delta x)$ by solving one or more quadratic programming problems:

minimum $0.5 \Delta x^{T} H \Delta x+\Delta x^{T} g(x), d \in R^{n}$

subject to $c(x)+A(x)^{T} \Delta x \leq 0$

where:

$A(x) \quad$ is Jacobian

$H$ is symmetric approximation to the Hessian of the Lagrangian function.
The next estimate of the sought solution would be:

$x^{+}=x+\alpha \Delta x$

where nonnegative step size $\alpha$ is obtained by line search techniques with a unit initial step size.

A satisfactory agreement between the measured and the calculated heat flux and temperature distribution can be achieved by experiments and measurements. However, the calculated data can only correspond well with the measured ones with the correct thermal properties, which means that the thermal properties can be correctly determined only when the difference between the measured and calculated data approaches zero.

For example, in Reference [26] the SQP method was used to find the best thermal properties of a building, which will result in indoor thermal comfort and minimum energy use for heating and cooling of the investigated building.

The method proposed in this section uses the $\mathrm{N}$-segment method to obtain ideal $C p(T)_{i}, i=1, \ldots, N$. The temperature range, in which the experiment is performed, is divided into $N$ equal temperature segments, and $C p(T)^{i}, i=1, \ldots, N$ is distributed in those $N$ segments. Subsequently, the $C p(T)^{i}, i=1, \ldots, N$ is adjusted to obtain the minimum of the objective function which is given by the Eq. (11), by using a non-linear constrained optimization method such as the SQP method [27-29]. Eq. (11) gives the objective function for the optimization problem.

Min $f=\left|q_{\text {calculated }} 1, j-q_{\text {measured } 1, j}\right|$

where:

$q_{\text {calculated } 1, j}$ is the calculated heat flow to the sample at the sample surface, $\mathrm{W}$

$q_{\text {measured } 1, j}$ is the measured heat flow to the sample at the sample surface, $\mathrm{W}$.

Taking results obtained from the first to third methods presented in this paper into consideration, the upper and lower bound for the chosen parameter, which in this investigation is the specific heat capacity, is chosen as $0<C p(T)_{i}<2000 \mathrm{~J} /(\mathrm{kgK})$. Due to the fact that the division of temperature segments may influence the accuracy of the results, the division should be adjusted until the relative error is acceptable. In the calculation presented in this paper, the temperature segment $(N)$ has the length of $0.5{ }^{\circ} \mathrm{C}$. It should be kept in mind that the governing equation for the problem is the same as in the "numerical simple method", Eq. (6).

The results of the "inverse method" are presented for 4 (wt.\%) and 6 (wt.\%) PCM concrete, but only for the third measurement series (Figs 12 and 13).

To determine the discrepancy between the measurements and the calculations, the measured and calculated vertical temperature profiles are compared, and the total average relative error is calculated. What is more, the number and location of nodes for solving the heat equation in the inverse method lines up with the real position of the thermocouples in the specimen. As an example, the calculated and measured temperature profiles are compared for the 4\% PCM concrete specimen, see Fig. 14. The total average relative error in all time steps for 4 (wt.\%) and 6 (wt.\%) PCM concrete is calculated to be approximately $0.5 \%$ and $0.5 \%$ respectively.

\subsection{Comparison of methods}

In this section, results obtained from all presented methods are compared with each other. The third measuring series for the specimen containing 4 (wt.\%) of PCM is chosen for the comparison. 

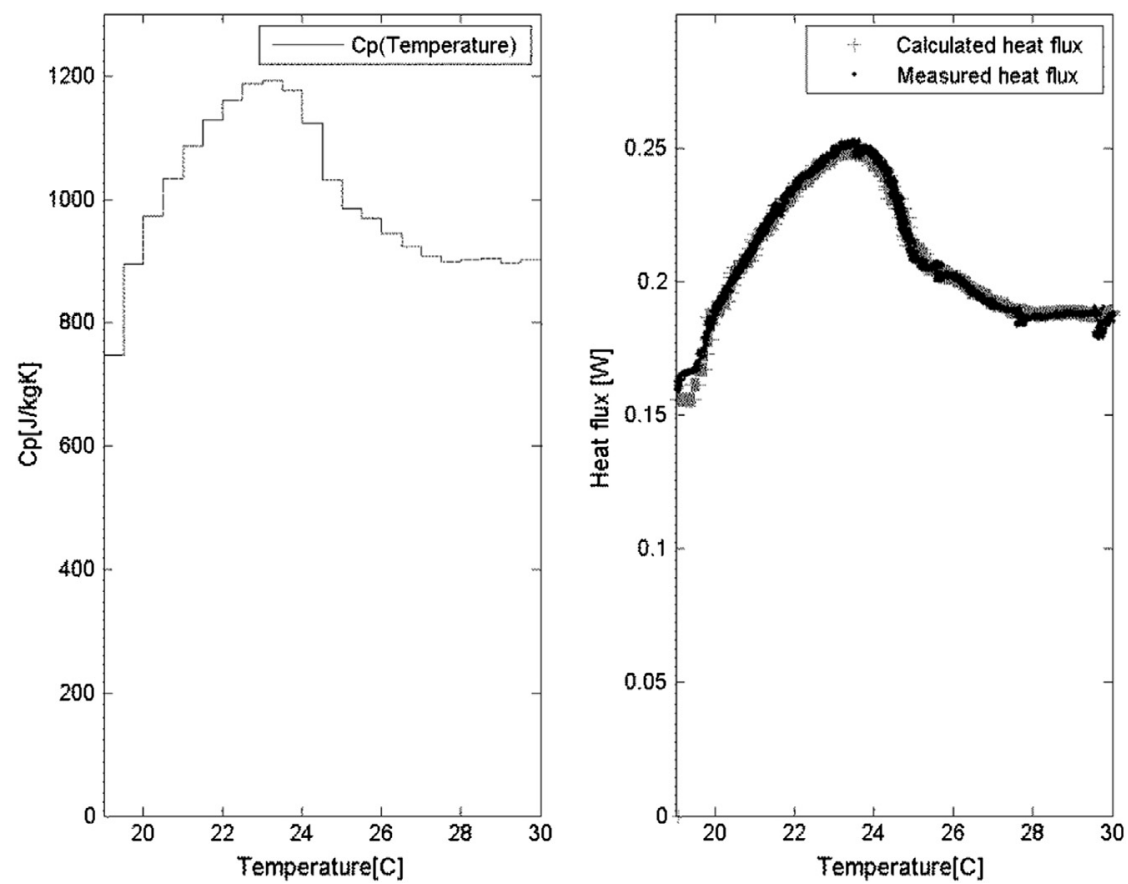

Fig. 12. (left) Calculated optimized $C p$ in function of temperature, (right) measured and calculated heat flux on the specimen surface: $4 \%$ PCM concrete.

Fig. 15, depicts the results obtained by using all methods presented in this paper.

As shown in Fig. 15, various calculation methods lead to various results. Firstly, it is noticeable that the peak $C p$ obtained by the theoretical method is much higher than the peaks obtained from the methods utilizing experimental data. The peak obtained from the "simple method" is higher than the ones obtained from the "simple numerical method" and the "inverse method", but as discussed in Section 3.2, this method is expected to give overestimated results. The curves of the calculated $C p(T)$ from the "simple numerical method" and "inverse method" lie very close to each other, but still the "inverse method" should give a more realistic representation of the $C p(T)$ since this method is based on optimization algorithm.

What is more, the peak of the calculated $C p(T)$ for all methods lies at approximately $23^{\circ} \mathrm{C}$, which is expected.

\section{Conclusion and discussion}

The used experimental set-up and temperature ramp between $18{ }^{\circ} \mathrm{C}$ and $32{ }^{\circ} \mathrm{C}$ presented in this paper made it possible to activate the microencapsulated PCM directly integrated in the concrete mixture. The method for measuring the temperature of the concrete sample profile
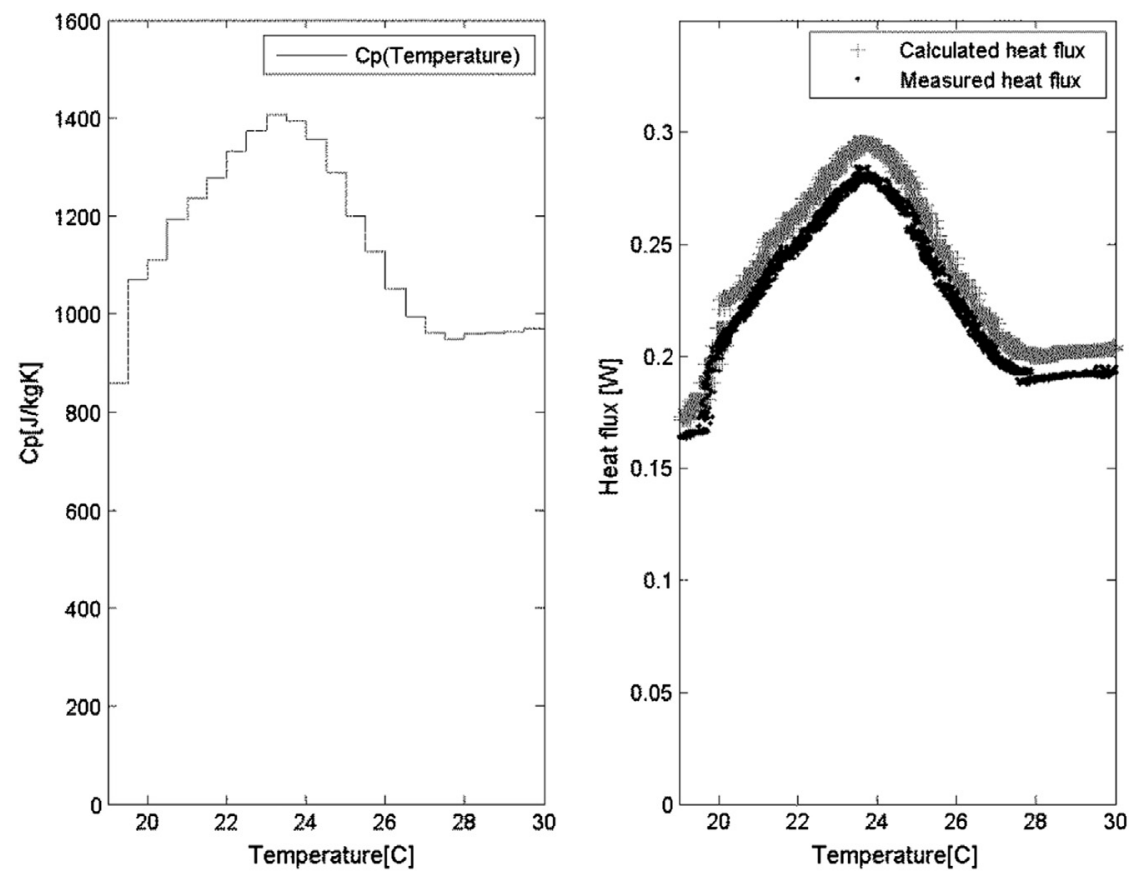

Fig. 13. (left) Calculated optimized $C p$ in function of temperature, (right) measured and calculated heat flux on the specimen surface: $6 \%$ PCM concrete. 


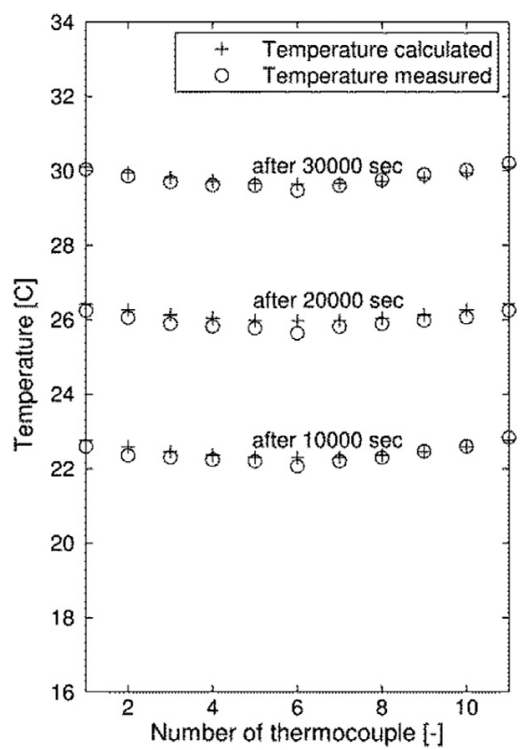

Fig. 14. Comparison of measured and calculated vertical temperature profile at chosen time steps for $4 \%$ PCM concrete specimen.

was validated and confirmed to give accurate results by using a plaster sample. Moreover, the size of the heat flux film was determined by using the finite element software COMSOL. The proper design of the flux film resulted in measuring only the 1D heat flow to the specimen.

The outcome from the experimental investigation indicates that in order to linearly heat up the sample from $18{ }^{\circ} \mathrm{C}$ to $32^{\circ} \mathrm{C}$, the hot plate apparatus has to provide more heat to the samples with the PCM than those without it. The heat of fusion for temperatures ranging between $19{ }^{\circ} \mathrm{C}$ and $27{ }^{\circ} \mathrm{C}$ can be distinctly observed for the samples containing $4 \%$ and $6 \%$ of the microencapsulated PCM. On the other hand, for the sample with $1 \%$ PCM the measured heat flux did not increase substantially. The insignificant heat flux peak can be explained by the small amount of incorporated PCM. What is more, some of the capsules could have been damaged during the mixing process. Although, the CRYO-SEM investigation has been performed, it has been indicated that this method cannot be used to check whether or not the capsules have been damaged during the mixing process of the concrete.

The problem of the heat flux stability can also be observed for the reference specimen without PCM. The heat flux is expected to increase and stabilize at a certain level during the heating process. On the contrary, a small fluctuation is observed and then an insignificant linear increase of the heat flux. It is concluded that the unstable heat flux is either due to temperature control problems of the dynamic mode in

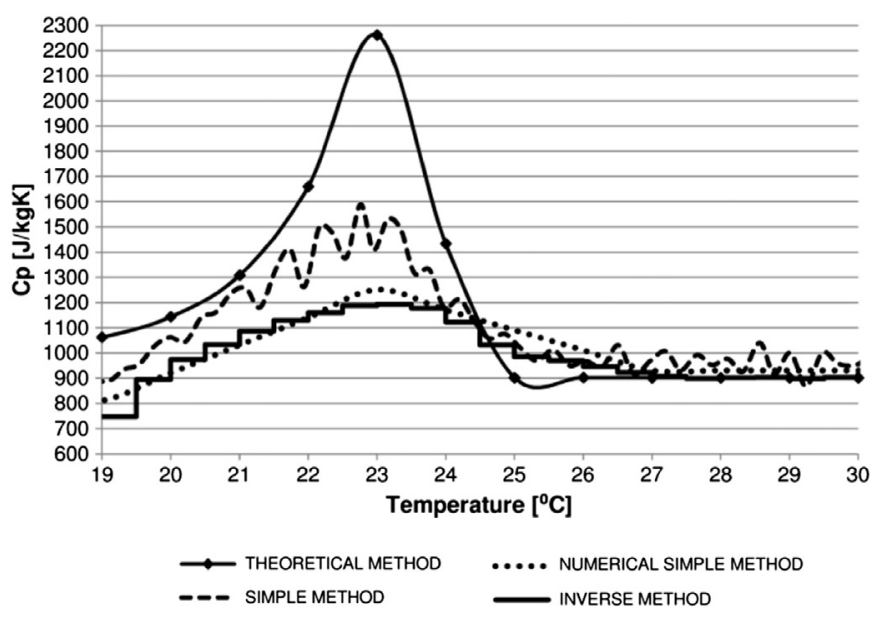

Fig. 15. Comparison of results from various proposed calculation methods of $C p(T)$. the hot plate apparatus or fluctuation in the temperature of the surroundings. Still, the instability of the heat flux is insignificant, and the results can be considered as reliable.

Regarding the calculation of the specific heat capacity, various methods naturally give various results. The "theoretical method" that uses the weight-average method results in the highest $C p$ values. On the contrary, the results based on the measurements generally indicate that the peak of the specific heat capacity is much lower and has a wider shape than the theoretically calculated one.

The second presented method called the "simple method" is indeed fast and simple, but it overestimates the actual specific heat capacity of the measured specimens. In Eq. (5), the heat flux measured at the surface of the specimen is used for all temperature gradients $d T$ / $d t$, even the ones measured in the interior of the specimen. In reality, the heat flux decreases in the direction of the centre of the specimen, and so the real specific heat capacity should be lower than the calculated one.

The third method called the "numerical simple method" simplifies the problem by the linearization of the specific heat capacity as a function of temperature. The method is not too complex and, at the same time, provides acceptable accuracy. On the other hand, the weakness of the method is the manual iterative process for finding a satisfactory linear approximation of $C p(T)$.

The fourth method, the "inverse method", is the most advanced of all of the presented methods. It uses a non-linear constrained optimization method to calculate $C p(T)$. The calculated optimized results correspond very well with the measurements. For the $4 \%$ PCM concrete sample, the accuracy is better than for the 6\% PCM concrete. The conclusion is that if the number of $N$ temperature segments was increased for the calculation of 6\% PCM concrete, the accuracy would probably be improved.

A general conclusion can be drawn that for practical purposes to be able to perform a simulation of an entire building and to calculate the indoor temperature and energy use of a room with PCM concrete elements, the third and fourth methods - the "numerical simple method" and "inverse method" - would probably be the most suitable ones. The reason is that the obtained $C p(T)$ is directly represented either by a function or a pair of points that can easily and conveniently be transferred to any building simulation programme. The "simple method" could also be used, but as stated earlier the results obtained are considered to be overestimated, and therefore the method will not be recommended.

The advantage of the experimental method presented in the paper is the very small heating rate of approximately $0.023 \mathrm{~K} / \mathrm{min}$, which can imitate the temperature increase in a real building construction element and thus simulate realistic thermal conditions at which the PCM concrete would be activated.

The present development of the hardware used in the experiment allows determination of the $C p(T)$ but only for the melting process. An experiment, where the sample would be cooled down in order to define the $C p(T)$ of the solidification process is also possible. However, due to the limited accuracy of the presently available hardware, these experiments have not been performed.

The thermal activation of PCMs and their efficient application in buildings are strongly limited by their very low thermal conductivity. Therefore, in order to increase the thermal conductivity, pure PCMs have to be mixed with other highly conductive materials that could carry the heat to deeper layers over short time. It is expected that the experimental method for determining the heat capacity of a concrete material with PCM proposed in this paper should also work for other inhomogeneous composites with PCM.

\section{Acknowledgements}

This work was supported by the Danish National Advanced Technology Foundation. The authors would also like to express their thanks to the Danish Technological Institute, Spæncom and BASF for a fruitful co-operation. 


\section{References}

[1] F. Kuznik, J. Virgone, Experimental investigation of wallboard containing phase change material: data for validation of numerical modelling, Energy Build. 41 (5) (2009) 561-570.

[2] N. Artmann, H. Manz, P. Heiselberg, Parametric study on the dynamic heat storage capacity of building elements, 2nd PALENC Conference and 28th AIVC Conference on Building Low Energy Cooling and Advanced Ventilation Technologies, Crete, Greece, 2007.

[3] M. Pomianowski, P. Heiselberg, L.R. Jensen, Initial development of a combined PCM and TABS for heat storage and cooling, Proceedings of the 9th Nordic Symposium on Building Physics: NSB, Tampre, Finland, 2011, (Personal communication).

[4] B. Zalba, J.M. Martin, L. Cabeza, H. Mehling, Free cooling of buildings with phase change materials, Int. J. Refrig. 27 (8) (2004) 839-849.

[5] B. Zalba, J.M. Marin, Review on thermal energy storage with phase change: materials, heat transfer analysis, applications, Appl. Therm. Eng. 23 (3) (2003) 251-283.

[6] N. Zhu, Z. Ma, S. Wang, Dynamic characteristics and energy performance of buildings using phase change materials: a review, Energy Conserv. Manage. 50 (12) (2009) 3169-3181.

[7] F. Kuznik, J. Virgone, Experimental assessment of phase change material for wall building use, Appl. Energy 86 (10) (2009) 2038-2046.

[8] P. Schossig, H.M. Henning, S. Gschwander, T. Haussmann, Micro-encapsulated phase-change materials integrated into construction materials, Sol. Energy Mater. Sol. Cells 89 (2-3) (2005) 297-306.

[9] Chi-ming Lai, R.H. Chen, Heat transfer and thermal storage behaviour of gypsum boards incorporating micro-encapsulated PCM, Energy Build. 42 (8) (2010) 1259-1266.

[10] Z. Yinping, Y. Jiang, A simple method, the T-history method, of determining the heat of fusion, specific heat and thermal conductivity of phase change materials, Meas. Sci. Technol. 10 (3) (1999) 201-205.

[11] H. Hiki, K.K. Sun, K. Yong-Shik, Accuracy improvement of T-history method for measuring heat of fusion of various materials, Int. J. Refrig. 27 (4) (2004) 360-366.

[12] A. Lázaro, E. Günther, H. Mehling, S. Hiebler, M.J. Martin, B. Zalba, Verification of T-history installation to measure enthalpy versus temperature curves of phase change materials, Meas. Sci. Technol. 17 (8) (2006) 2168-2217.

[13] L.F. Cabeza, C. Castellón, M. Nogués, M. Medrano, R. Leppers, O. Zubillaga, Use of microencapsulated PCM in concrete walls for energy savings, Energy Build. 39 (2) (2007) 113-119.
[14] A.G. Entrop, H.J.H. Brouwers, A.H.M.E. Reinders, Experimental research on the use of micro-encapsulated phase change materials to store solar energy in concrete floors and to save energy in Dutch houses, Sol. Energy 85 (5) (2011) 1007-1020.

[15] M. Hunger, A.G. Entrop, The behavior of self-compacting concrete containing micro-encapsulated phase change materials, Cem. Concr. Compos. 31 (10) (2009) 731-743.

[16] H. Mehling, H.P. Ebert, Development of standards for materials testing and quality control of PCM, 7th IIR Conference on Phase Change Materials and Slurries for Refrigeration and Air Conditioning, Paris, 2006.

[17] M.Z. Pomianowski, P. Heiselberg, R.L. Jensen, Experimental investigation of therma conductivity of concrete containing micro-encapsulated phase change materials, ISHVAC conference, Shanghai, China, 2011, (Personal communication).

[18] E. Lund, T. Condra, Notes and exercises for numerical methods, Aalborg University, Denmark, 2010.

[19] K. Atchonouglo, M. Banna, C. Valée, J.C. Dupré, Inverse transient heat conduction problems and identification of thermal parameters, Heat Mass Transfer 45 (2008) 23-29.

[20] Cheng-Hung Huang, Jan-Yuan Yan, An inverse problem in simultaneously measuring temperature dependent thermal conductivity and heat capacity, Int. J. Heat Mass Transfer 38 (18) (1995) 3433-3441.

[21] Ching-yu Yang, A linear inverse model for the temperature-dependent therma conductivity determination in one-dimensional problems, Appl. Math. Model. 22 (1998) 1-9.

[22] R. Fletcher, Practical Methods of Optimization, John Wiley and Sons, 1987.

[23] P.E. Gill, W. Murray, M.H. Wright, Practical Optimization, Academic Press, London, 1981.

[24] M.J.D. Powell, Variable metric methods for constrained optimization, in: A. Bachem, M. Grotschel, B. Korte (Eds.), Mathematical Programming: The State of the Art, Springer Verlag, 1983, pp. 288-311.

[25] W. Hock, K. Schittkowski, A comparative performance evaluation of 27 nonlinear programming codes, Computing, vol. 30, 1983. 335.

[26] R. Zeng, X. Wang, H. Di, F. Jiang, Y. Zhang, New concept and approach for developing energy efficient buildings: ideal specific heat for building internal thermal mass, Energy Build. 43 (5) (2011) 1081-1090.

[27] P.E. Gill, W. Murray, M.H. Wright, Numerical Linear Algebra and Optimization, 1991.

[28] P.E. Gill, W. Murray, M.A. Saunders, Procedures for optimization problems with a mixture of bounds and general linear constraints, ACM Trans. Math. Softw. 10 (1984) 282-298.

[29] S.P. Han, Globally convergent method for nonlinear-programming, J. Optim. Theory Appl. 22 (3) (1977) 297-309. 


\title{
NUMERICAL ANALYSIS OF HEAT STORAGE AND HEAT CONDUCTIVITY IN THE CONCRETE HOLLOW CORE DECK ELEMENT
}

\author{
Michal Pomianowski ${ }^{1}$, Per Heiselberg ${ }^{1}$, Rasmus Lund Jensen ${ }^{1}$, and Hicham Johra ${ }^{1}$ \\ ${ }^{1}$ Aalborg University, Civil Engineering Department, Aalborg, Denmark
}

\begin{abstract}
In order to minimize energy used for cooling and heating, one of the passive solutions is to efficiently utilize heat storage of a building construction. Presently, heat storage calculations in whole building simulation programs are based on 1D heat transfer models. This paper investigates to what extent these simplified models estimate the heat storage potential of precast hollow-core concrete decks correctly. This study investigates various approaches on how to model the heat transfer within the air void in the deck. Furthermore, it is analysed how different heat transfer models influence the overall heat transfer and heat storage in the hollow-core decks.
\end{abstract}

The presented results allow comparison between detailed results from 2D-COMSOL simulations and simple 1D calculations from the whole building simulation tool such as BSim program and moreover, it is possible to validate the calculation method in BSim for the concrete deck element with air voids.

Finally, this paper presents a comparison of the calculated heat conductivity of the hollow-core concrete deck and the measured heat conductivity for the same deck by using hot box apparatus.

\section{INTRODUCTION}

The building simulation tools, which are currently being applied, are exceptionally useful and very important when buildings' energy use and indoor climate need to be foreseen. However, it is always a challenge to precisely reflect a real life condition and obtain reliable results when using whole building simulation programs. As a consequence of poor modeling, the incorrect and inefficient HVAC system can be selected and poor indoor climate achieved. The same concerns utilization of passive technologies such as, for example, day light utilization, heat storage, passive cooling and heating. On the contrary, correct simulation can highlight possible energy savings and improvements in the indoor thermal environment.

Generally, in well designed buildings, energy use and indoor climate are dependent on each other and usually, the final effect is a compromise between one and another. At the modeling stage of the building, these two parameters are dependent, among other factors, on stationary and transient thermo-physical parameters of materials used for construction.

Normally in simulation programs, such as for example BSim, construction elements are defined as one homogeneous layer or combination of homogeneous layers with defined density, thermal conductivity and specific heat capacity. Knowing these thermal properties of the construction materials allows performance of transient simulations which considers heat storage. In the building simulation, concrete construction elements are usually defined as homogenous and isotropic materials. Additionally, many building simulation programs consider constructions, as 1-D elements, in order to decrease simulation time and become more time efficient. This means that possible inhomogenities within one layer, such as air voids, are not taken into consideration, although they might have a significant influence on the heat storage calculation of the building.

During the past years, several studies have been done on thermal behavior of hollow-core concrete slabs. A theoretical study (P. Gandhidasan, 1985) indicated that heat flux, which enters through the roof, made of hollow-core concrete slabs is independent of location of air cavity within the depth of the slab. However, the study presents a one dimensional approach to the problem without including the complexity of thermal bridges through the air cavity. Additionally, the air cavity is considered as a uniform cavity that separates the outer and inner layer of the concrete. Therefore, the model does not sufficiently present the thermal conditions within the hollow-core concrete slab presented in Figure 1 and thus, it cannot be used as a methodology to calculate this type of construction in the whole building simulation programs.

Another approach was presented in (Z.L. Zhang, 2009) where a model of a hollow-core concrete slab was created in the COMSOL program in order to study heat transfer and the heat storing capacity in the concrete elements with air cavities. However, in the research presented by (Zhang), the focus was on investigation of how the cavity area influences heat storage of the deck. This paper's focus is on various heat transfer mechanisms within the air void in the deck and on validation of a simplified model for 
whole building simulation tool. Moreover, it is investiagted if heat transfer by convection and radiation within the air void is an important parameter that strongly influences the overall heat transfer and overall heat storage of the hollow-core deck element.

The first objective of this study is to investigate various approaches on how to model the heat transfer in the slab with the air voids. This is done by creating steady- state 2D models of the hollow-core concrete deck using the COMSOL program. Secondly, the 2D model is simplified to be presented as a 1D model. Two various approaches are considered when simplifying the 2D model into a 1D model in COMSOL; 1D-one layer model and 1Dthree layer model. Thirdly, results from the steadystate 2D modeling of heat conductivity are used to calculate equivalent thermal conductivity in 1D models. Furthermore, equivalent thermal conductivity is used to find equivalent thermal mass of the the hollow-core deck element presented by the 1D models. This part of the investigation ends with comparison of calculated diurnal heat storage of the deck for the 2D COMSOL model, 1D-one layer and 1D-three layer COMSOL model and the 1DCOMSOL model callculated according to the present BSim methodology for simulating hollow-core decks.

Afterwards, the calculation methodology of heat storage in the hollow-core concrete deck in BSim is validated based on results from the 2D COMSOL detailed simulations.

Finally, this paper presents the measured thermal conductivity of the hollow-core deck when using hot box apparatus. The intention is to define which of the approaches to calculate heat transfer is the closest to the real life condition and to state how important proper assumption is to simulate heat transfer within the air void in the hollow-core deck.

The paper is finished with discussion and conclusion.

\section{SIMULATION}

This paper presents computational and experimental investigations. The numerical model that was created in the COMSOL and BSim program was based on the real cast of the hollow-core concrete deck element which is presented in Figure 1 in section view.

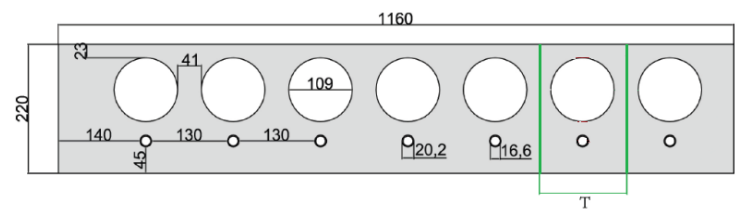

Figure 1 Section view of hollow-core deck.

Thermal properties of the concrete used in COMSOL are assumed to be as follows: thermal conductivity $1,8\left[\mathrm{~W} / \mathrm{m}^{2} \mathrm{~K}\right]$, density $2300\left[\mathrm{~kg} / \mathrm{m}^{3}\right]$ and specific heat capacity $1000[\mathrm{~J} / \mathrm{kgK}]$. In order to save simulation time and due to symmetry of the element, only one section " $T$ " presented in Figure 1 is modelled. The model presented in Figure1 was used for both steadystate and transient simulations.

The small circular voids that can be seen on the bottom of the deck represents water pipes that were used in another experiment where the deck was thermally activated. Due to the small size of these pipes, they only have a minor importance on the experimental investigation of thermal conductivity. In the modeling part, they were not included in the model and substituted by the concrete material.

\section{Steady-state simulation}

For the steady-state models, the temperature on the upper and lower surface of the deck is presented as a constant temperature and the temperature on the bottom is different from the temperature on the top of the deck.

Heat transfer within the air void is modelled according to the following four various assumptions:

1. Air void is presented as an adiabatic boundary.

2. Air in the void is given real air thermal properties such as: density, thermal conductivity, specific heat capacity. However, air is standing still thus no convection is considered. In this model, radiation between surfaces is not considered.

3. Air void cavity is given radiation surface to surface boundary.

4. Air void is given equivalent thermal conductivity calculated based on norm [DS EN ISO 10077-2, 2004]. This thermal conductivity considers heat transfer by convection and radiation in closed voids.

In this study, parametrization of the heat transfer within the air void is distributed along with 4 various assumptions presented above in this section. In the first model, the air void is excluded from the heat transfer through the slab with air voids, in the second model, the air void is included in the heat transfer through the slab but neither convection nor radiation is considered. The third model considers only heat transfer by radiation between air void surfaces and in the fourth model, both radiation and convection in the air voids is included.

During the steady-state simulations, firstly, the 2D models were calculated as per assumption given in points 1 to 4 in this section. Afterwards, the 2D models were simplified to $1 \mathrm{D}$ models as presented in Fig. 2. 


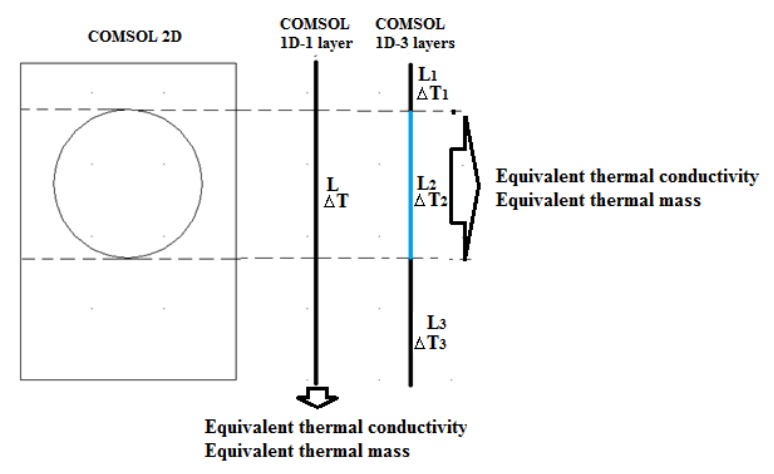

Figure 2 Transformation of 2D model intolD model.

The 2D model is represented by 1D one-layer model and 1D three-layer model. As stated in (Zhang), for the 1D one-layer model, equivalent thermal conductivity $\lambda^{\mathrm{e}}$ can be calculated directly from the 2D model. For the 1D three-layer model, the length of the layer with the void is calculated as $\mathrm{L}_{2}=\mathrm{L}-$ $\left(\mathrm{L}_{1}+\mathrm{L}_{3}\right)$, see Figure 2 . The thermal conductivity for layer $\mathrm{L}_{1}$ and $\mathrm{L}_{3}$ is taken as the value of bulk concrete $\lambda_{\mathrm{c}}=1,8 \quad\left[\mathrm{~W} / \mathrm{m}^{2} \mathrm{~K}\right]$. Then equivalent thermal conductivity of layer $\mathrm{L}_{2}$ can be calculated as:

$\lambda_{2}^{e}=L_{2} \times \alpha_{2}=L_{2} \times \frac{\alpha}{1-\frac{\alpha}{\alpha_{1}}-\frac{\kappa}{\alpha_{2}}}$

Where $\alpha=\lambda^{\mathrm{e}} / \mathrm{L}, \alpha_{1}=\lambda_{\mathrm{c}} / \mathrm{L}_{1}, \alpha_{3}=\lambda_{\mathrm{c}} / \mathrm{L}_{3}$ and for steadystate condition can be written that:

$\alpha_{1} \times \Delta \mathrm{T}_{1}=\alpha_{2} \times \Delta \mathrm{T}_{2=} \alpha_{3} \times \Delta \mathrm{T}_{3}=\alpha \times \Delta \mathrm{T}$

Where: $\Delta \mathrm{T}=\Delta \mathrm{T}_{1}+\Delta \mathrm{T}_{2}+\Delta \mathrm{T}_{3}$

\section{Transient simulation}

For the transient simulation, total heat transfer coefficient on the upper and lower surface of the deck is given as $8\left[\mathrm{~W} / \mathrm{m}^{2} \mathrm{~K}\right]$. The total heat transfer coefficient represents both heat transfer by convection and radiation.

In transient simulation, a diurnal temperature fluctuation on the upper and lower side of the deck is represented by the sin curve varying from 20 to $26^{\circ} \mathrm{C}$. To reach quasi steady-state, each simulation is run for 5 days and results are taken from the last day.

\section{BSim simulation}

In the BSim program, two approaches for calculating the heat storage of the hollow-core deck element were investigated. The first one (in this paper called "BSim methodology") is implementing existing methodology suggested in the BSim program, see Figure 3 and Equation 3. The second one, (in this paper called "BSim reference") is utilizing findings obtained from transformation of the 2D model of hollow-core deck element into a 1D three-layer model, which, as displayed in Figure 6 and 7, gives very good results. In the second method, equivalent thermal conductivity for layer with air void was taken from the 1D three-layer model where air void is simulated as air standing still (see section steady- state simulation). The reason for this apporoach is that the heat transfer is probably closest to the methodology presently valid in the BSim program which was developed along with development and validation of calcualtion method for the heat transfer in water-based radiant systems (M. Scarpa et al., 2009).
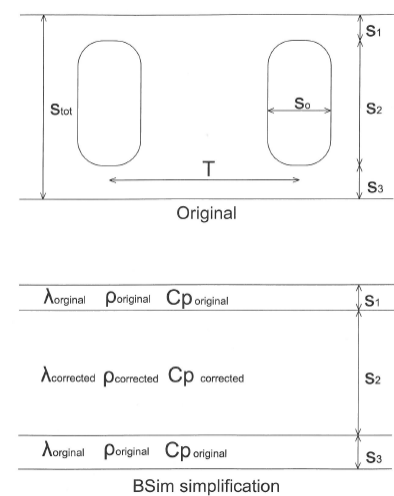

Figure 3 BSim simplification of hollow-core deck.

$\lambda_{\text {corrected }}=\lambda_{\text {original }} *\left(\mathrm{~T}-\mathrm{s}_{0}\right) / \mathrm{T}$
$\rho_{\text {corrected }}=\rho_{\text {original }} *\left(\mathrm{~T}-\mathrm{s}_{0}\right) / \mathrm{T}$
$\mathrm{C} \mathrm{p}_{\text {corrected }}=\mathrm{C} \mathrm{p}_{\text {original }}$

Where: $\lambda$ is thermal conductivity $[\mathrm{W} / \mathrm{mK}], \rho$ is density $\left[\mathrm{kg} / \mathrm{m}^{3}\right]$ and $\mathrm{Cp}$ is specific heat capacity $[\mathrm{J} / \mathrm{kgK}]$.

Equivalent thermal mass used in the BSim reference model was chosen in order to give the same diurnal heat storage as calculated for the transient 2D model with air void simulated as standing still air and is determined with use of Figure 6.

\section{EXPERIMENT}

\section{Experimental investigation of thermal conductivity of hollow-core concrete deck element}

The purpose of experimental investigation of the thermal conductivity of the concrete hollow-core deck element is to estimate which of the modeling assumption for the heat transfer within the air void is closest to the real life conditions.

To measure the thermal conductivity of the deck, a guarded hot box apparatus is used, see Fig. 4.

Presented in Figure 4, the hot box apparatus has a sandwich wall construction made of: $10 \mathrm{~mm}$ MDF plate, $300 \mathrm{~mm}$ EPS and again $10 \mathrm{~mm}$ MDF plate. Metering box has walls constructed as following: 10 $\mathrm{mm} \mathrm{MDF}$ and $40 \mathrm{~mm}$ EPS. 


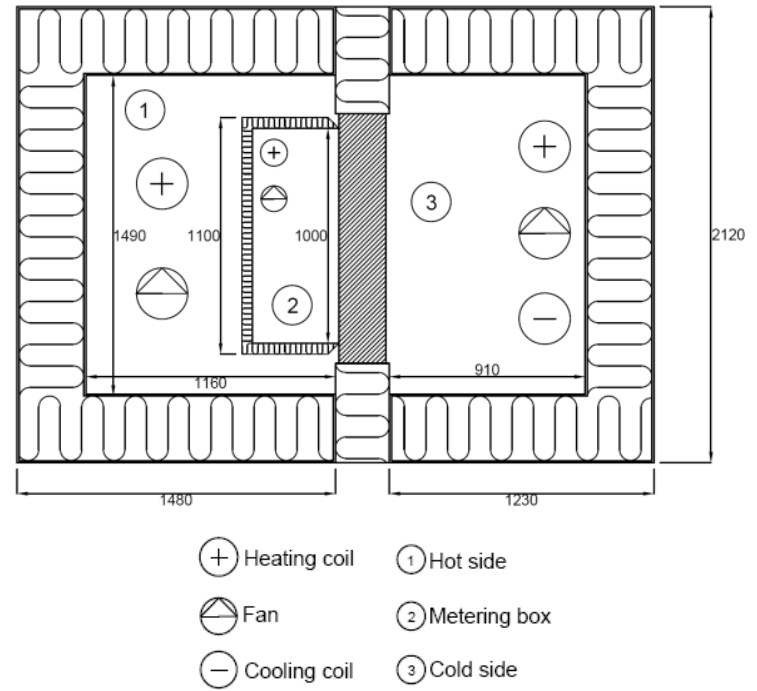

Figure 4 Set up of the deck in the hot box, vertical section.

The concrete deck is inserted between the hot and cold side of the deck. Secondly, the air temperature on the hot and cold side is stabilized, see Figure 5. Additionally, necessary time is taken untill the air temperature between the hot side and the metering zone stabilizes and reaches equilibrium. If this happens, it is known that all energy, (which is measured), provided to the metering box is transfered through the deck to the lower temperature in the cold zone.

In order to calculate the thermal conductivity of the deck, a heat supply to the guarding box was measured by a watmeter. Surface temperature of the deck on the hot and cold side was measured with 6 thermocouples type " $\mathrm{K}$ " on each side of the deck. Temperatures were logged by the data logger Fluke Helios Plus 2287A.

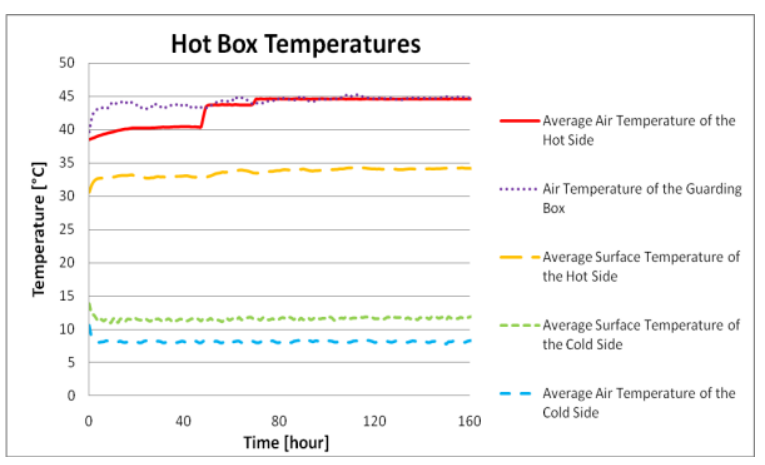

Figure 5 Temperature stabilization in hot box apparatus.

\section{RESULTS}

\section{D heat transfer calculation}

In Table 1, the results of the obtained thermal conductivity for the 2D models from COMSOL simulations are presented, where the results are the average values for the entire deck.
Table 1. Overall heat transfer in the hollow-core

deck modelled as 2D model.

\begin{tabular}{|l|c|}
\hline \multicolumn{1}{|c|}{ HEAT TRANSFER WITHIN AIR VOID } & $\lambda$ \\
\hline \multicolumn{1}{|c|}{$[-]$} & {$[\mathrm{W} / \mathrm{mK}]$} \\
\hline Air void: adiabatic & 0,982 \\
\hline Air void: standing still air & 1,002 \\
\hline Air void: radiation & 1,246 \\
\hline Air void: equivalent conductivity & 1,261 \\
\hline
\end{tabular}

\section{Equivalent thermal conductivity of 1D-one layer models}

The calculated results of thermal conductivity from the simulation analysis of the 2D models presented in Table 1 are exactly the same for equivalent thermal conductivity of the 1D one-layer model. For the 1D tree-layer model, equivalent thermal conductivities of layer $\mathrm{L}_{2}$ with air cavity were calculated according to Equation 1. For the four considered cases, results are presented in Table 2.

Table 2. Heat transfer of the layer with the air void in the hollow-core deck modelled as $1 D$ three-layer model.

\begin{tabular}{|l|c|}
\hline \multicolumn{1}{|c|}{ HEAT TRANSFER WITHIN AIR VOID } & $\lambda^{\mathrm{e}}$ \\
\hline \multicolumn{1}{|c|}{$[-]$} & {$[\mathrm{W} / \mathrm{mK}]$} \\
\hline Air void: insulation & 0,648 \\
\hline Air void: standing still air & 0,666 \\
\hline Air void: radiation & 0,923 \\
\hline Air void: equivalent conductivity & 0,941 \\
\hline
\end{tabular}

Equivalent thermal mass-transient simulation

In order to be able to properly calculate thermal storage with the use of 1D models, it is necessary to find proper thermal mass of the layer with air cavities. This adjustment can be done by varying either material density or specific heat capacity. In this study, it was chosen to vary material density.

In the transient simulation of 1D one-layer model for the study presented in this paper, which is for void simulated as standing still air, the thermal conductivity is taken from Table 1.Then thermal mass is varied from 2100 to $4500\left[\mathrm{~J} / \mathrm{m}^{3} \mathrm{~K}\right]$ by varying material's density, see Figure 6.

In the transient simulation of 1D three-layer model, for the study presented in this paper, which is for void simulated as standing still air, the thermal conductivity is taken from Table 2 . Then thermal mass is varied from 1000 to $2500\left[\mathrm{~J} / \mathrm{m}^{3} \mathrm{~K}\right]$ by varying material's density, see Figure 6.

Results of heat stored for the 1D one-layer model and the 1D three-layer model are compared with heat storage obtained from the 2D simulation analysis. Obtained heat storage for the $2 \mathrm{D}$ analysis is a value and not a function of thermal mass, however, it was depicted in the Figure 6 and 7 as a line. The purpose is to illustrate equivalent thermal mass for the 1D models that will give the same heat storage as from the 2D simulation. Another condition is that in 1D models an equivalent thermal conductivity is applied. 
The vertical blue line represents the decks actual thermal mass which was callculated based on known decks geometry.

A purple dot represents heat storage calculated by the COMSOL but according to the BSim methodology for calculating hollow-core decks, see Equation 3.

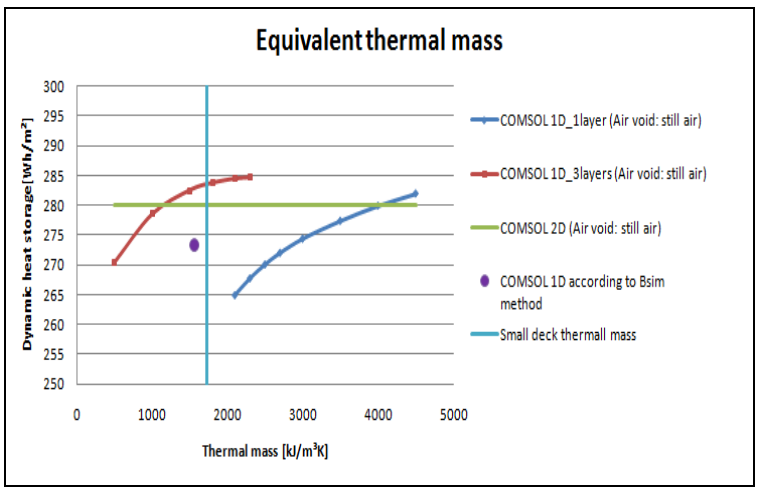

Figure 6 Calculation of equivalent thermal mass.

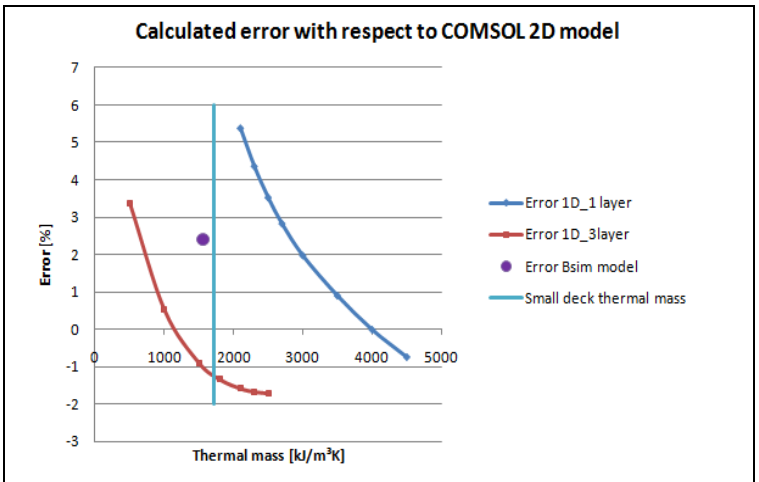

Figure 7 Calculated error of heat storage in function of equivalent thermal mass.

Validation of BSim heat storage calculation methodology for hollow-core concrete deck

Results from the investigation, presented in the previous section, indicate that the 1D three-layer model should be much more accurate than the 1D one-layer model. This also fits with the methodology used in the BSim program.

The reference 2D model of the concrete hollow-core deck element was created in COMSOL Multiphysics to validate heat storage calculation of inhomogeneous construction elements in the BSim program. In this investigation, the simulation of the deck is parameterised by the heat transfer coefficient on the bottom and top surface of the deck and this heat transfer coefficient varies from 4 to 30 $\left[\mathrm{W} / \mathrm{m}^{2} \mathrm{~K}\right]$.

Dynamic heat storage capacity for each parameterised heat transfer coefficient on the surface is calculated as integral of diurnal normal total heat flux.

Results from this investigation are presented in Figure 8 and 9.

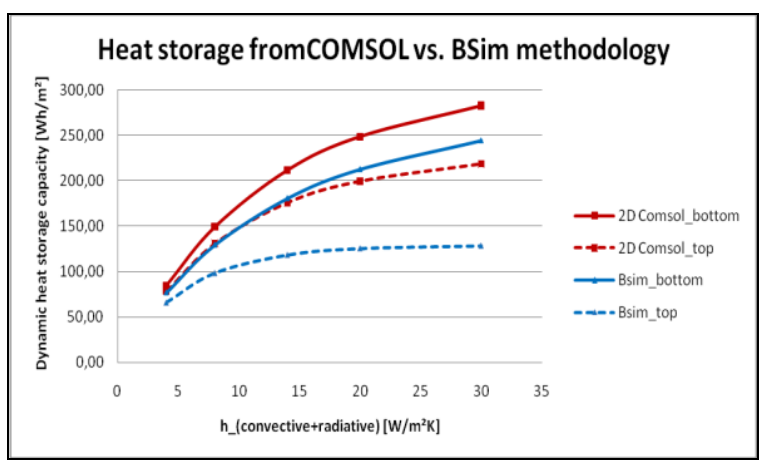

Figure 8 Validation of calculation methodology for heat storage in BSim.

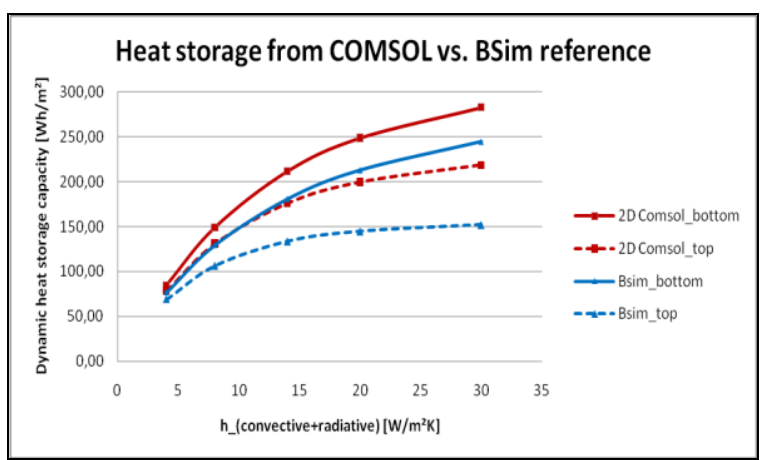

Figure 9 Validation of improved calculation methodology for heat storage in BSim.

Table 3. Calculated difference between heat storage obtained from 2D COMSOL and respectively model "BSim methodology" and "BSim reference."

\begin{tabular}{|c|c|c|}
\hline $\mathbf{H}$ & $\begin{array}{c}\text { ERROR "BSIM } \\
\text { METHODOLOGY" }\end{array}$ & $\begin{array}{c}\text { ERROR "BSIM } \\
\text { REFERENCE" }\end{array}$ \\
\hline$\left[\mathrm{W} / \mathrm{m}^{2} \mathrm{~K}\right]$ & {$[\%]$} & {$[\%]$} \\
\hline 4 & 13,8 & 12,3 \\
\hline 8 & 21,9 & 18,9 \\
\hline 14 & 28,9 & 23,3 \\
\hline 20 & 32,3 & 25,3 \\
\hline 30 & 35,2 & 26,4 \\
\hline
\end{tabular}

Error in Table 3 is given with respect to the results from the 2D COMSOL models and is calculated for sum of heat flux on the bottom and on the top of the deck.

\section{Experimental determination of the thermal conductivity of the hollow-core deck element}

The thermal conductivity was calculated after temperatures had been stabilized, see Figure 5 . Thermal conductivity was calculated for two various temperature setups, see Table 4.

Table 4 Measured thermal conductivity of hollowcore concrete deck.

\begin{tabular}{|c|c|}
\hline SETUP & THERMAL CONDUCTIVITY \\
\hline$[-]$ & {$[\mathrm{W} / \mathrm{mK}]$} \\
\hline $1^{\text {st }}$ & 1,50 \\
\hline $2^{\text {nd }}$ & 1,52 \\
\hline Average: & 1,51 \\
\hline
\end{tabular}




\section{DISCUSSION}

Based on the results from the COMSOL 2D steadystate simulations, it can be observed that for the first two cases, where the air void is represented by adiabatic boundary and respectively air standing still, the obtained thermal conductivity is almost the same. These results are in agreement with expectations because standing still air has very poor thermal conductivity and it can be considered as a good insulator.

The following two cases, where heat transfer within air void in the first case is including surface to surface radiation and in the second equivalent thermal conductivity that includes convection and radiation, gave considerably higher thermal conductivity than the first two cases. These results and the fact that the model with equivalent conductivity gives highest thermal conductivity of the deck comply with the expectations.

The same dependence can be observed for the calculated equivalent thermal conductivity, see Table 2 , for 1D-three layer model.

Results from investigation of equivalent thermal mass presented in Figure 6 indicate that the 1D-three layer model is much more accurate than the 1D-one layer model. For the 1D-three layer model, error with respect to the $2 \mathrm{D}$ model is only $1,2 \%$ and for the $1 \mathrm{D}$ one layer model, it is higher than $7 \%$ at the real decks thermal mass, see Figure 7. Furthermore, results indicate that for the 1D one-layer model, it is necessary to use very high equivalent thermal mass in order to obtain heat storage that is close to the reference $2 \mathrm{D}$ calculation.

As presented in Figure 6, results from the COMSOL 1D model that calculates according to BSim method are in agreement with the COMSOL 1D-three layer model and with the COMSOL 2D model.

It can also be noticed that with respect to the COMSOL models, the BSim methodology is slightly underestimating thermal mass and also heat storage capacity of the hollow-core deck element.

Figure 8 presents results of validation of calculation methodology of dynamic heat storage capacity in BSim. Heat storage is presented as a function of heat transfer coefficient on the surface of the deck. The heat storage was presented separately for the heat flux on the top and on the bottom of the deck. It can be observed that the higher heat transfer coefficient on the surface, the bigger the discrepancy is between BSim and reference 2D COMSOL results. In Figure 9, methodology for presenting results was preserved from Figure 8. It can be observed that results presented in Figure 9 indicate improvement with regards to results presented in Figure 8, however, especially for high heat transfer coefficients. All in all, discrepancies between both presented BSim methods "BSim methodology" and "BSim reference" and COMSOL reference results are high. These results indicate that any simplification of heat transfer in inhomogeneous construction, such as hollow-core slab from 2D to $1 \mathrm{D}$ can result in deformation of results. Moreover, it can be observed that when applying BSim methodology into COMSOL, see Figure 6 and 7, error of calculated dynamic heat storage with respect to detail 2D COMSOL model is of only approximately $2,5 \%$ for heat transfer coefficient on the surface of $8\left[\mathrm{~W} / \mathrm{m}^{2} \mathrm{~K}\right.$ ]. On the contrary, the same BSim methodology but calculated in BSim and compared with detail 2D COMSOL model and for heat transfer coefficient on the surface of $8\left[\mathrm{~W} / \mathrm{m}^{2} \mathrm{~K}\right]$ gives discrepancy of $21,9 \%$, see table 3 .

Finally, results presented in Table 4 are valid for thernal conductivity obtained from the measurements. With respect to simulation results, it can be observed that the model which include heat transfer by coanvection and radiation within the air void is the closest to the results obtained from the experiments.

Based on the obtained results, it can be concluded that BSim methodology for calculating equivalent thermal conductivity for hollow-core deck element might underestimate this parameter and thus underestimate dynamic heat storage of this type of building construction.

\section{CONCLUSION}

The simulation results indicated that 1D-three layer model is better aproximation of the hollow-core deck than 1D-one layer model.

The validation of heat storage calculation ín BSim indicated that disagreement with reference COMSOL model is high, see Figure 8 and 9. Furthermore, the high disagreement is not due to inaccurate simplification of the 2D inhomogeneous hollow-core deck element into 1D model as presented in Figure 6 and 7 but due to other numerical reasons that need to be clarified.

It can be also observed that the disagreement of the heat storage is mainly due to the discrepancy of the heat flux on the upper surface of the deck. This can be explained by the air void closer location to the upper surface of the deck. The discrepancy would be minimized if the deck was simulated with the floor. Therfore, it is recommended to take a real design of the internal flooring into consideration. As a consequence of the revealed results, a closer look into the heat storage calculation mothod in BSim will be given.

Finally, when comparing obtained thermal conductivity of the hollow-core deck for various modeling assumptions regarding heat transfer in the air void, it can be observed that the overall deck thermal conductivity varies from 0,98 to 1,26 $[\mathrm{W} / \mathrm{mK}]$. This variation is rather substantial and indicates that proper modeling of the heat transfer within the hollow-core deck element might be crucial 
to properly calculate the heat storage in this type of building construction element.

To sum up, the discrepancy between measured and simulated thermal conductivity can not only be due to various approaches to modeling heat transfer within closed air void but also due to different thermal counductivity of bulk concrete that was assumed in the simualtion models and that is in the deck used in the experiment. Moreover, the simulation model does not include steel reinforcement that is located in the deck and which should have an impact on the overall thermal conductivity as it has larger thermal conductivity than pure concrete.

\section{REFERENCES}

Gandhidasan P., Ramamurthy K. N. 1985. Thermal Behaviour of Hollow-Cored Concrete Slabs, Applied Energy 19 pp. 41-48.

Scarpa M., Grau K., Bjarne W.O. 2009. Development and validation of a versatile method for the calculation of heat transfer in water-based radiant systems. Building Simulation.

Zhang Z.L., Wachenfeldt B.J. 2009. Numerical study on the heat storing capacity of concrete walls with air cavities. Energy and Buildings 41 pp.769-773.

DS/EN ISO 10077-2, 1.udgave 2004-01-23, Thermal performance of windows, doors and shuttersCalculation of thermal transmittance-Part2: Numerical method for frames. 



\title{
Dynamic heat storage and cooling capacity of a concrete deck with PCM and thermally activated building system
}

\author{
Michal Pomianowski*, Per Heiselberg, Rasmus Lund Jensen \\ Department of Civil Engineering, Aalborg University, Sohngaardsholmsvej 57, Aalborg, Denmark
}

\section{A R T I C L E I N F O}

\section{Article history:}

Received 22 February 2012

Received in revised form 22 June 2012

Accepted 8 July 2012

\section{Keywords:}

Phase change material

Latent heat storage

Thermally activated building system

Energy efficiency

Dynamic heat storage

Concrete deck element

Cooling capacity

\begin{abstract}
A B S T R A C T
This paper presents a heat storage and cooling concept that utilizes a phase change material (PCM) and a thermally activated building system (TABS) implemented in a hollow core concrete deck. Numerical calculations of the dynamic heat storage capacity of the hollow core concrete deck element with and without microencapsulated PCM are presented. The new concrete deck with microencapsulated PCM is the standard deck on which an additional layer of the PCM concrete was added and, at the same time, the latent heat storage was introduced to the construction. The challenge of numerically simulating the performance of the new deck with PCM concrete is the thermal properties of such a new material, as the PCM concrete is yet to be well defined. The results presented in the paper include models in which the PCM concrete material properties, such as thermal conductivity, and specific heat capacity were first calculated theoretically and subsequently the models were updated with the experimentally determined thermal properties of the PCM concrete. Then, the heat storage of the decks with theoretically and experimentally determined thermal properties were compared with each other.

Finally, the results presented in the article highlight the potential of using TABS and PCM in a prefabricated concrete deck element.
\end{abstract}

(c) 2012 Elsevier B.V. All rights reserved.

\section{Introduction}

The concept developed in this article presents the dynamic heat storage potential of combined high latent heat storage, due to the phase change material (PCM) and the thermally activated building system (TABS). The two technologies are combined in a prefabricated concrete deck element, see Figs. 1 and 6, in order to investigate their potential to: decrease energy use for cooling in the building, shift the high indoor temperature peaks to the hours when the building is not occupied, improve indoor thermal comfort by flattering the diurnal temperature variations and determine limitations and challenges, if any.

The advantage of PCM is its very high latent heat storage capacity. On the other hand, PCM has very low thermal conductivity and not that high density. The combination of such material with a concrete material of high density and a rather high thermal conductivity might result in a new technology for energy storage in buildings. TABS is a system that can provide heat and cold to a room and, at the same time, activate the thermal mass of the building. The advantage of the system is its low operation temperature

\footnotetext{
* Corresponding author. Tel.: +45 99407234; fax: +45 99408552.

E-mail addresses: map@civil.aau.dk (M. Pomianowski),ph@civil.aau.dk (P. Heiselberg), rlj@civil.aau.dk (R.L. Jensen).
}

close to indoor temperatures. The disadvantage is its slow response to the cooling or heating need.

The combination of the two technologies might result in an increase of the heat storage capacity of the building interior and, at the same time, in a possibility to actively respond to increased heating or cooling needs that cannot be covered solely by the passive heat storage.

The TABS concept started in the 1990s in Switzerland and involved an idea of activating the thermal mass of concrete slabs located between each storey of the building. As a consequence, when circulating hot or cold water in the slabs, the building can be respectively heated or cooled. TABS was investigated in many theoretical studies and was implemented in a number of full scale projects, presented for example in [1]. Additionally, laboratory tests and theoretical studies have indicated that this technology can be energy efficient and has a significant potential to reduce operational costs for the cooling/heating of buildings and provide an appreciated indoor thermal comfort [2].

There is also a substantial amount of research focused on PCM application in the refurbished light weight buildings and light weight constructions in order to increase thermal mass of the building $[3,4]$. There are also numerous publications on thermal properties of various PCMs, but in the pure state [5-7].

The development of the microencapsulation technique of paraffin, which allows its direct integration into the building materials, 


\begin{tabular}{|c|c|}
\hline \multicolumn{2}{|c|}{ Nomenclature } \\
\hline \multicolumn{2}{|c|}{ Symbols } \\
\hline VHC & volumetric heat capacity $\left[\mathrm{J} /\left(\mathrm{m}^{3} \mathrm{~K}\right)\right]$ \\
\hline$\rho$ & density of material $\left[\mathrm{kg} / \mathrm{m}^{3}\right]$ \\
\hline Cp & specific heat capacity $[\mathrm{J} /(\mathrm{kg} \mathrm{K})]$ \\
\hline I & thermal inertia $\left[\mathrm{J} /\left(\mathrm{m}^{3} \mathrm{~K}\right)\right]$ \\
\hline $\mathrm{Cp}(T)$ & $\begin{array}{l}\text { specific heat capacity in function of temperature } \\
{[\mathrm{J} /(\operatorname{kg~K})]}\end{array}$ \\
\hline$X$ & weight ratio $(0-1)$ \\
\hline$\lambda$ & thermal conductivity [W/mK] \\
\hline \multicolumn{2}{|c|}{ Abbreviations } \\
\hline PCM & phase change material \\
\hline TABS & thermally activated building system \\
\hline DSC & differential scanning calorimetry \\
\hline DTA & differential thermal analysis \\
\hline
\end{tabular}

e.g. such as concrete or plaster, is a relatively new technology that has not received much attention yet. Therefore, few research studies on mixtures of concrete and microencapsulated PCMs are available. On the other hand, well developed numerical models that can calculate construction elements with PCM $[8,9]$ are already available.

Although an extensive amount of publications on TABS and PCM can be found, these two technologies are usually investigated as separate technologies. The exceptional development of the prototype for the thermally activated plaster ceiling panel with PCM was proposed by [10]. The developed panels are a composite of microencapsulated PCM mixed with gypsum. In these panels, the capillary tubes are integrated to circulate water and by that activate the deck/discharge heat stored by the deck. The paper starts with the conceptual design, continues with the numerical optimization of the model and finishes with the initial numerical and experimental investigation of the developed panel performance. The investigation highlights that the panels need to integrate highly conductive aluminium fins in order to overcome the discovered low thermal conductivity of the new PCM gypsum composite and to be able to store sufficient amount of heat. Moreover, although the paper presents the effective specific heat capacity in function of temperature of the new composite of the PCM gypsum, it does not explain how that property was determined. The outcome of the simulation indicated that, in a typical summer week, the developed panel can maintain an indoor temperature within comfort range of a standard office room. The experimental investigation indicated that the panel was able to store $290 \mathrm{Wh} / \mathrm{m}^{2}$ during the $7.5 \mathrm{~h}$ of

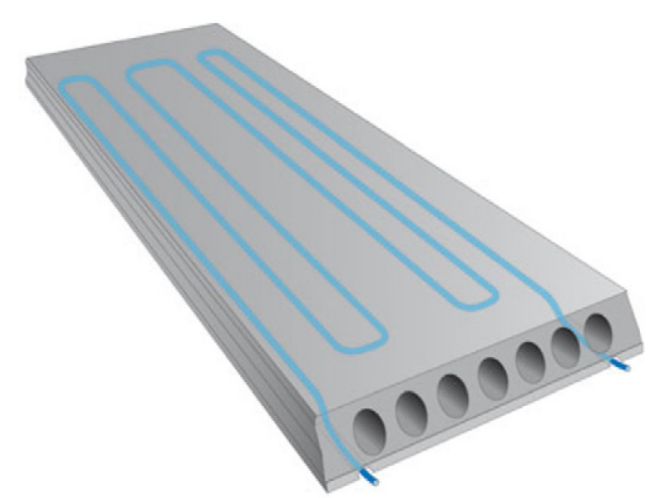

Fig. 1. ThermoMax - Spæncom: prefabricated concrete ceiling deck element with integrated water pipes. the melting process which was less than the expected $320 \mathrm{Wh} / \mathrm{m}^{2}$. The lower heat storage was explained by a lower quantity of incorporated paraffin than initially designed and by a lack of complete control of the new composite density during the mixing and filling in the panel process. The research presented in [11] takes into account the challenge of measuring the specific heat capacity of self-compacting concrete with microencapsulating PCM, but the proposed calculation methodology simplifies the problem and the experimental set-up disregards the influence of the surrounding temperature on the heat transfer within the sample. This subject is further discussed in [12].

The study presented by [13] investigates the use of PCM in concrete floors. Four chambers of the same size are constructed; two with PCM concrete floor and two with ordinary concrete floor. The only heat source in each chamber is the solar irradiation through the windows. In the study, the PCM in the floor is activated by direct sun irradiation, however in practice, it would be very unusual to find concrete floor without any kind of covering such as wood, polyvinyl or tiles that would protect the PCM from thermal activation. Therefore, although the research indicates that this technology could save some energy and decrease the temperature fluctuations in the houses, it would be very difficult to implement it on a broader scale in practice. Similar research to the one presented in [13] can be found in [14]. The proposed experimental set-up consists of two identical cubicles made of concrete where one is built of conventional concrete and one of the new concrete with admixed $5 \mathrm{wt} \%$ of microencapsulated PCM. The results obtained revealed a decrease in temperature fluctuation in the room with PCM concrete and a shift of the temperature peak in the wall of $2 \mathrm{~h}$. On the other hand, neither [13] nor [14] clearly distinguished how much of the decrease of temperature fluctuation is due to the reduced thermal conductivity and how much is due to the increase of the heat storage capacity of the concrete with PCM. What is more, the diurnal indoor temperature fluctuates from very low to very high temperatures in both cases, which would not be acceptable by any means in a real building, and therefore the energy accumulation would be lower in practice than in the presented experimental set-ups.

Due to the fact that the extensive initial work to the study presented in this paper has been done in [12,15-17], the paper includes many cross-references to these four studies. However, to make this article understandable and reader-friendly, some of the critical assumptions and methodologies will be repeated and presented yet again.

In the presented investigation, the numerical model of the hollow core concrete deck element initially developed and presented in [15] is updated with the new, measured thermal properties of the new concrete composite mixed with microencapsulated PCM. The experimental investigation of the thermal conductivity of the PCM concrete samples, by use of the standard hot plate apparatus, was proposed in [16]. The methodology of measuring the thermal conductivity of the PCM concrete is summarized and shortly presented in Section 2.3 and the key results are presented in Section 2.5. The results of the experimental investigation revealed that the theoretical calculation of the thermal conductivity based on weight average method gives much higher results than the ones obtained from the experiments. The experimental procedure to determine so-called "effective heat capacity" of PCM concrete in function of temperature was proposed and investigated in [12]. The developed methodology from [12] to experimentally determine $\mathrm{Cp}(T)$ is shortly presented and summarized in Section 2.4. In [12], various methods to calculate $\mathrm{Cp}(T)$ were also found to give various results. Based on the conclusion made in [12], it seems that the "inverse method" should provide the most accurate results, but on the other hand, the "numerical simple method" is still accurate and provides results that could be implemented more easily and give 
better stability of the numerical models developed in the study presented in this paper. Therefore, in the research presented in this paper, the results obtained from the "numerical simple method" will be used. Moreover, findings from the numerical study on the heat transfer in the inhomogeneous hollow core concrete deck elements presented in [17] were taken into consideration when the models presented in this study were developed. Presented in [17] is the numerical investigation of the four various assumptions to the heat transfer within the air hollow in the air hollow core and how they influence the total thermal conductivity of such an inhomogeneous construction. In [17], the air void is modelled as:

- adiabatic boundary;

- air in the void is given thermal properties, however air is standing still and neither convection nor radiation is considered;

- air cavity is given surface to surface radiation boundary;

- air in the void is given equivalent thermal conductivity calculated based on [18] which considers heat transfer by convection and radiation in closed voids.

Concurrently, the experimental measurement of the thermal conductivity of the concrete hollow core deck was performed in the guarded hot box apparatus. The investigation indicated that the air void simulated with equivalent thermal conductivity that includes convection and radiation gives the closest results of total thermal conductivity determined experimentally with use of hot box apparatus. Therefore, in this investigation this approach to simulate heat transfer within air void was implemented in the models.

Firstly, this paper presents the concept development of the integrated PCM and TABS in the prefabricated hollow core slab element. Secondly, the developed concept is transferred to the COMSOL Multiphysics program. The initial findings regarding the best location of the PCM concrete presented in [15] will be elaborated. The boundary assumptions to calculate the models will be illustrated and elucidated. Consequently, the theoretically and experimentally determined thermal properties of concrete with various amounts of PCM will be compared with each other. What is more, the diurnal dynamic heat storage capacities are compared for the passive approach for the theoretically and experimentally determined thermal properties of PCM concrete. After this, the same passive models are thermally activated for $24 \mathrm{~h}$ /day with use of embedded water pipes. The cooling power of the thermally activated approach is compared between the reference deck without PCM and the deck with the theoretically and experimentally determined thermal properties of the PCM concrete material.

\section{Methodology}

\subsection{Development of specification of PCM and TABS deck element}

If PCM is directly incorporated in the construction material such as concrete, it can be located either in floors, walls, ceilings or in various combinations of these in the building. As stated in the previous section, the floor would most likely give the best results since this is the construction element that has the most direct solar irradiation exposure. However, floors are usually obscured with a miscellaneous covering that would protect PCM concrete from the direct solar irradiation. Walls cover a relatively large area and are also a strong candidate for incorporating PCM. However, they are often hidden behind furniture, and therefore the final effect of PCM would be limited and difficult to predict. If PCM is located in the ceiling, then the risk of having the element be hidden is minimized. On the other hand, this solution would require more cautious architectural design since a suspended ceiling would not be recommended in that case.
In this study, the development and design of the combined PCM and TABS concrete deck element was based on the existing and commercially introduced product called ThermoMax, see Fig. 1. Yet, ThermoMax is produced as deck made solely of concrete - without PCM.

The advantage of using the prefabricated elements is that the quality is repeatable and the thermal properties of PCM concrete in these elements can be accurately predefined. As a consequence, the performance of these elements can be simulated in a building simulation program where the indoor climate and the energy use can be calculated and predesigned.

\subsection{Sensitivity analysis of location and percentage of integrated $P C M$}

As presented in [15], the best exploitation of the latent heat storage is when the layer of the PCM concrete material is located on the very bottom surface of the deck. The initial investigation also revealed that the PCM concrete layer should not be thicker than approximately $3 \mathrm{~cm}$ otherwise the PCM in the deeper layers is not sufficiently activated and cannot contribute to the heat storage of the concrete deck element. This thickness, however, will have to be revised in this article since the theoretically determined thermal properties vary significantly from the experimentally determined.

The advantage of only casting a PCM concrete in the thin layer on the bottom of the deck is that the strength and other physical properties of the deck will be kept unchanged since all reinforcement and bearing properties would not be affected by the PCM presence in the concrete.

\subsection{Thermal conductivity measurement of PCM concrete}

Measurements of thermal conductivity of PCM concrete were conducted with use of a hot plate apparatus type EP500 fabricated by Lambda Messtechnik. The apparatus was upgraded to the version which allows measurements of concrete samples of thermal conductivity up to $2 \mathrm{~W} / \mathrm{mK}$.

The samples are inserted between a hot (upper) plate and a cold (lower) plate with dimensions $50 \mathrm{~cm} \times 50 \mathrm{~cm}$. The upper plate is lowered with the given pressure until the pressure set point is reached. The measuring area is the innermost square of dimensions $15 \mathrm{~cm} \times 15 \mathrm{~cm}$, and the rest is a frame which should be made of a highly insulating material. In the experiments with concrete samples, it was discovered that the frame made of elastic foam gives the best result repeatability. Additionally, the apparatus is equipped with perimeter zones which surround the measured sample and which control the temperature according to an embedded algorithm. Finally, a 1D heat flow is achieved, from the hot to the cold plate, within the measured sample. One set of experiments includes three measurements at three various mean temperatures. In this investigation, mean temperatures of 10,20 and $40^{\circ} \mathrm{C}$ were chosen for measurements. Moreover, the temperature difference between the hot and the cold plate is set to be $15^{\circ} \mathrm{C}$ in all series of measurements. In that manner, one measurement $\left(10^{\circ} \mathrm{C}\right)$ is done for the temperatures across the sample below PCM melting point, one measurement $\left(20^{\circ} \mathrm{C}\right)$ is done for the temperatures across the sample within PCM melting point and one measurement $\left(40^{\circ} \mathrm{C}\right)$ is done for the temperatures across the sample above PCM melting point. However, measurements revealed that thermal conductivity of PCM concrete material is almost independent of the temperature within the investigated temperature range.

In order to ensure a good attachment between the apparatus plates and the measured samples, a thin layer of ultrasound gel should be applied on the sample surfaces attached to the plates of the hot plate apparatus. The complete methodology and results 
of measured thermal conductivity of PCM concrete samples are presented in [16].

\subsection{Experimental methodology to determine specific heat capacity of PCM concrete}

As stated in $[7,11,19]$, the PCM samples or samples with PCM have to be of a substantial size in order to represent the bulk material used in practice. The PCM concrete samples can have aggregate particles up to $8 \mathrm{~mm}$ in size. This means that in the case of concrete materials, it is the aggregate size that determines whether or not a sample is representative. Concrete samples of only few milligrams have to be considered as inhomogeneous materials and secondly, as not representative samples, and therefore neither Differential Thermal Analysis (DTA) DTA nor Differential Scanning Calorimetry (DSC) methodology, cannot be used. Even the T-history method that allows measurements of bigger cylindrical samples is not applicable. First of all, in order to treat concrete samples as semi-homogeneous, the diameter of that cylindrical sample would have to be a couple of centimetres at least, and second of all, in order to fulfil the criteria of $\mathrm{Bi}<0.1$ (the temperature distribution can be considered as uniform), the sample would have to be very long. This would make the experimental set-up unfeasible. Nevertheless, if a sample is measured by a DSC method or other method in order to define material specific heat capacity, the focus has to be put on accurate temperature and heat flow measurements. For the sake of good reliable results, it is also crucial to prepare correct samples of representative dimensions in order to overcome the challenge with inhomogeneity. Moreover, the measured samples have to be under dynamic temperature load and both heat flux provided to the sample and the temperature of the sample have to be registered in time.

In [12] is a complete description of the novel proposed experimental methodology to determine specific heat capacity, and in this section only the essential summary of activities done in [12] will be presented.

The experimental set-up to determine $\mathrm{Cp}(T)$ of the PCM concrete consists of a modified hot plate apparatus and specially prepared concrete samples with PCM. For the purpose of the experiments, the standard hot plate apparatus was modified in order to be able to conduct dynamic thermal experiments. The control system of the hot plate apparatus was upgraded with the new mode enabling definition of a dynamic temperature load. A steady temperature at $18^{\circ} \mathrm{C}$ on upper and lower plate is defined in the dynamic mode first. This steady state is maintained for at least $5 \mathrm{~h}$ in order to ensure that the whole sample reaches the same temperature. Afterwards, the sample is heated symmetrically by both the upper and lower plate from $18^{\circ} \mathrm{C}$ to $32^{\circ} \mathrm{C}$ over $10 \mathrm{~h}$, and then the temperature is stabilized at $32^{\circ} \mathrm{C}$. For the designed temperature range and heating time, the temperature change within dynamic mode is only $0.023^{\circ} \mathrm{C} / \mathrm{min}$.

In each measured sample, 9 thin thermocouples measuring the vertical temperature profile in the sample are evenly distributed. A very thin, square-shaped heat flux film of dimensions $8 \mathrm{~cm} \times 8 \mathrm{~cm}$ manufactured by Captec is then positioned in the middle of the top surface of the sample. The prepared sample is surrounded with an elastic insulating frame and an upper "hot" plate is lowered until it reaches the top of the concrete sample. The dynamic test is triggered after the last visual inspection is performed to verify if the sample is attached properly to the lower and upper plate of the apparatus. At the same time, logging process of signals from the thermocouples and heat flux sensor film is started with the use of Helios Data logger type 2287A.

The measured temperature and heat flux results are used to develop four various methods to calculate specific heat capacity of PCM concrete in function of temperature ("simple method", "numerical simple method" and "inverse method"). The calculation methodologies of all three proposed methods are presented fully in [12]. As stated in [12], "simple method" has its shortcomings and is therefore not suggested for present investigation. The "numerical simple method" and "inverse method" give very similar results and are considered as more reliable than the "simple method". However, although the "inverse methodology" should provide the most accurate results the results of the "numerical simple method" are still very accurate, are much easier to implement in the present study and give better stability of numerical model than the results of the "inverse method". Therefore the results from "numerical simple methodology" were chosen to be implemented in the models developed in this investigation.

\subsection{Thermal properties of combined PCM and concrete material: theoretical vs experimental}

In order to be able to calculate the dynamic heat storage capacity of any material, three parameters have to be known: density- $\rho$, thermal conductivity $-\lambda$ and specific heat capacity $-\mathrm{Cp}$.

The initial theoretical calculation of the thermal properties (thermal conductivity and specific heat capacity) of the new composite of the PCM concrete presented in [15] are based on weight average calculation of the concrete and PCM. The initial theoretical calculations utilizing weight average method, see Eqs. (1) and (2), have been used due to lack of experimental data of PCM concrete material.

$\mathrm{Cp}_{\mathrm{PCM}-\text { concrete }}(T)=\mathrm{CP}_{\mathrm{PCM}}(T)_{\mathrm{DSC}} \times X+\mathrm{Cp}_{\text {concrete }} \times(1-X)$

$\lambda_{\mathrm{PCM} \text {-concrete }}=\lambda_{\mathrm{PCM}} \times X+\lambda_{\text {concrete }} \times(1-X)$

The results of the theoretical calculation are depicted respectively in Figs. 3-5. The calculation of the theoretical specific heat capacity for combined concrete and PCM is based on the results of $\mathrm{Cp}(T)$ obtained from Differential Scanning Calorimetry (DSC) of pure microencapsulated PCM type DS 5040X from BASF. Due to the fact that PCM specific heat capacity varies with its temperature, the same was assumed analogically for the combined concrete and PCM material.

To experimentally determine the thermal properties of the PCM concrete material, special samples with $0 \mathrm{wt} \%, 1 \mathrm{wt} \%$, $4 \mathrm{wt} \%$ and $6 \mathrm{wt} \%$ (by weight) of microencapsulated PCM type DS 5040X from BASF have been cast. The procedure and design of the casts and as well the experimental methodology to determine thermal conductivity and specific heat capacity can be found in $[12,16]$ respectively and a short summary of the measurements methodology was presented in paragraphs 2.3 and 2.4 of this paper. The results of the experimentally determined thermal conductivity are presented in Fig. 3 and experimentally determined specific heat capacity results (by the numerical simple method) are presented in Figs. 4 and 5.

The density of the samples is determined by the direct measurements of the cast samples and is depicted in Fig. 2.

The effective specific heat capacity of the reference sample that does not contain PCM, which also means that it only reflects sensible heat storage properties, was measured at approximately $785 \mathrm{~J} /(\mathrm{kg} \mathrm{K})$. The results for the $1 \mathrm{wt} \%$ PCM concrete are not presented as the measurements on this sample gave uncertain results. For that reason, further investigation presented in this article will consider only the $0 \mathrm{wt} \%, 4 \mathrm{wt} \%$ and $6 \mathrm{wt} \%$ PCM concrete material. Moreover, it was discovered that with the presently available superplasticizers the concrete samples with PCM higher than $6 \mathrm{wt} \%$ showed bad workability and therefore will not be taken into consideration for further investigation.

Finally, there is significant drop of density and thermal conductivity between the reference sample and the sample with $1 \mathrm{wt} \%$ of 


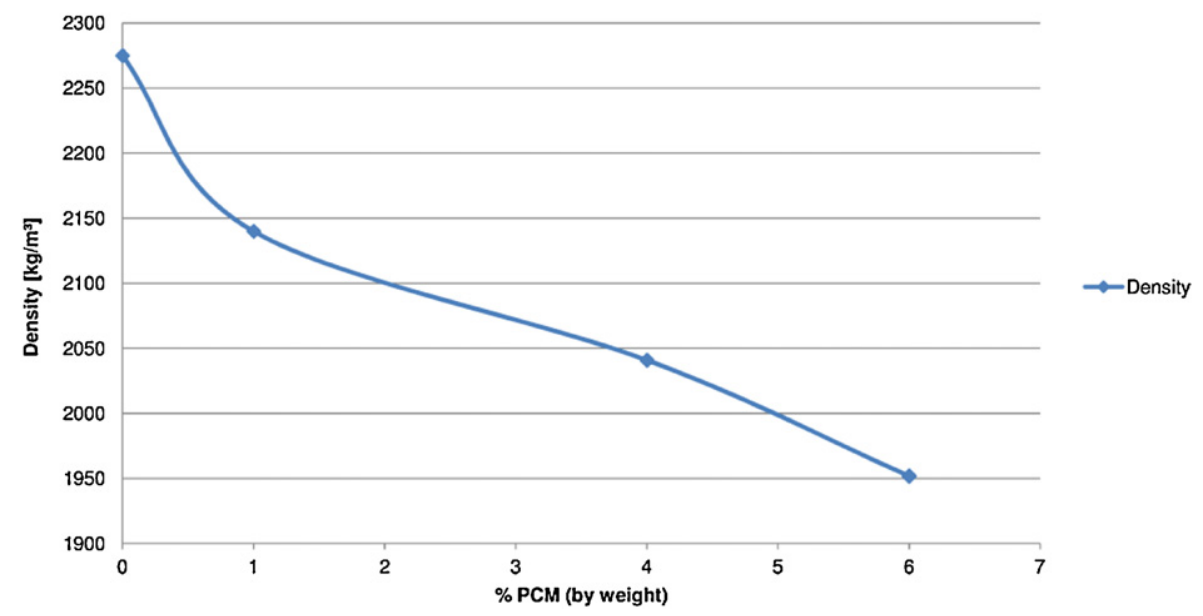

Fig. 2. Density of the PCM concrete samples.

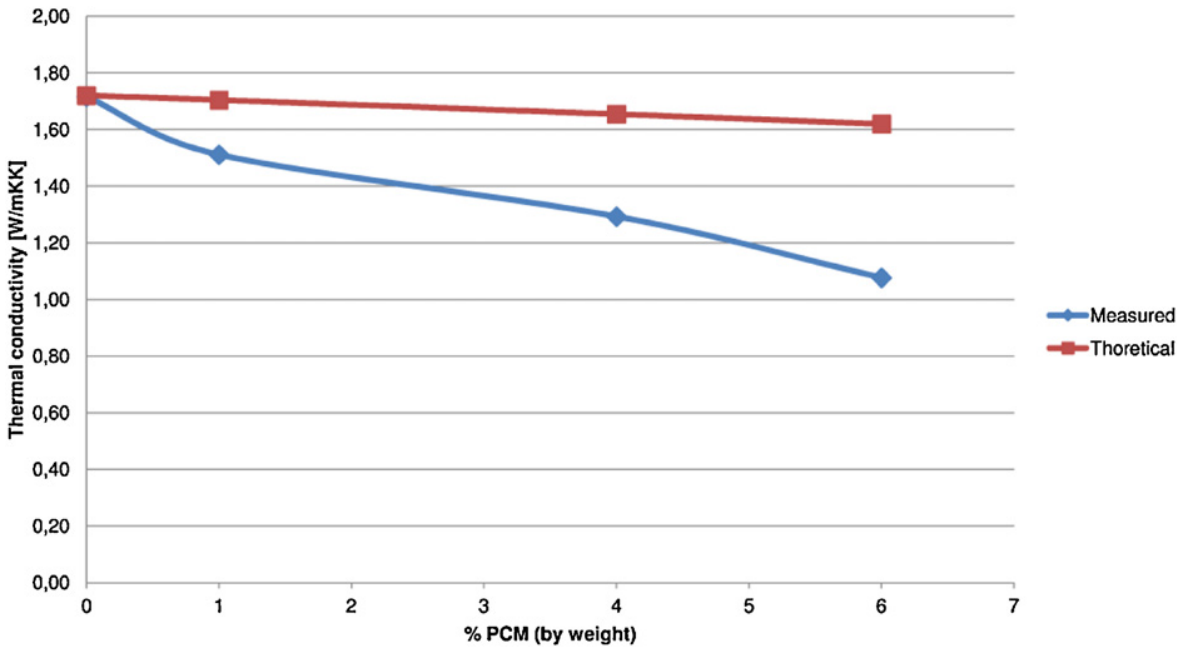

Fig. 3. Thermal conductivity of PCM concrete samples.

PCM. This drop is due to a higher air content in the samples with PCM than the one without PCM. For $0 \mathrm{wt} \%, 1 \mathrm{wt} \%, 4 \mathrm{wt} \%$ and $6 \mathrm{wt} \%$ PCM, the air content was measured at $1.4 \%, 4.9 \%, 4.6 \%$ and $3.8 \%$ respectively.

\subsection{Boundary condition}

For the purposes of this study, the hollow core deck simulated in the COMSOL Multiphysics is simplified to 2D model and a section

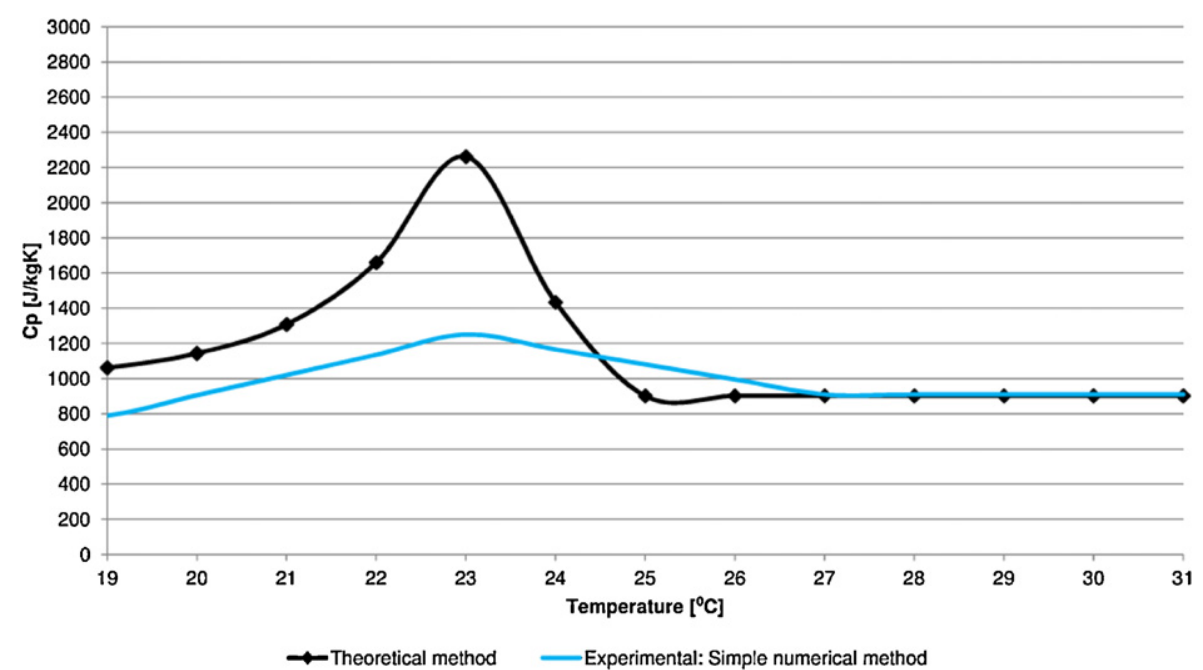

Fig. 4. Theoretically and experimentally determined effective specific heat capacity in function of temperature for 4 wt\% PCM concrete sample. 


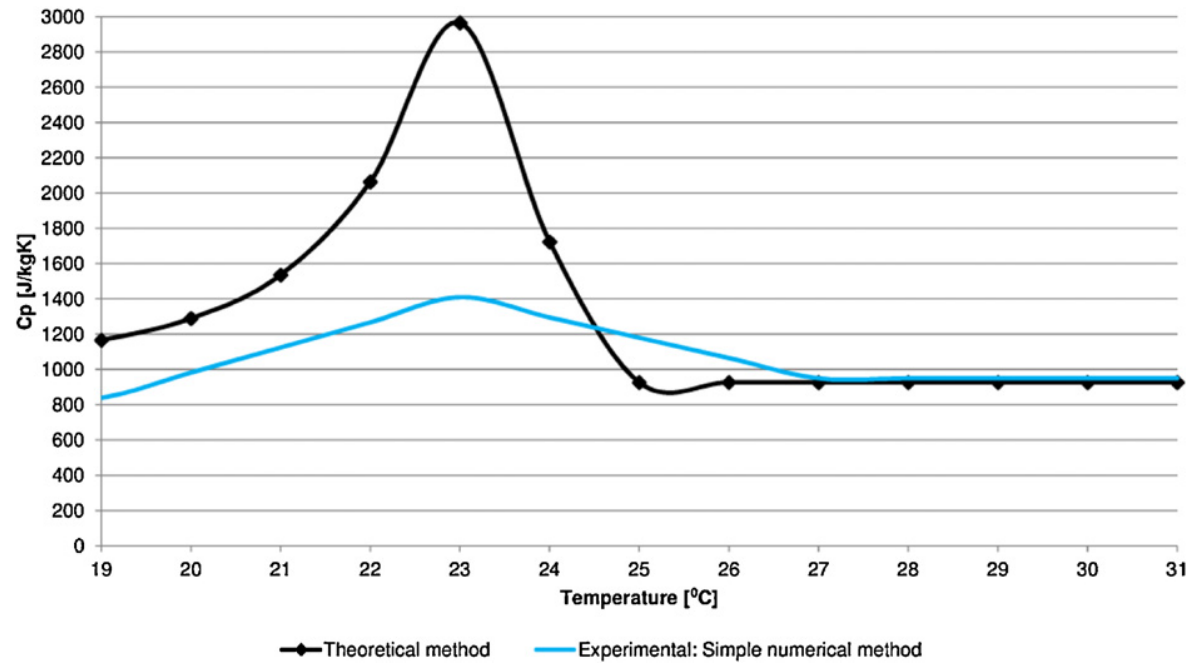

Fig. 5. Theoretically and experimentally determined effective specific heat capacity in function of temperature for 6 wt\% PCM concrete samples.

with a pipe and a hollow air core, see Fig. 6 . Due to the fact that in the real deck, vertical boundaries of such model are facing almost the same sections, these boundaries are defined as symmetric (adiabatic). Furthermore, it is assumed that the temperature on the upper and lower surface fluctuates with a diurnal sinusoidal pattern between $20^{\circ} \mathrm{C}$ and $26^{\circ} \mathrm{C}$ in order to imitate indoor temperature condition in the building. Moreover, combined heat transfer coefficient for convection and radiation, which in this study is varied between 4 and $30 \mathrm{~W} /\left(\mathrm{m}^{2} \mathrm{~K}\right)$, is applied on the upper and lower surface. Also, when the diurnal dynamic heat storage capacity is calculated, which means that the deck is passive, water in the pipe is only defined as a material and no boundary is applied. However, when the deck is simulated as thermally activated, the pipe perimeter is defined as heat flux boundary condition, and the heat transfer coefficient on the internal surface of the pipe is defined at $15,000 \mathrm{~W} /\left(\mathrm{m}^{2} \mathrm{~K}\right)$. That high heat transfer coefficient was chosen to imitate the temperature boundary condition and to obtain the same heat flux effect as from temperature boundary type. There are two purposes of choosing the heat flux boundary condition instead of simply applying a temperature boundary. First, is to be able to switch TABS on and off in selected time segments, which is not possible in a temperature boundary condition. Although in this paper the TABS is modelled as constantly active in the scope of future activities, it is expected to model decks with various activation schedules. And to be able to compare models, the compatibility of model boundary condition has to be preserved. Second reason is to always simulate maximum TABS cooling performance at defined water temperature, and this is done for a high heat transfer coefficient that result in the same cooling capacity as would be obtained if temperature boundary were applied to represent water pipe.

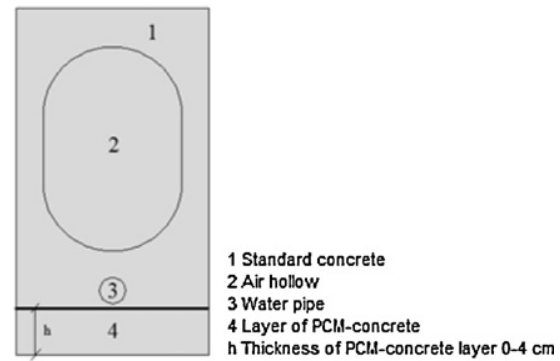

Fig. 6. Section of the hollow core concrete deck element with TABS and PCM.
In this study, the temperature of the water is defined at $16^{\circ} \mathrm{C}$. Finally, the heat transfer within the air void is given as an equivalent thermal conductivity that combines the heat transfer due to convection and radiation, and this was calculated according to [18]. The broader analysis on the heat transfer within the hollow core concrete decks was published in [17] and is shortly summarized in the introduction in this paper. The listed boundary conditions are conserved for all simulated models considered in this study. The conservation of the boundary condition allows for comparison of results between all models.

\subsection{Thermal activation of the hollow core deck element}

Although the TABS concept can be used for both heating and cooling, in this study focus is put solely on its cooling performance. The research on TABS presented in [20] indicated that the cooled ceiling temperatures are not an issue with respect to the normative requirements for the temperature asymmetry of the construction elements. However, the limit for cooled ceiling temperature is connected with the risk of condensation on the construction elements. The lowest permitted temperature of the cooling agent in the radiant systems depends on the relative humidity of the indoor air but it usually does not drop below $16^{\circ} \mathrm{C}$, which is the limit of surface temperature for buildings equipped with a dehumidification system. In the present study, this temperature was chosen to investigate the dependency of the cooling performance on the amount of incorporated PCM and thickness of the layer of PCM concrete.

Moreover, in this study, the centre of the pipe with water is $50 \mathrm{~mm}$ from the bottom surface of the hollow core slab. The diameter of the water pipe is set to $20 \mathrm{~mm}$ and spacing between pipes is $150 \mathrm{~mm}$.

The study is carried out for full-time control mode meaning TABS are in operation constantly $24 \mathrm{~h}$ a day, see Fig. 7. The purpose of the present study was to investigate how the presence of PCM in the deck will affect the maximum cooling capacity of the deck which is always in operation and in which the cooling agent temperature is close to the lowest possible.

\subsection{Dynamic heat storage capacity}

Due to the cyclic temperature on the boundary of the deck, the model reaches periodic steady-state after a certain time. The length of this time depends on the geometry of the model, thermal properties of the model, amplitude and period of the cyclic boundary 


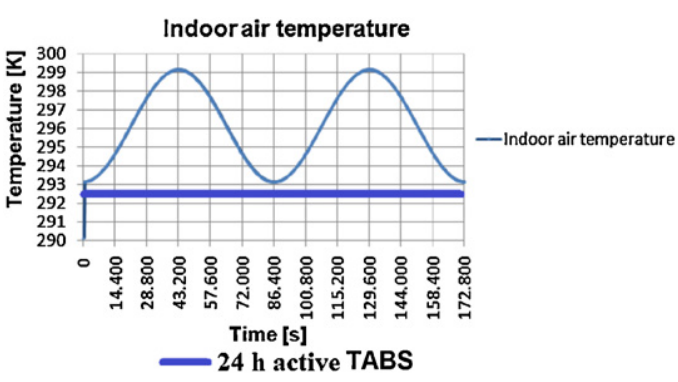

Fig. 7. TABS activation time.

condition. When the model reaches this periodic steady-state, it means that the amount of the energy transferred to the model during the charging period is equal to the amount of energy taken from the model during its discharging. The dynamic heat storage capacity is the energy/heat stored in the model during either charging or discharging period. The dynamic heat storage capacity can be also calculated on the chosen boundary of the model. Then it is calculated as the total normal heat flux transferred to or from the model during either charging or discharging period but only through that chosen boundary.

In the developed model of the concrete hollow core deck element, the cyclic temperature imitating the indoor temperature fluctuations is applied on the top and the bottom of the deck. However, it is only interesting to calculate the heat stored in the deck due to the heat transfer through the bottom surface of the deck. Firstly, the top surface of the deck would in practice be covered with various type of flooring resulting in various heat transfer to the deck on its top surface. Secondly, the construction of the deck is not changing on the top, and the layer of the various PCM concrete is applied only on the bottom of the deck. This means that the total heat storage of the deck will vary only due to the various PCM concrete layer thickness and amount of PCM in that layer.

\section{Results}

Firstly, the volumetric heat capacity and thermal inertia of the standard concrete material and theoretically and experimentally determined concrete with $4 \mathrm{wt} \%$ and $6 \mathrm{wt} \%$ of PCM will be presented in the function of temperature. These thermal properties shall help to better understand the results obtained for the dynamic heat storage capacity and cooling capacity of respectively passive and thermally activated decks.

Secondly, this section will present and compare the calculated diurnal heat storage capacity of the decks with theoretically and experimentally determined thermal properties of PCM concrete material, but only with the decks considered as passive elements (the water in the water pipe is not flowing). Afterwards, the increase of the heat storage capacity of the decks with various layers of the PCM concrete will be calculated with regards to the reference deck consisting only of ordinary concrete. The potential of the increase of the heat storage capacity will be parameterized with regards to the total heat transfer coefficient that represents both convective and radiative heat transfer on the surface of the deck.

Finally, the results will be presented for the calculated cooling capacity of the thermally activated deck (water in the water pipe is flowing) with and without PCM both for models calculated with theoretically and experimentally determined thermal properties of the PCM concrete. As for the passive deck, the performance of the deck with various amounts and thicknesses of the PCM concrete will afterwards be compared to the performance of the reference deck without PCM.

\subsection{Volumetric heat capacity and thermal inertia}

Figs. 8 and 9 respectively depict volumetric heat capacity and thermal inertia of standard (reference) concrete and the PCM concrete with $4 \mathrm{wt} \%$ and $6 \mathrm{wt} \%$ of microencapsulated PCM.

The volumetric heat capacity is calculated according to the equation:

$\mathrm{VHC}=\rho \times \mathrm{Cp}$

and describes material ability to store energy in a given volume while undergoing a given temperature change. By using volumetric heat capacity instead of directly using specific heat capacity, results take also into consideration the material's density which is decreasing for PCM concrete with increasing content of PCM.

The thermal inertia is calculated according to the equation:

$I=\sqrt{\rho \times \mathrm{Cp} \times \lambda}$

and combines volumetric heat capacity with thermal conductivity of a bulk material. The high thermal inertia describes materials that characterize high thermal mass and high thermal conductivity. The higher thermal inertia the faster material can be thermally activated and more thermal load can be stored during the dynamic thermal process.

\subsection{Passive approach: calculated dynamic heat storage}

The results presented in Figs. 10 and 12 illustrate the diurnal dynamic heat storage of the decks with respectively $0 \%$ (reference), $4 \mathrm{wt} \%$ and $6 \mathrm{wt} \%$ PCM in the concrete. The calculated results are for the deck with the PCM concrete layer with a thickness from 1 up to $4 \mathrm{~cm}$. Moreover, results are presented as function of the total heat transfer coefficient that is combining convective and radiative heat transfer, and was parameterized in the ranges from 4 up to $30 \mathrm{~W} /\left(\mathrm{m}^{2} \mathrm{~K}\right)$. The continuous curves represent results obtained from the models where the PCM concrete properties were calculated according to the theoretical weight average method that deploys the thermal properties determined for the separated standard concrete and pure PCM. The dashed lines represent the results obtained from the models where the PCM concrete properties were obtained from experimental investigations where measurements were conducted on the PCM and concrete combined into one material.

Figs. 11 and 13 respectively show calculated improvement of diurnal dynamic heat storage of respectively decks with $4 \mathrm{wt} \%$ and $6 \mathrm{wt} \% \mathrm{PCM}$ in the concrete and the improvement is calculated with regards to the reference deck made of standard concrete (no PCM).

\subsection{Active approach: calculated cooling capacity}

The results presented in Figs. 14 and 16 illustrate the diurnal cooling capacity of the decks with respectively $0 \%$ (reference), $4 \mathrm{wt} \%$ and $6 \mathrm{wt} \%$ PCM in the concrete and water in the decks circulates $24 \mathrm{~h} /$ day (always). As in the passive approach, the performance of the decks is calculated with the PCM concrete layer that has a thickness from 1 up to $4 \mathrm{~cm}$, and the total heat transfer coefficient on the surface is a parameter varying from 4 up to $30 \mathrm{~W} /\left(\mathrm{m}^{2} \mathrm{~K}\right)$.

\section{Discussion}

As seen in Fig. 8, volumetric heat capacity calculated based on weight average (theoretical) calculations give much higher results than the ones determined experimentally. Furthermore, the left side of the peak of the volumetric heat capacity in function of temperature has comparable width for the theoretical and experimental data where, on the other hand, the right side of the peak is 


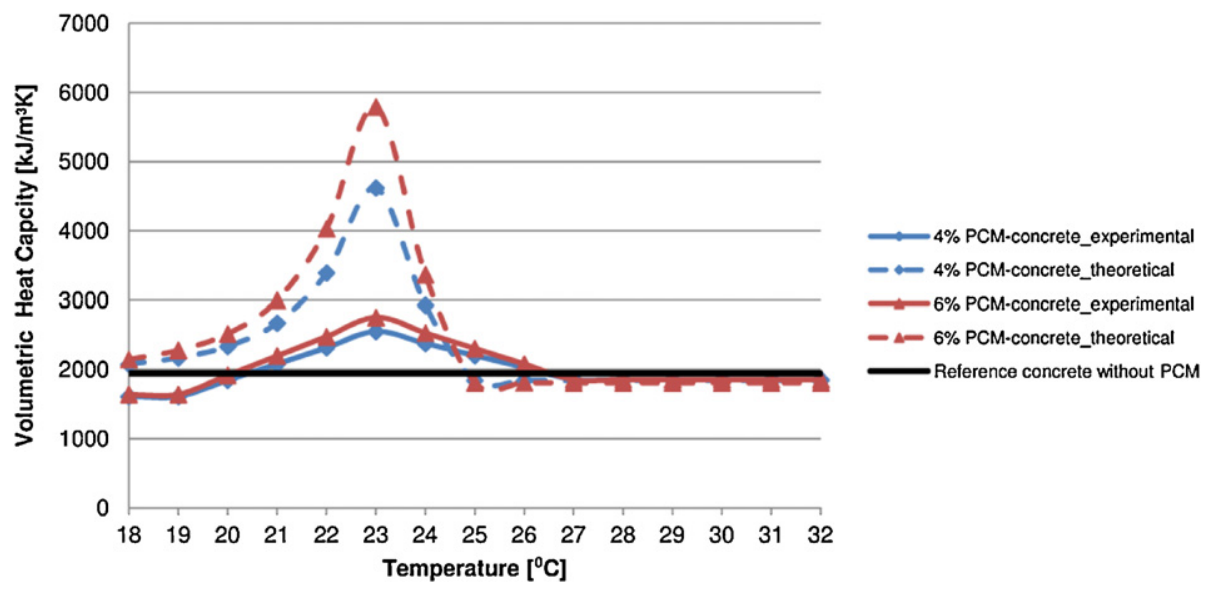

Fig. 8. Volumetric heat capacity of standard concrete and PCM concrete in function of temperature.

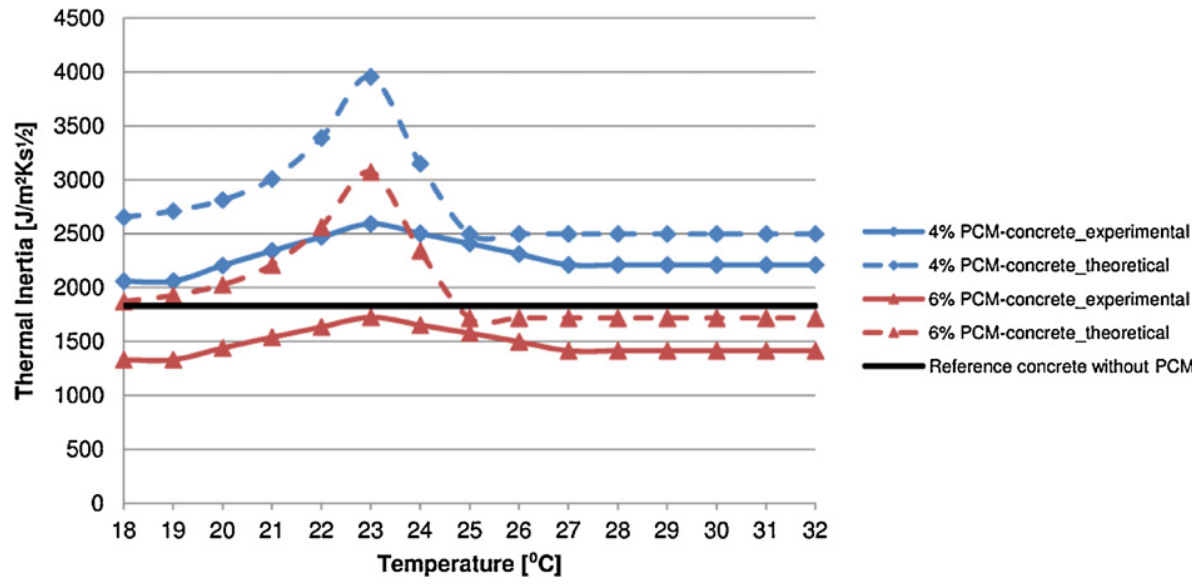

Fig. 9. Thermal inertia of standard concrete and PCM concrete in function of temperature.

much shorter for the theoretical data than for the experimentally determined results. Moreover, the difference between the volumetric heat capacity of the $4 \mathrm{wt} \%$ and $6 \mathrm{wt} \%$ PCM concrete is quite insignificant. This can be explained by the decreasing density with the increasing content of PCM in the concrete.

The results of thermal inertia presented in Fig. 9 indicate that this thermal parameter is lower for the experimentally determined $6 \mathrm{wt} \%$ PCM concrete than for the reference concrete. The low thermal inertia of the $6 \mathrm{wt} \%$ PCM concrete is the reason for the negative or almost neutral heat storage capacity improvement with regards to the reference deck presented in Fig. 13. Due to its significantly higher thermal conductivity than the experimental 6 wt\% PCM concrete, the experimental 4 wt\% PCM concrete has higher thermal inertia than the reference concrete and therefore the heat storage improvement is also higher with regards to the deck made only of reference concrete.

The thermal inertia for the theoretically calculated thermal properties of the $4 \mathrm{wt} \%$ and $6 \mathrm{wt} \%$ PCM concrete is significantly higher than the thermal inertia of the reference concrete but only within the melting range where the specific heat capacity is high.

\section{TABS not active}

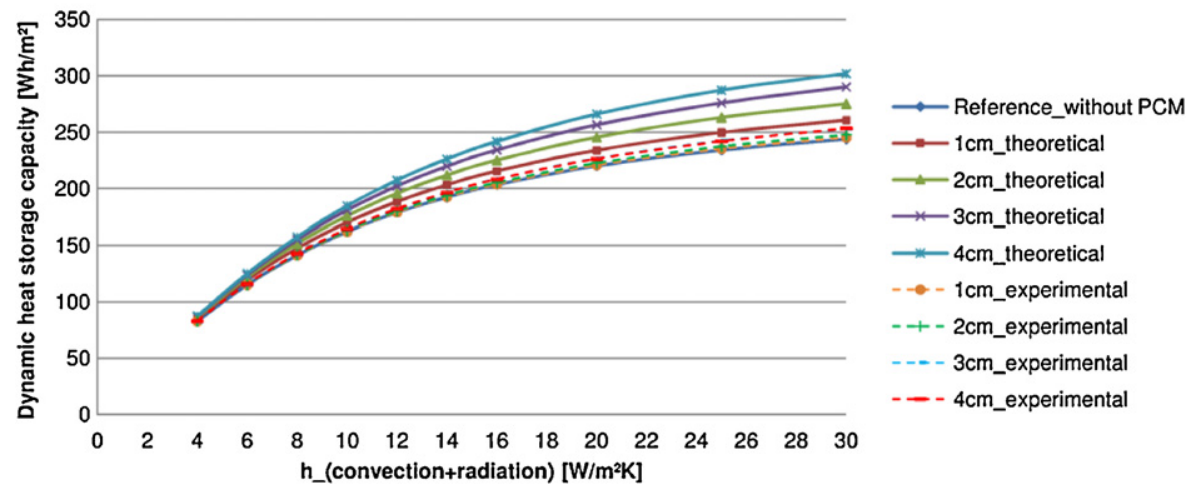

Fig. 10. Daily dynamic heat storage capacity of the deck with reference concrete and theoretically/experimentally determined 4 wt\% PCM concrete. 


\section{TABS not active}
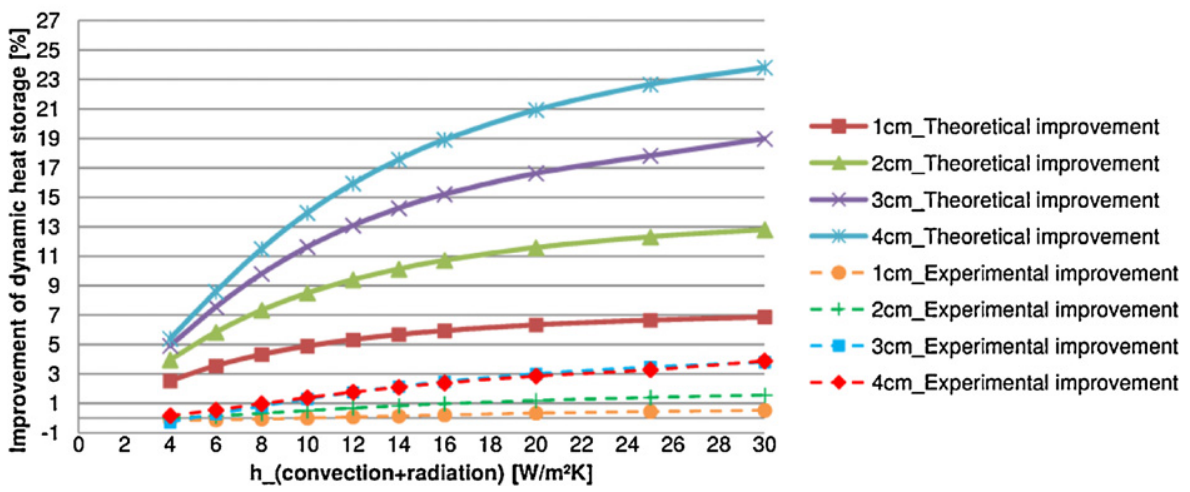

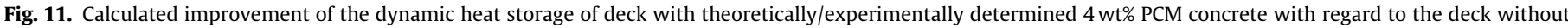
PCM.

TABS not active

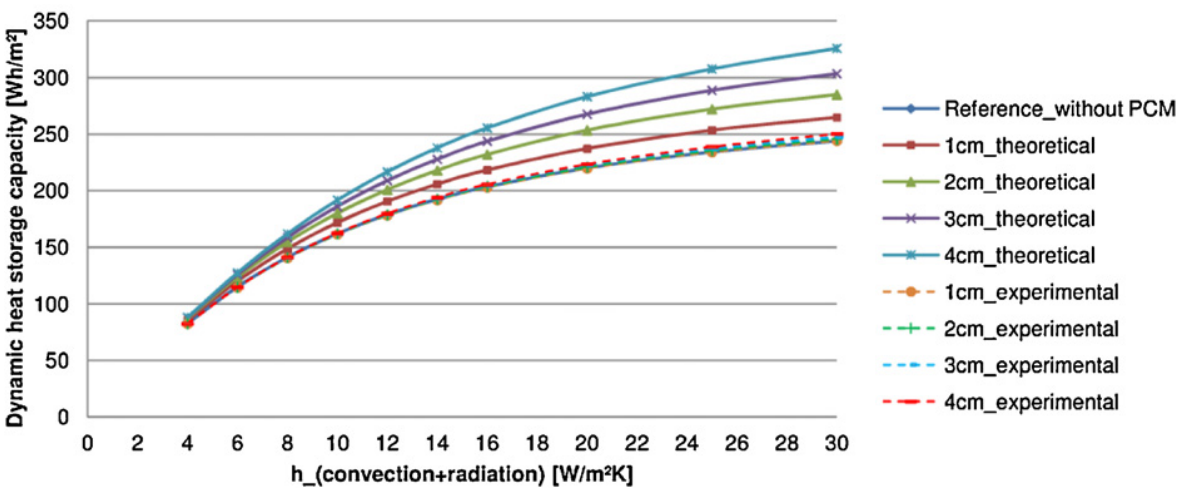

Fig. 12. Daily dynamic heat storage capacity of the deck with reference concrete and theoretically/experimentally determined 6 wt\% PCM concrete.

Above the melting range the theoretical $6 \mathrm{wt} \% \mathrm{PCM}$ concrete has slightly lower thermal inertia than the reference concrete.

The conclusion is therefore that when using PCM concrete in buildings, it has to be ensured that the indoor temperature swing fluctuates within the melting range of the PCM or that the used PCM has a melting range that covers expected and acceptable temperature swing in the building. In this manner, the latent heat of fusion will be utilized most efficiently. Moreover, for both theoretical and experimental parameters, the thermal inertia of the $4 \mathrm{wt} \%$ PCM concrete is correspondingly higher than the thermal inertia of the $6 \mathrm{wt} \%$ PCM concrete.
This can be explained by the increasing specific heat capacity and decreasing thermal conductivity and density while the percentage of the incorporated PCM is increasing. As stated, the drop in the density and thermal conductivity of the concrete effectively counteracts the increase of the specific heat capacity due to the latent heat available within the melting range of PCM.

In Figs. 10 and 12, the increase of the dynamic heat storage in the decks with PCM with respect to the reference deck without PCM becomes more distinct the higher the heat transfer coefficient on the surface is. Also, the curves representing dynamic heat

TABS not active

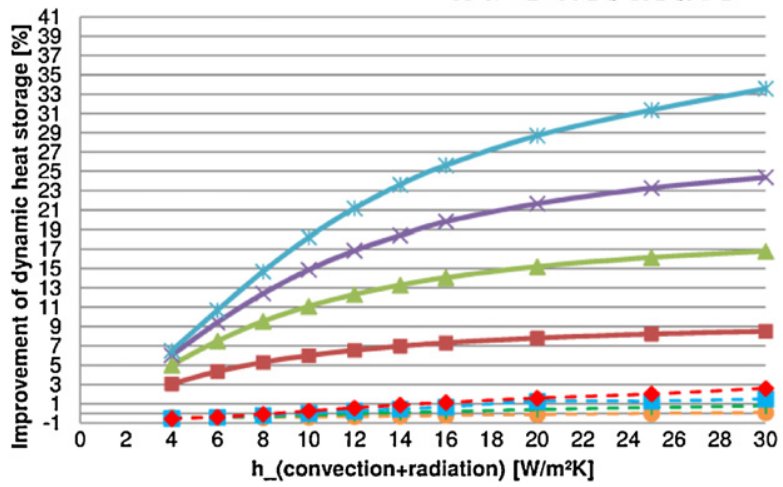

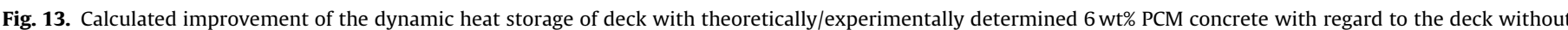
PCM. 
TABS active $24 \mathrm{~h}$

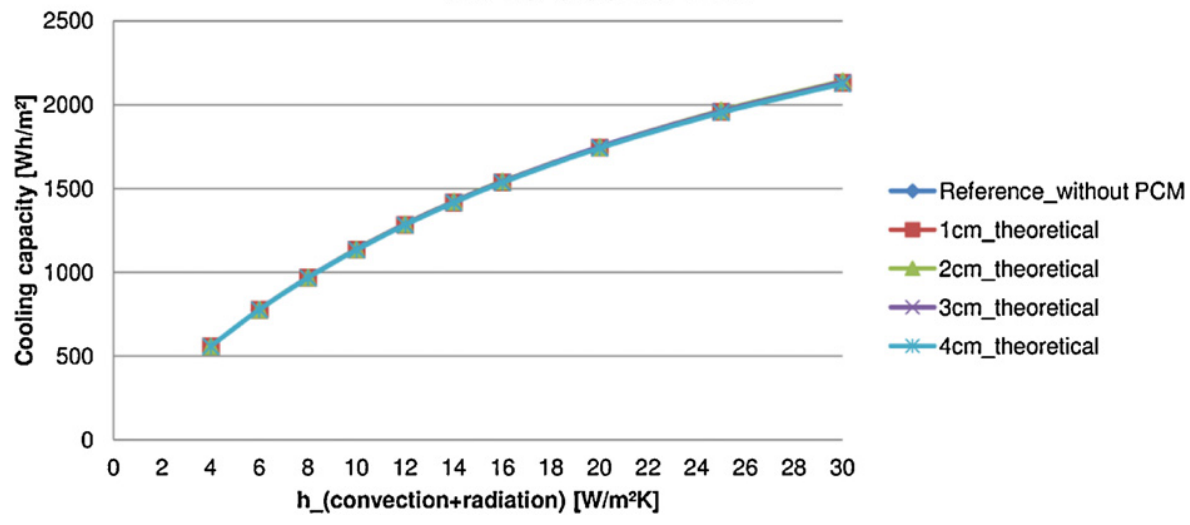

Fig. 14. Daily cooling capacity of the deck with reference concrete and theoretically determined 4 wt\% PCM concrete.

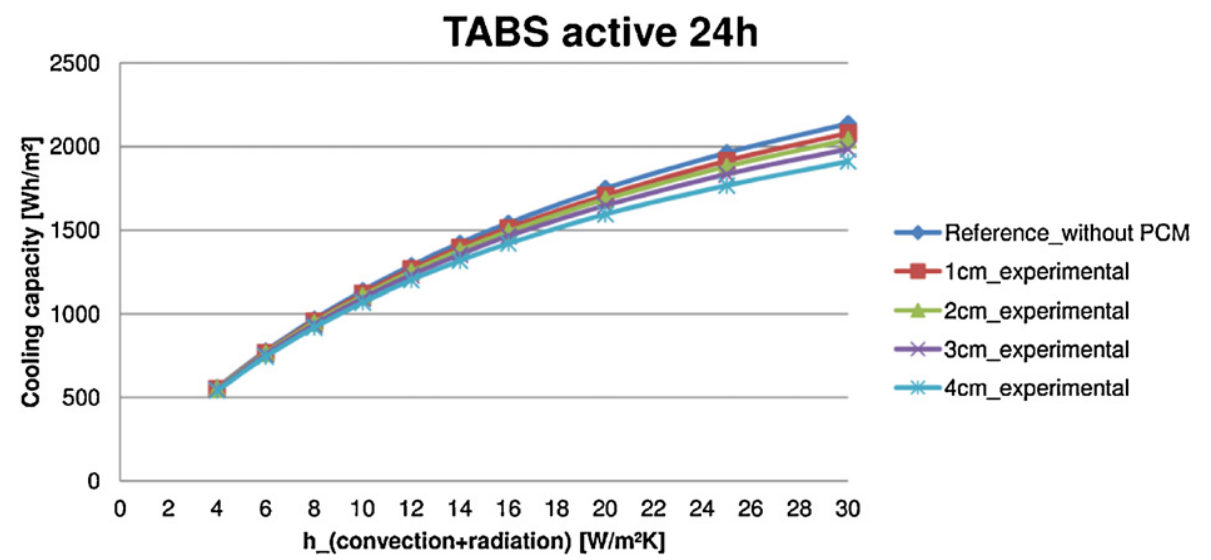

Fig. 15. Daily cooling capacity of the deck with reference concrete and experimentally determined 4 wt\% PCM concrete.

storage are continuously rising with the increased heat transfer coefficients, which is the indication that the thermal mass in any decks is not fully utilized.

Moreover, presented in Figs. 11 and 13 is the improvement of the heat storage with respect to the reference deck which indicates that for the assumptions made in the theoretical calculations the improvement can be significant, but on the other hand the total heat transfer coefficient still has to be as high as possible. Contrary to the results obtained based on the theoretical assumptions for the thermal properties of the combined PCM and concrete, the improvement of the heat storage of the deck with the experimentally determined properties does not exceed $5 \%$ even for a quite high heat transfer coefficient that reaches $30 \mathrm{~W} /\left(\mathrm{m}^{2} \mathrm{~K}\right)$. As seen in Figs. 11 and 13, the improvement is not higher than $1 \%$ for the total heat transfer coefficient that is lower than $10 \mathrm{~W} /\left(\mathrm{m}^{2} \mathrm{~K}\right)$. What is more, the performance of the $4 \mathrm{wt} \%$ PCM concrete is surprisingly better than the performance of the $6 \mathrm{wt} \%$ PCM concrete. The reason is explained in Figs. 8 and 9 and at the beginning of this section.

Regarding the cooling capacity of the thermally activated decks presented in Figs. 14 and 16, the results are overlapping each other regardless of the amount of PCM and the thickness of the layer

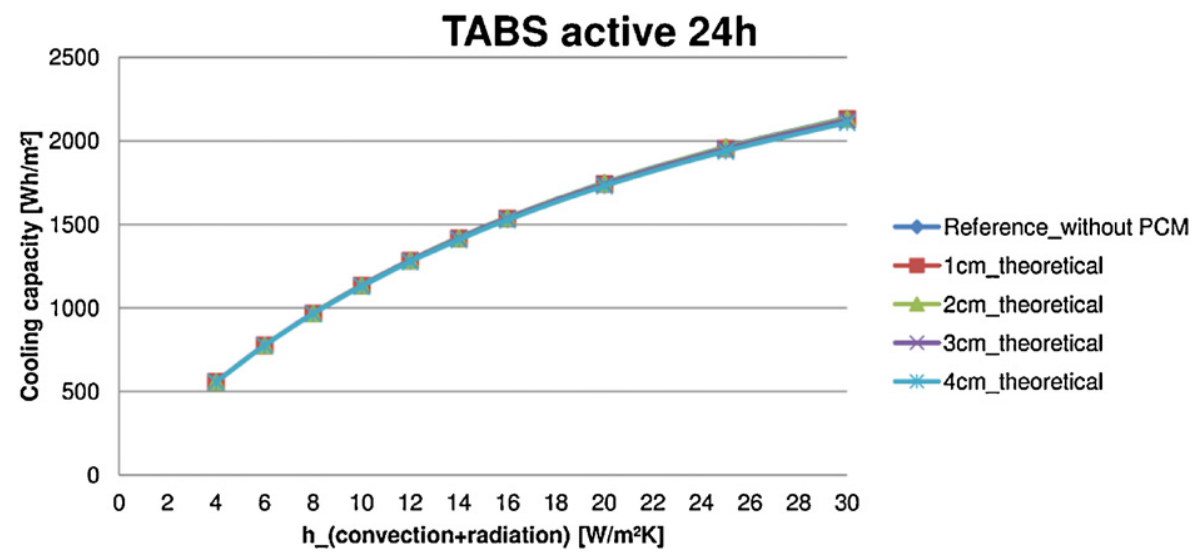

Fig. 16. Daily cooling capacity of the deck with reference concrete and theoretically determined 6 wt $\%$ PCM concrete. 


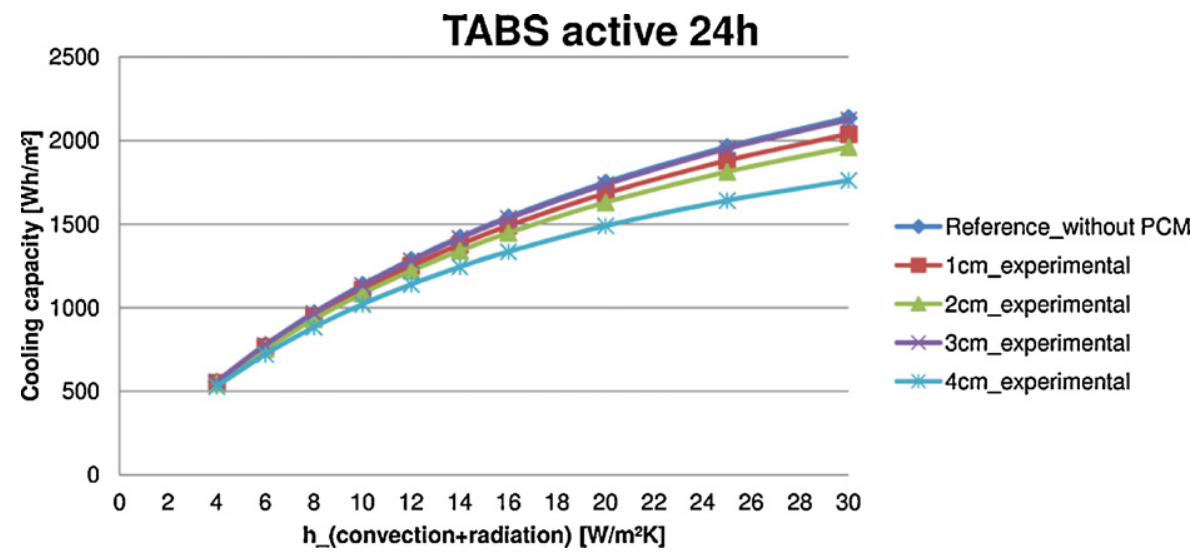

Fig. 17. Daily cooling capacity of the deck with reference concrete and experimentally determined 6 wt\% PCM concrete.

with PCM for the theoretically determined thermal properties of the PCM concrete. The reason for that is the calculated insignificant drop in the thermal conductivity with the increase of the PCM amount in the concrete. Contrary to that, the cooling capacity obtained from the decks with the experimentally determined properties of the PCM concrete is considerably lower with regards to the reference deck, see Figs. 15 and 17. This is because of the drastic drop in measured thermal conductivity discovered during the investigation on the new PCM concrete material. Obtained and presented results are valid only for a $24 \mathrm{~h} /$ day activated deck element, where in reality TABS are usually operated in time segments. The aim of the present study was to indicate that the low thermal conductivity of PCM concrete material can decrease the efficiency of TABS. However, simulating TABS 24/day does not allow PCM to undergo the phase shift, and therefore the low thermal conductivity can have predominant influence and decrease the heat transfer. On the other hand, the investigation for passive deck highlighted that heat storage improvement due to PCM presence in concrete is very insignificant.

With respect to time, the operation of TABS in the deck with PCM concrete becomes a very complex issue. The challenge is to include all the variables that could influence the heat storage of PCM integrated in concrete, e.g. time of operation with respect to surrounding temperature, heat transfer coefficient on the surface of the deck, water temperature in the deck. Then the potential for improvement and energy savings could be analysed, for example, by comparing relevant models with and without PCM to each other. This however should be considered as standing alone study and due to the size of the task that investigation will not be included in the scope of this article.

\section{Conclusions}

The presented work combines numerical and experimental investigation of the new combined material that consists of standard concrete and microencapsulated PCM. The paper indicates the discrepancy between the theoretically and experimentally determined thermal properties of the PCM concrete material. Furthermore, the paper points out that the theoretical assumptions regarding the thermal properties of the PCM concrete overestimates the performance of this material with respect to the obtained experimental properties. What is more, the experimentally determined thermal properties of PCM concrete highlighted that the use PCM concrete in decks with TABS can have decreasing effect on cooling capacity of TABS. It was also concluded that further studies should be made with focus on optimization of TABS operation with respect to indoor temperature fluctuations.
Finally, further studies should be focused on experimental investigation of additional samples of various PCM and concrete mixes and full-scale measurements of the decks with the PCM concrete material.

\section{Acknowledgements}

The authors would like to express their gratitude to BASF, DTI and Spæncom for providing materials and help in preparation of samples for experimental investigation. The Danish National Advanced Technology Foundation is acknowledged for financial support of the present research.

\section{References}

[1] R. Meierhans, B.W. Olesen, Art museum in Bregenz - soft HVAC for strong architecture, ASHRAE Transactions 108 (Part 2) (2002) 708-713.

[2] B. Lehmann, V. Dorer, M. Koschenz, Application range of thermally activated building systems TABS, Energy and Buildings 39 (5) (2007) 593-598.

[3] F. Kuznik, J. Virgone, Experimental assessment of phase change material for wall building use, Applied Energy 86 (10) (2009) 2038-2046.

[4] P. Schossig, H.-M. Henning, S. Gschwander, T. Haussmann, Micro-encapsulated phase-change materials integrated into construction materials, Solar Energy Materials and Solar Cells 89 (2-3) (2005) 297-306.

[5] E. Günther, S. Hiebler, H. Mehling, R. Redlich, Enthalpy of phase change materials as a function of temperature: required accuracy and suitable measurement method, International Journal of Thermophysics 30 (2009) 1257-1269.

[6] Z. Yinping, Y. Jiang, A simple method, the T-history method, of determining the heat of fusion, specific heat and thermal conductivity of phase change materials, Measurement Science and Technology 10 (3) (1999) 201-205.

[7] A. Lázaro, E. Günther, H. Mehling, S. Hiebler, M.J. Martin, B. Zalba, Verification of T-history installation to measure enthalpy versus temperature curves of phase change materials, Measurement Science and Technology 17 (2006)2168-2174.

[8] D. Heim, Isothermal storage of solar energy in building construction, Renewable Energy 35 (2010) 788-796.

[9] J. Rose, A. Lahme, U.N. Christensen, P. Heiselberg, M. Hansen, K. Grau, Numerical method for calculating latent heat storage in constructions containing phase change material, in: 11th Building Simulation Conference, Glasgow, 2009.

[10] M. Koschenz, B. Lehmann, Development of a thermally activated ceiling panel with PCM for application in lightweight and retrofitted buildings, Energy and Buildings 36 (2004) 567-578.

[11] M. Hunger, A.G. Entrop, The behavior of self-compacting concrete containing micro-encapsulated phase change materials, Cement and Concrete Composites 31 (2009) 731-743.

[12] M.Z. Pomianowski, P. Heiselberg, R.L. Jensen, Y. Zhang, R. Cheng, H. Johra, The new experimental methodology to determine specific heat capacity of inhomogeneous concrete material with incorporated microencapsulated PCM, Cement and Concrete Research (unpublished results).

[13] A.G. Entrop, H.J.H. Brouwers, A.H.M.E. Reinders, Experimental research on the use of micro-encapsulated phase change materials to store solar energy in concrete floors and to save energy in Dutch houses, Solar Energy 85 (2011) 1007-1020.

[14] L.F. Cabeza, C. Castellón, M. Nogués, M. Medrano, R. Leppers, O. Zubillaga, Use of microencapsulated PCM in concrete walls for energy savings, Energy and Buildings 39 (2007) 113-119.

[15] M.Z. Pomianowski, P. Heiselberg, R.L. Jensen, Initial development of a combined PCM and TABS for heat storage and cooling, in: Proceedings of the 9th Nordic Symposium on Building Physics: NSB, Tampre (personal communication). 
[16] M.Z. Pomianowski, P. Heiselberg, R.L. Jensen, Experimental investigation of thermal conductivity of concrete containing micro-encapsulated phase change materials, in: ISHVAC Conference, Shanghai (personal communication).

[17] M.Z. Pomianowski, P. Heiselberg, R.L. Jensen, H. Johra, Numerical analysis of heat storage and heat conductivity in the concrete hollow core deck element, in: 12th Building Simulation Conference, Sydney (personal communication).
[18] DS EN ISO 10077-2, Thermal Performance of Windows, Doors and Shutters Calculation of Thermal Transmittance - Part 2: Numerical for Frames, 2004.

[19] H. Mehling, H.P. Ebert, Development of standards for materials testing and quality control of PCM, in: 7th IIR Conference on Phase Change Materials and Slurries for Refrigeration and Air Conditioning, Paris, 2006.

[20] J. Babiak, Low temperature heating and high temperature cooling - thermally activated building system, Doctoral Thesis, Bratislava, 2007. 


\title{
Full-scale investigation of the dynamic heat storage of concrete decks with PCM and enhanced heat transfer surface area
}

\author{
Michal Pomianowski*, Per Heiselberg, Rasmus Lund Jensen \\ Department of Civil Engineering, Aalborg University, Sohngaardsholmsvej 57, Aalborg, Denmark
}

\section{A R T I C L E I N F O}

\section{Article history:}

Received 23 October 2012

Received in revised form 6 December 2012

Accepted 14 December 2012

\section{Keywords:}

Thermal mass activation

Dynamic heat storage

Latent heat

Phase change material

Heat transfer enhancement

\begin{abstract}
A B S T R A C T
The paper presents the full-scale experimental investigation of the dynamic heat storage potential of the prefabricated hollow core deck elements with and without phase change material (PCM) and with and without increased bottom surface area of the decks.

In the presented investigation five types of hollow core decks with different surfaces on the bottom are investigated: reference deck made of standard concrete and flat surface, deck with special mortar grooved tiles, deck with flat mortar tiles, deck with grooved mortar and phase change material tiles, deck with flat mortar and phase change material tiles.

The experimental investigation presented in the paper is performed in the specially designed modified hot box apparatus that allows maintaining periodic steady-state tests with the full-scale concrete deck elements. The presented research investigates if the extended surface area and PCM can result in the increased heat amount that can be transferred and stored in the heavy construction element during the diurnal indoor temperature fluctuations.
\end{abstract}

(c) 2012 Elsevier B.V. All rights reserved.

\section{Introduction and objectives}

Thermal energy storage (TES) can be an attractive concept to reduce operational cost for heating and cooling buildings [1]. All the components of the building possess their heat storage capacity or thermal mass and therefore all the elements, both the furnishing and construction elements, should be considered when defining the thermal mass of the building. However, not necessarily all thermal mass of building and in the building is equally utilized and not all thermal mass is of equal interest. Firstly, the light materials, due to their low density are of almost no interest, since they are not able to store significant amount of energy. Hidden elements that do not exchange heat by neither convection nor radiation or conduction are also of no interest since their thermal mass is hardly thermally activated. Utilization of the deeper layers of the thermal mass of the very thick building elements is also unrealistic due to usually short period of temperature variation and limited permissible temperature swing. On the contrary, of special interest are elements that are characterized by, for example: high thermal mass, high exposure to convective and radiative heat transfer, elements with extended surface area, high thermal conductive materials and possibly materials that undergo phase change and therefore are characterized by not only sensible, but also latent heat storage capacity.

\footnotetext{
* Corresponding author. Tel.: +45 99407234; fax: +45 99408552.

E-mail addresses: map@civil.aau.dk (M. Pomianowski), ph@civil.aau.dk (P. Heiselberg), rlj@civil.aau.dk (R.L. Jensen).
}

Building construction elements, such as walls and ceilings represent big exposed areas which are exposed to heat transfer, are often made of heavy concrete materials. This type of construction elements has high density, rather high thermal conductivity and is considered as heavy elements that represent high thermal mass. The matter is, if the dynamic heat storage capacity of such construction elements could be improved even further and by that more energy could be stored and released in the building during the day-night indoor temperature fluctuations. For example, savings for cooling and heating could be obtained if the excess heat during the day could be stored in the construction and released during the night and opposite if cold could be stored in construction during the night and released during the day.

Therefore, the objective of this work is to indicate and investigate if the extension of construction element surface area and presence of the latent heat storage in the construction element could influence the dynamic heat storage capacity of the concrete element, such as, for example, hollow core deck element. The work is initiated with numerical investigation which aims to indicate if there is a potential to increase dynamic heat storage capacity by extending construction element surface area and by integrating PCM in the concrete material. The numerical investigation is followed by full-scale experimental investigation showing that increase of dynamic heat storage capacity due to extension of surface area cannot be unanimously indicated. What is more, numerical and full-scale experimental investigation highlighted that the presence of PCM in concretes and mortars might not be advantageous and the reason for that is explained by 
experimental analysis of thermal properties of new composite of mortar with micro-encapsulated PCM. The paper focuses on holistic approach to the challenge of determining the dynamic performance of buildings' construction elements. This means that numerical initial results are validated using full-scale experimental measures. Additionally, some of the obtained results are further analyzed and explained by doing further experimental analysis of thermal properties of materials used.

In the past, numerous activities have been documented on the heat transfer enhancement and these activities can be grouped in two sub-activities: thermal conductivity enhancement and heat transfer enhancement on the surface by, for example, extension of the surface area (fins, porosity). Although the presented study is focused on the heat transfer enhancement due to the increase of the surface area a short review on the heat transfer enhancement by increase of thermal conductivity is also presented. With regards to the thermal conductivity enhancement the review is focused on phase change materials (PCM) since two types of investigated ceiling concrete decks are investigated with incorporated microencapsulated PCM in the specially designed mortar tiles. What is more, in number of publications it was reported that high latent heat of various PCM could not have been efficiently utilized due to their low thermal conductivities.

The latent heat storage of phase change materials (PCMs) is considerable but the limitation factor is their very low thermal conductivities that prevent from efficient utilization of these materials, for example, [2]. Numerous studies have been conducted on enhancement of thermal conductivity of phase change materials. For example, Velraj et al. [3] have investigated three different thermal conductivity enhancement methods: longitudinal fins, lessing metal rings of $1 \mathrm{~cm}$ diameter and steam bubbles in the cylindrical sample of paraffin wax. The experimental results indicated that the heat transfer enhancement with fins and lessing rings is appreciable for solidification enhancement and bubble agitation is applicable to enhance melting. Hoogendoorn and Bart [4] have investigated the heat enhancement of thermal conductivity of the paraffin wax by embedding the metal matrix structure that is known under the trade name Explofoil. It was found that improvement in thermal conductivity due to the introduction of an aluminum strip matrix is linearly related to the volumetric fraction of the metal in the wax. For example, for $1.6 \%$ fraction of the metal matrix the thermal conductivity was 4 times higher than for the pure wax. The research presented in [5] investigated the paraffin wax RT58 with and without embedded copper foam. The addition of copper foam can increase the overall heat transfer rate by 3-10 times (depending on the metal foam structures and material). Another experimental investigation on thermal conductivity enhancement of PCMs is elaborated in [6]. The article indicates that addition of graphite fractions to the shape-stabilized PCM results in great increase of thermal conductivity. For the $20 \%$ mass fraction of graphite, the thermal conductivity is $221 \%$ higher than the original. The [2] presents experimental investigation where the thermal conductivity enhancement of paraffin wax is due to the presence of an aluminum powder of particles of only $80 \mu \mathrm{m}$. In the investigation the mass fraction of aluminum is 0.5 and the resulting decrease of charging time of composite was reduced by $60 \%$ with regards to pure paraffin wax.

To sum up, various investigations indicate that in order to increase the low thermal conductivity of PCMs a material of very high thermal conductivity has to be added. However, in the presented investigation PCM was added to the mortar without adding any additional highly conductive materials.

There are also a numerous publications on surface heat transfer enhancement. For example, the research on internally finned tube where PCM is located in the annular shell space around the tube is presented in [7]. By placing the internal fins the convective heat transfer is enhanced. It is documented that the melting volume fraction of PCM is significantly increased with regards to plain pipe. In that case, the melting fraction can be increased by increasing the thickness, height and number of fins. In [8], numerical and experimental investigation on finned tubes with the objective of using them in TES with PCM is presented. It was concluded that the number of fins, fin length, fin thickness, the degree of super heat and the aspect ratio of the annular spacing are found to influence the time for complete solidification, solidified mass fraction and the total energy. In [9], the study on the heat transfer characteristics has been determined for the circular finned and not finned-tube units during the freezing of PCM. The ratio of outside heat transfer coefficient in the finned to the not finned tube system was determined at 3.5 within the finned section and this ratio decreases gradually far from the finned section with an increase in crystal volume. Another study on heat enhancement by increase of surface and roughness of the tube is presented in [10]. The study illustrates that patented Vipertubes increase the overall heat transfer by more than $100 \%$ with regards to conventional plain tubes. Another research on grooved tubes was presented in [11]. For different geometric grooved shapes: circular, trapezoidal and rectangular, the heat transfer enhancement is obtained respectively up to $63 \%, 58 \%$ and $47 \%$ in comparison with the smooth tube at the highest investigated Reynolds number $=38,000$.

Whereas in TES in buildings the aim is usually to charge thermal mass in possibly short time, the need in electronic components is to remove high density heating rates from small components. Nevertheless, if heat is to be charged or discharged the aim in both cases is to enhance the heat transfer on the surface. In electronic science to cool high-heat-flux components the jet impingement and pinfin and extended surfaces were studied by numerous researchers [12-15]. For example, in [12] the total fin effectiveness was computed for the pinned heat sinks relative to the unpinned ones, and was in range of 2.4-9.2. In the investigation the heat transfer coefficients were significantly increased by application of pin-fined surfaces. What is more, it was presented that the higher the air flow rate was the higher convective heat transfer coefficient was. In [14] enhancement factor as high as 3.03 or about 200\% increase in the heat transfer coefficients were observed when the area was enhanced by use of pin-fins with factor 2.44 with regards to smooth surface. In [15] one of the roughened surfaces consisted of a grid pattern of saw cuts, $0.3 \mathrm{~mm}$ deep and $0.3 \mathrm{~mm}$ wide, which doubled the total active heat transfer area. The roughness of the second was achieved by the placement of random dimples with a typical pit depth of $0.1-0.3 \mathrm{~mm}$. Compared to smooth surface spreader, the reduction in thermal resistance as high as $60 \%$ was demonstrated with the largest jet diameter.

The literature review indicated that although in electronics there is a en extensive number of publication on extended surface area and heat transfer on the surface on the contrary, in building physics there is lack of research dealing with this problem with regards to, for example, building construction elements such as walls and ceilings.

The study presented in [16] investigated and compared the performance of collector-storage walls using masonry and PCMs. One of the conclusions was that the containers in which the PCM would be stored must provide an efficient heat transfer surface for energy exchange between storage material and the building however no further study on that was performed. It can be expected, that the heat enhancement due to increased surface area that was documented, for example, for pipes and for electronic components with impingement jet could be also observed for the flat construction elements such as walls or ceilings.

The presented study illustrates the experimental investigation of the dynamic heat storage capacity and the heat transfer enhancement due to the increase of the heat transfer surface area of 


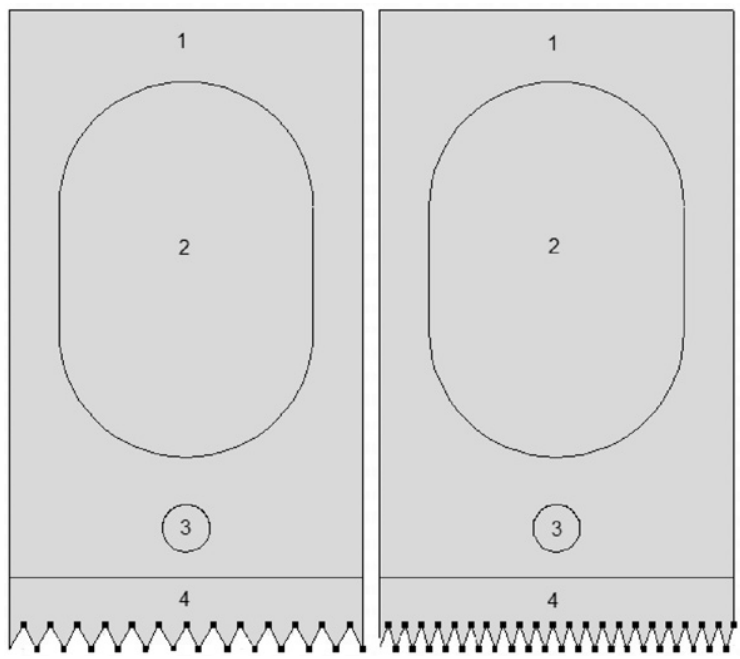

1 Standard concrete

2 Air void

3 Place for water pipe

4 Layer with PCM-concrete / standard concrete

Fig. 1. COMSOL 2D models of the hollow core deck with extended bottom surface by factors 2 and 3.

the full-scale hollow core concrete deck element with and without incorporated microencapsulated-PCM (approximately 6\% by weight of PCM). The PCM used in the mixture is Micronal type DS5040X from BASF and has melting temperature at $23^{\circ} \mathrm{C}$. In total 5 different deck elements are investigated:

- DECK_1: Hollow core concrete deck with grooved PCM mortar tiles on the bottom.

- DECK_2: Hollow core concrete deck with flat PCM mortar tiles on the bottom.

- DECK_3: Hollow core concrete deck with grooved mortar tiles on the bottom.

- DECK_4: Hollow core concrete deck with flat mortar tiles on the bottom.

- DECK_5: Reference standard hollow core concrete deck with flat bottom surface.

All investigated decks are located separately in the specially constructed chamber, called in this article "modified hot box apparatus", in which the temperature can be maintained according to the predesigned dynamic temperature profile that imitates indoor daily temperature swing. During the experiment, all decks are investigated for the same periodic steady-state temperature condition. Moreover, chamber is constructed in the manner that there are no random heat losses or heat gains to and from the chamber. What is more, energy balance is calculated so that the total energy provided or removed from the chamber is known. Having the same dynamic temperature boundaries for various decks and also knowing the energy balance in time it is possible to calculate the heat storage capacity of various types of decks and also to compare decks with each other.

Firstly, the paper presents numerical investigation of potential to increase dynamic heat storage capacity of construction element by increase of heat transfer surface area and implementation of latent heat due to PCM integration in the concrete material.

Secondly, the paper illustrates the design and casting procedure of all investigated decks. Presented casts of prefabricated deck elements are the prototypes of their kind. Consecutively, this paper presents the development of the specially modified hot box apparatus. Contrary to the standard hot box apparatus the developed modified hot box apparatus can be used to run periodic steady-state tests. Moreover, the apparatus is specially tailored to accommodate the full-scale hollow core deck elements. What is more, careful design was performed in order to avoid cold bridges, to properly insulate the hot box, to separate it from the surrounding temperature condition and to be able to control and measure temperature and energy balance over the time. What is more, an experimental investigation of thermal properties (thermal conductivity, heat capacity and density) of materials used to cast decks was performed and obtained results are illustrated. Finally, the paper illustrates the methodology of measurements of energy balance and calculated dynamic heat storage capacity of the decks.

To sum up, presented work can be used as a guidance indicating which steps should be taken to experimentally investigate dynamic performance and heat storage of full-scale building construction elements located under controlled boundary conditions. What is more, to fully understand obtained results from full-scale experiments a set of measurements determining thermal properties of materials used have been carried out.

\section{Methodology}

\subsection{Numerical investigation of potential of extended bottom surface area}

Investigation of potential to increase dynamic heat storage capacity of concrete deck elements due to extension of the bottom area of the decks was studied in COMSOL Multiphysics using dynamic heat transfer model. The geometry of the two-dimensional models developed in COMSOL are presented in Fig. 1. In the models all the assumptions regarding the boundary condition are preserved from models presented in [17]. Moreover, findings regarding the heat transfer in hollow cores documented in [18] were included in the model. Since the hollow core deck has repetitious construction it is allowed to simplify model to only one section of the deck. The models presented in Fig. 1 have increased bottom surface area by factor of 2 (left) and factor of 3 (right) with respect to ordinary deck with flat bottom surface.

The dynamic heat storage capacity of decks has been calculated only due to heat transfer on the bottom surface of the decks. Results obtained from the numerical analysis indicated that increased surface area might have a potential to help thermally activate thermal mass only due to diurnal indoor temperature fluctuations in the room, see Fig. 2. On the contrary, numerical prediction did not indicate any significant improvement of dynamic heat storage capacity due to addition of PCM to concrete. 


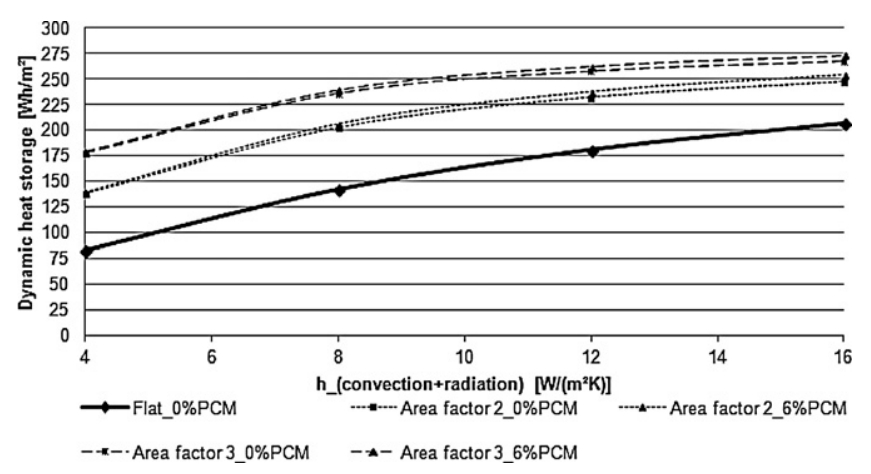

Fig. 2. Dynamic heat storage capacity.

\subsection{Deck development}

Five various decks are investigated in the presented research. In Fig. 3, drawings of cast hollow core decks are presented. The reference hollow core deck is made of standard concrete. The four remaining hollow core decks integrate mortar tiles with and without PCM. Each deck has in total 6 tiles of one type integrated, next to each other, and they cover almost the whole bottom surface of the hollow core deck.

The tiles are cast in specially prepared moulds prior to cast of prefabricated hollow cores. Consequently, tiles are demoulded and the necessary time is taken for the tiles to obtain their required strength before they are cast in the bigger moulds, where the big hollow cores are cast. The tiles are located at the bottom of the big mould, and the reinforcement of the tiles is connected to the reinforcement prepared for the big hollow cores. Afterwards, concrete is poured in the moulds in the same manner as for the standard hollow core deck. This way, specially designed tiles become an integral part of the big hollow core concrete deck element.

For the profiled mould on the bottom, triangular wooden elements were located which gave the tiles a designed surface. The triangular profile was designed to be $10 \mathrm{~mm}$ high and $8 \mathrm{~mm}$ width at the base. This triangular profile on the surface increases the original flat surface by factor 2.7. At the present moment, surface increase factor of 2.7 was the highest possible at which demoulding of tiles was still possible without damaging the surface of the tiles.

The tiles were cast with special mortar without stones. If they were cast with concrete with stone aggregate, then the profiled shapes would be damaged while demoulding. Finally, in total two decks of each kind were cast, and in total 10 full-scale decks measuring $3.5 \times 1.2 \times 0.32$ were cast.
It is worth to stress that all hollow cores were cast at the same time and were stored in the same indoor condition. Therefore, it is assumed that moisture content in all the decks is at a similar level.

\subsection{Modified hot box apparatus}

The standard hot box apparatuses are usually operated in order to maintain steady-state conditions and measure the overall heat transfer through large, homogenous or inhomogeneous structures and from that thermal conductivity of elements can be determined. According to EN ISO 8990, two types of hot box apparatus can be distinguished: guarded hot box (GHB) and calibrated hot box (CHB). In the presented research, the constructed hot box was developed based on the GHB concept. However, the purpose of the presented experimental analysis is not to determine the overall thermal conductivity, but to determine and compare thermal performance (dynamic heat storage capacity) of the investigated various decks under the periodic steady-state temperature conditions.

The vertical section view of the developed modified hot box apparatus is presented in Fig. 4. Four zones can be distinguished in the hot box. In each zone, air is re-circulated through the air handling unit (AHU) that can provide cold and heat to the individual zone depending on the predefined temperature profile.

Zones 2 and 3 directly influence the two hollow core decks mounted in the hot box. In zones 2 and 3, air temperature profile is designed to vary daily between $20^{\circ} \mathrm{C}$ and $26^{\circ} \mathrm{C}$ according to a sine curve. Thus, the chosen temperature range would be close to the recommended design values of the indoor operative temperature for design of buildings and HVAC systems in office buildings according to DS/EN 15251 and would almost entirely cover the melting temperature range of used PCM which was determined to be between $19^{\circ} \mathrm{C}$ and $27^{\circ} \mathrm{C}$ with melting point at $23^{\circ} \mathrm{C}$, see $[17,19]$ and Fig. 8.

In the presented hot box, the guarding zones for zones 2 and 3 are zones 1 and 4 . The set temperature in zones 1 and 4 is identical to zones 2 and 3. In this way, it can be assumed that no heat is gained or lost due to the temperature differences between zones 2 and 3 and the air in the surrounding laboratory. In zone 4, the air circulates around zones 2 and 3 in specially designed chambers of height of $120 \mathrm{~mm}$ and width of $600 \mathrm{~mm}$.

Additionally, the zones are separated from each other with thick layers of thermal insulation to minimize the risk of any uncontrolled heat gains or losses, as presented in Fig. 4. For example, zones 2 and 3 are separated from each other with $150 \mathrm{~mm}$ of mineral wool, zones 2 and 3 are separated from guarding zone 4 with $25 \mathrm{~mm}$ of expanded polystyrene, and from guarding zone 1 with $100 \mathrm{~mm}$ of mineral wool. Additionally, zone 4 was separated from

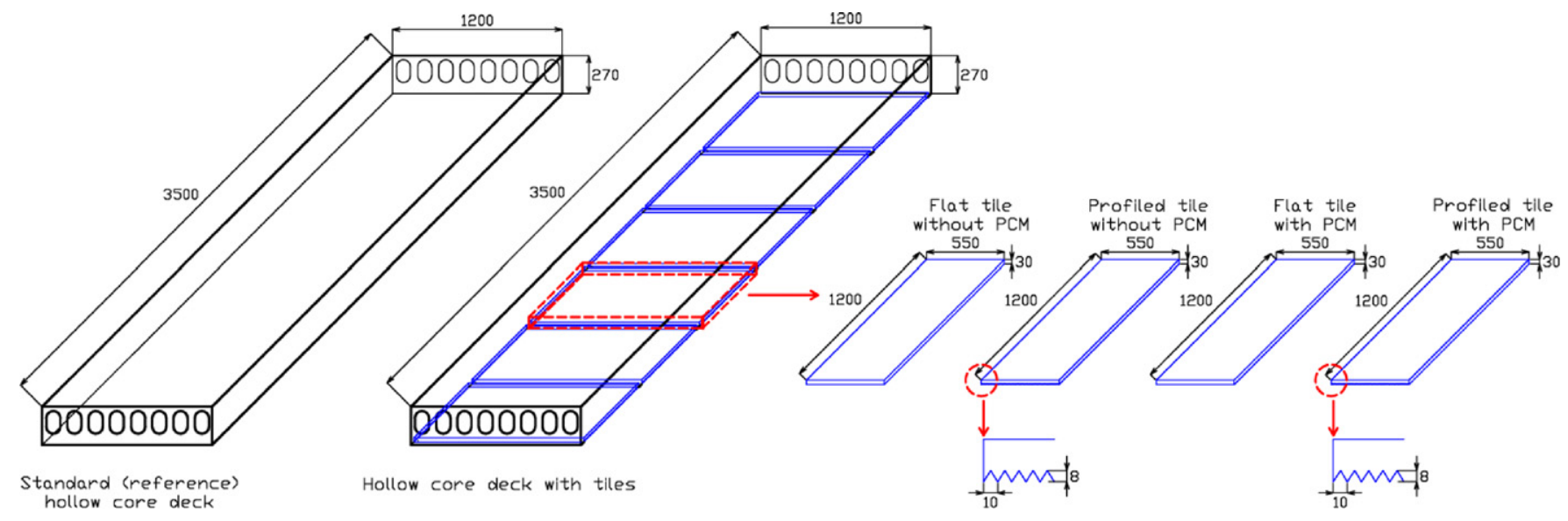

Fig. 3. Design of five different types of hollow core deck elements. 


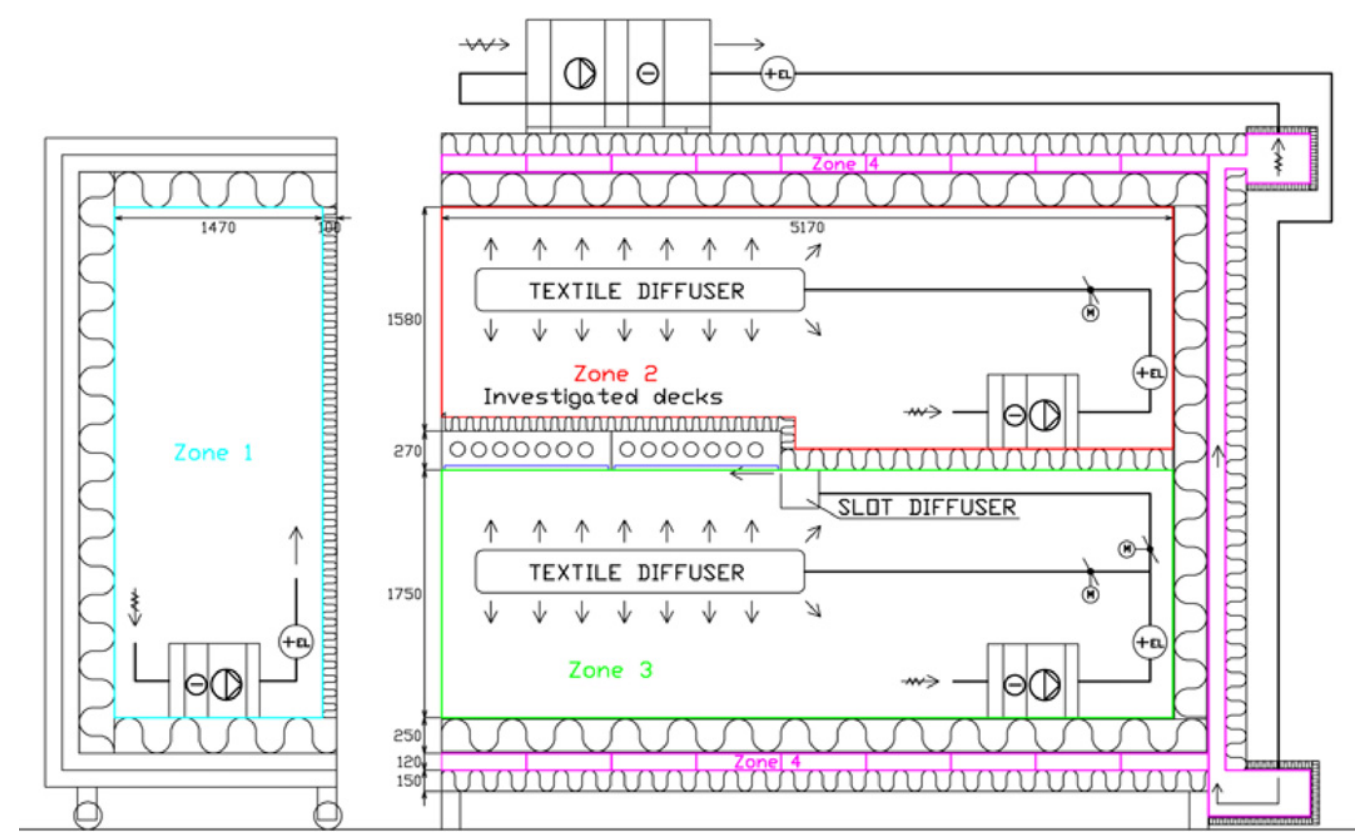

Fig. 4. Vertical section view of developed modified hot box apparatus with distinguished thermal zones, dimensions are given in mm.

the surrounding laboratory with $150 \mathrm{~mm}$ expanded polystyrene, and distribution boxes and ventilation channels were insulated with $50 \mathrm{~mm}$ of mineral wool. Moreover, special focus was put on ensuring that all zones were air tight and that there was no uncontrolled air exchange between zones.

Zone 1 presented in Fig. 4 is designed on wheels and can be moved forth and back in order to close or open zones 2 and 3. During tests, the chamber 1 is clamped tightly against an insulated frame that surrounds chambers 2 and 3 .

As presented in Fig. 4, the only difference between zones 2 and 3 is the air distribution system. In zone 2 , air is distributed by the circular low impulse diffuser and air is fully mixed. In zone 3 , two various air distribution systems are available. The textile one is the same as in zone 2, and the other one is from the slot diffuser that is blowing air just under the two investigated decks. The inlet air can be directed by the mounted motor throttles either to the textile diffuser or to the slot diffuser or to both of them. In both designed distribution cases, air in zone 3 is fully mixed, but the air velocities close to the bottom of the investigated decks are expected to be different. All experiments presented in this paper were conducted with use of only the ventilation slot diffuser in zone 3 . The slot diffuser is $3.6 \mathrm{~m}$ long (covers all length of the decks) and the opening has height of $3 \mathrm{~cm}$. Moreover, ventilation aggregate is set to operate at its maximum capacity which results in air change rate (ACR) approximately at $35 \mathrm{1} / \mathrm{h}$. Here, air velocity in the inlet slot diffuser is approximately $5 \mathrm{~m} / \mathrm{s}$. Consequently, the convective heat transfer coefficient is as high as possible for the available ventilation system, and therefore the thermal mass of the deck should be sufficiently activated.

\subsection{Control system}

To control HVAC components in each zone a LabVIEW program that cooperates with Compact RIO system from National Instruments was designed. The temperature in each zone is controlled with PI controller which adjusts the heating energy to each separate zone in order to obtain the predefined reference temperature profile. In the middle of each zone are located two shielded from radiation PT 100 sensors and according to average reading of each pair of sensor the air temperature in each zone is regulated. Moreover, due to the low thermal inertia of the hot box construction elements and the fact that all zones are given the same temperature profile the temperature was decided to be controlled according to the air temperature and not the operative temperature. Moreover, vertical air temperature profile in the zones 2 and 3 is checked in two different places to check if air is well mixed.

The cooling load to zones 1, 2, 3 and 4 is provided continuously at almost constant rate. The constant heating rate in each zone is provided from running the fans and pumps. The control of dynamic temperature profile in zones $1,2,3$ and 4 is obtained by varying heat load from electrical heaters mounted in the ventilation channels.

\subsection{Data acquisition}

Data acquisition system includes following measurements: air temperature, cooling water temperature, air velocity under decks, cold water flow, heat provided to the electrical components (fans, pumps, heaters) and deck weight.

Regarding temperature measurements, beside PT 100 sensors located in each zone to control temperature there are in total $86 \mathrm{~K}$ type calibrated thermocouples to monitor the temperature. Thermocouples are scanned every $10 \mathrm{~s}$, and temperatures are logged by the Helios Fluke data logger type 2287A. Thermocouples are used to measure vertical air temperature profiles, horizontal air temperature profile under the investigated decks, hot box internal walls, temperature, ceiling and floor temperatures, temperature on the bottom and top surface of the investigated decks and in the investigated concrete decks, cold water inlet and outlet to cooling coils in zones 2 and 3.

Air velocity measurements are done with use of omnidirectional thermal anemometers. In total 16 anemometers are used, and they are all located in two axes. Each axis is placed $5 \mathrm{~cm}$ from the bottom of the investigated decks. Each anemometer is scanned every $30 \mathrm{~s}$ and velocity is measured as mean value from $10 \mathrm{~s}$. Velocities are logged by Dantec multichannel flow analyzer type 54N10 (Figs. 5 and 6).

Electrical power measurements to all components located in zones 2 and 3 are measured at transformers type GP- 1 from Noratel and logged through the special LabVIEW script. 


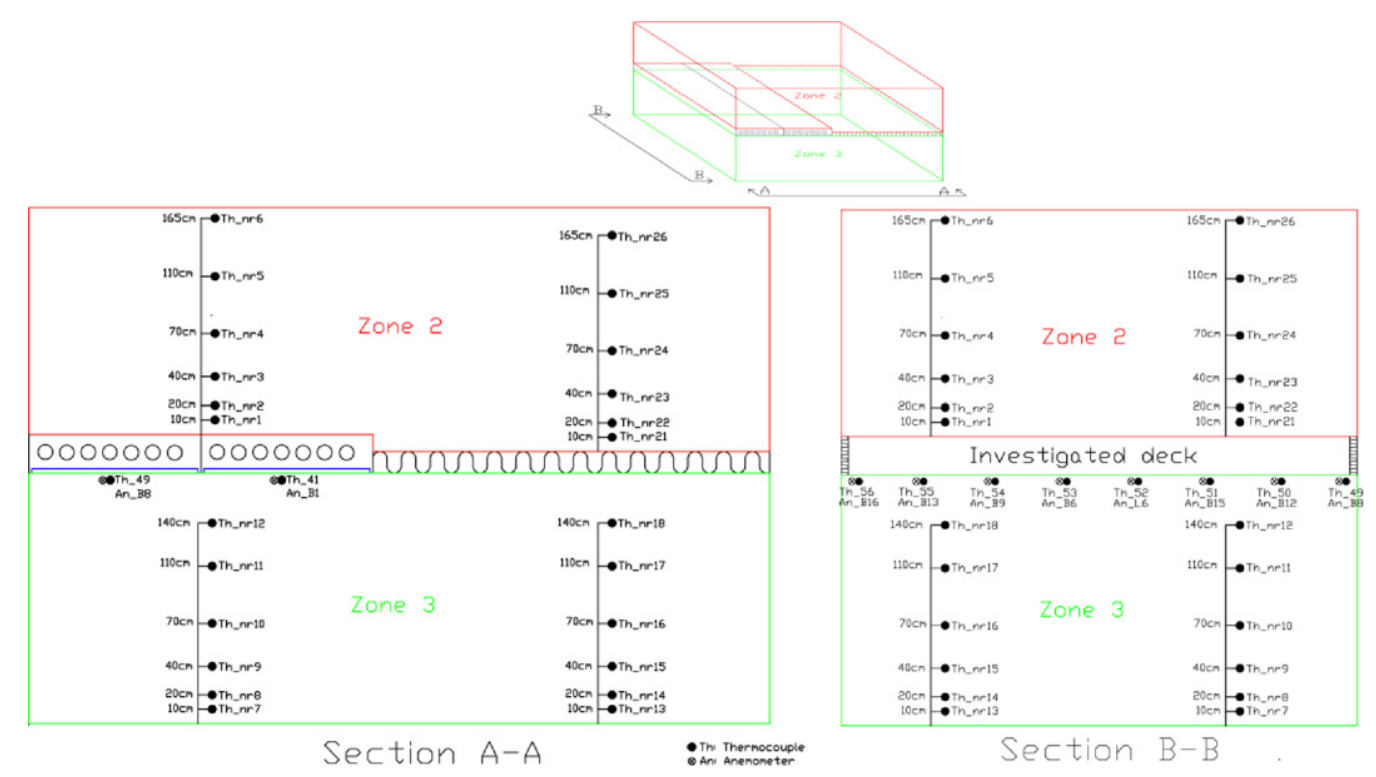

Fig. 5. Vertical and horizontal location of thermocouples in the zones 2 and 3, and anemometers location in zone 3.

Cooling effect provided to zones 2 and 3 is calculated from water flow registered by Brunata energy meter type HGQ1 and thermocouples located at the inlet and outlet to zones 2 and 3 . The water flow is logged through special LabVIEW script and at the same time temperature from thermocouples is scanned every $10 \mathrm{~s}$.

Weight of each deck is measured by four force transducers type S9/5 manufactured by HBM mounted to the carriage supporting the decks in the hot box. Measured data is amplified by the Spider 8 amplifier from HBM. Data acquisition is done by Catman professional software.

\subsection{Dynamic heat storage capacity}

The test specimen behavior under dynamic temperature conditions can be described by various coefficients, for example the thermal lag, reduction in heat flux/temperature amplitude, total heat flow ratio or decrement factor presented, as seen in some former investigations $[20,21]$. These parameters however are usually derived for a construction where one side is in steady-state condition and the other is in dynamic thermal condition. For example, a simplified model of external wall where external temperature is varying and internal temperature is assumed constant.
The purpose of the investigation presented in this article is to determine dynamic heat storage capacity of concrete decks. In the experiments thermal mass of concrete hollow cores is activated only by the temperature fluctuations of the indoor air in the chamber.

The dynamic heat storage capacity of each deck element, but only with respect to the heat transfer through the bottom surface of the deck, can be derived from known energy balance in zone 3 in the modified hot box apparatus. The dynamic heat storage capacity of zone 3 would be then a half of the difference of the cumulative electric (heating) energy provided to zone 3 during charging period and discharging period decreased by the cooling load provided to zone 3 . To calculate absolute dynamic heat storage capacity of only concrete deck elements excluding the heat capacity of hot box construction and all components in zone 3 (ventilation aggregate, ventilation channels, pump and fittings, two steel carriages to support decks) one experiment was conducted for hot box apparatus where instead of two concrete decks a ceiling built of a very light extruded polystyrene (EPS ceiling) was mounted. The thermal mass of such ceiling can be neglected, and the absolute dynamic heat storage capacity of zone 3 without concrete decks can be calculated in the same manner as for zone 3 with concrete decks. Then the difference of absolute dynamic heat storage capacity of zone 3

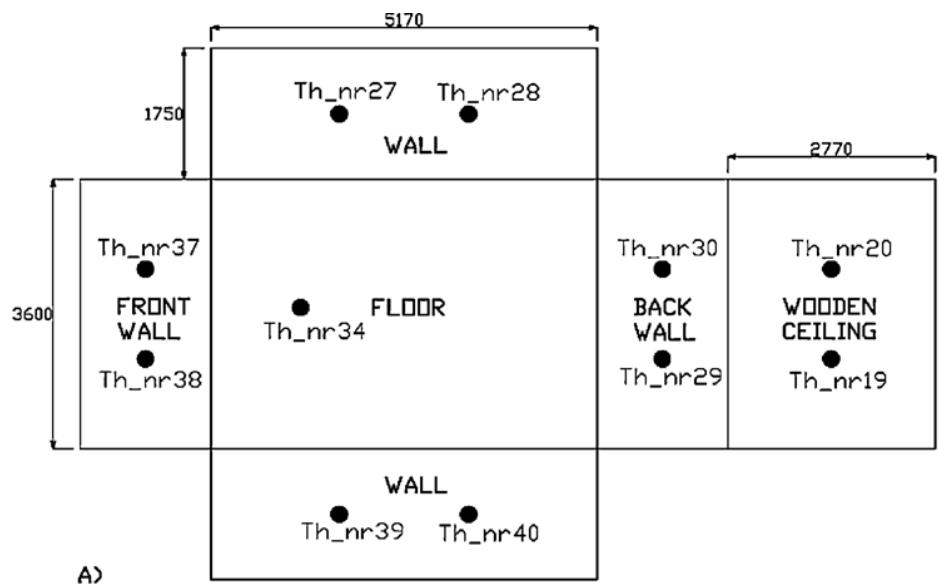

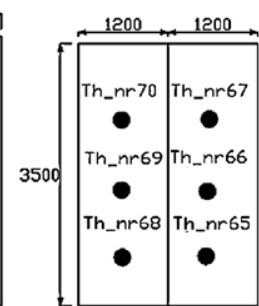

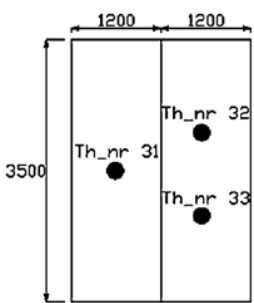

B)

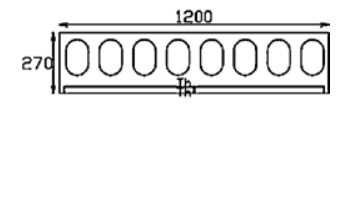

C)
D)

Fig. 6. Thermocouples location on: (A) the hot box walls in the zone 3; (B) the bottom of the investigated decks; (C) the top of the investigated decks; (D) in the investigated deck, 1.5 and $2.5 \mathrm{~cm}$ from the bottom surface. 
with concrete decks and absolute dynamic heat storage capacity of zone 3 without concrete decks (but with all other components kept in zone 3), results in absolute dynamic heat storage capacity of each pair of decks investigated.

A comparison between different decks can be assessed based on energy delivered to zone 3 , because the only variable parameter in the whole setup is the finish on the bottom surface of the deck facing zone 3. The reference deck for the investigation is standard deck made of concrete (DECK_5). The comparison of absolute dynamic heat storage capacity of decks can be done, since in all experiments and for all types of investigated decks, the same dynamic temperature profile in zones 2 and 3 is maintained, the same control technique is implemented and the same air distribution system is preserved.

In the charging period (when temperature is varying from $23^{\circ} \mathrm{C}$ to $26^{\circ} \mathrm{C}$ ), the more heat that has to be provided to zone 3 , the higher the heat storage capacity of particular deck element will be. Conversely, in the discharging period (when temperature is varying from $23^{\circ} \mathrm{C}$ to $20^{\circ} \mathrm{C}$ ), the less heating that has to be provided to zone 3 , the higher the heat storage capacity of particular deck element will be.

Periodic temperature cycles are repeated until the quasi steadystate situation is obtained. As stated in [20], such repetition is typically attained within 2 days for lightweight frame walls systems and 4 days for heavy masonry wall system. In the conducted experiments, each deck was exposed to $24 \mathrm{~h}$ periodic steady-state cycles over 7 days, where the first 2 days are considered as the stabilization period and the five remaining days are taken into consideration for calculation of dynamic heat storage capacity of the decks.

\section{Results}

\subsection{Thermal properties}

Along with full-scale experiments conducted in the modified hot box apparatus, an experimental investigation of thermal properties of concrete, mortar and PCM mortar used in hollow core deck elements was performed using a modified hot plate apparatus.

Small specimens of concrete, mortar and PCM mortar measuring $15 \mathrm{~cm} \times 15 \mathrm{~cm} \times 8 \mathrm{~cm}$ were cast aside full-size hollow core deck elements to determine their thermal properties. Firstly, a thermal conductivity of materials was measured. The methodology and the experimental setup to measure a thermal conductivity of concretes and mortars with use of the hot plate apparatus can be found in $[19,22]$. Measurements were conducted for three mean temperatures of each specimen: $10^{\circ} \mathrm{C}, 20^{\circ} \mathrm{C}$ and $40^{\circ} \mathrm{C}$ respectively, and in all measurements the temperature difference between hot and cold plate was at $15^{\circ} \mathrm{C}$. Measurements were repeated three times for each specimen and average thermal conductivity for each mean temperature was calculated. Results of the average measurements are depicted in Fig. 7. Moreover, the repeatability of results was very satisfactory. As can be observed, thermal conductivity of investigated materials is almost independent of temperature within which measurements were conducted. Therefore, an average thermal conductivity of three mean temperatures was calculated and results are presented in Table 1.

Secondly, the same specimens were used to experimentally determine their specific heat capacity. A new method to determine specific heat capacity of inhomogeneous concrete and mortar materials with PCM was used. The specific heat capacity of the samples was determined as an inverse problem, and sequential quadratic programming (SQP) algorithm was used. A detailed description of the calculation methodology with SQP algorithm, experimental setup and specimen preparation can be found in [19].

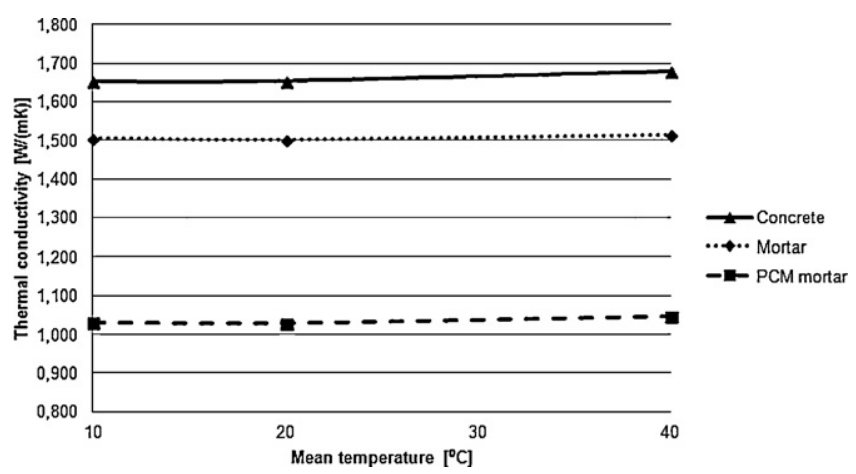

Fig. 7. Measured thermal conductivity of concrete, mortar and PCM mortar used to cast decks and tiles.

Table 1

Thermal properties: thermal conductivity, density and specific heat capacity of concrete, mortar and PCM mortar.

\begin{tabular}{lllc}
\hline Material & $\begin{array}{l}\text { Thermal } \\
\text { conductivity } \\
{[\mathrm{W} /(\mathrm{mK})]}\end{array}$ & $\begin{array}{l}\text { Density } \\
{\left[\mathrm{kg} / \mathrm{m}^{3}\right]}\end{array}$ & $\begin{array}{l}\text { Specific heat } \\
\text { capacity } \\
{[\mathrm{J} /(\mathrm{kg} \mathrm{K})]}\end{array}$ \\
\hline Concrete & 1.661 & 2283 & 755 \\
Mortar & 1.507 & 2090 & 797 \\
PCM mortar & 1.035 & 1848 & - \\
\hline
\end{tabular}

Results of specific heat capacity of the PCM mortar sample which is dependent on temperature are presented in Fig. 8, and specific heat capacity of mortar and concrete is presented in Table 1. Each specimen was measured 3 times in order to control repeatability of results, and they were concluded to be satisfactory. In Table 1 , mean average values from three measurements of each specimen are given.

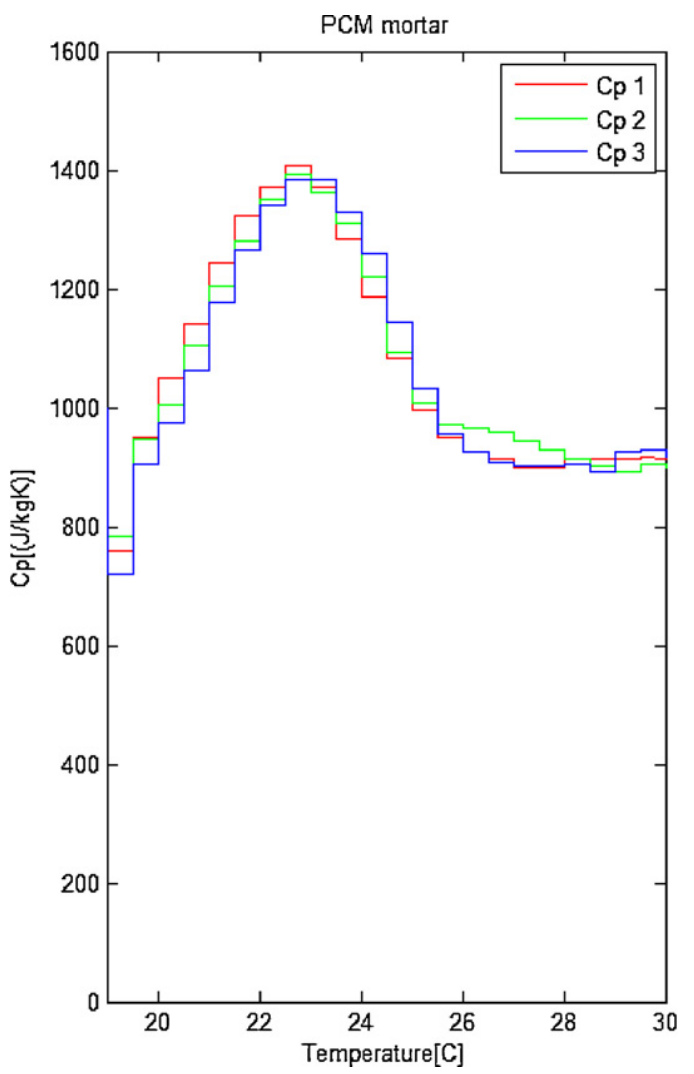

Fig. 8. Measured specific heat capacity (latent and sensible) of PCM mortar as a function of temperature. 

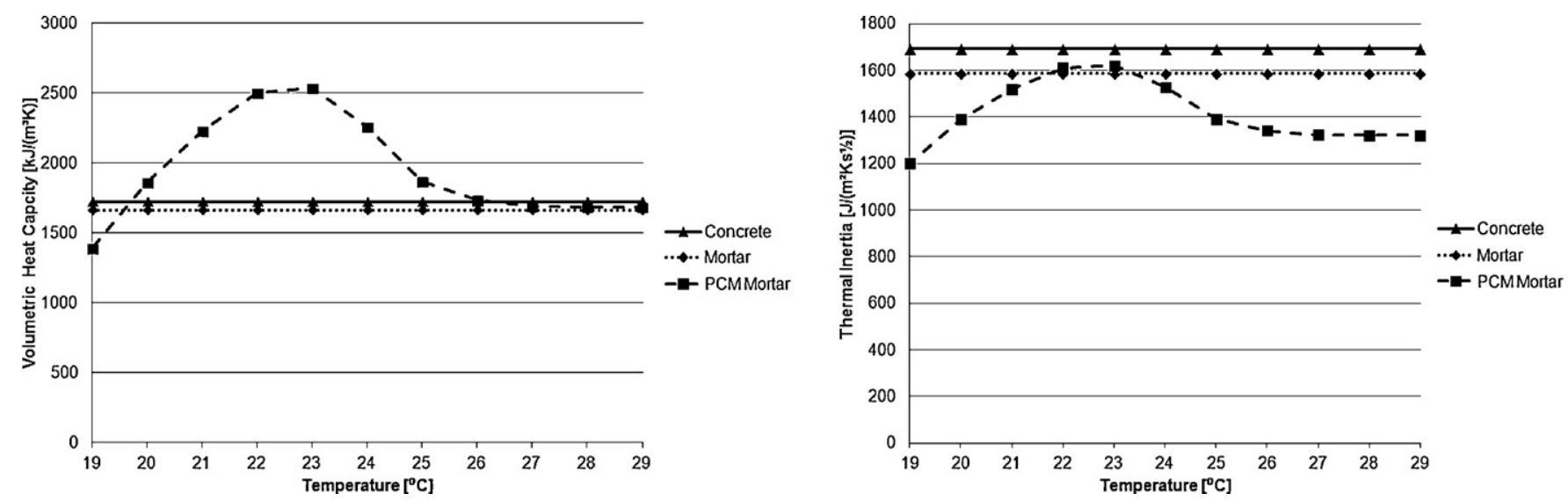

Fig. 9. (Left) Volumetric heat capacity and (right) thermal inertia of concrete, mortar and PCM mortar used to cast decks and tiles.

Knowing thermal properties of materials, a volumetric heat capacity (VHC) and thermal inertia (TI) can be calculated using Eqs. (1) and (2) respectively. Calculated VHC and TI are presented in Fig. 9 as function of temperature.

$V H C=\rho \times C p$

$T I=\sqrt{\rho \times C p \times \lambda}$

where $\rho$ is the density $\left[\mathrm{kg} / \mathrm{m}^{3}\right] ; \lambda$ is the thermal conductivity $[\mathrm{W} /(\mathrm{mK})] ; C_{p}$ is the specific heat capacity $[\mathrm{J} /(\mathrm{kg} \mathrm{K})]$.

\subsection{Temperature and velocity in zone 3}

Temperature of the air in each zone is the parameter that is controlled during the experiments with different decks. To be able to compare and measure dynamic heat storage capacity of the decks, the same temperature has to be maintained from experiment to experiment. In this section, chosen temperatures are presented and these illustrate that thermal condition in the hot box were periodically steady-state and repeated from experiment to experiment and from day to day, see Fig. 10.

As seen in Fig. 10, air is very well mixed and no temperature gradient can be noticed (logged temperatures at different heights in zone 3 overlap each other). Moreover, from experiment to experiment the same temperature amplitude and period can be observed.

Air velocity was registered by 16 anemometers distributed along two axes: each axis was $3.5 \mathrm{~m}$ long. Anemometers on both axes were approximately $5 \mathrm{~cm}$ from the bottom of the decks, and each axis was in the middle of the deck, see also Fig. 6 . The velocities were stable over the time period and therefore results are presented as mean velocities, see Fig. 11 .
As seen in Fig. 11, velocities in the axis closer to the inlet slot diffuser are highest closest to the walls, and in the axis further from the inlet slot diffuser, air jet attaches to one of the sides. In the conducted measurements, it was always the right side wall. Moreover, air velocity range and air velocity profiles follow very similar patterns for all conducted experiments. What is more, air velocities are generally higher under the decks located closer to the inlet slot diffuser than velocities under the decks further from the inlet slot diffuser.

\subsection{Heating load}

Heating load to zones 2 and 3 is provided by the following components: electric heater (modulated), fans, pumps, 3-way valves and P-line controllers. Heating load was measured at transformers and logged each $1 \mathrm{~s}$. A graphical presentation of logged heating load during measurements of all decks as a function of time is presented in Fig. 12.

Fig. 12 presents results which indicate satisfactory repeatability of hourly and daily heating load to zone 3 suggesting that periodic steady-state is obtained for each deck element.

\subsection{Cooling load}

Although volumetric flow of cooling water to the cooling coil is measured at a constant rate, the temperature of cold water entering zones 3 and 2 was fluctuating insignificantly from experiment to experiment. Any water temperature fluctuations from experiment to experiment caused by air temperature variations that influenced the piping installation between the chiller and the hot box were taken into consideration in the cooling load calculations. As
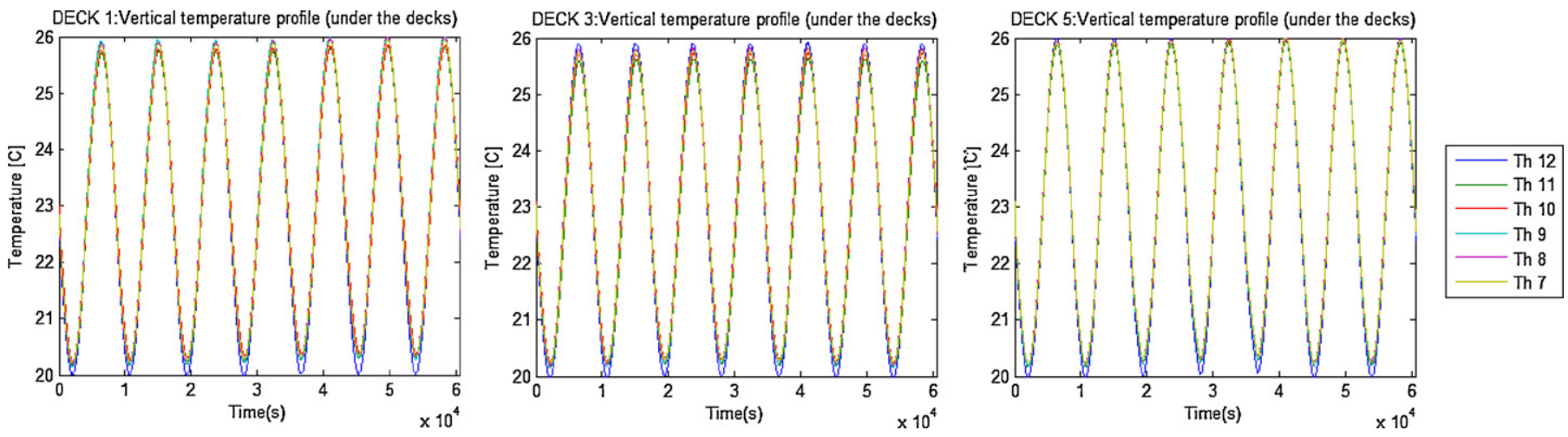

Fig. 10. Measured vertical air temperature profile for chosen deck experiments. 

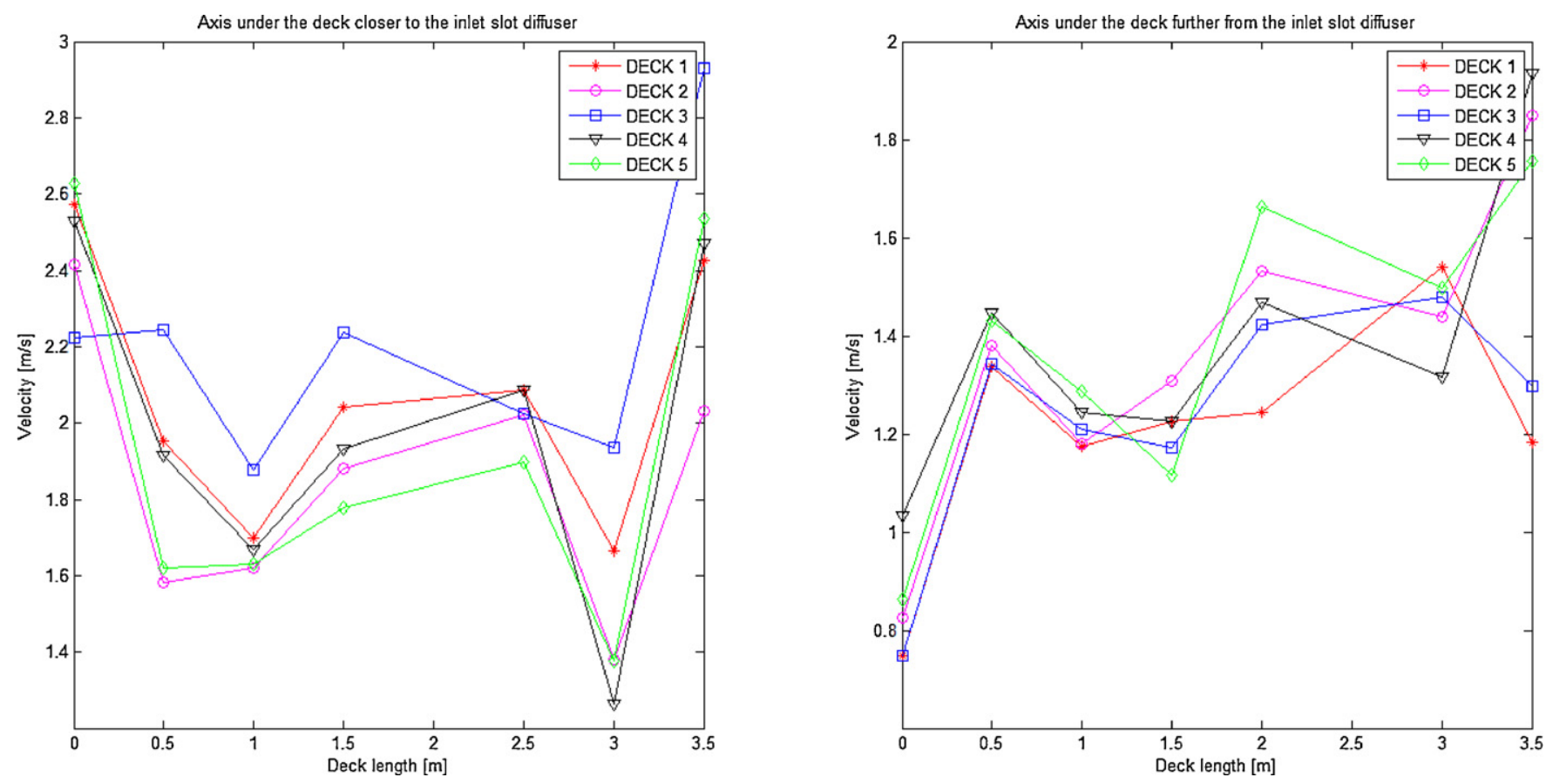

Fig. 11. Mean air velocities under investigated decks.

mentioned in data acquisition section, water temperature at the inlet and outlet to/from zones 2 and 3 was logged with a step of each $10 \mathrm{~s}$. Using Eq. (3) the cooling load to each zone as a function of time can be calculated.

$Q_{c}=v \times \rho \times C_{p} \times\left(T_{\text {out } i}-T_{\text {ini }}\right)$

where $Q_{c}$ is the cooling energy [W]; $v$ is the volumetric flow rate $\left[\mathrm{m}^{3} / \mathrm{s}\right] ; \rho$ is the water density $\left[\mathrm{kg} / \mathrm{m}^{3}\right] ; C_{p}$ is the water specific heat
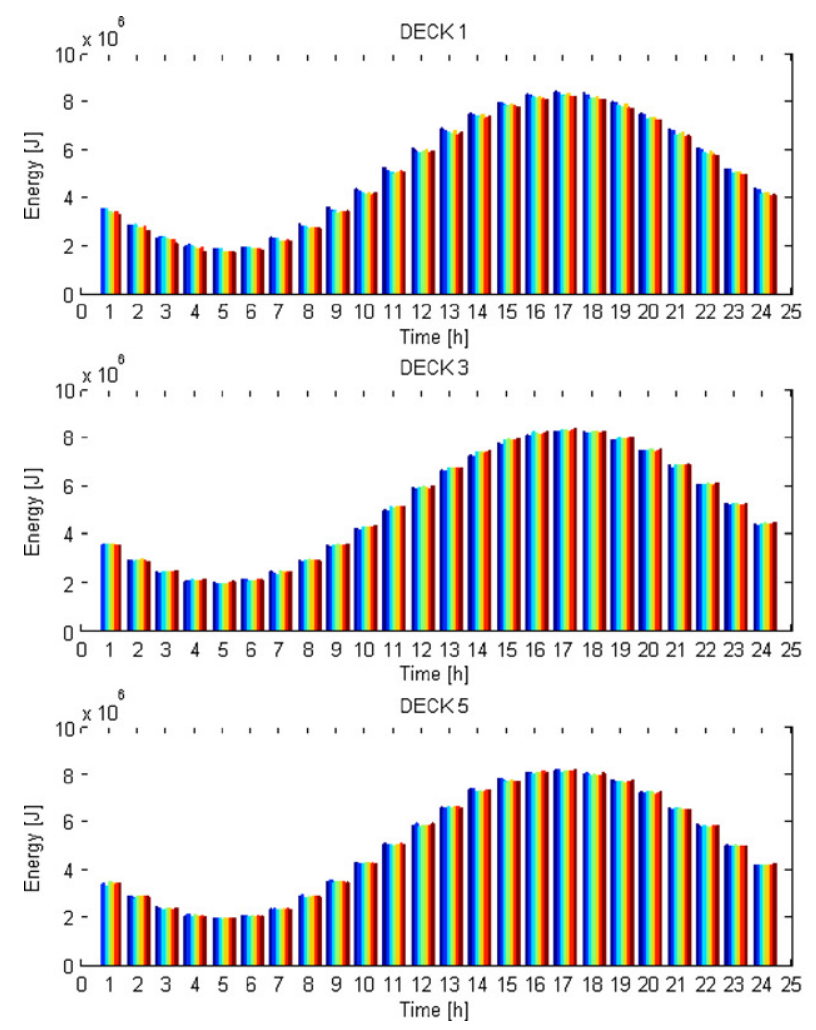

Fig. 12. Hourly integrated heating load delivered to zone 3 for 7 measuring days of each investigated deck. capacity $[\mathrm{J} /(\mathrm{kg} \mathrm{K})] ; T_{\text {out } i}$ is the outlet water temperature measured in time $\left[{ }^{\circ} \mathrm{C}\right] ; T_{\text {in } i}$ is the outlet water temperature measured in time $\left[{ }^{\circ} \mathrm{C}\right]$.

\subsection{Absolute dynamic heat storage capacity}

Absolute dynamic heat storage capacity of concrete elements can be determined with use of Eq. (4).
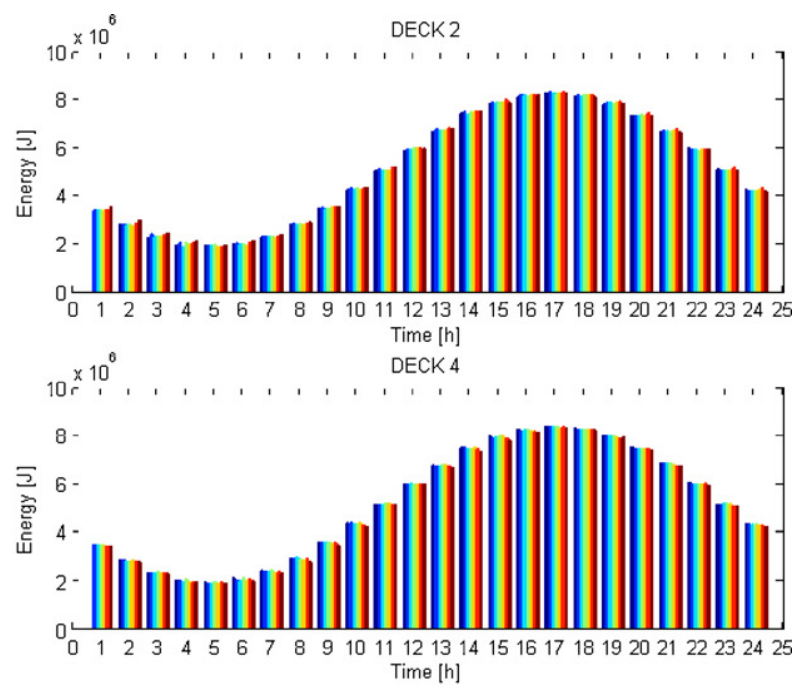

day $1 \square$ day $2 \square$ day $3 \quad$ day $4 \quad$ day $5 \square$ 


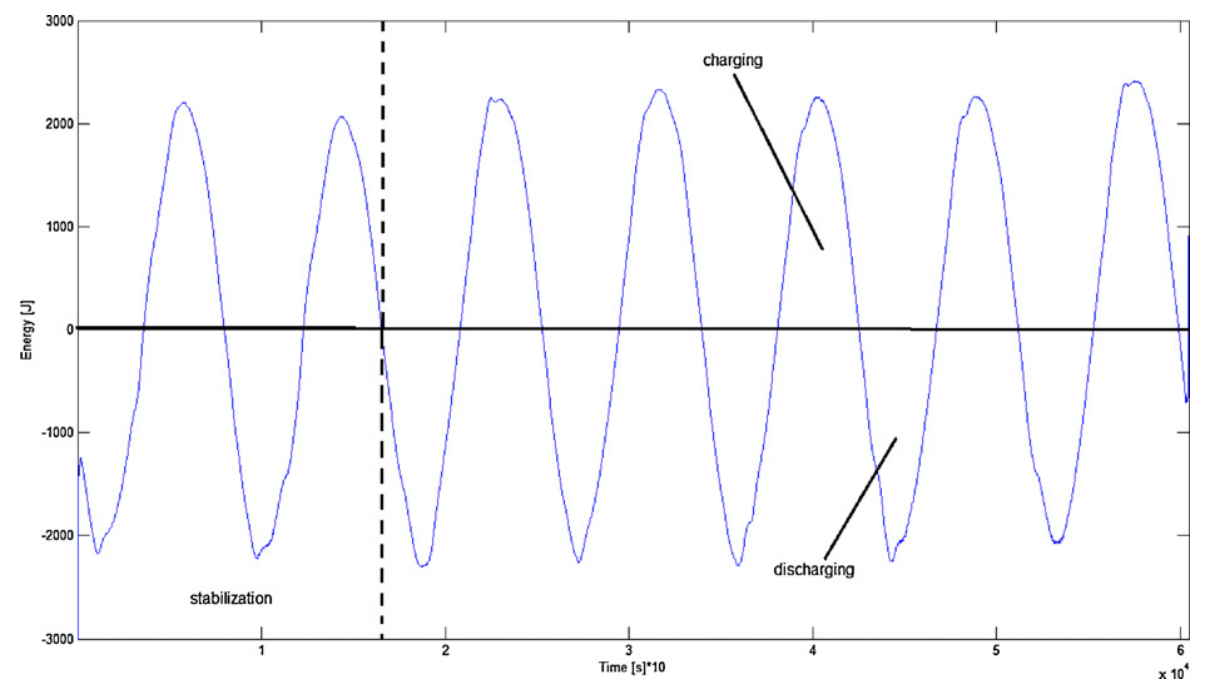

Fig. 13. Absolute energy delivered to zone 3 during seven consecutive days of charging and discharging of DECK_3 (grooved mortar tiles).

$$
\begin{aligned}
Q= & \int_{12}^{24}\left(Q_{h \text {-deck }}(t) d t-Q_{c \text {-deck }}(t) d t-Q_{h \text {-hot-box }}(t) d t-Q_{c \text {-hot-box }}(t) d t\right) \\
& -\int_{0}^{12}\left(Q_{h \text {-deck }}(t) d t-Q_{c \text {-deck }}(t) d t-Q_{h \text {-hot-box }}(t) d t-Q_{c \text {-hot-box }}(t) d t\right)
\end{aligned}
$$

where $Q$ is the dynamic heat storage capacity of concrete deck; $Q_{h \text {-deck }}(t) d t$ is the heating energy provided to zone 3 in hot box with decks, logged each $1 \mathrm{~s} ; Q_{c \text {-deck }}(t) d t$ is the cooling energy provided to zone 3 in hot box with decks, logged each $10 \mathrm{~s} ; Q_{h \text {-hot-box }}(t) d t$ is the heating energy provided to zone 3 in hot box without decks (EPS ceiling), logged each $1 \mathrm{~s} ; Q_{c \text {-hot-box }}(t) d t$ is the cooling energy provided to zone 3 in hot box without decks (EPS ceiling), logged each $10 \mathrm{~s}$.

The calculation in Eq. (4) can be done for each day which means for each consecutive 24-h period.

An example of absolute charging and discharging energy is presented for DECK_3 (deck with grooved mortar tiles) as a function of time, see Fig. 13.

The absolute dynamic heat storage of each type of the deck is calculated as a difference of energy integrated over charging cycle and discharging cycle. In a graphical manner, the dynamic heat storage is a sum of the area between the curve and zero axis for the charging and discharging period which is then divided by two, see Fig. 13.

In the calculations, the last 5 days of measurements, when the system reaches periodic steady-state condition, are taken into consideration. Results of the absolute dynamic heat storage capacity are gathered and presented in Table 2 . Results from the first 2 days are highlighted in bold.

Calculated average daily dynamic heat storage capacities of investigated decks presented in Table 2 are also depicted in the chart presented in Fig. 14.

The estimation of uncertainty of measurements in the hot box apparatus can be studied based on the absolute energy balance calculated for each deck type. The design of the experiment assumes that all thermal mass within zones 2 and 3 reaches quasi steadystate which means that in ideal condition for each charging and discharging period the absolute energy transfer to/from, for example, concrete decks is the same. However, in Fig. 13 it can be observed that, for example, DECK_3 does not reach ideal quasi steady-state condition (the areas under the curve for charging periods are not exactly equal to areas under the curve for discharging periods for consecutive days). The discrepancy from quasi steady-state is used to estimate inaccuracy of results obtained from modified hot box apparatus. The reference dynamic heat storage capacity of each type of concrete deck is assumed as average dynamic heat storage capacity from last 5 days of measurements (see Eq. (5) and standard deviation for each deck is then calculated with use of Eq. (6). Results of measurements uncertainty are presented in Table 2 .

$m_{x}=\frac{x_{1}+x_{2}+x_{3}}{n}$

and standard deviation then is calculated from:

$S_{x}=\sqrt{\frac{\left(x_{1}-m_{x}\right)^{2}+\left(x_{2}-m_{x}\right)^{2}+\left(x_{3}-m_{x}\right)^{2}}{n-1}}$

\subsection{Comparison between numerical and experimental results}

Comparison of numerical and experimental results is done for reference concrete deck with flat bottom surface finish: DECK_5. In order to be able to compare the dynamic heat storage from experiments to numerical results it is necessary to calculate radiative and convective heat transfer coefficients during measurements.

The radiative heat transfer coefficient on the bottom of the concrete deck can be calculated because temperature on the inner surfaces in zone 3 was logged during each experiment, see Fig. 6. Knowing temperatures and geometry of zone 3 it is possible to calculate radiative heat transfer coefficient on the bottom of the decks. Radiative heat transfer coefficient was calculated using Eq. (7) proposed in [23] to calculate radiative heat transfer between two enclosures and Eq. (8) which takes into consideration view factors between enclosures. Simplification of radiative heat transfer to only two enclosures was possible because all constructions in zone 3 except bottom surface of the concrete decks have the same thermal properties and the same finish and their temperatures are almost the same. In that manner heat due to radiation is only transfer between inner surfaces of walls in zone 3 and bottom of the concrete decks. Radiative heat transfer coefficient on the bottom of the DECK_ 5 was calculated for the last 5 days of measurements.

$$
\begin{aligned}
q_{\text {rad }} & =\frac{\sigma\left(T_{1}^{4}-T_{2}^{4}\right)}{\left(1-\varepsilon_{1} / \varepsilon_{1} A_{1}\right)+\left(1 / A_{1} F_{12}\right)+\left(1-\varepsilon_{2} / \varepsilon_{2} A_{2}\right)} \\
h_{\text {rad }} & =\frac{q_{\text {rad }}}{T_{\text {ceiling }}-\text { AUST }}
\end{aligned}
$$

where $\sigma$ is the Stefan-Boltzman constant: $5.67 \times 10^{-8}\left[\mathrm{~W} /\left(\mathrm{m}^{2} \mathrm{~K}^{4}\right)\right]$; $T$ is the temperature $[\mathrm{K}] ; \varepsilon$ is the emissivity; $A$ is the area $\left[\mathrm{m}^{2}\right] ; F$ is 
Table 2

Calculated average daily dynamic heat storage capacity of investigated concrete decks.

\begin{tabular}{|c|c|c|c|c|c|}
\hline \multirow[b]{2}{*}{ Day } & $\begin{array}{l}\text { DECK_1 (grooved } \\
\text { PCM mortar) }\end{array}$ & $\begin{array}{l}\text { DECK_2 (flat PCM } \\
\text { mortar) }\end{array}$ & $\begin{array}{l}\text { DECK_3 (grooved } \\
\text { mortar) }\end{array}$ & $\begin{array}{l}\text { DECK_4 (flat } \\
\text { mortar) }\end{array}$ & $\begin{array}{l}\text { DECK_5 (reference: } \\
\text { concrete) }\end{array}$ \\
\hline & \multicolumn{5}{|c|}{ Average hourly heat capacity $\left[\mathrm{Wh} / \mathrm{m}^{2}\right]$} \\
\hline 1 & 176 & 168 & 166 & 177 & 139 \\
\hline 2 & 176 & 161 & 166 & 173 & 151 \\
\hline 3 & 160 & 168 & 174 & 177 & 148 \\
\hline 4 & 170 & 162 & 175 & 171 & 138 \\
\hline 5 & 177 & 172 & 170 & 173 & 143 \\
\hline 6 & 157 & 170 & 171 & 170 & 152 \\
\hline 7 & 168 & 145 & 175 & 173 & 149 \\
\hline Average (standard deviation) & $166( \pm 6.5 \%)$ & $163( \pm 6.1 \%)$ & $173( \pm 1.8 \%)$ & $173( \pm 2.9 \%)$ & $145( \pm 6.3 \%)$ \\
\hline
\end{tabular}

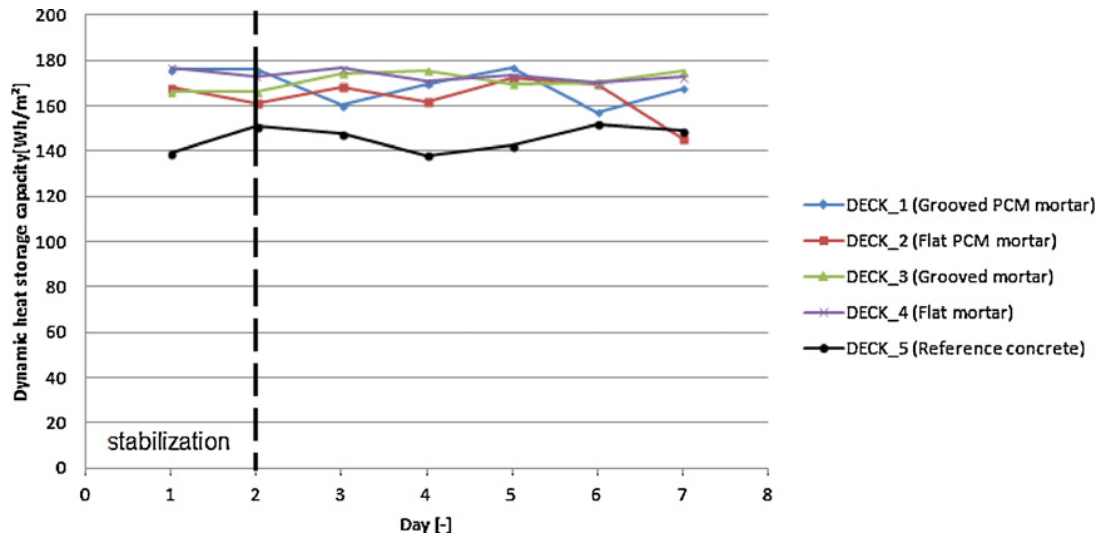

Fig. 14. Average daily dynamic heat storage capacity of investigated concrete decks.

the view factor; AUST is the average unheated surface temperature $[\mathrm{K}]$.

Calculated radiative heat transfer coefficient fluctuates according to sine curve due to temperature periodic steady-state fluctuations in the hot box and fluctuations oscillate between 5.05 and $5.28\left[\mathrm{~W} /\left(\mathrm{m}^{2} \mathrm{~K}\right)\right]$. For further analysis an average radiative heat transfer coefficient is used $h_{\mathrm{rad}}=5.16\left[\mathrm{~W} /\left(\mathrm{m}^{2} \mathrm{~K}\right)\right]$.

Knowing radiative heat transfer coefficient $h_{\text {rad }}=5.16$ $\left[\mathrm{W} /\left(\mathrm{m}^{2} \mathrm{~K}\right)\right]$ and measured dynamic heat storage capacity of DECK_5 $Q=145\left[\mathrm{Wh} / \mathrm{m}^{2}\right]$ it is possible to estimate average convective heat transfer with use of numerical results from COMSOL Multiphysics program. From that approach average convective heat transfer coefficient on the bottom of DECK_5 is approximately $h_{\text {conv }}=3[\mathrm{~W} /(\mathrm{mK})]$, see Fig. 15 .

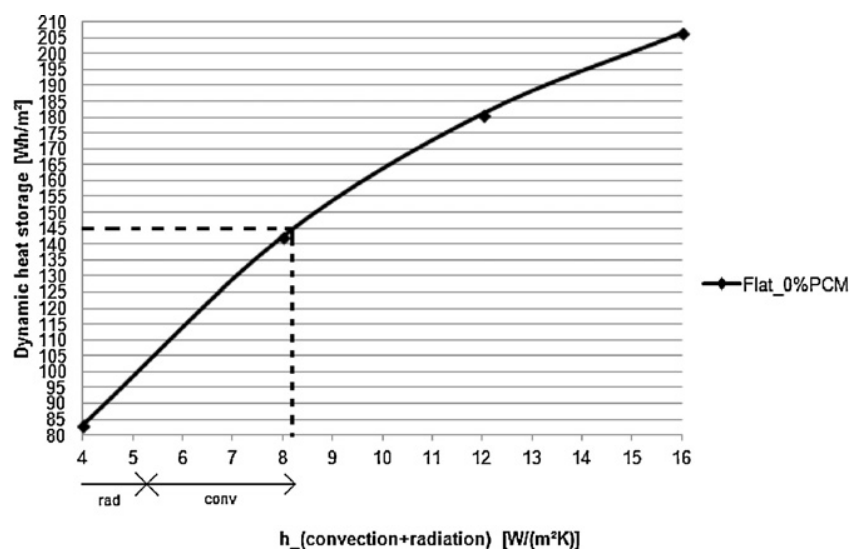

Fig. 15. Determination of convective heat transfer coefficient from numerical COMSOL model.
Having measured velocities under the decks it is also possible to estimate average convective heat transfer coefficient on the bottom of the decks by using analytical approach (valid only for flat surfaces). Calculations are presented only for DECK_5 (reference deck). The analytical approach proposed in [24] is used for laminar flow (because $\operatorname{Re}<10^{5}$ ) and forced convection case on flat surfaces. The convective heat transfer coefficient is calculated using Eq. (9):

$h_{\text {conv }}=\frac{\lambda \times 0.664 \times R e^{0.5} \times \operatorname{Pr}^{0.55}}{L}$

where $\lambda$ is the thermal conductivity [W/(mK)]; Re is Reynold's number; Pr is Prandtl's number; $L$ is the characteristic length (in this case it is length of decks along air flow) [m].Based on the analytical calculations the average convective heat transfer coefficient on the bottom of the DECK 5 is equal $h_{\text {conv }}=2.18\left[\mathrm{~W} / \mathrm{m}^{2} \mathrm{~K}\right]$ which is very close to estimation based on numerical model from COMSOL.

\subsection{Correlation between dynamic heat storage capacity and weight}

During measurements, the weight of concrete decks located in the modified hot box apparatus was also monitored. As stated earlier in the paper, each deck was located on four force transducers. During measurements, it was observed that decks had a tendency to decrease in weight (except DECK_5). The fluctuations of dynamic heat storage capacity could be caused by a moisture release from the concrete decks to the air and then after to outside of the hot box apparatus. This could also explain deck weight decrease. Correlation of measured weight and average daily dynamic heat storage capacity is presented in Fig. 16. 

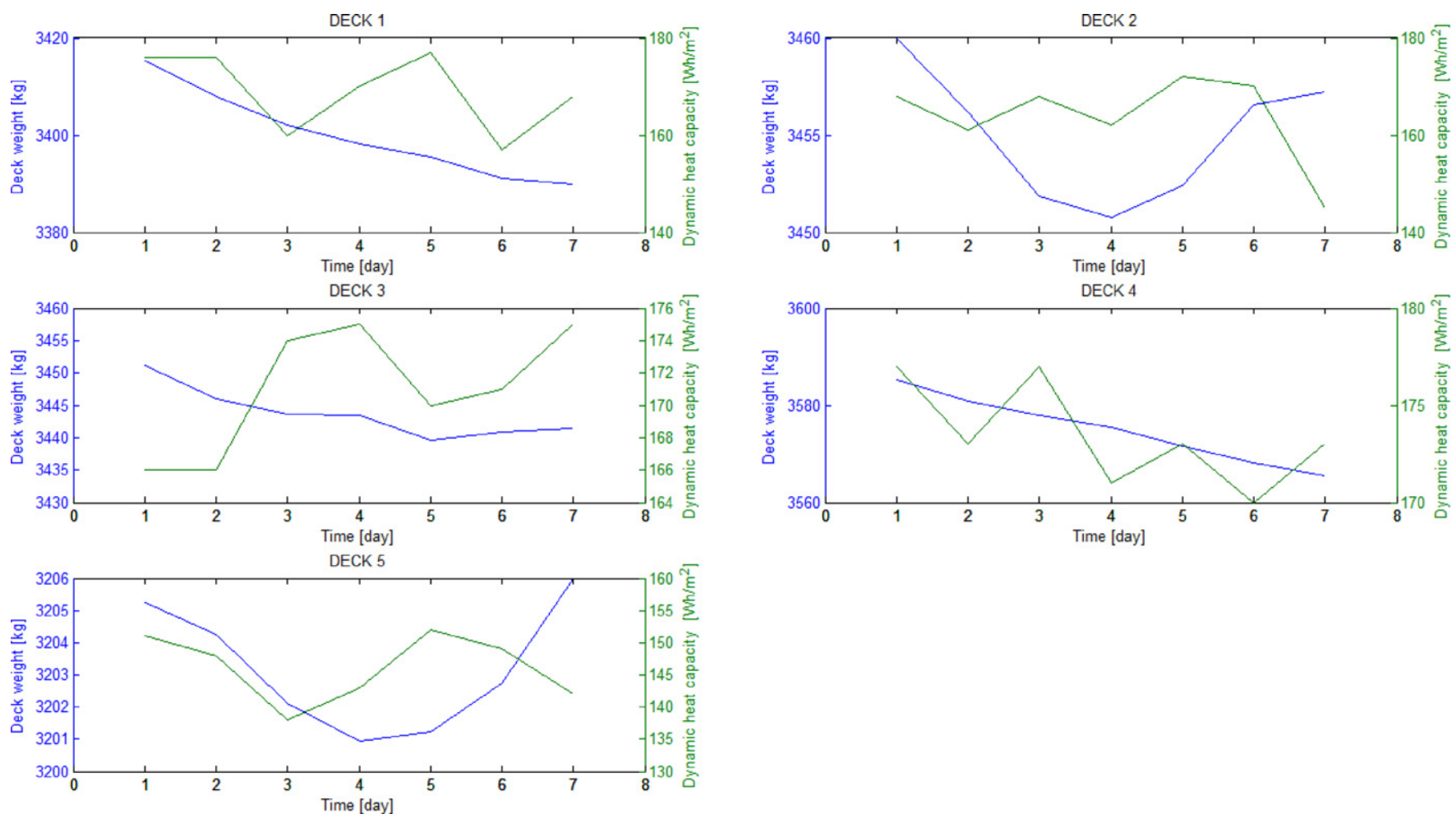

Fig. 16. Correlation between deck weight and dynamic heat storage capacity of investigated decks.

\section{Discussion}

Investigation of thermal properties of materials used to cast deck elements (concrete, mortar and PCM mortar) indicated that, on one hand, PCM can increase heat storage of the mortar material/concrete within PCM melting and solidification temperature range. On the other hand, thermal conductivity of such materials drastically drops due to addition of low thermally conductive microencapsulated PCM and this will have negative influence on heat storage performance of such materials. These properties were illustrated using VHC and TI in Fig. 9. Moreover, it was discovered that the VHC of concrete is comparable to VHC of mortar. However, the TI of concrete was measured to be higher than for mortar, and this is due to the higher thermal conductivity of concrete than of mortar, see Table 1 .

Regarding periodic steady-state experiments conducted in the specially developed modified hot box apparatus, the repeatability of periodic condition was found to be satisfactory. Designed temperature profiles were found to be repeated with sufficient accuracy, see Fig. 10. The measured velocity profiles and ranges under the decks resemble each other, and the repeatability can be concluded as satisfactory, see Fig. 11. Finally, measured heating loads for different decks presented in Fig. 12 indicate a good repeatability and stability of the system. However, the calculated absolute average daily dynamic heat storage capacity of different decks, presented in Table 2 and depicted in Fig. 14, indicate that results vary from day to day. The very small differences in energy delivered to zone 3 for respective hours from day to day, see Fig. 12, built up when the total energy is integrated over a 24-h period. Final discrepancy of results from day to day is observed to be approximately $\pm 10 \mathrm{Wh} / \mathrm{m}^{2}$ which in some cases result in standard deviation higher than $6 \%$. The fluctuation of the obtained dynamic heat storage capacity over the days makes it almost impossible to compare results for the different decks. The only heat storage that is observed to be significantly smaller from the rest of the decks is for reference deck, DECK_5, which is made of ordinary concrete. This result, however, is surprising since VHC and TI of concrete material is measured to be higher than, e.g. mortar material used to cast DECK_3 and DECK_4. In that sense, it can be concluded that expectation based on measured material properties does not correlate with full-scale experimental results, and these results should be analyzed in further investigations. What is more, due to fluctuations of measured dynamic heat storage capacity, it is also impossible to draw a conclusion if the extended surface area of the bottom of the decks (DECK_1 and DECK_3) has a positive influence on heat transfer enhancement.

The comparison between numerical modeling and experimental results is presented for DECK_5 (reference) with flat bottom and results are with good agreement. Comparison of grooved decks is not presented due to challenge of calculating radiative heat transfer on the profiled bottom area. What is more, simplified COMSOL modeling do not include view factors and real radiative heat transfer that occurs between profiled surface of concrete decks and surrounding walls in zone 3 of modified hot box in the experimental setup.

Fig. 16 presents the correlation between deck weight and dynamic heat storage which indicate that, during the experiments, the challenge to obtain very stable results could be made difficult due to moisture release from the decks. It could be assumed that moisture released from the decks penetrates through the hot box apparatus walls to the surrounding laboratory, in which the air temperature for most of the time is below the temperature maintained in the hot box. What is more, in Fig. 16 it can be observed that some of the decks are heavier than others, for example, DECK_4. The difference in weight is because, in some of the decks, the concrete used to cast the layer with air voids was too dry and could not carry the load of the layer of concrete located above the air voids during the casting process. In these places it was necessary to fill in air voids with concrete to keep the shape of the decks. However, this additional concrete in some places in the air void layer should 
not be of significant importance for overall heat storage capacity of the decks, since the inner layer (air void layer) of concrete decks does not participate as significantly in thermal mass activation as external layers.

With regards to technical challenges and risk of cracks due to addition of $6 \%$ by weight of PCM to mortar tiles, no implications or damages have been observed. However, it should be stressed that trial casts with higher amount of PCM than 6\% caused significant problems and could not be successfully proceed. The trial cast also indicated that with presently available super plasticizers $6 \%$ by weight of microencapsulated PCM is the highest amount that results with satisfactory workability of concretes and mortars. What is more, due to location of mortar tiles with PCM on the very bottom (under decks' reinforcement) the bearing strength of the decks has not been changed.

Presented results, both from full-scale experiments in modified hot box and from hot plate apparatus indicate that extra cost due to addition of PCM into mortars or concretes might not be economically justified due to very insignificant improvement in dynamic heat storage capacity of the new composite. Also further increase of PCM content in mortars or concretes than $6 \%$ by weight, though doubtful due to observed significant challenges with workability and decreased strength, would be rather not promising due to even further drop of density and thermal conductivity that would negatively affect dynamic heat storage capacity of such a new composite.

\section{Conclusions}

A full-scale experiment to determine dynamic heat storage capacity of concrete deck elements has been carried out. Moreover, an experimental investigation of thermal properties of materials used to cast concrete elements has been carried out. What is more, a full-scale modified hot box has been developed to perform periodic steady-state and steady-state full-scale experiments to determine thermal properties of homogeneous and inhomogeneous construction materials.

From the experimental results it can be concluded, that it is doubtful that the presence of latent heat (due to implementation of PCM) and heat transfer enhancement due to extended heat transfer surface area could have significant positive influence on increase of dynamic heat storage of concrete or mortar elements, such as hollow core deck elements. Obtained results of dynamic diurnal heat storage capacity, see Table 2, indicate that grooved surface area with regards to flat surface area results in no improvement for tiles with PCM and only $1.8 \%$ improvement for tiles without PCM. Such a small improvement is even lower than standard deviation of obtained results and therefore might be considered as insignificant. Comparing decks with and without PCM it can be observed that these with PCM perform slightly worse than the ones without PCM. The reason for that can be due to decreased thermal conductivity in one with PCM or due to inaccuracy of measurements. The utilization of available thermal mass represented by decks could be of course increased by increasing temperature swing. However, the higher temperature swing used the less realistic would be performance of decks due to indoor temperature comfort criteria that usually do not appreciate operative temperatures lower than $20^{\circ} \mathrm{C}$ and higher than $26^{\circ} \mathrm{C}$.

All in all, experimental measurements were carried out with special care to details and to be as accurate as possible, see also Sections 2.3-2.5 of this paper. Also numerous solutions implemented in the modified hot box apparatus and experimental setup allows energy balance monitoring in zones of interest and uncontrolled heat gains or losses minimization.
Further research should be focused to investigate potential of very high conductive construction materials, for example, metals with extended surface area since concrete and mortars could not have sufficiently high thermal conductivity to efficiently transfer significant amount of energy from air to the deeper layer of construction element over available in the buildings diurnal air temperature fluctuations. What is more, PCMs could be promising when mixed in high ratios with materials of similar thermal conductivities and densities to them self, for example, gypsum, but only in thin layers and located as the finish of the very internal sides in the spaces.

\section{Acknowledgements}

The authors would like to express their gratitude to BASF, DTI and Spæncom for providing materials and help in preparation of decks for experimental investigation. The Danish National Advanced Technology Foundation is acknowledged for financial support of the present research.

\section{References}

[1] R. Parameshwaran, S. Kalaiselvam, S. Harikrishna, A. Elayaperumal, Sustainable thermal energy storage technologies for buildings: a review, Renewable and Sustainable Energy Reviews 16 (2012) 2394-2433.

[2] S. Eman-Bellah Mettawee, M.R. Ghazy Assassa, Thermal conductivity enhancement in a latent heat storage system, Solar Energy 81 (2007) 839-845.

[3] R. Velraj, R.V. Seeniraj, B. Hafner, C. Faber, K. Schwarzer, Heat transfer enhancement in a latent heat storage system, Solar Energy 65 (3) (1998) $171-180$.

[4] C.J. Hoogendoorn, G.C.J. Bart, Performance and modeling of latent heat stores, Solar Energy 48 (1) (1992) 53-58.

[5] C.Y. Zhao, W. Lu, Y. Tian, Heat transfer enhancement for thermal energy storage using metal foams embedded within phase change materials (PCMs), Solar Energy 84 (2010) 1402-1412.

[6] Y. Zhang, J. Ding, X. Wang, R. Yang, K. Lin, Influence of additives on thermal conductivity of shape-stabilized phase change material, Solar Energy Materials and Solar Cells 90 (2006) 1692-1702.

[7] Y. Zhang, A. Faghri, Heat transfer enhancement in latent heat thermal energy storage system by using the internally finned tube, International Journal of Heat and Mass Transfer 39 (15) (1996) 3165-3173.

[8] K.A.R. Ismail, C.L.F. Alves, M.S. Modesto, Numerical and experimental study on the solidification of PCM around a vertical axially finned isothermal cylinder, Applied Thermal Engineering 21 (2001) 53-77.

[9] J.C. Choi, S.D. Kim, Heat-transfer characteristics of a latent heat storage system using $\mathrm{MgCl}_{2} \cdot 6 \mathrm{H}_{2} \mathrm{O}$, Energy 17 (1992) 1153-1164.

[10] D.J. Kukulka, R. Smith, K.G. Fuller, Development and evaluation of enhanced heat transfer tubes, Applied Thermal Engineering 31 (2011) $2141-2145$

[11] K. Bilen, M. Cetin, H. Gul, T. Balta, The investigation of grooved geometry effect on heat transfer for internally grooved tubes, Applied Thermal Engineering 29 (2009) 753-761.

[12] H.A. El-Sheikh, S.V. Garimella, Enhancement of air jet impingement heat transfer using pin-fin heat sinks, IEEE Transactions on Components and Packaging Technologies 23 (2) (2000) 300-308.

[13] H.A. El-Sheikh, S.V. Garimella, Heat transfer from pin-fin heat sinks under multiple impinging jets, IEEE Transactions on Components and Packaging Technology 23 (1) (2000) 113-120.

[14] S. Ndao, H.J. Lee, Y. Peles, M.K. Jensen, Heat transfer enhancement from micro fins subjected to an impinging jet, International Journal of Heat and Mass Transfer 55 (2012) 413-421.

[15] P.F. Sullivan, S. Ramadhyani, F.P. Incropera, Use of smooth and roughened spreader plates to enhance impingement cooling of small heat sources with single circular liquid jets, Topics in Heat Transfer HTD 206 (2) (1993) $103-110$.

[16] A.A. Ghoneim, S.A. Klein, J.A. Duffie, Analysis of collector-storage building walls using phase-change materials, Solar Energy 47 (3) (1991) 237-242.

[17] M. Pomianowski, P. Heiselberg, R.L. Jensen, Dynamic heat storage and cooling capacity of a concrete deck with PCM and thermally activated building system, Energy and Buildings 53 (2012) 96-107.

[18] M. Pomianowski, P. Heiselberg, R. Lund Jensen, H. Johra, Numerical analysis of heat storage and heat conductivity in the concrete hollow core deck element, in: Building Simulation Conference, Sydney, Australia, 2011.

[19] M. Pomianowski, P. Heiselberg, R.L. Jensen, R. Cheng, Y. Zhang, A new experimental methodology to determine specific heat capacity of inhomogeneous concrete material with incorporated microencapsulated PCM, Cement and Concrete Research, submitted for publication. 
[20] M.G. Van Geem, Measuring thermal performance of wall assemblies under dynamic temperature conditions, Journal of Testing and Evaluation 15 (3) (1987) 178-187.

[21] H. Asan, Y.S. Sancaktar, Effect of wall's thermophysical properties on time lag and decrement factor, Energy and Buildings 28 (1998) 159-166.

[22] M. Pomianowski, P. Heiselberg, R.L. Jensen, Experimental investigation of thermal conductivity of concrete containing micro-encapsulated phase change material, in: Proceedings of 7th International Symposium on Heating, Ventilation and Air-Conditioning, Shanghai, China, 2011, pp. 185-191.

[23] F.P. Incropera, D.P. Dewitt, T.L. Bergman, A.S. Lavine, Fundamentals of Heat and Mass Transfer, 6th edition, 2007.

[24] ASHRAE, Heat transfer, in: ASHRAE Fundamental Handbook, Part 1, 2009 (Chapter 4). 